\title{
INVESTIGAÇÃO DAS SOLICITAÇÕES DE CISALHAMENTO EM EDIFÍCIOS DE ALVENARIA ESTRUTURAL SUBMETIDOS A AÇÕES HORIZONTAIS
}

Engo. JOEL ARAÚJO DO NASCIMENTO NETO

Dissertação apresentada à Escola de Engenharia de São Carlos, da Universidade de São Paulo, como parte dos requisitos para a obtenção do título de Mestre em Engenharia de Estruturas.

ORIENTADOR: Prof. Dr. Márcio Roberto Silva Corrêa

São Carlos 
Clase $\frac{\text { TESE-EESC }}{3829} \frac{-0134199}{\text { Tombo }}$

$5 / 151034448$

Ficha catalográfica preparada pela Seção de Tratamento da Informação do Serviço de Biblioteca - EESC/USP

Nascimento Neto, Joel Araújo do

Investigação das solicitações de cisalhamento em edifícios de alvenaria estrutural submetidos a ações horizontais / Joel Araújo do Nascimento Neto. -- São Carlos, 1999.

Dissertação (Mestrado) -- Escola de Engenharia de São Carlos-Universidade de São Paulo, 1999.

Área: Engenharia de Estruturas.

Orientador: Prof. Dr. Márcio Roberto Silva Corrêa.

1. Alvenaria estrutural. 2. Edifícios. 3. Ação horizontal. 4. Torção. 5. Cisalhamento. I. Título. 


\section{FOLHA DE APROVACÃO}

\section{Candidato: Engenheiro JOEL ARAUJO DO NASCIMENTO NETO}

Dissertação defendida e aprovada em 24-03-1999 pela Comissão Julgadora:

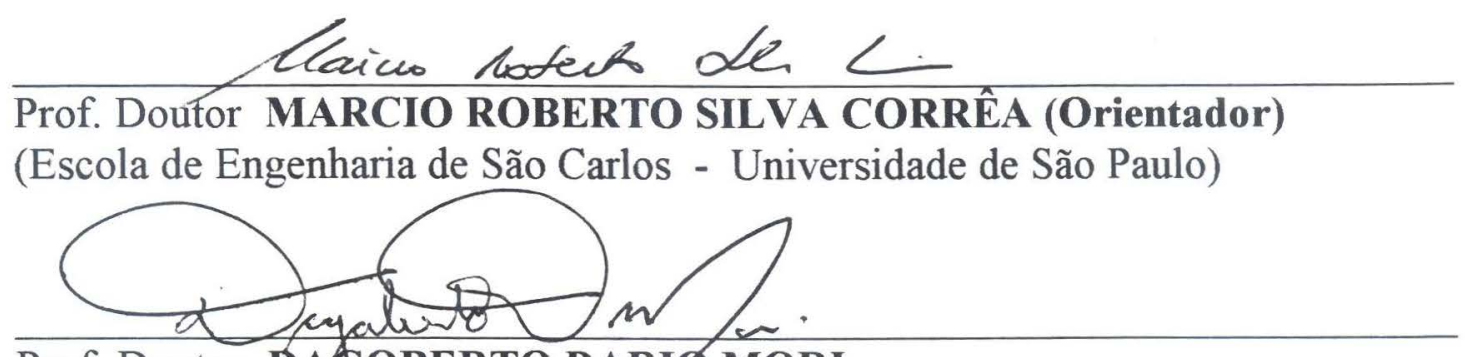

\section{Prof. Doutor DAGOBERTO DARIO MORI}

(Escola de Engenhlaria de São Carlos - Universidade de São Paulo)

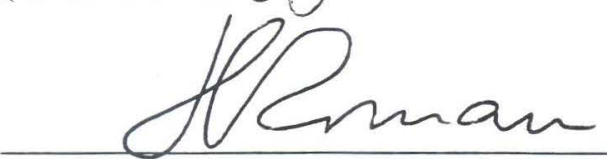

Prof. Doutor HUMBERTO RAMOS ROMAN

(Universidade Federal de Santa Catarina)

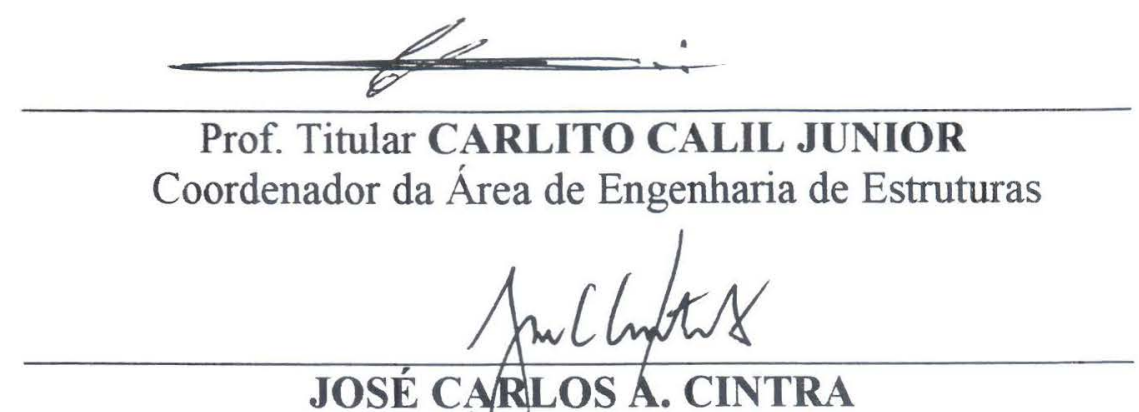

Presidente da Comissão de Pós-Graduação da EESC 
"O caminho de Deus é perfeito; a palavra do Senhor é provada: é um escudo para todos os que nele confiam".

Salmos - 18:30.

"Bem-aventurado é o homem a quem tú repreendes, ó Senhor, e a quem ensinas a tua lei".

Salmos - 94:12. 
Aos meus pais Ivan e Tânia, e irmãos Rômulo e Ivan Júnior. Em especial à minha mãe que sempre me aconselhou e orientou nos momentos mais difíceis. 


\section{AGRADECIMENTOS}

A Deus que sempre me protege, e me iluminou durante mais essa etapa da minha vida.

Ao Professor Márcio Roberto Silva Corrêa, pela orientação, dedicação, paciência e amizade demonstrados durante a elaboração desse trabalho.

Ao Professor Pablo Aníbal López-Yánez, da Universidade Federal da Paraíba, pelos conselhos e ensinamentos durante a graduação, e pelo apoio e incentivo para ingresso na pós-graduação.

À toda minha família, em especial a Fernanda, Renata, Davi, João, e Anne, e aos meus primos Kelvin e Phillipe, pelo carinho e apoio durante todos esses anos.

A todos os amigos do Departamento, em especial a Adriano, Alonso, Carlos Humberto, Osvaldo, Suzana e Tibério, pelo agradável convívio.

Aos funcionários do Departamento de Engenharia de Estruturas da Escola de Engenharia de São Carlos - USP, pela amizade e serviços prestados durante esses dois anos.

À Coordenadoria de Aperfeiçoamento de Pessoal de Nível Superior CAPES, pela bolsa concedida durante o período do mestrado.

Aos demais professores e funcionários e a todos os colegas do Departamento de Engenharia de Estruturas que de uma forma ou de outra colaboraram na elaboração desse trabalho. 


\section{SUMÁRIO}

LISTA DE FIGURAS................................................... i

LISTA DE TABELAS........................................................ vii

LISTA DE SÍMBOLOS.......................................................... viii

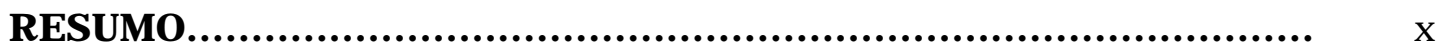

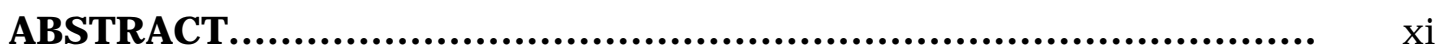

1 - INTRODUÇÃO......................................................... 1

1.1 - Generalidades............................................................ 1

1.2 - Objetivos................................................................ 5

1.3 - Justificativas........................................................ 6

1.4 - Estrutura da dissertação.......................................... 7

2 - SISTEMA ESTRUTURAL DE CONTRAVENTAMENTO............... 9

2.1 - Comportamento dos elementos estruturais....................... 10

2.2 - Tipos de construções em alvenaria................................. 15

2.3 - Modelos para análise de paredes estruturais....................... 16

3 - MODELOS ADOTADOS PARA ANÁLISE................................. 23

3.1 - Modelo de barras isoladas............................................ 23

3.1.1 - Apresentação...................................................... 23

3.1.2 - Deformação por cisalhamento.................................. 32

3.1.3 - Exemplo preliminar........................................... 38

3.2 - Modelo de pórtico tridimensional................................... 46

3.2.1 - Apresentação...................................................... 46

3.2.2 - Deformação por cisalhamento..................................... 51

3.2.3 - Barras horizontais rígidas e lintéis............................ 52

3.2.4 - Interação entre paredes....................................... 55

3.2 .5 - Efeitos de torção nos edifícios.................................. 56

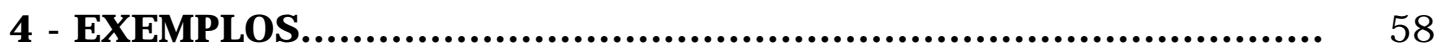

4.1 - Introdução............................................................ 58

4.2 - Exemplos de consolidação dos modelos............................. 60 
4.3 - Exemplo básico para análise geral dos resultados................ 67

4.4 - Exemplo de carregamento simétrico................................. 91

4.5 - Exemplo de carregamento com torção................................. 101

5 - CONCLUSÕES.......................................................... 118

REFERÊNCIAS BIBLIOGRÁFICAS........................................ 122 


\section{LISTA DE FIGURAS}

FIGURA 1.1 - Edifício Monadnock, símbolo da alvenaria estrutural [Retirado do manual da ABCI (1990)].....................

FIGURA 1.2 - Edifício Muriti, em São José dos Campos, SP [Retirado do manual da ABCI(1990)]......................................

FIGURA 2.1 - Sistema estrutural de contraventamento dos edifícios em alvenaria [Retirado de DRYSDALE et al(1994)]

FIGURA 2.2a - Idealizações das paredes de contraventamento dos edifícios em alvenaria estrutural - Paredes perpendiculares à direção de ação do vento...............

FIGURA 2.2b - Idealizações das paredes de contraventamento dos edifícios em alvenaria estrutural - Paredes paralelas à direção de ação do vento.

FIGURA 2.3 - Liberty Park East Tower, Pittsburg [Retirado de Drysdale et al (1994)].

FIGURA 2.4 - Modelo real utilizado para obtenção dos resultados experimentais [Retirado de HENDRY et al (1981)].........

FIGURA 2.5 - Analogia de coluna larga com contraventamento...

FIGURA 2.6 - Analogia de pórtico contraventado

FIGURA 2.7 - Parede com aberturas e modelo de pórtico com trecho.....

FIGURA 3.1 - Representação em planta de painéis de contraventamento.

FIGURA 3.2 - Modelagem com elementos barra tridimensional.

FIGURA 3.3 - Graus de liberdade dos nós.

FIGURA 3.4 - Distribuição assimétrica de paredes de contraventamento (adaptado de HENDRY and SINHA[1981]).

FIGURA 3.5 - Viga de seção transversal delgada e largura unitária.......

FIGURA 3.6 - Elemento de viga com rotações $\theta_{i}$ e $\omega_{i}$ nas extremidades...

FIGURA 3.7a - Pavimento tipo do edifício.

FIGURA 3.7b - Diagrama unifilar das paredes em planta. 
FIGURA 3.8 - Deslocamentos horizontais

FIGURA 3.9 - Distribuição dos esforços cortantes entre as paredes de contraventamento.

FIGURA 3.10 - Distribuição dos momentos fletores entre os painéis de contraventamento

FIGURA 3.11 - Diagrama de esforço cortante ao longo da altura da parede mais solicitada - PY28

FIGURA 3.12 - Diagrama de momento fletor ao longo da altura da parede mais solicitada - PY28.

FIGURA 3.13 - Planta baixa da modelagem tridimensional dos painéis de contraventamento com elementos barra

FIGURA 3.14 - Eixos de referência para os graus de liberdade dos elementos barra.

FIGURA 3.15 - Incidência das barras horizontais rígidas no modelo tridimensional

FIGURA 3.16 - Modelagem das paredes de contraventamento.

FIGURA 3.17 - Simulação de trechos rígidos utilizando-se elementos barra [adaptado de CORRÊA(1991)].

FIGURA 3.18a - Paredes com aberturas - Modelagem com elementos de chapa

FIGURA 3.18b - Paredes com aberturas - Modelagem com elementos barra.....

FIGURA 3.19a - Forças de interação entre paredes [adaptado de CORRÊA E RAMALHO (1998)] - Paredes com interseção.

FIGURA 3.19b - Forças de interação entre paredes [adaptado de CORREAA E RAMALHO (1998)] - Paredes ligadas por lintéis.

FIGURA 3.20 - Excentricidades da ação do vento.

FIGURA 4.1a - Modelo reduzido ensaiado por U. C. KALITA and A. W. HENDRY (1970) - Vista Lateral..

FIGURA 4.1b - Modelo reduzido ensaiado por U. C. KALITA and A. W. HENDRY (1970) - Vista Frontal.

FIGURA 4.1c - Modelo reduzido ensaiado por U. C. KALITA and A. W. HENDRY (1970) - Planta Baixa. 
FIGURA 4.2a - Modelo de pórtico tridimensional do exemplo experimental ensaiado em KALITA U. C. and HENDRY A. W. (1970) - Vista superior.

FIGURA 4.2b - Modelo de pórtico tridimensional do exemplo experimental ensaiado em KALITA U. C. and HENDRY A. W. (1970) - Vista em perspectiva........................

FIGURA 4.3 - Deslocamentos horizontais da Parede A...................... 62

FIGURA 4.4 - Deslocamentos horizontais da Parede B..................... 63

FIGURA 4.5 - Planta baixa do modelo reduzido ensaiado por KESKIN, O. (1974).

FIGURA 4.6a - Modelo de pórtico tridimensional do exemplo experimental ensaiado por KESKIN, O. (1974) - Vista superior

FIGURA 4.6b - Modelo de pórtico tridimensional do exemplo experimental ensaiado por KESKIN, O. (1974) - Vista em perspectiva.

FIGURA 4.7 - Rotações das lajes

FIGURA $4.8 \mathrm{a}$ - Planta baixa do pavimento tipo.

FIGURA $4.8 \mathrm{~b}$ - Diagrama unifilar das paredes em planta.

FIGURA 4.9 - Deslocamentos horizontais, vento Y.

FIGURA 4.10 - Distribuição dos esforços cortantes entre as paredes de contraventamento, vento $\mathrm{Y}$

FIGURA 4.11 - Distribuição dos momentos fletores entre as paredes de contraventamento, vento $\mathrm{Y}$

FIGURA 4.12 - Diagrama de esforço cortante da parede mais solicitada, PY30.

FIGURA 4.13 - Diagrama de momento fletor da parede mais solicitada, PY30.

FIGURA 4.14 - Deslocamentos horizontais, vento X

FIGURA 4.15 - Deslocamentos horizontais, vento Y.

FIGURA 4.16a - Distribuição dos esforços cortantes entre as paredes de contraventamento com atuação do vento segundo as direções X e Y - Comparação entre os modelos 1 e 4. 
FIGURA 4.16b - Distribuição dos esforços cortantes entre as paredes de contraventamento com atuação do vento segundo as direções X e Y - Comparação entre os modelos 3 e 4 .

FIGURA 4.17a - Distribuição dos momentos fletores entre as paredes de contraventamento com atuação do vento segundo as direções $\mathrm{X}$ e $\mathrm{Y}$.

FIGURA 4.17b - Momento de tombamento devido à força horizontal originando momentos na base e binário formado pelas reações verticais

FIGURA 4.18 - Diagrama de esforço cortante da parede mais solicitada, PY30.

FIGURA 4.19 - Diagrama de momento fletor da parede mais solicitada, PY30.

FIGURA 4.20 - Esforços cortantes máximos nos lintéis

FIGURA 4.21a - Flexão dos lintéis - Aspectos do diagrama de momentos.....

FIGURA 4.21b - Flexão dos lintéis - Seção duplamente armada

FIGURA 4.22 - Distribuição dos esforços cortantes entre as paredes de contraventamento, análise do efeito da torção para vento segundo as direções $\mathrm{X}$ e $\mathrm{Y}$.

FIGURA 4.23a - Distribuição dos esforços cortantes entre as paredes de contraventamento, modelos 3 e 4 com torção Vento X com excentricidade.

FIGURA 4.23b - Distribuição dos esforços cortantes entre as paredes de contraventamento, modelos 3 e 4 com torção Vento Y com excentricidade.

FIGURA 4.24a - Distribuição dos esforços cortantes entre as paredes de contraventamento, análise dos efeitos da torção Vento X

FIGURA 4.24b - Distribuição dos esforços cortantes entre as paredes de contraventamento, análise dos efeitos da torção Vento Y.....

FIGURA 4.25a - Distribuição dos esforços cortantes entre as paredes de contraventamento, análise geral dos resultados Vento X. 
FIGURA 4.25b - Distribuição dos esforços cortantes entre as paredes de contraventamento, análise geral dos resultados Vento Y.....

FIGURA 4.26a - Planta baixa do pavimento tipo 92

FIGURA 4.26b - Diagrama unifilar das paredes em planta 93

FIGURA 4.27 - Deslocamentos horizontais, vento Y

FIGURA 4.28a - Distribuição dos esforços cortantes entre as paredes de contraventamento, vento Y - Comparação entre os modelos 1 e 4 .

FIGURA 4.28b - Distribuição dos esforços cortantes entre as paredes de contraventamento, vento Y - Comparação entre os modelos 3 e 4 .

FIGURA 4.29 - Distribuição dos momentos fletores entre as paredes de contraventamento com vento segundo a direção Y, comparação entre os modelos 3 e 4 .

FIGURA 4.30 - Diagrama de esforço cortante da parede mais solicitada PY68, comparação entre todos os modelos

FIGURA 4.31 - Diagrama de momento fletor da parede mais solicitada PY68, comparação entre os modelos 3 e 4

FIGURA 4.32 - Esforços cortantes nos lintéis.

100

FIGURA 4.33a - Planta baixa do pavimento tipo.

102

FIGURA 4.33b - Diagrama unifilar das paredes em planta

103

FIGURA 4.34a - Distribuição dos esforços cortantes entre as paredes de contraventamento, análise do efeito da torção Ação do vento segundo a direção $\mathrm{X}$.

FIGURA 4.34b - Distribuição dos esforços cortantes entre as paredes de contraventamento, análise do efeito da torção Ação do vento segundo a direção Y.

FIGURA 4.35a - Distribuição dos esforços cortantes entre as paredes de contraventamento, comparação entre os modelos 3 e 4 - Ação do vento segundo a direção X.

FIGURA 4.35b - Distribuição dos esforços cortantes entre as paredes de contraventamento, comparação entre os modelos 3 e 4 - Ação do vento segundo a direção Y. 
FIGURA 4.36a - Distribuição dos esforços cortantes entre as paredes de contraventamento para vento segundo a direção $\mathrm{X}$, comparação entre os modelos 2 e 3 - Intervalo de paredes entre PY1 e PY28.

FIGURA 4.36b - Distribuição dos esforços cortantes entre as paredes de contraventamento para vento segundo a direção $\mathrm{X}$, comparação entre os modelos 2 e 3 - Intervalo de paredes entre PY29 ePY57.

FIGURA 4.37a - Distribuição dos esforços cortantes entre as paredes de contraventamento para vento segundo a direção Y, comparação entre os modelos 2 e 3 - Intervalo de paredes entre PY58 e PY86.

FIGURA 4.37b - Distribuição dos esforços cortantes entre as paredes de contraventamento para vento segundo a direção Y, comparação entre os modelos 2 e 3 - Intervalo de paredes entre PY87 e PY113.

FIGURA 4.38a - Distribuição dos esforços cortantes entre as paredes de contraventamento para vento segundo a direção $\mathrm{X}$, análise de todos os modelos - Intervalo de paredes entre PX1 e PX28.

FIGURA 4.38b - Distribuição dos esforços cortantes entre as paredes de contraventamento para vento segundo a direção X, análise de todos os modelos - Intervalo de paredes entre PX29 e PX57.

FIGURA 4.39a - Distribuição dos esforços cortantes entre as paredes de contraventamento para vento segundo a direção Y, análise de todos os modelos - Intervalo de paredes entre PY58 e PY86.

FIGURA 4.39b - Distribuição dos esforços cortantes entre as paredes de contraventamento para vento segundo a direção Y, análise de todos os modelos - Intervalo de paredes entre PY87 e PY113.

FIGURA 4.40 - Esforços cortantes nos lintéis, avaliação das modificações devidas à torção do edifício. 


\section{LISTA DE TABELAS}

TABELA 3.1 - Comparação entre fatores de forma.......................... 33

TABELA 3.2 - Excentricidades da ação do vento............................... 56 


\section{LISTA DE SÍMBOLOS}

A - área de seção transversal

$\mathrm{A}_{\mathrm{sw}}$ - área de aço para estribos

$\mathrm{A}_{\mathrm{S}}$ - área de estribo necessária para absorver as tensões tangenciais no lintel

c - fator de forma de seção transversal

C.G. - centro geométrico do edifício

C.E. - centro elástico do edifício

E - módulo de elasticidade longitudinal do material

$\mathrm{e}_{\mathrm{X}}$ - excentricidade da força do vento que atua segundo a direção $\mathrm{X}$ do sistema global de referência

$\mathrm{e}_{\mathrm{y}}$ - excentricidade da força do vento que atua segundo a direção $\mathrm{Y}$ do sistema global de referência

$\mathrm{f}_{\mathrm{bk}}$ - resistência característica do bloco de concreto

$f_{\text {cis }}$ - tensão de cisalhamento admissível no elemento estrutural em alvenaria não-armada

$\overline{\mathrm{f}}_{\text {cisl }}$ - tensão de cisalhamento admissivel no elemento estrutural em alvenaria armada para dispensar o reforço com estribos

$\overline{\mathrm{f}}_{\text {cis2 }}$ - tensão de cisalhamento admissível no elemento estrutural em alvenaria armada

G - módulo de elasticidade transversal do material

$I_{i}$ - momento de inércia máximo segundo eixo principal de inércia

$\Delta_{\mathrm{i}}$ - deslocamento no topo do painel genérico $\mathbf{i}$

$\alpha$ - fator corretivo de matriz de rigidez para consideração da deformação por cisalhamento

$\eta$ - eficiência de prisma

$v$ - coeficiente de Poisson 
$\theta_{i}$ - rotação nodal sem acréscimo devido ao esforço cortante

$\sigma_{X}$ - tensão normal à seção transversal

$\sigma_{\mathrm{Y}}$ - tensão normal ao plano horizontal perpendicular à seção transversal

$\tau$ - tensão de cisalhamento prevista no lintel

$\tau_{1}$ - tensão de cisalhamento prevista na parede, associada ao modelo 1

$\tau_{2}$ - tensão de cisalhamento prevista na parede, associada ao modelo 2

$\tau_{3}$ - tensão de cisalhamento prevista na parede, associada ao modelo 3

$\tau_{4}$ - tensão de cisalhamento prevista na parede, associada ao modelo 4

$\tau_{\mathrm{XY}}$ - tensão de cisalhamento em seção transversal

$\omega_{i}$ - rotação nodal com acréscimo devido ao esforço cortante 


\section{RESUMO}

NASCIMENTO NETO, J. A. Investigação das solicitações de cisalhamento em edificios de alvenaria estrutural submetidos a ações horizontais. São Carlos, 1999. 127p. Dissertação (Mestrado) - Escola de Engenharia de São Carlos, Universidade de São Paulo.

Este trabalho apresenta uma análise minuciosa das solicitações de cisalhamento nas paredes de edifícios em alvenaria estrutural submetidos a ações horizontais. O estudo compreende a análise do comportamento global da estrutura, empregando-se diferentes modelagens numéricas para o sistema de contraventamento do edifício. Os modelos utilizados incluem a deformabilidade por cisalhamento das paredes e os efeitos provenientes da torção do edifício. Os resultados apresentados consistem em deslocamentos horizontais, distribuição dos esforços cortantes e momentos fletores entre as paredes, e análise das tensões de cisalhamento das paredes e lintéis. Avaliam-se, também, os diagramas de esforço cortante e momento fletor das paredes mais solicitadas.

Palavras-chave: alvenaria estrutural, edifícios, ações horizontais, torção, cisalhamento 


\begin{abstract}
NASCIMENTO NETO, J. A. Shear stress analysis on masonry buildings under lateral loads. São Carlos, 1999. 127p. Dissertação (Mestrado) Escola de Engenharia de São Carlos, Universidade de São Paulo.
\end{abstract}

This work presents a shear stress study of the shear walls of masonry buildings under lateral loads. The study consists of building overall structural behavior, with the use of different theoretical models for the lateral-load-resisting system of the building. The models include shear deformation and torsion effects. The results comprise horizontal displacement, shear force and bending moment distribution on shear walls, enhancing the shear stress verification of greater internal-forces values in walls and lintels. Shear force and bending moment diagrams related to the walls with the greater internal forces are also shown.

Keywords: structural masonry, buildings, horizontal forces, torsion, shear stress 


\section{INTRODUÇÃO}

\section{1 - Generalidades}

A alvenaria pode ser considerada como uma das mais antigas formas de construção utilizada pelo homem. Pode-se dizer que este tipo de sistema estrutural vem sendo utilizado desde a Antigüidade na construção de habitações, monumentos e templos religiosos, podendo ser citados: a pirâmide de Queops, o farol de Alexandria, e as grandes Catedrais Góticas.

O termo alvenaria estrutural refere-se ao tipo de construção cuja resistência depende unicamente das unidades de alvenaria argamassadas (blocos de concreto, blocos cerâmicos, tijolos cerâmicos maciços, etc) com grande capacidade resistente à compressão. Essas unidades devem agir como uma combinação íntegra para resistir aos esforços de compressão, bem como aos esforços cortantes. Resumidamente, são estruturas de paredes estruturais, capazes de resistir a grandes cargas verticais e, desde que não surjam tensões de tração ou se surgirem, que sejam determinados os reforços com barras de aço, também são capazes de apresentar considerável resistência às ações horizontais. Essas importantes considerações indicam o uso da alvenaria não armada preponderantemente nas regiões geográficas mais estáveis, onde não haja a possibilidade de ocorrência de abalos sísmicos, como é o caso do Brasil. 
As principais vantagens das construções em alvenaria estrutural consistem na utilização do mesmo elemento para atender as funções de estrutura, divisor do espaço físico, isolador térmico e acústico, e protetor contra o fogo e intempéries. Essa funcionalidade múltipla diminui significativamente a complicação de detalhes construtivos.

$\mathrm{Na}$ primeira metade do século atual os edifícios de múltiplos andares em estruturas aporticadas de aço e concreto armado foram preferidos em substituição às construções em alvenaria estrutural. Uma das principais razões para que isso ocorresse, segundo HENDRY et al (1981), é que as paredes estruturais eram analisadas por métodos empíricos que resultavam em dimensionamentos de paredes com espessuras excessivas. Um exemplo que demonstra a dificuldade enfrentada pelos projetistas de épocas anteriores é o Edifício Monadnock com 16 pavimentos, uma estrutura em alvenaria não armada de tijolos cerâmicos, construído em Chicago por volta de 1889-1891, FIGURA 1.1. As paredes estruturais que constituem o sistema de contraventamento, possuem em sua base uma espessura de aproximadamente 1,80m. Se tivessem sido utilizadas técnicas e métodos construtivos modernos, os projetistas do Monadnock utilizariam uma espessura de parede em torno de $30 \mathrm{~cm}$ ou menos. Estudos mais apurados, isto é, baseados em princípios científicos e análises laboratoriais, só tiveram um avanço significativo por volta de 1920, de acordo com DICKEY (1994). A partir de 1950, com a introdução das normas de cálculo estrutural, tornou-se possível o cálculo de paredes utilizando-se espessuras mais adequadas bem como resistências baseadas em métodos mais racionais. 


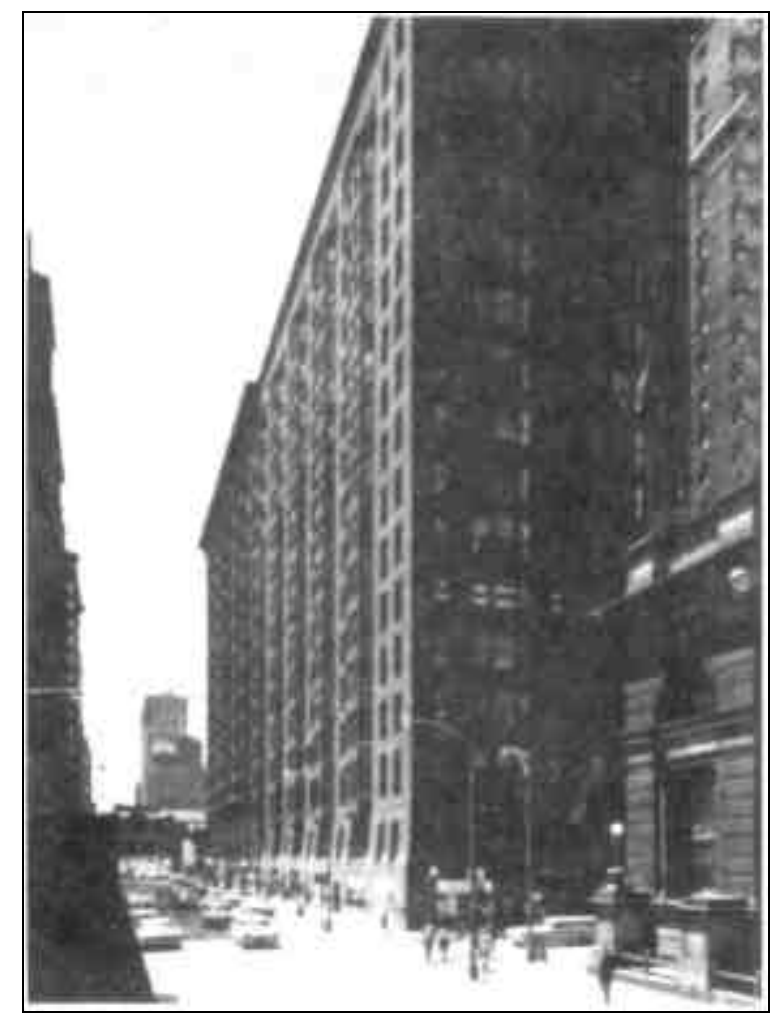

FIGURA 1.1 - Edifício Monadnock, símbolo da alvenaria estrutural [Retirado do manual da ABCI (1990)]

Apesar da alvenaria ser um dos mais antigos materiais de construção utilizado pelo homem, é provavelmente o menos conhecido no que diz respeito à idealização do seu comportamento estrutural. Relacionam-se muitos conceitos errôneos a esse tipo de material, alguns dos quais evidenciam-se através de uma utilização incorreta, como resultado de uma análise imprópria ou uma inadequada prática de construção.

Com o objetivo de diminuir cada vez mais a espessura das paredes, projetistas e construtores desenvolveram técnicas de análise que se aproximam mais do comportamento real da estrutura, permitindo assim, uma utilização mais racional do material, bem como o desenvolvimento de projetos mais econômicos, fundamentados em teorias mais bem elaboradas. O acúmulo de pesquisas e experiência prática ao longo dos últimos vinte anos tem levado à melhoria e refinamento das várias normas de cálculo, de modo que o projeto de edifícios em alvenaria estrutural pode 
ser desenvolvido em nível semelhante aos projetos em estruturas de aço e concreto.

No Brasil, o desenvolvimento da alvenaria estrutural de blocos de concreto ocorreu na década de 70, de acordo com a ABCI(1990). Nessa época já haviam sido construídos vários edifícios, podendo-se citar: o conjunto Central Parque Lapa, com quatro blocos de doze andares; o edifício Muriti, em São José dos Campos, de dezesseis andares, FIGURA 1.2; treze prédios de quatro andares e cinco de oito, na cidade de São Paulo. Esses exemplos pioneiros iniciaram uma nova etapa na construção de edifícios com a aplicação de tecnologias alternativas.

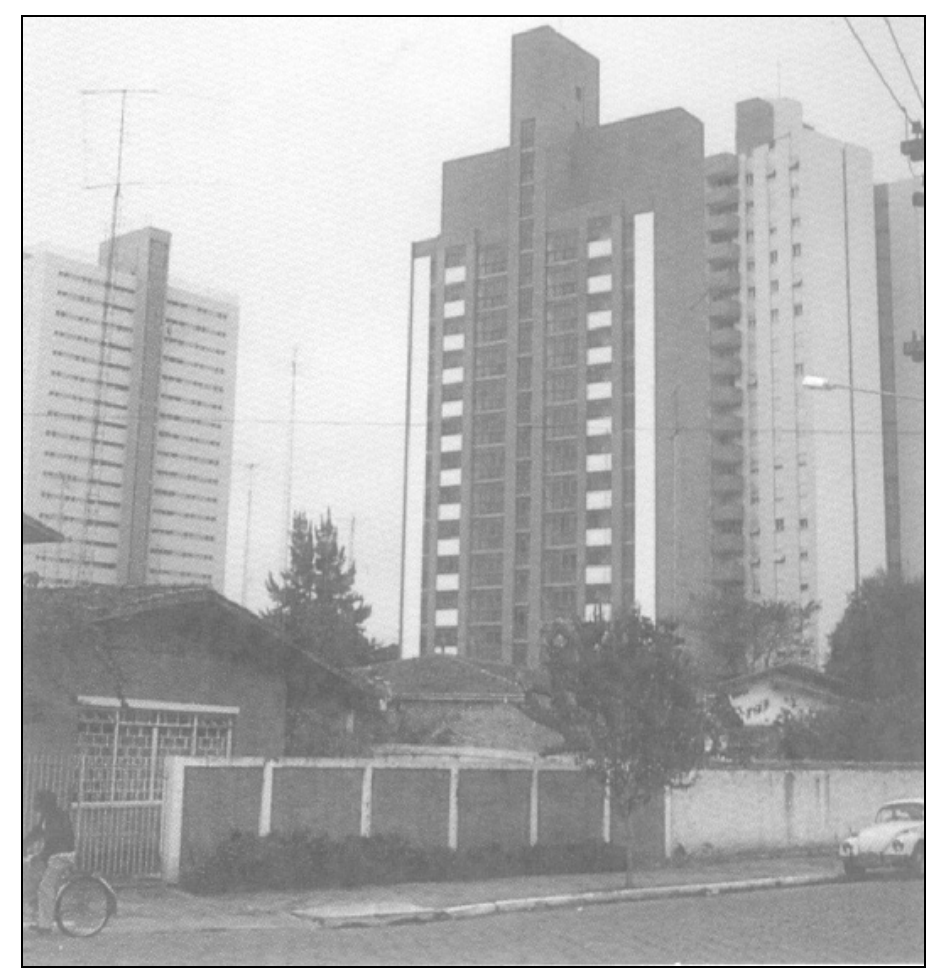

FIGURA 1.2 - Edifício Muriti, em São José dos Campos, SP [Retirado do manual da ABCI(1990)]

Ainda segundo a ABCI(1990), até 1972 os projetistas brasileiros não ousavam elaborar projetos de edifícios com mais de quatro pavimentos para serem construídos com blocos de concreto. Essa ousadia só foi estimulada após a passagem do projetista norte-americano Green Ferver 
pelo Brasil, que foi contratado como consultor pela empresa Regional, responsável pela construção do Central Parque Lapa.

Atualmente tem-se uma crescente demanda por projetos de edifícios em alvenaria estrutural, com a progressiva elevação do número de pavimentos e disposições menos simples das paredes em planta. Desse modo observam-se modificações consideráveis na distribuição da rigidez relativa dos diversos painéis de contraventamento, exigindo portanto, uma análise mais adequada do sistema estrutural do edifício. Dentro desse contexto insere-se a presente pesquisa, buscando estimar a intensidade das tensões de cisalhamento presentes nesses edifícios quando submetidos a ações horizontais, em que esse efeito é mais significativo, bem como ressaltar os cuidados que devem ser tomados pelo projetista estrutural quando da elaboração de seus cálculos e verificações. Analisou-se uma série de edifícios em alvenaria estrutural variando-se o arranjo de paredes em planta e o número de pavimentos de acordo com a prática de construção empregada no Brasil. Com a variação do arranjo de paredes observam-se diferenças apreciáveis nas rigidezes relativas dos painéis de contraventamento. Nesse caso, as paredes com maior comprimento em planta absorvem uma parcela maior da ação horizontal, e podem apresentar influência significativa das deformações por cisalhamento em seu comportamento estrutural.

\section{2 - Objetivos}

O objetivo da presente pesquisa consiste em se fazer uma análise teórica sobre sistemas estruturais de edifícios em alvenaria, de modo a obter informações com respeito ao nível das solicitações de cisalhamento. Pretende-se, também, melhorar a ferramenta de cálculo computacional atualmente disponível no SET/EESC/USP, introduzindo a possibilidade de modelar a torção do edifício, bem como elaborar um estudo de casos, dentro da análise de cisalhamento com e sem a inclusão da torção. Por fim, objetiva-se estudar a influência da deformação por cisalhamento na distribuição das solicitações provenientes das ações horizontais entre os painéis de contraventamento lateral do edifício. 


\section{3 - Justificativas}

O emprego da alvenaria estrutural na construção de edifícios tem apresentado um forte crescimento nos últimos anos. Este fato deve-se ao reconhecimento, entre muitas construtoras, das vantagens proporcionadas por esse sistema construtivo, entre elas: redução de fôrmas, do consumo de aço e revestimentos ${ }^{1}$; possibilidade de pré-fabricação de componentes estruturais; limpeza do canteiro de obras; redução dos desperdícios e diminuição dos procedimentos em obra, principalmente quando empregase a alvenaria não-armada. Semelhantemente a outros sistemas construtivos, a alvenaria estrutural apresenta algumas desvantagens, podendo-se citar: exigência de mão-de-obra qualificada; impedimento de reformas que modifiquem a disposição das paredes estruturais; e provável condicionamento do projeto arquitetônico.

A alvenaria estrutural tem sido utilizada como uma alternativa muito competitiva na construção de habitações, mesmo sem dispor-se do domínio tecnológico necessário para uma utilização mais racional desse sistema estrutural. Por essas razões, o interesse de projetistas, construtores e proprietários nesse sistema construtivo tem crescido bastante. Os métodos utilizados para concepção e projeto baseiam-se, segundo ACCETTI (1998), em normas nacionais pouco consolidadas ou na aplicação de normas estrangeiras baseadas em outras condições e critérios. Isso tem levado à ocorrência generalizada de patologias com conseqüente comprometimento das edificações. Desse modo, escolheu-se essa linha de pesquisa, buscando-se soluções mais adequadas para os sistemas estruturais dos edifícios em alvenaria, dentro do contexto da análise estrutural, tentando-se modelar o comportamento desses sistemas de forma racional e segura.

1 A redução do consumo de revestimento está associada a um controle mais rigoroso durante a execução das alvenarias, onde limitam-se os erros de prumo e alinhamento a valores pequenos. 


\section{4 - Estrutura da dissertação}

O trabalho foi divido em cinco capítulos: introdução, sistema estrutural de contraventamento, modelos de análise adotados, exemplos e conclusões.

O segundo capítulo contém informações a respeito do comportamento do sistema de contraventamento dos edifícios em alvenaria estrutural. Apresentam-se os elementos essenciais do sistema, tais como: paredes perpendiculares à ação do vento, paredes de contraventamento ou "shear walls”, diafragmas horizontais e as ligações entre esses elementos. Comenta-se o comportamento estrutural do sistema de contraventamento quando submetido a ações do vento que provoquem torção do edifício, bem como o avanço obtido na análise estrutural desses sistemas. Da mesma forma, apresentam-se alguns tipos de construções em alvenaria estrutural. Por fim, descrevem-se vários modelos empregados na análise estrutural de paredes de contraventamento, tanto para estruturas de alvenaria quanto para estruturas convencionais de concreto armado.

O terceiro capítulo apresenta minuciosamente os modelos adotados nesse trabalho para a análise dos edifícios utilizados no capítulo de exemplos. Os modelos são descritos com detalhes, tais como os efeitos da deformação por cisalhamento em elementos estruturais e a consideração dessa deformação, e a inclusão das barras horizontais rígidas e lintéis no sistema de contraventamento. São apresentadas análises prévias de um edifício.

O capítulo de exemplos contém análises para validação dos modelos adotados, sendo avaliados mediante comparação com estudos experimentais de modelos reduzidos em alvenaria estrutural de tijolos cerâmicos e blocos de concreto. Define-se um projeto básico que apresenta uma análise geral de um edifício de sete pavimentos, de modo que sejam determinados os resultados mais significativos a serem analisados nos exemplos consecutivos. Em seguida apresentam-se dois exemplos que finalizam as análises estruturais dos edifícios. O primeiro consiste num edifício de treze pavimentos, analisado com uma ação horizontal simétrica, 
sendo avaliados as modificações no comportamento estrutural empregando-se os dois modelos previamente adotados. O segundo consiste num edifício de nove pavimentos com uma forma mais alongada, sendo submetido a uma ação horizontal excêntrica, permitindo-se avaliar os acréscimos dos esforços devidos à torção do edifício.

No quinto capítulo são apresentadas as conclusões do presente trabalho, enfatizando-se os resultados obtidos com as modelagens utilizadas para análise das solicitações de cisalhamento bem como ressaltando-se os cuidados que devem ser tomados pelos engenheiros estruturais quando da utilização desses modelos. 


\section{SISTEMA ESTRUTURAL DE CONTRAVENTAMENO}

Existe vários tipos de sistemas estruturais de edifícios para resistir às ações laterais provenientes do vento e as transferir, a partir dos níveis dos pavimentos, para as fundações. Dentre os elementos estruturais verticais utilizados nesses sistemas, pode-se citar: paredes estruturais, pórticos de contraventamento, núcleos estruturais, e suas combinações. No caso dos elementos estruturais horizontais, responsáveis pela distribuição das ações laterais entre os elementos verticais, podem-se citar as lajes dos pavimentos agindo como diafragmas rígidos horizontais.

Os pavimentos dos edifícios em alvenaria estrutural necessitam de paredes com comprimento suficiente para garantir suas condições de apoio, além de garantir rigidez para o sistema de contraventamento. Em alguns casos, torna-se necessário considerar a influência das paredes dispostas perpendicularmente à direção analisada para garantir a estabilidade lateral. A resistência de uma parede de contraventamento é, primordialmente, dependente da rigidez desenvolvida no seu plano, não considerando-se portanto, a rigidez aos deslocamentos fora desse plano.

No caso dos edifícios em alvenaria estrutural, os elementos estruturais que garantem sua estabilidade lateral constituem-se, em parte, pelas paredes estruturais e pelos diafragmas horizontais. Vale salientar que esse sistema estrutural é solicitado tanto pelas ações horizontais quanto pelas ações verticais. 


\section{1 - Comportamento dos elementos estruturais}

O sistema estrutural de contraventamento dos edifícios em alvenaria pode ser idealizado por quatro elementos essenciais, FIGURA 2.1: as paredes perpendiculares à direção da carga lateral; os diafragmas rígidos horizontais ao nível das lajes; as paredes de contraventamento, também denominadas "shear walls", paralelas à direção de atuação da carga lateral; e as interseções ou conexões entre esses elementos que garantam a transferência de esforços.

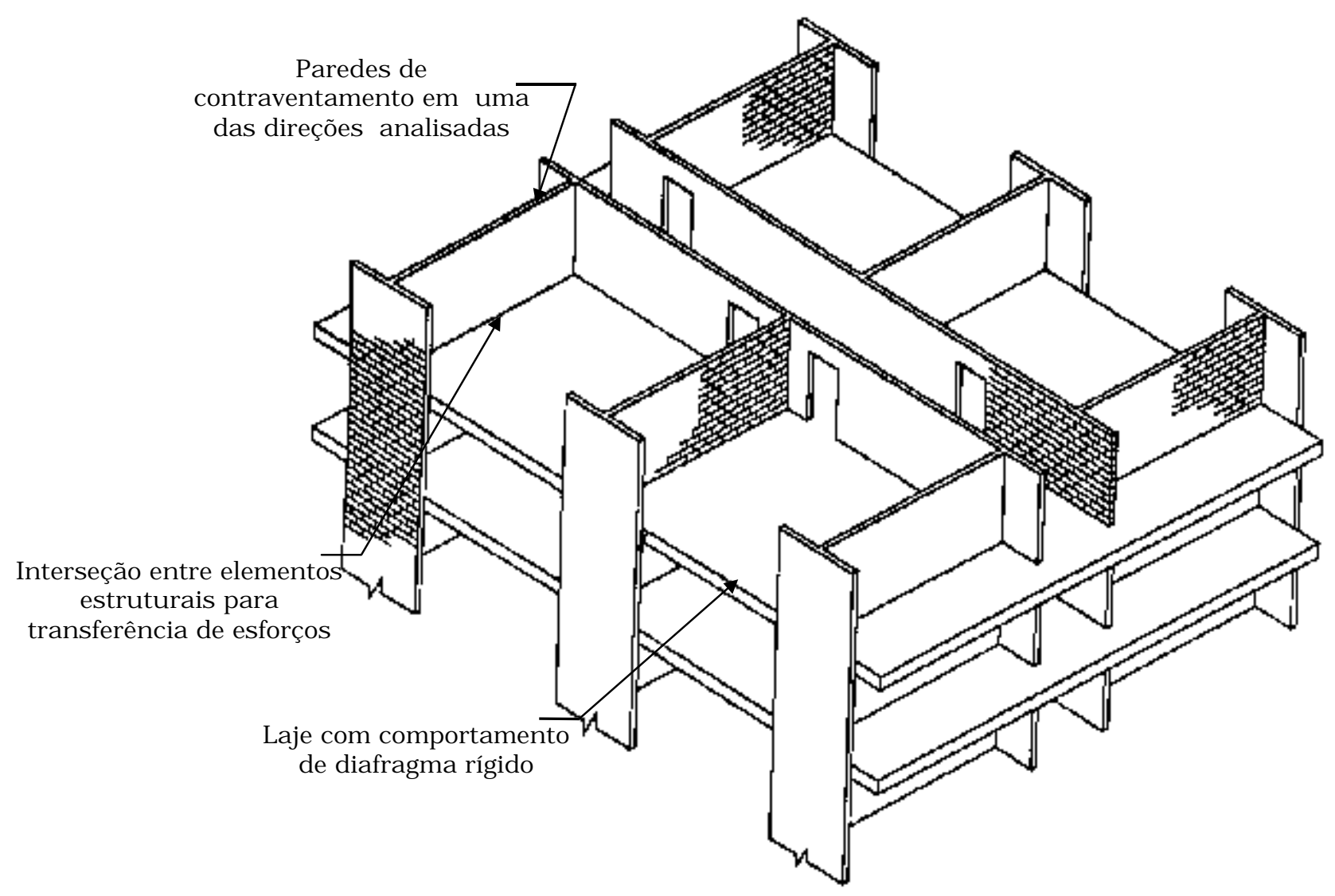

FIGURA 2.1 - Sistema estrutural de contraventamento dos edifícios em alvenaria [Retirado de DRYSDALE et al(1994)] 
As paredes perpendiculares a determinada direção de análise devem possuir seu vão livre limitado por diafragmas consecutivos, de modo que o efeito da ação do vento que age na faixa limitada pela metade desse vão, tanto acima quanto abaixo do pavimento em questão, possa ser considerado como atuante nesse diafragma.

As lajes agindo como diafragma rígido distribuem os esforços cortantes entre as paredes de contraventamento de acordo com suas rigidezes, cuja grandeza é influenciada significativamente tanto pelas deformações por flexão quanto pelas deformações por cisalhamento. O diafragma horizontal possui vãos livres delimitados pelas paredes de contraventamento, possibilitando a transferência da ação horizontal, esforços cortantes horizontais no contorno da laje, para as paredes de contraventamento ou "shear walls".

As interseções ou ligações entre paredes e lajes e entre paredes têm grande importância no comportamento estrutural do sistema de contraventamento. As interseções entre paredes e diafragmas devem ser capazes de transferir os esforços cortantes horizontais desses diafragmas para as paredes de contraventamento. Nas alvenarias não-armadas, a resistência das ligações depende basicamente da resistência de atrito ao cisalhamento que, segundo HENDRY et al(1981), pode ser associada a uma aderência inicial e à compressão vertical, conforme o critério de Coulomb². No caso das alvenarias armadas, a resistência antes da fissuração também depende da resistência de atrito ao cisalhamento, ao passo que a resistência após a fissuração depende tanto das barras verticais que passam pela interseção da parede com o diafragma quanto da correspondente resistência de atrito ao cisalhamento.

As paredes de contraventamento são capazes de absorver os esforços cortantes totais desenvolvidas nas interseções com os diafragmas rígidos. Com um projeto adequado dessas paredes, essas forças serão transferidas sem maiores problemas para as fundações. No caso em que o centro geométrico do edifício e o centro elástico do sistema de contraventamento não coincidem, deve-se acrescentar ao esforço cortante

${ }^{2}$ Vale salientar que neste trabalho não se fez uso do Critério de Coulomb e não se avaliou a resistência de atrito ao cisalhamento 
de cada parede uma parcela proveniente da rotação dos diafragmas rígidos, isto é, da torção do edifício. Um método de cálculo para considerar essa parcela adicional de esforço cortante é apresentado em HENDRY et al(1981).

Quando o arranjo estrutural apresenta uma distribuição em planta com algumas paredes oblíquas em relação ao sistema de eixos adotado, seria de enorme importância a inclusão dessas paredes no sistema de contraventamento. Essa importância pode ser associada a um efetivo acréscimo de rigidez do edifício, tanto nos casos de carregamentos simétricos quanto de carregamentos que mobilizem a torção do sistema estrutural. A incorporação das paredes oblíquas contribui para o refinamento da modelagem da estrutura do sistema de contraventamento.

De acordo com DRYSDALE et al(1994), alguns edifícios em alvenaria de grande e média alturas foram projetados e construídos utilizando-se as paredes de fachada como sistema de contraventamento do edifício. O último e mais alto edifício projetado nessas condições foi o Monadnock, construído em Chicago entre 1889 e 1891. Suas paredes exteriores, construídas com alvenaria de tijolos maciços e que consistem no sistema de contraventamento do edifício, possuem uma espessura na base em torno de $1,80 \mathrm{~m}$ que transmite uma carga muito elevada às fundações. Devido a este e outros fatores, passou-se a utilizar os pórticos metálicos, e posteriormente os pórticos em concreto armado, no sistema de contraventamento dos edifícios de múltiplos andares, deixando a alvenaria em segundo plano, utilizando-a apenas como elemento de fechamento.

Vinte anos depois, reconheceu-se que as paredes de alvenaria num edifício de múltiplos andares apresentam comportamento de paredes estruturais, resistindo às solicitações que se desenvolvem no seu próprio plano. Assim, na década de 60, alguns edifícios de múltiplos andares foram construídos em vários países utilizando-se paredes estruturais em alvenaria para garantir a estabilidade estrutural.

Para compreender-se melhor o avanço obtido na utilização dos sistemas estruturais em alvenaria, segundo DRYSDALE et al(1994), pode-se dividi-lo em dois tipos: edifícios cujo sistema de contraventamento é constituído pelas paredes dispostas perpendicularmente à direção de ação do vento, de modo que a espessura dessas paredes torna-se o fator 
principal do sistema, FIGURA 2.2a; e edifícios onde as paredes dispostas paralelamente à direção de ação do vento constituem um dos elementos do sistema de contraventamento, elegendo-se então, o comprimento em planta dessas paredes como a dimensão mais importante para a rigidez do sistema de contraventamento, FIGURA 2.2b. O ganho de eficiência estrutural dos edifícios analisados com técnicas mais bem elaboradas em relação àqueles analisados com técnicas menos apuradas, pode ser evidenciado pelo edifício Liberty Park East em Pittsburg, com 21 andares e paredes com espessura de $38 \mathrm{~cm}$, FIGURA 2.3.

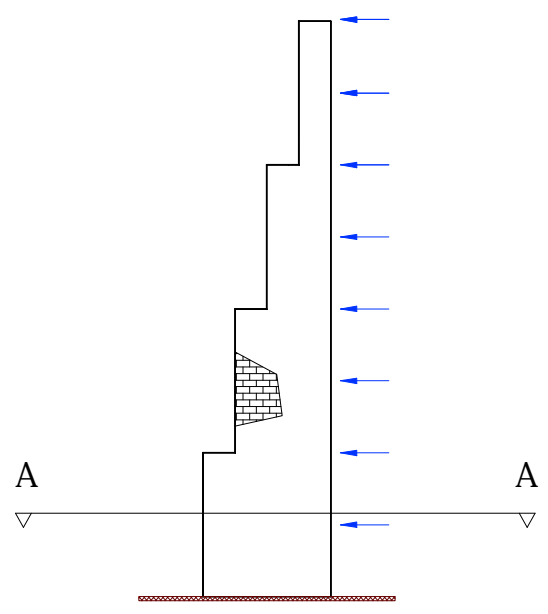

Elevação

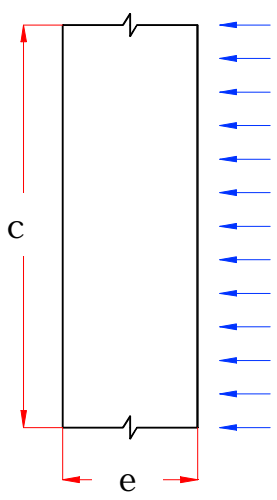

Corte A-A

a - Paredes perpendiculares à direção de ação do vento

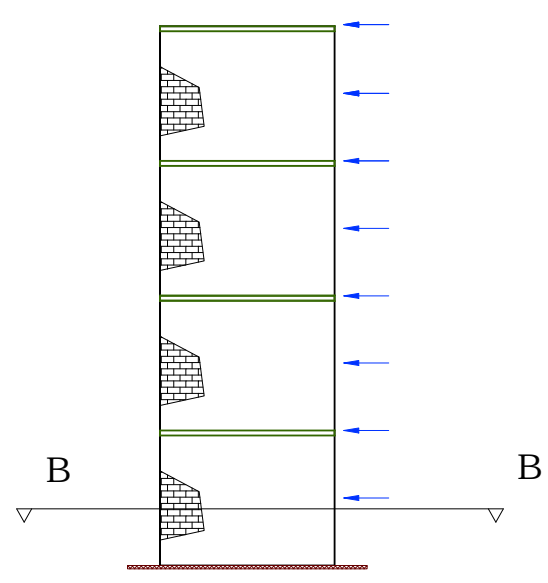

Elevação

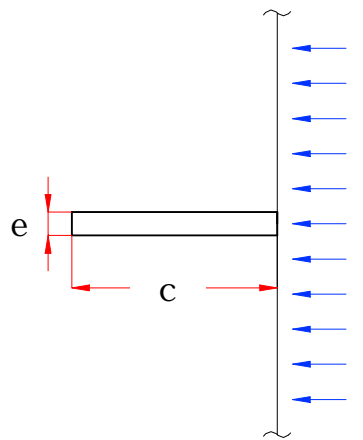

Corte B-B

b - Paredes paralelas à direção de ação do vento

FIGURA 2.2 - Idealizações das paredes de contraventamento dos edifícios em alvenaria estrutural 


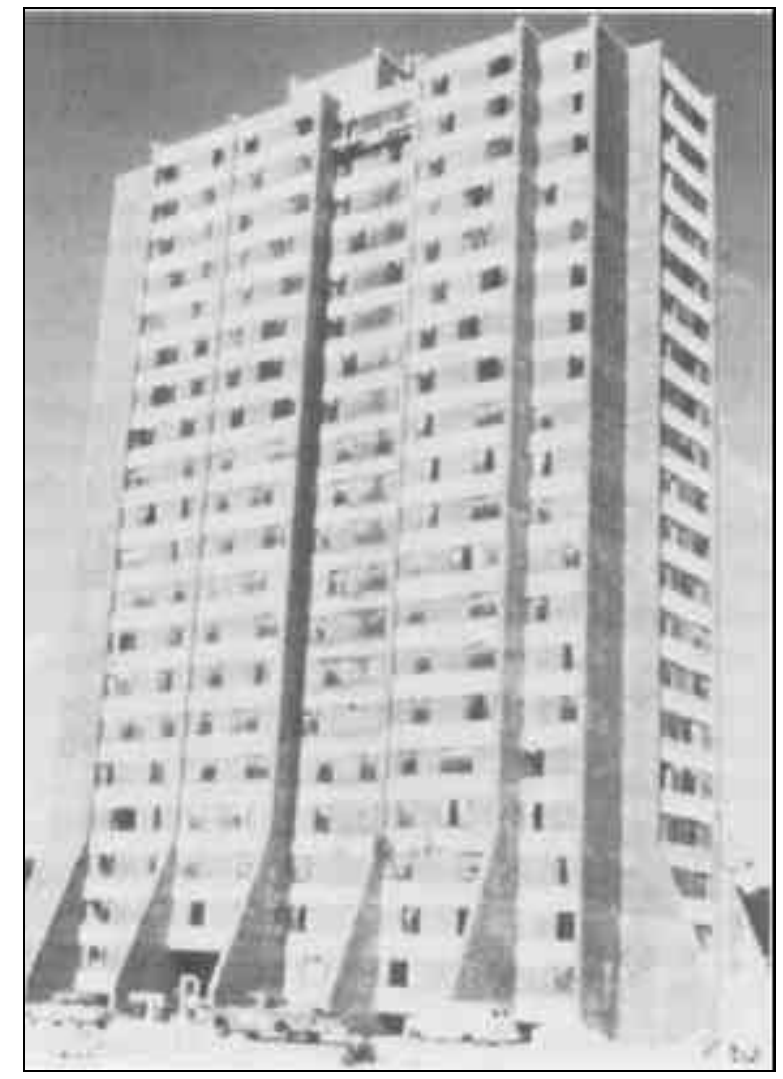

FIGURA 2.3 - Liberty Park East Tower, Pittsburg [Retirado de Drysdale et al (1994)]

Um outro fato bastante interessante é a utilização da alvenaria em conjunto com outros materiais para formar um sistema estrutural híbrido, segundo DRYSDALE et al(1994). Paredes estruturais em alvenaria têm sido utilizadas nos poços de elevadores e escadas dos sistemas estruturais em aço, sendo solicitadas tanto pelas ações verticais quanto pelas ações horizontais. Um outro exemplo é o preenchimento de estruturas aporticadas onde, para controlar os deslocamentos laterais do edifício, toma-se partido do acréscimo de rigidez que as paredes de alvenaria proporcionam. Estudos considerando-se esse acréscimo de rigidez podem ser encontrados em várias publicações, a exemplo de: SMITH, B. S.(1966); LIAUW, T. C.(1977). 


\section{2 - Tipos de construções em alvenaria}

Visto que as espessuras de parede têm diminuído ao mesmo tempo que a distância entre apoios (vãos) têm aumentado, torna-se imprescindivel a citação de alguns tipos de construção em alvenaria. DRYSDALE et al (1994) destaca três tipos de construções: alvenaria estrutural não-armada, alvenaria estrutural armada e alvenaria estrutural pré-tensionada.

A alvenaria estrutural não-armada tem sido utilizada em edifícios de pequena a média altura em regiões de baixa atividade sísmica. Pode-se considerar como a forma mais simples de construção, devido à ausência de reforço com armadura para absorver as tensões de tração atuantes, não inibindo-se no entanto, a utilização de armaduras que tenham como objetivo diminuir a fissuração. Devido ao bom desempenho da alvenaria à compressão e mal desempenho à tração, a alvenaria não-armada apresenta elevadas solicitações de compressão e solicitações de tração limitadas a valores de pequena intensidade.

A alvenaria estrutural armada não foi usualmente empregada em edifícios até, provavelmente, o século passado, data a partir da qual foi, principalmente, empregada em regiões de alta atividade sísmica da Índia, do Japão e dos Estados Unidos, sendo vastamente utilizada nos dias atuais em vários países. O reforço com barras de aço é adicionado à alvenaria de modo a absorver as tensões de tração e cisalhamento bem como acrescentar ductilidade à estrutura. O emprego da alvenaria armada tornou possível a construção do Hotel Excalibur em Las Vegas, uma estrutura com 28 pavimentos, no ano de 1989. As paredes dos pavimentos inferiores foram construídas com blocos de concreto e espessura de $30 \mathrm{~cm}$.

Uma inovação que ainda não tem grande divulgação no Brasil é a alvenaria estrutural pré-tensionada, que utiliza tirantes de aço de alta resistência para pré-tensionar a alvenaria. Nesta forma de construção, os tirantes de aço são posicionados em pontos pré-estabelecidos de uma parede em alvenaria não-armada para serem tracionados, de modo a aplicar uma compressão no trecho em que se localizam. A vantagem do 
pré-tensionamento torna-se evidente pela garantia da seção ficar totalmente comprimida. Além disso, os tirantes podem ser posicionados antes ou depois da construção da parede, do mesmo modo que suas ancoragens, e não necessitam ser grauteados, caso estejam protegidos contra a corrosão. Os princípios gerais do concreto protentido em pós-tração são aplicáveis à alvenaria pré-tensionada, considerando-se as diferenças entre as duas formas de construção.

\section{3 - Modelos para análise de paredes estruturais}

A interação de paredes de um edifício em alvenaria estrutural é um comportamento comprovado tanto teórica quanto experimentalmente, segundo CORRÊA E RAMALHO(1994). Esse comportamento é observado, inclusive em paredes que não estejam contidas no mesmo plano, desde que haja linhas de interseções verticais capazes de desenvolver as forças de interação. A conseqüência direta no comportamento estrutural das paredes é uma tendência de uniformização das tensões normais ao longo da altura do edifício, para análise com carregamento vertical, onde as paredes mais solicitadas descarregam seus excessos nas menos solicitadas. No caso da análise de ações horizontais, essa interação é atribuída à colaboração de flanges provenientes de paredes que apresentem interseções. De acordo com ACCETTI(1998), uma das vantagens da consideração das flanges é a diminuição dos deslocamentos das lajes pois, no caso de vãos usuais de edifícios residenciais, a contribuição das flanges aumenta a inércia dos painéis, com conseqüente redução das tensões normais.

Um outro fato bastante interessante é a equivalência que pode ser verificada entre a análise de paredes portantes, que se interceptem, de um edifício em alvenaria estrutural submetido a ações laterais, e o estudo de barras de seção transversal aberta e paredes delgadas, o que, de certo modo, assemelha-se à análise das paredes de núcleos estruturais em concreto armado. Ambos apresentam uniformidade de suas características geométricas bem como variação do esforço solicitante de torção ao longo da altura da edificação e impedimento dos deslocamentos axiais ao nível das fundações. Assim, os modelos de análise dos núcleos estruturais podem ser 
utilizados, com pequenas adaptações, na análise da estrutura de edifícios em alvenaria.

Em estudo desenvolvido por BARBOSA(1978) as paredes de um núcleo estrutural, constituindo uma seção aberta, são consideradas como elementos lineares (elementos de barra) com sete coordenadas por andar, as seis da análise tridimensional mais a referente ao empenamento. Sendo essa análise baseada na teoria de flexo-torção, faz-se necessária a determinação do centro de cisalhamento e o cálculo das áreas setoriais da seção. Também é analisada a contribuição dos lintéis no comportamento global da estrutura, permitindo-os que resistam aos esforços normais e cortantes, bem como aos momentos fletores e torçores.

Uma modelagem bastante conhecida no meio técnico, consiste na discretização do tramo de parede entre andares por meio de um pórtico plano, constituído por uma barra vertical acoplada a dois trechos rígidos horizontais ao nível dos andares. Nesse processo não é necessária a determinação do centro de cisalhamento e áreas setoriais. YAGUI(1978) utiliza esse processo considerando-se os lintéis como elementos de barra que contribuem diretamente na matriz de rigidez global. Simulações utilizando o modelo apresentado por Yagui podem ser encontradas em SERRA(1994) e PEREIRA(1997).

Um outro procedimento é desenvolvido por MORI(1994), que analisa os núcleos por meio das equações diferenciais das elásticas dos centros de torção em teorias de primeira e segunda ordem. Nessas equações não considera-se a influência das deformações por cisalhamento e sua solução resulta na matriz de rigidez do tramo de barra entre andares.

No que diz respeito às publicações relativas à análise de sistemas estruturais em alvenaria, pode-se citar KALITA \& HENDRY(1969) que fizeram testes experimentais em uma estrutura de múltiplos andares construída na escala 1:6 em tijolos cerâmicos e submetida a um carregamento lateral. O objetivo foi verificar se as teorias existentes para a análise de paredes estruturais poderiam ser utilizadas para analisar 
estruturas de edifícios de múltiplos andares em alvenaria de tijolos cerâmicos.

Algo semelhante foi investigado em KALITA \& HENDRY(1970), porém submetendo o modelo reduzido da estrutura a uma força horizontal excêntrica, de modo a acrescentar o efeito da torção.

Alguns métodos teóricos para análise de estruturas em alvenaria podem ser encontrados em HENDRY et al(1981). Os autores propõem que o cálculo da rigidez lateral e tensões em um sistema de paredes, sem a consideração de aberturas e disposto simetricamente, envolve uma simples teoria de flexão. Investigam-se cinco métodos básicos de análise para estimar os deslocamentos e tensões provenientes de ações horizontais: paredes isoladas, pórtico equivalente, pórtico equivalente com a inclusão de trechos rígidos, meio contínuo e elementos finitos. Também é proposto um equacionamento para distribuição das ações horizontais entre paredes de contraventamento dispostas assimetricamente em planta. A falta de simetria elimina a coincidência entre o centro elástico do edifício e o centro geométrico, onde normalmente consideram-se aplicadas as forças horizontais, de modo a gerar esforços adicionais provenientes da torção do edifício.

Analisou-se o comportamento de uma estrutura tridimensional de alvenaria em tijolos cerâmicos e a validade dos métodos analíticos citados, através de um modelo real de um edifício, utilizando-se uma pedreira desativada como estrutura de reação, FIGURA 2.4. A análise teórica foi desenvolvida substituindo-se a estrutura tridimensional por um sistema bidimensional equivalente de paredes e vigas com as mesmas áreas e momentos de inércia da estrutural real. 


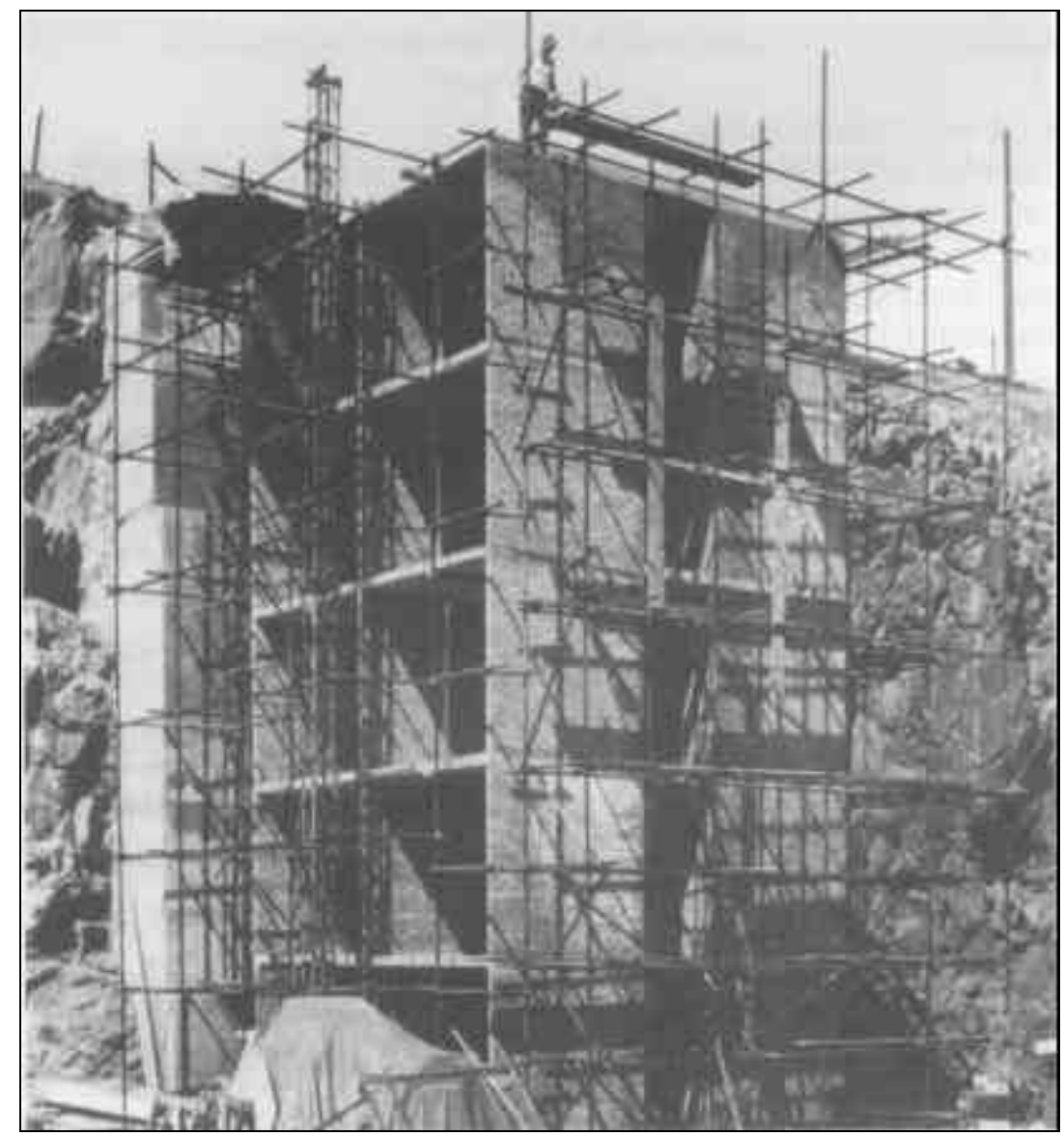

FIGURA 2.4 - Modelo real utilizado para obtenção dos resultados experimentais [Retirado de HENDRY et al (1981)]

No contexto da análise de paredes utilizando-se elementos de barra, cita-se o trabalho de STAFFORD SMITH \& GIRGIS(1984). Os autores desenvolveram dois modelos de pórtico equivalente. $\mathrm{O}$ primeiro é semelhante ao modelo de pórtico com trechos rígidos, diferenciando-se pela adição de uma diagonal de contraventamento em cada módulo, FIGURA 2.5. Um módulo simples consiste de vigas horizontais rígidas, com comprimento igual à largura do segmento de parede, conectadas a uma coluna central. Diagonais de contraventamento com extremidades articuladas são conectadas às extremidades das vigas.

$\mathrm{O}$ segundo modelo também inclui trechos rígidos horizontais e diagonais de contraventamento, no entanto a coluna central é substituída por uma coluna conectada a uma das extremidades dos trechos rígidos e por uma barra articulada conectada à outra extremidade, FIGURA 2.6. 


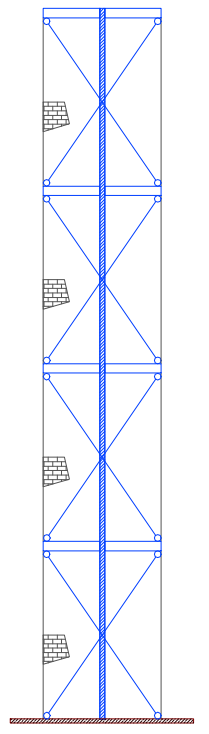

FIGURA 2.5 - Analogia de coluna larga com contraventamento

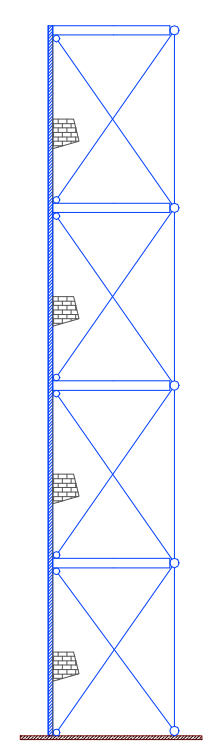

FIGURA 2.6 - Analogia de pórtico contraventado

O estudo de métodos analíticos foi, também, objetivo do trabalho de KWAN(1991) que investigou os problemas da deformação por esforço cortante e dos graus de liberdade rotacionais ao se aplicar o método do pórtico equivalente na análise de estruturas de paredes acopladas. Propõese a consideração da deformação por cisalhamento das paredes na matriz de rigidez dos trechos rígidos ao invés de considerá-la na matriz do elemento de barra da parede. Desenvolveu-se, também, um elemento sólido de parede, que incorpora trechos rígidos, com graus de liberdade rotacionais e consideração da deformação por cisalhamento.

Uma análise teórica para modelagem do comportamento de painéis de alvenaria com abertura pode ser encontrada em CORRÊA E RAMALHO(1994), onde propõe-se a determinação de uma estrutura linear que represente a rigidez do painel e estime as tensões na parede. Para isso são feitas comparações entre o modelo de barras e o modelo em elementos finitos. A princípio verifica-se a importância da consideração da deformação por cisalhamento no modelo de barras, através de resultados obtidos com 
modelagens de uma parede sem abertura. Em seguida investiga-se a representatividade do modelo de pórtico que utiliza trechos rígidos horizontais, FIGURA 2.7.
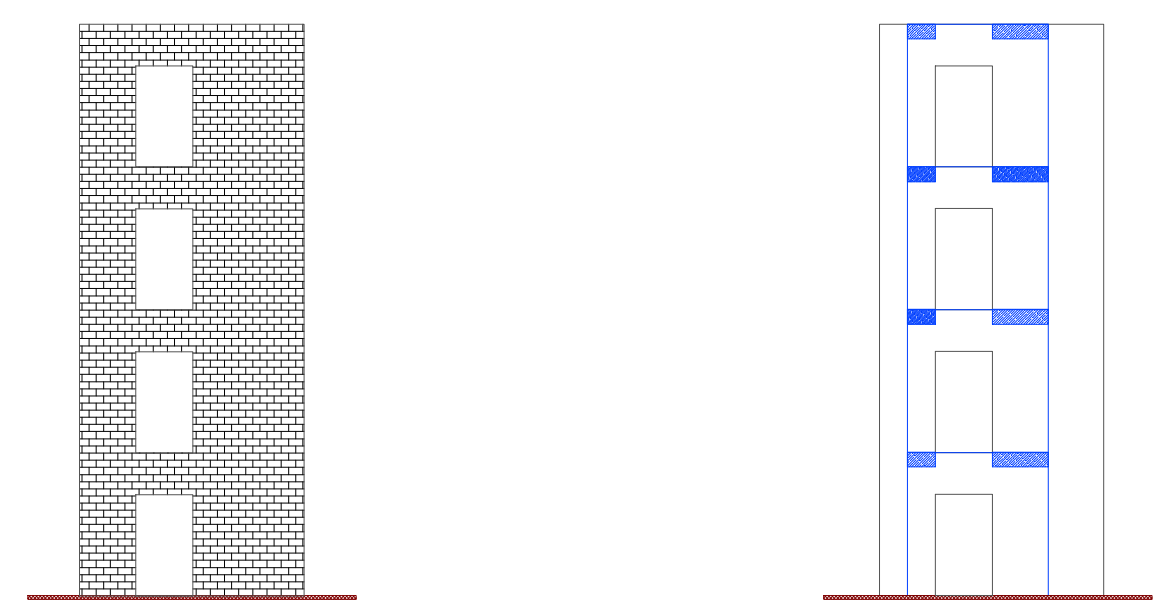

FIGURA 2.7 -Parede com aberturas e e modelo de pórtico com trecho rigído

Análise semelhante foi desenvolvida por LA ROVERE(1994), que estudou o comportamento de uma parede constituída de quatro pavimentos com uma distribuição variada de aberturas e submetida a ações horizontais. Nessa análise foram utilizados quatro métodos para modelagem. O método dos elementos finitos, onde as paredes foram discretizadas com um elemento híbrido de 4 nós. O método do pórtico equivalente, onde as paredes estruturais com aberturas são modeladas com elementos de barra cujos eixos coincidem com as linhas médias entre as aberturas e os nós são formados pela interseção entre essas linhas. O método das ligações rígidas, que é uma modificação do método do pórtico equivalente, onde a estrutura é modelada por elementos de pórtico plano com ligações infinitamente rígidas. A inclusão desses trechos rígidos ocorre por meio de uma translação de coordenadas da matriz de rigidez dos elementos barra. Por fim, o método das ligações flexíveis, desenvolvido em SAFFARINI E WILSON(1983), que modela a estrutura com elementos de barra ligados por elementos flexíveis. Esses elementos flexíveis são 
elementos finitos de estado plano de tensão com quatro nós, denominados elementos de junta.

Um estudo do efeito do vento em edifícios de alvenaria estrutural enfatizando-se os aspectos relacionados à modelagem das paredes foi desenvolvido por SILVA(1996). As paredes foram analisadas utilizando-se o método simplificado (associação plana de paredes isoladas) e o método do pórtico equivalente (associação plana de pórticos) com e sem inclusão de trechos rígidos. Nesses modelos é permitida à parede deformar-se sob solicitações axiais e de flexão e aos lintéis apenas sob solicitação de flexão. Foram, também, analisadas as modificações no comportamento de painéis com abertura, considerando-se algumas variações nas dimensões dessas aberturas. Nesse caso, identificaram-se os comportamentos de paredes isoladas, quando as aberturas não apresentam influência significativa no comportamento estrutural; e de pórticos, quando as aberturas influenciam significativamente a rigidez da estrutura. Os exemplos processados permitiram verificar a importância dos lintéis e dos trechos rígidos no comportamento global da estrutura bem como a influência benéfica da consideração de flanges, no entanto não verificou-se nesses modelos a influência das deformações por cisalhamento das paredes e os efeitos causados pela torção do edifício, sendo esses dois dos objetivos do presente estudo. 


\section{MODELOS ADOTADOS PARA ANÁLISE}

As análises dos edifícios basearam-se em dois modelos distintos que permitiram avaliar-se globalmente o comportamento do sistema de contraventamento. O primeiro consiste em uma modelagem bastante simples, utilizada em alguns escritórios de projetos, escolhido aqui para que sejam feitas análises, comparações e recomendações a respeito dos processos de cálculo utilizados por profissionais da área de engenharia de estruturas. O segundo consiste em uma modelagem mais precisa que permite uma análise mais elaborada, incluindo no comportamento global da estrutura a deformabilidade por cisalhamento das paredes e os efeitos da torção no edifício. Todas as análises são desenvolvidas adotando-se comportamento elástico linear para o sistema de contraventamento. A descrição detalhada desses modelos é apresentada nos itens 3.1 e 3.2.

\section{1 - Modelo de barras isoladas}

\subsection{1 - Apresentação}

A modelagem descrita nesse item foi utilizada para desenvolverem-se as análises iniciais dos edifícios, objetivando-se avaliar as modificações que ocorrem na distribuição da rigidez relativa entre os painéis de 
contraventamento, acrescentando-se às suas deformações aquelas provenientes das solicitações de cisalhamento.

O modelo utilizado nessa etapa foi o de barras isoladas, que é uma modelagem usual em alguns escritórios de projeto por apresentar simplicidade em sua aplicação. O método consiste basicamente na determinação da rigidez relativa de cada painel, para em seguida obter-se a parcela da ação do vento absorvida, bem como os respectivos momentos fletores e tensões normais.
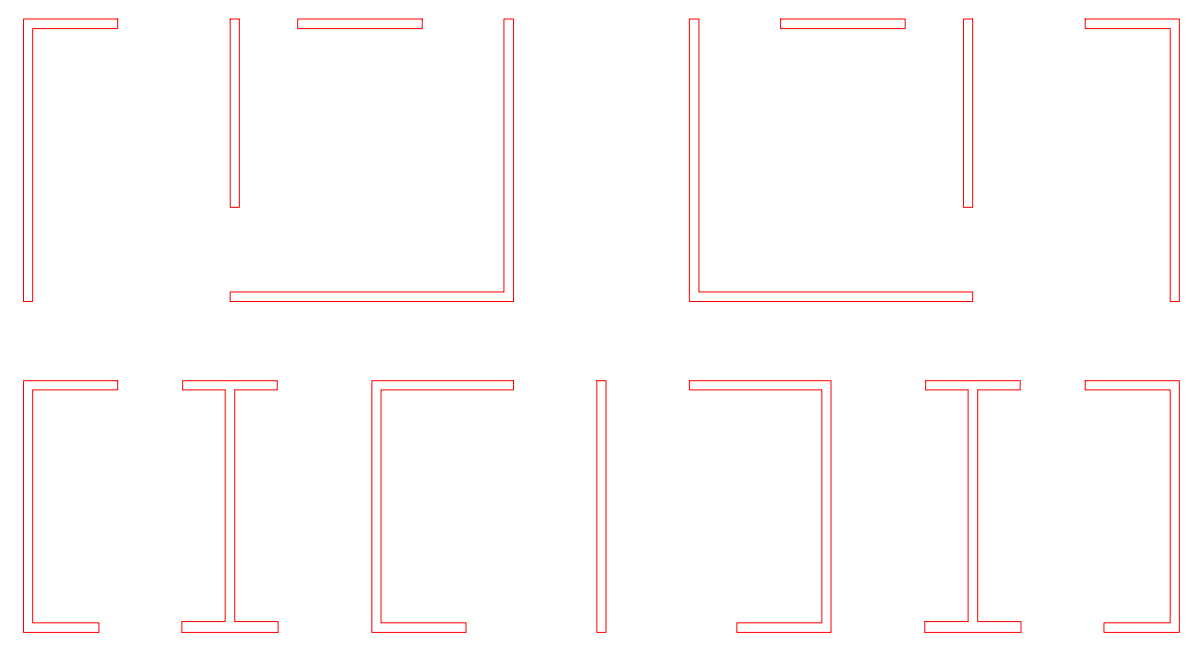

FIGURA 3.1 - Representação em planta de painéis de contraventamento

A rigidez relativa pode ser entendida como a razão entre a rigidez de cada painel $\underline{i}$ e a rigidez total ou somatório das rigidezes de todos os painéis.

Uma análise simplificada utilizando-se uma associação plana de painéis, empregada para obter-se a distribuição aproximada das rigidezes, é proposta pela $\mathrm{ABCI}(1990)$. Nesse caso, a estrutura é idealizada como painéis constituídos por paredes sem abertura e em balanço, de modo que a rigidez relativa pode ser expressa pelo quociente entre deslocamentos da seguinte forma: 


$$
\mathrm{R}_{\mathrm{i}}=\frac{\Delta_{\mathrm{i}}}{\sum_{1}^{\mathrm{m}} \Delta_{\mathrm{j}}}
$$

sendo $\underline{i}$ o painel em análise e $\underline{m}$ o número de painéis.

Os deslocamentos $\Delta$ podem ser obtidos considerando-se uma força unitária concentrada no topo da parede, sendo associados a duas parcelas:

$$
\Delta_{\mathrm{i}}=\frac{\mathrm{H}^{3}}{3 \mathrm{EI}}+\frac{\mathrm{cH}}{\mathrm{GA}}
$$

onde: $\quad \mathrm{H}=$ altura da parede

$\mathrm{c}=$ fator corretivo da distribuição da tensão de cisalhamento (para seções retangulares vale 1,2 )

$\mathrm{E}, \mathrm{G}=$ módulos de elasticidade longitudinal e transversal, respectivamente

$\mathrm{I}, \mathrm{A}=$ inércia $\mathrm{e}$ área da seção transversal da parede, respectivamente

O primeiro termo na equação (3.2) refere-se aos deslocamentos devidos à flexão, enquanto que o segundo aqueles devidos aos esforços cortantes.

De acordo com indicações da resistência dos materiais, paredes altas podem ser definidas como aquelas que apresentam altura total superior a cinco vezes a maior dimensão em planta. Ao contrário, paredes baixas podem ser aquelas onde essa relação é menor que cinco. No caso de paredes altas que apresentem uniformidade em suas características geométricas ao longo da altura, os deslocamentos devidos à flexão são predominantes em relação aos devidos ao esforço cortante, podendo-se desse modo desprezar a segunda parcela na equação (3.2). Tomando-se o caso particular de seção retangular (fator de forma $c=1,2$ ), paredes altas, 
que corresponde a se adotar no mínimo $\mathrm{H}=5 \mathrm{~L}$, e considerando-se a relação entre módulos elástico $\mathrm{G}=\frac{\mathrm{E}}{2(1+\mathrm{v})}$ (adotando-se $v=0,15$ ), obtém-se:

$$
\Delta_{\mathrm{i}}=\frac{41,7 \mathrm{~L}^{3}}{\mathrm{EI}}+\frac{1,15 \mathrm{~L}^{3}}{\mathrm{EI}}
$$

sendo L o comprimento da parede em planta.

A equação 3.3 demonstra a predominância dos deslocamentos devidos à flexão em relação aos deslocamentos devidos aos esforços cortantes, onde a segunda parcela representa $3 \%$ da primeira, no caso de paredes altas.

Nesse caso, a rigidez relativa pode ser associada, tão somente, aos deslocamentos devidos à flexão, de modo que a equação 3.1 ganha a seguinte redação:

$$
\mathrm{R}_{\mathrm{i}}=\frac{\mathrm{I}_{\mathrm{i}}}{\sum_{1}^{\mathrm{m}} \mathrm{I}_{\mathrm{j}}}
$$

Determinada a rigidez relativa, obtém-se a parcela da ação do vento (quinhão de carga) absorvida em cada painel:

$$
\mathrm{F}_{\mathrm{i}}=\mathrm{F}_{\text {tot }} \mathrm{xR}_{\mathrm{i}}
$$

sendo: $\quad \mathrm{F}_{\text {tot }}=$ força do vento em determinado pavimento

Em seguida determinam-se os respectivos momentos fletores, para finalmente obterem-se as tensões normais com a formulação da resistência dos materiais: 


$$
\sigma=\frac{\mathrm{M}}{\mathrm{W}}
$$

sendo: $\mathrm{M}=$ momento fletor atuante na seção

$\mathrm{W}$ = módulo resistente da seção

Vale salientar que a NBR-10837 recomenda a consideração das flanges provenientes de paredes que interceptem o painel de contraventamento. Nesse caso, essas flanges devem ter um comprimento máximo igual a 6t, sendo $\mathbf{t}$ a espessura da parede que contribui com a aba.

As seções compostas finais, segundo ACCETTI(1998), apresentam uma série de vantagens, podendo-se citar como uma das principais o considerável ganho de inércia dos painéis. Como mencionado em itens anteriores, para os vãos usuais de edifícios residenciais, dobram-se as inércias dos painéis com a consideração das flanges, de modo que constituem um dos fatores para redução das tensões normais nas paredes. Se a aba ou flange não for considerada, a rigidez obtida pode não representar adequadamente o comportamento do painel, de modo que podese obter uma distribuição incorreta das ações do vento como conseqüência de uma má representação das rigidezes relativas.

Deve-se ressaltar que o procedimento de associação plana de paredes isoladas só apresenta resultados satisfatórios para uma ação do vento que atue segundo um eixo de simetria. Em caso contrário, torna-se imprescindível a utilização de rotina de cálculo que permita considerar as rotações que ocorrem no plano das lajes. Nesse sentido as paredes podem ser modeladas com elementos barras tridimensionais admitindo-se às lajes o comportamento de diafragma rígido, de modo que o procedimento de paredes isoladas ainda pode ser utilizado, FIGURA 3.2. 


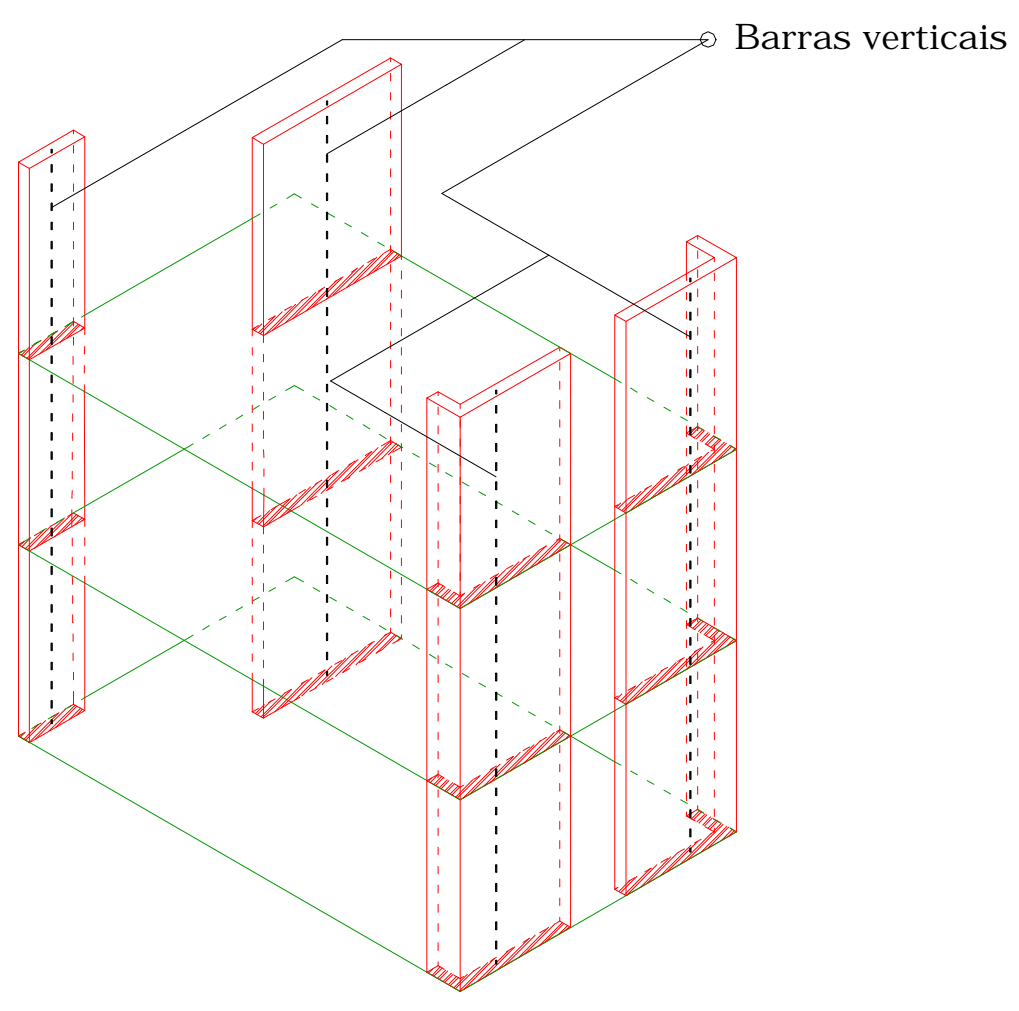

FIGURA 3.2 - Modelagem com elementos barra tridimensional

Segundo CORRÊA \& RAMALHO(1996) é suficiente a utilização de um programa que modele as paredes com elementos barra tridimensionais e que possua o recurso do nó mestre. O elemento de barra simula o tramo de parede situado entre lajes adjacentes, onde os deslocamentos desses pavimentos são relacionados com seus respectivos nós mestres. $O$ comportamento de diafragma rígido é garantido na modelagem no instante em que associam-se os deslocamentos no plano do pavimento aos deslocamentos do nó mestre, compatibilizando-os e diminuindo o número de graus de liberdade associados aos nós do pavimento. Os deslocamentos de cada nó são dependentes dos do nó mestre que podem ser definidos como duas translações no plano do pavimento e uma rotação em torno do eixo normal ao mesmo plano. Para os demais nós consideram-se os graus de liberdade relativos a duas rotações segundo os eixos contidos no plano 
do pavimento e uma translação na direção do eixo normal a esse plano, FIGURA 3.3.

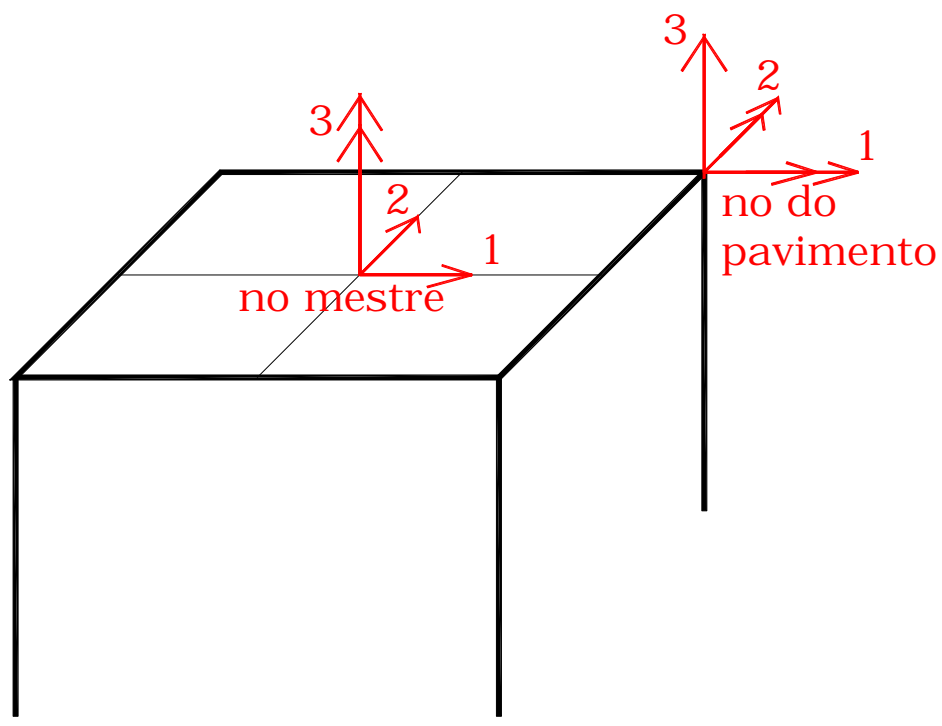

FIGURA 3.3 - Graus de liberdade dos nós

Um procedimento para determinação do acréscimo de esforços devidos à rotação do pavimento, utilizando-se a associação plana de paredes isoladas, foi desenvolvido em HENDRY et al(1981). Seja a FIGURA 3.4 que representa uma distribuição assimétrica de paredes em planta. O nó mestre deve ser posicionado no centro elástico do edifício ao invés do centro geométrico, onde serão aplicadas as respectivas forças concentradas e momentos torçores. O comportamento estrutural é analisado sob dois aspectos: o primeiro é devido às translações das lajes, que são associadas ao efeito das cargas concentradas, cuja análise pode ser feita pelo procedimento exposto anteriormente; e o segundo é devido às rotações dessas lajes, que são associadas ao efeito dos momentos torçores. O efeito desses momentos determina uma modificação nos deslocamentos dos nós do pavimento, gerando esforços cortantes adicionais que podem aumentar ou diminuir os esforços de cisalhamento absorvidos em cada painel. 


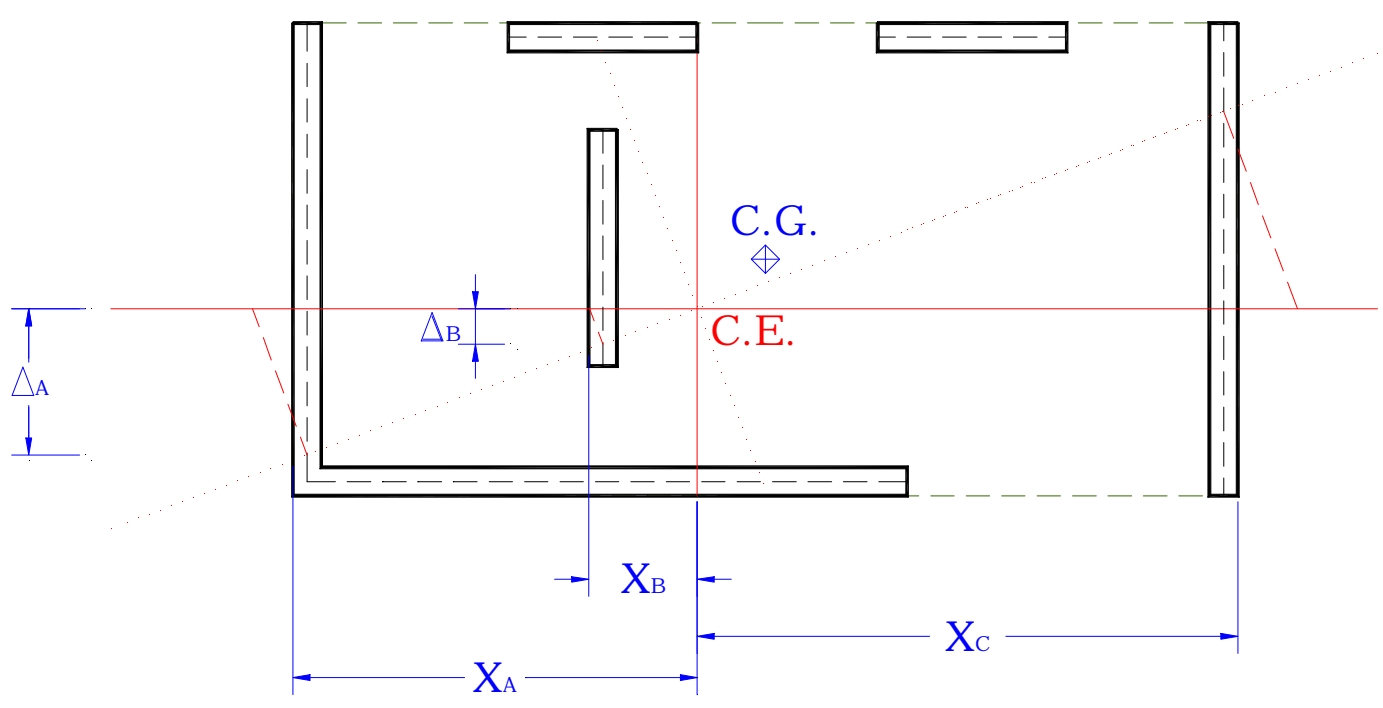

FIGURA 3.4 - Distribuição assimétrica de paredes de contraventamento (adaptado de HENDRY and SINHA[1981])

Ao rotacionar, a laje fornece um acréscimo no deslocamento dos nós, que foram definidos, respectivamente, para as paredes A,B e C como: $\Delta_{\mathrm{A}}$, $\Delta_{\mathrm{B}}$ e $\Delta_{\mathrm{C}}$, FIGURA 3.4. Sendo a laje idealizada com o comportamento de diafragma rígido, pode-se dizer que esses acréscimos são proporcionais à distância entre os referidos nós e o centro elástico do edifício:

$$
\frac{\Delta_{\mathrm{A}}}{\mathrm{X}_{\mathrm{A}}}=\frac{\Delta_{\mathrm{B}}}{\mathrm{X}_{\mathrm{B}}}=\frac{\Delta_{\mathrm{C}}}{\mathrm{X}_{\mathrm{C}}}
$$

Definindo-se $\mathrm{F}_{\mathrm{A}}, \mathrm{F}_{\mathrm{B}}$ e $\mathrm{F}_{\mathrm{C}}$ como os esforços cortantes nas paredes devidas à translação da laje, e $\quad F_{\mathrm{A}^{\prime}}, \mathrm{F}_{\mathrm{B}^{\prime}}$ e $\mathrm{F}_{\mathrm{C}^{\prime}}$ como aquelas devidas à rotação dessa mesma laje, e fazendo-se o equilíbrio de momentos pode-se escrever:

$$
\mathrm{F}_{\mathrm{A}^{\prime}} \mathrm{X}_{\mathrm{A}}+\mathrm{F}_{\mathrm{B}^{\prime}} \mathrm{X}_{\mathrm{B}}+\mathrm{F}_{\mathrm{C}^{\prime}} \mathrm{X}_{\mathrm{C}}=\mathrm{F} \cdot \mathrm{e}
$$


Os deslocamentos na equação (3.7) podem ser determinados pela equação (3.2), obtendo-se:
$\Delta_{\mathrm{A}}=\frac{\mathrm{F}_{\mathrm{A}^{\prime} \mathrm{H}^{3}}}{3 \mathrm{EI}_{\mathrm{A}}}$
$\Delta_{\mathrm{B}}=\frac{\mathrm{F}_{\mathrm{B}^{\prime}} \mathrm{H}^{3}}{3 \mathrm{EI}_{\mathrm{B}}}$
$\Delta_{\mathrm{C}}=\frac{\mathrm{F}_{\mathrm{C}^{\prime} \mathrm{H}^{3}}}{3 \mathrm{EI}_{\mathrm{C}}}$

Fazendo-se a análise da parede A, obtêm-se as seguintes relações da equação (3.7):

$\mathrm{F}_{\mathrm{B}^{\prime}}=\frac{\mathrm{I}_{\mathrm{B}} \mathrm{X}_{\mathrm{B}}}{\mathrm{I}_{\mathrm{A}} \mathrm{X}_{\mathrm{A}}} \mathrm{F}_{\mathrm{A}^{\prime}} \quad \mathrm{F}_{\mathrm{C}^{\prime}}=\frac{\mathrm{I}_{\mathrm{C}} \mathrm{X}_{\mathrm{C}}}{\mathrm{I}_{\mathrm{A}} \mathrm{X}_{\mathrm{A}}} \mathrm{F}_{\mathrm{A}^{\prime}}$

Substituindo-se essas relações na equação (3.8) obtêm-se:

$$
\begin{aligned}
& \frac{I_{A} X_{A}}{I_{A} X_{A}} X_{A^{\prime}} F_{A^{\prime}}+\frac{I_{B} X_{B}^{2}}{I_{A} X_{A}} F_{A^{\prime}}+\frac{I_{C} X_{C}^{2}}{I_{A} X_{A}} F_{A^{\prime}}=F \cdot e \\
& \mathrm{~F}_{\mathrm{A}^{\prime}}=\left(\frac{\mathrm{I}_{\mathrm{A}} \mathrm{X}_{\mathrm{A}}}{\mathrm{I}_{\mathrm{A}} \mathrm{X}_{\mathrm{A}}^{2}+\mathrm{I}_{\mathrm{B}} \mathrm{X}_{\mathrm{B}}^{2}+\mathrm{I}_{\mathrm{C}} \mathrm{X}_{\mathrm{C}}^{2}}\right) \mathrm{F} \cdot \mathrm{e}
\end{aligned}
$$

A equação (3.9) determina a parcela adicional de esforço cortante na parede A devida à rotação da laje. Do mesmo modo determinam-se os acréscimos de esforço cortante para as demais paredes, o que pode ser expresso escrevendo-se a equação (3.9) de uma forma mais genérica:

$$
F_{i^{\prime}}=\frac{I_{i} X_{i}}{\sum_{1}^{m} I_{j} X_{j}^{2}} F \cdot e
$$


O esforço cortante total em uma parede genérica $\underline{i}$ é obtido pela superposição dos efeitos:

$$
\mathrm{F}_{\mathrm{Ti}}=\mathrm{F}_{\mathrm{i}}+\mathrm{F}_{\mathrm{i}^{\prime}}
$$

sendo: $\quad \mathrm{F}_{\mathrm{i}}=$ esforço cortante devido à translação da laje, ou seja, parcela devida à força concentrada no pavimento

$\mathrm{F}_{\mathrm{i}^{\prime}}=$ acréscimo de esforço cortante devido à rotação da laje, isto é, parcela associada ao momento de torção aplicado no pavimento

\subsection{2 - Deformação por cisalhamento}

A primeira modificação desenvolvida na ferramenta computacional utilizada (Sistema Laser), consiste na incorporação das deformações por cisalhamento no modelo de barras isoladas. A consideração dessas deformações consiste basicamente na determinação de um fator de forma $\underline{c}$ da seção, equação 3.12, de modo a obter-se a correspondente área de cisalhamento que é utilizada para modificar-se a matriz de rigidez do elemento de barra da respectiva parede.

O fator de forma da seção pode ser obtido de modo simplificado, segundo GERE, J. M. y WEAVER JR., W.(1970). Esse método simplificado consiste no quociente entre áreas expresso como:

$$
\mathrm{c}=\frac{\mathrm{A}_{\mathrm{T}}}{\mathrm{A}_{\mathrm{alma}}}
$$

sendo: $\mathrm{A}_{\mathrm{T}} \quad=$ área total da seção

$\mathrm{A}_{\mathrm{alma}}=$ área da alma da seção, isto é, área total sem a contribuição das abas ou flanges 
Para os tipos de seções encontradas em edifícios de alvenaria estrutural, essa aproximação apresenta resultados satisfatórios quando comparados com soluções mais exatas, como por exemplo a solução utilizando-se a Viga de Timoshenko. Nessa segunda solução o fator de forma depende de uma quantidade maior de parâmetros geométricos, tornando muito mais trabalhosa sua obtenção.

Como ilustração apresentam-se os fatores de forma obtidos com o método simplificado e com a Viga de Timoshenko para dois tipos de seções bastante comuns em paredes de contraventamento, Tabela 3.1. Esses resultados foram obtidos utilizando-se seções com espessura constante de $14 \mathrm{~cm}$, alma com comprimento de $202 \mathrm{~cm}$ e mesas com $37 \mathrm{~cm}$.

Tabela 3.1 - Comparação entre fatores de forma

\begin{tabular}{c|c|c}
\hline \multicolumn{2}{c}{ Fator de forma para seção transversal } \\
\hline Tipo da seção & $\begin{array}{c}\text { Método } \\
\text { simplificado }\end{array}$ & $\begin{array}{c}\text { Determinação pela } \\
\text { Viga de Timoshenko }\end{array}$ \\
\hline $\mathbf{I}$ & 1,37 & 1,43 \\
\hline $\mathbf{T}$ & 1,18 & 1,33 \\
\hline
\end{tabular}

O efeito causado pelas deformações provenientes das solicitações de cisalhamento pode ser melhor entendido através de alguns exemplos encontrados em TIMOSHENKO(1980). Como ilustração apresenta-se o exemplo de uma barra engastada numa extremidade e livre na outra.

Considere a barra prismática da FIGURA 3.5 com seção transversal retangular delgada e largura unitária submetida à flexão por uma força $\mathbf{P}$ aplicada em sua extremidade livre. 

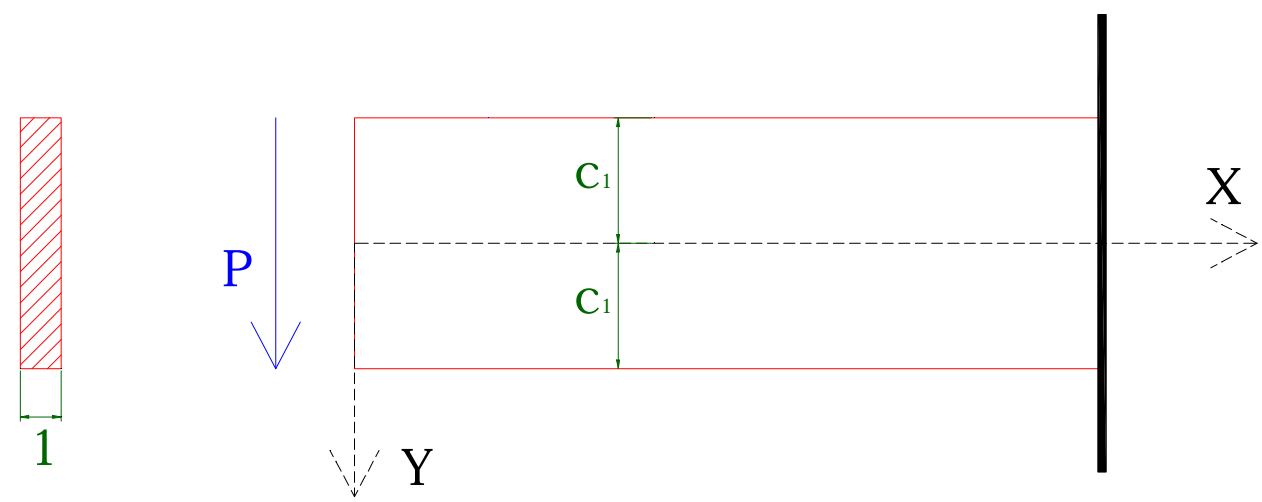

FIGURA 3.5 - Viga de seção transversal delgada e largura unitária

Segundo TIMOSHENKO(1980) a solução de problemas bidimensionais resume-se à integração das equações diferenciais de equilíbrio satisfazendose à equação de compatibilidade e às condições de contorno. Durante a resolução dessas equações pode-se utilizar o que se denomina função de tensão, onde as equações das tensões no elemento estrutural dependem dessa função.

No caso do exemplo da barra em balanço, sua solução resulta nas seguintes equações de tensões:

$$
\begin{aligned}
& \sigma_{X}=-\frac{P}{I} X Y \\
& \sigma_{Y}=0 \\
& \tau_{X Y}=-\frac{P}{2 \cdot I}\left(c_{1}^{2}-Y^{2}\right)
\end{aligned}
$$

sendo I a inércia da seção transversal.

Aplicando-se a Lei de Hooke às equações 3.13, integrando-se e substituindo-se as condições de contorno válidas nessa solução, obtêm-se as seguintes equações para os deslocamentos das seções transversais: 


$$
\begin{aligned}
& u=-\frac{P}{2 E I} X^{2} Y-\frac{v P}{6 E I} Y^{3}+\frac{P}{6 G I} Y^{3}+\left(\frac{P^{2}}{2 E I}-\frac{P_{1}^{2}}{2 G I}\right) Y \\
& v=\frac{v P}{2 E I} X Y^{2}+\frac{P}{6 E I} X^{3}-\frac{P^{2}}{2 E I} X+\frac{P^{3}}{3 E I}+\frac{P c_{1}^{2}}{2 G I}(L-X)
\end{aligned}
$$

Considerando-se a equação 3.14 a para uma posição $X=X_{1}$ observa-se que os deslocamentos axiais da seção obedece uma equação do terceiro grau, o que leva a concluir que essa seção não permanece plana após a flexão da barra. Essa distorção das seções transversais está associada ao efeito das tensões de cisalhamento.

O termo $\frac{\mathrm{Pc}_{1}^{2}}{2 \mathrm{GI}}(\mathrm{L}-\mathrm{X})$ na equação $3.14 \mathrm{~b}$ pode ser entendido como uma estimativa do efeito do esforço cortante sobre os deslocamentos transversais dessa barra.

Um estudo da consideração da deformação por cisalhamento, no caso de modelos para análise de paredes estruturais acopladas a lintéis, pode ser encontrado em KWAN(1991). Nessa modelagem a deformação por cisalhamento foi incluída nas barras que simulam os lintéis.

Seja o elemento barra de viga que possui graus de liberdade de rotação e translação, FIGURA 3.6.

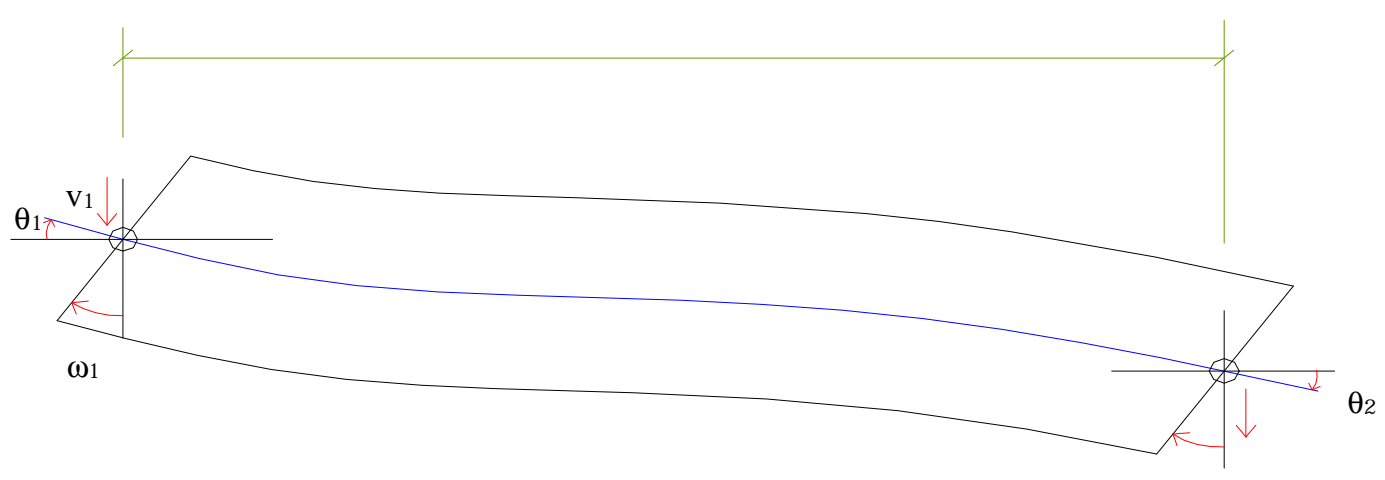

$\omega_{2}$

FIGURA 3.6 - Elemento de viga com rotações $\theta_{i}$ e $\omega_{i}$ nas extremidades 
A equação matricial típica para esse elemento pode ser escrita como:

$$
\left\{\begin{array}{l}
\mathrm{V}_{1} \\
\mathrm{M}_{1} \\
\mathrm{~V}_{2} \\
\mathrm{M}_{2}
\end{array}\right\}=\mathrm{EI}\left[\begin{array}{cccc}
\frac{12}{\mathrm{~L}^{3}} & \frac{6}{\mathrm{~L}^{2}} & \frac{-12}{\mathrm{~L}^{3}} & \frac{6}{\mathrm{~L}^{2}} \\
\frac{6}{\mathrm{~L}^{2}} & \frac{4}{\mathrm{~L}} & \frac{-6}{\mathrm{~L}^{2}} & \frac{2}{\mathrm{~L}} \\
\frac{-12}{\mathrm{~L}^{3}} & \frac{-6}{\mathrm{~L}^{2}} & \frac{12}{\mathrm{~L}^{3}} & \frac{-6}{\mathrm{~L}^{2}} \\
\frac{6}{\mathrm{~L}^{2}} & \frac{2}{\mathrm{~L}} & \frac{-6}{\mathrm{~L}^{2}} & \frac{4}{\mathrm{~L}}
\end{array}\right]\left\{\begin{array}{l}
\mathrm{v}_{1} \\
\theta_{1} \\
\mathrm{v}_{2} \\
\theta_{2}
\end{array}\right\}
$$

onde $\theta_{1}$ e $\theta_{2}$ são as rotações do eixo da viga (fibras horizontais) nos nós 1 e 2 respectivamente.

O esforço cortante $V$ pode ser obtida da equação 3.15 , sendo:

$$
\mathrm{V}=\mathrm{V}_{1}=-\mathrm{V}_{2}=\mathrm{EI}\left(\frac{12}{\mathrm{~L}^{3}} \mathrm{v}_{1}+\frac{6}{\mathrm{~L}^{2}} \theta_{1}-\frac{12}{\mathrm{~L}^{3}} \mathrm{v}_{2}+\frac{6}{\mathrm{~L}^{2}} \theta_{2}\right)
$$

Considerando-se a deformação por cisalhamento, as rotações $\theta_{i}$ e $\omega_{i}$ não são iguais, isto é, as fibras horizontais e verticais não permanecem perpendiculares após a flexão. Definindo-se $\omega_{1}$ e $\omega_{2}$ como a rotação das vibras verticais nos nós 1 e 2 respectivamente, pode-se escrever:

$$
\omega_{1}=\theta_{1}+\frac{\mathrm{V}}{\mathrm{GA}_{\mathrm{S}}}
$$

substituindo V, obtém-se:

$$
\omega_{1}=\theta_{1}+\frac{\mathrm{EI}}{\mathrm{GA}_{\mathrm{S}}}\left(\frac{12}{\mathrm{~L}^{3}} \mathrm{v}_{1}+\frac{6}{\mathrm{~L}^{2}} \theta_{1}-\frac{12}{\mathrm{~L}^{3}} \mathrm{v}_{2}+\frac{6}{\mathrm{~L}^{2}} \theta_{2}\right)
$$

da mesma forma determina-se: 


$$
\omega_{2}=\theta_{2}+\frac{\mathrm{EI}}{\mathrm{GA}_{\mathrm{S}}}\left(\frac{12}{\mathrm{~L}^{3}} \mathrm{v}_{1}+\frac{6}{\mathrm{~L}^{2}} \theta_{1}-\frac{12}{\mathrm{~L}^{3}} \mathrm{v}_{2}+\frac{6}{\mathrm{~L}^{2}} \theta_{2}\right)
$$

sendo $\mathrm{A}_{\mathrm{S}}$ a área de cisalhamento ${ }^{3}$ da seção da viga.

Resolvendo-se as equações (3.16) e (3.17) para $\theta_{1}$ e $\theta_{2}$, obtém-se a seguinte equação, escrita matricialmente:

$$
\left\{\begin{array}{c}
\mathrm{v}_{1} \\
\theta_{1} \\
\mathrm{v}_{2} \\
\theta_{2}
\end{array}\right\}=\left[\begin{array}{cccc}
1 & 0 & 0 & 0 \\
-\frac{\alpha / \mathrm{L}}{1+\alpha} & 1-\frac{\alpha / 2}{1+\alpha} & \frac{\alpha / \mathrm{L}}{1+\alpha} & -\frac{\alpha / 2}{1+\alpha} \\
0 & 0 & 1 & 0 \\
-\frac{\alpha / \mathrm{L}}{1+\alpha} & -\frac{\alpha / 2}{1+\alpha} & \frac{\alpha / \mathrm{L}}{1+\alpha} & 1-\frac{\alpha / 2}{1+\alpha}
\end{array}\right]\left\{\begin{array}{c}
\mathrm{v}_{1} \\
\omega_{1} \\
\mathrm{v}_{2} \\
\omega_{2}
\end{array}\right\}
$$

onde $\alpha=\left(\frac{12 \mathrm{EI}}{\mathrm{L}^{3}}\right)\left(\frac{\mathrm{L}}{\mathrm{GA}_{\mathrm{S}}}\right)$

Substituindo-se essa solução na equação 3.15 obtém-se:

$$
\left\{\begin{array}{l}
\mathrm{V}_{1} \\
\mathrm{M}_{1} \\
\mathrm{~V}_{2} \\
\mathrm{M}_{2}
\end{array}\right\}=\frac{\mathrm{EI}}{1+\alpha}\left[\begin{array}{cccc}
\frac{12}{\mathrm{~L}^{3}} & \frac{6}{\mathrm{~L}^{2}} & -\frac{12}{\mathrm{~L}^{3}} & \frac{6}{\mathrm{~L}^{2}} \\
\frac{6}{\mathrm{~L}^{2}} & (4+\alpha) \frac{1}{\mathrm{~L}} & -\frac{6}{\mathrm{~L}^{2}} & (2-\alpha) \frac{1}{\mathrm{~L}} \\
-\frac{12}{\mathrm{~L}^{3}} & -\frac{6}{\mathrm{~L}^{2}} & \frac{12}{\mathrm{~L}^{3}} & -\frac{6}{\mathrm{~L}^{2}} \\
\frac{6}{\mathrm{~L}^{2}} & (2-\alpha) \frac{1}{\mathrm{~L}} & -\frac{6}{\mathrm{~L}^{2}} & (4+\alpha) \frac{1}{\mathrm{~L}}
\end{array}\right]\left\{\begin{array}{l}
\mathrm{v}_{1} \\
\omega_{1} \\
\mathrm{v}_{2} \\
\omega_{2}
\end{array}\right\}
$$

O parâmetro $\alpha$ é adimensional e avalia os efeitos do esforço cortante. Para que esses efeitos não sejam considerados na análise basta tomar $\alpha=0$,

${ }^{3}$ A área de cisalhamento é obtida pelo quociente entre a área total da seção e o fator de forma, vide equação (3.19). 
de modo que a equação (3.18) torna-se a equação (3.15) substituindo-se $\omega_{i}$ por $\theta_{i}$.

De acordo com KWAN(1991), é importante alertar para o fato que, se as deformações por cisalhamento forem consideradas, as rotações nodais $\omega_{i}$ devem ser associadas àquelas das fibras verticais.

No caso do modelo de barras isoladas utilizado nesse trabalho, a consideração da deformação por cisalhamento é feita por meio de uma modificação na matriz de rigidez dos elementos barra que modelam as paredes, semelhante à apresentada em KWAN(1991). Determinam-se os fatores de forma para cada seção segundo a equação 3.12, para em seguida obterem-se as respectivas áreas de cisalhamento. A rotina de cálculo utilizada modifica a matriz de rigidez dependendo do fornecimento dessa área de cisalhamento. Caso $\mathrm{A}_{\mathrm{S}}=0$, toma-se um fator corretivo nulo, semelhante ao apresentado em KWAN(1991), de modo que a matriz de rigidez do elemento não é modificada. Caso contrário, determina-se o fator corretivo e modifica-se adequadamente a matriz de rigidez. Essa rotina de cálculo foi desenvolvida segundo a teoria da análise matricial, permitindo-se utilizar uma modelagem tridimensional com elementos barra. Nessa modelagem consideram-se os graus de liberdade associados aos eixos da FIGURA 3.14, não incorporando-se ao modelo a rigidez à torção das paredes.

\subsection{3 - Exemplo preliminar}

Com o propósito de verificar-se a influência das deformações devidas ao cisalhamento, foram realizadas análises de vários edifícios em alvenaria estrutural os quais apresentaram as mesmas tendências na distribuição dos esforços. Dentre esses edifícios escolheu-se um para apresentação dos resultados, sendo enfatizados:

- Deslocamentos horizontais da estrutura ao nível dos pavimentos;

- Distribuição dos esforços cortantes e dos momentos fletores entre as paredes de contraventamento; 
- Diagramas de esforço cortante e momento fletor ao longo da altura das paredes mais solicitadas.

Utilizou-se, nessa análise inicial, o modelo tridimensional de barras isoladas considerando-se a composição das seções das paredes com flanges. As comparações são feitas entre o modelo que não incorpora as deformações por cisalhamento (modelo 1), e o modelo que incorpora tais deformações (modelo 2).

O exemplo é um edifício com 10 pavimentos cuja planta do pavimento tipo é apresentada na FIGURA 3.7a e esquematizada em diagrama unifilar na FIGURA 3.7b. As paredes incluídas na análise são identificadas no

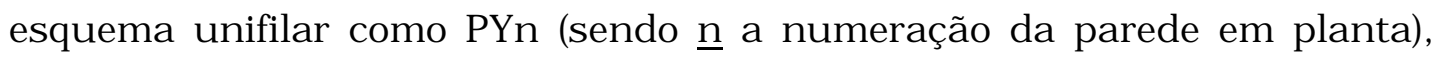
possuindo espessura de $14,5 \mathrm{~cm}$ e distância de piso a piso com $2,80 \mathrm{~m}$. Foram utilizados blocos de concreto que variam de 10,0MPa a 4,5MPa da base ao topo, considerando-se um módulo de elasticidade longitudinal $\mathrm{E}=2960 \mathrm{MPa}$ para todas as paredes. O carregamento do vento foi determinado segundo a NBR-6123, considerando-se uma velocidade básica $\mathrm{V}_{0}=38 \mathrm{~m} / \mathrm{s}$ e um edifício de classe 2 e categoria 4 . 


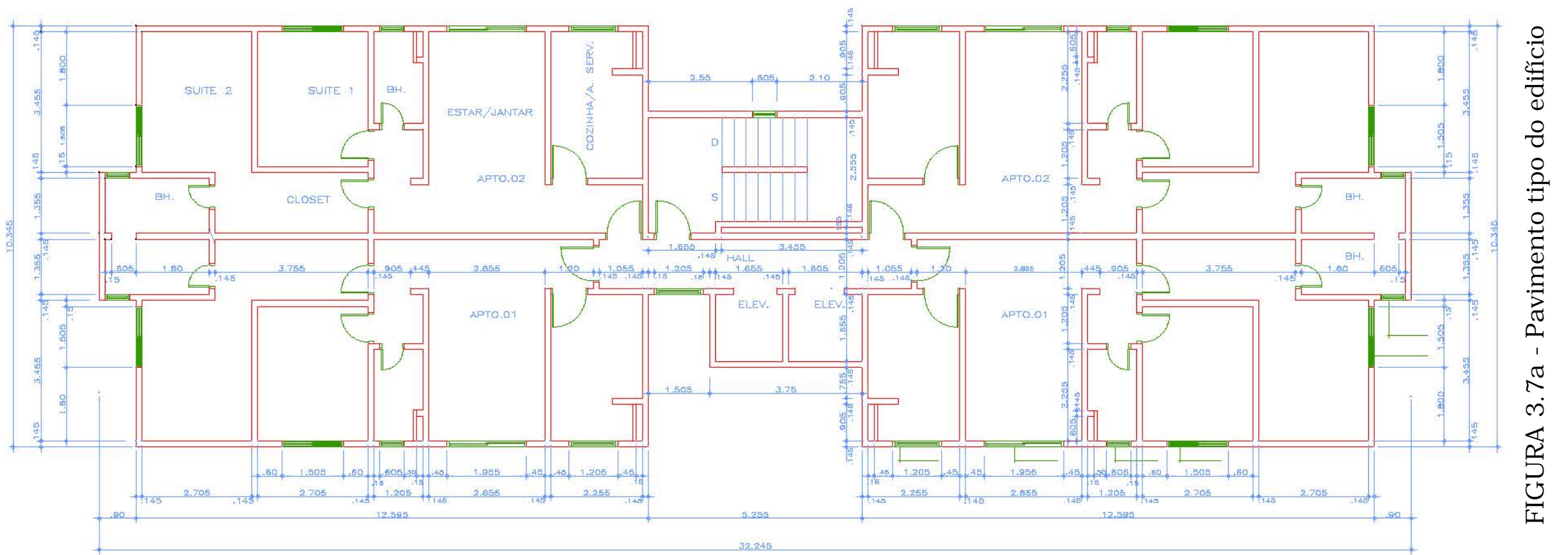




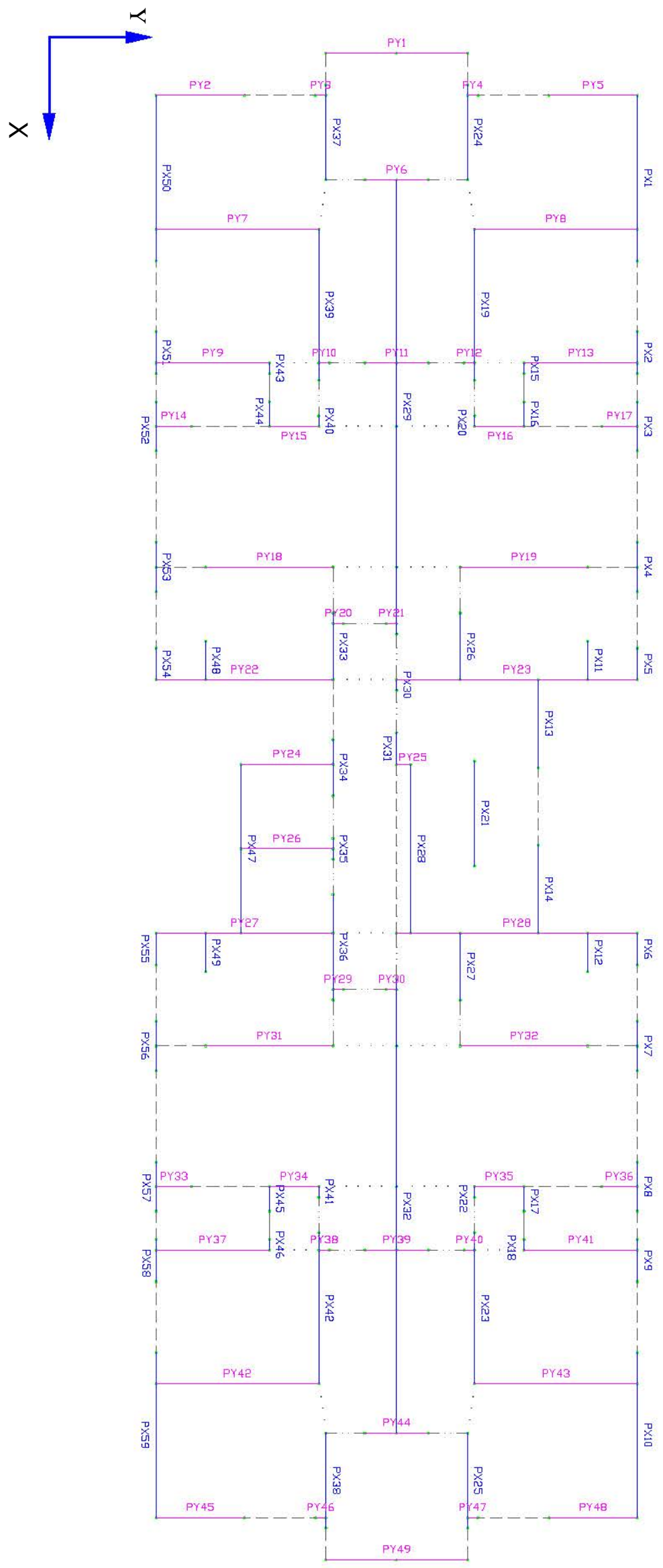

FIGURA 3.7b - Diagrama unifiliar das paredes em planta 
O gráfico de deslocamentos horizontais, FIGURA 3.8, apresentou um acréscimo pouco significativo com uma diferença de $4 \%$ no topo do edifício.

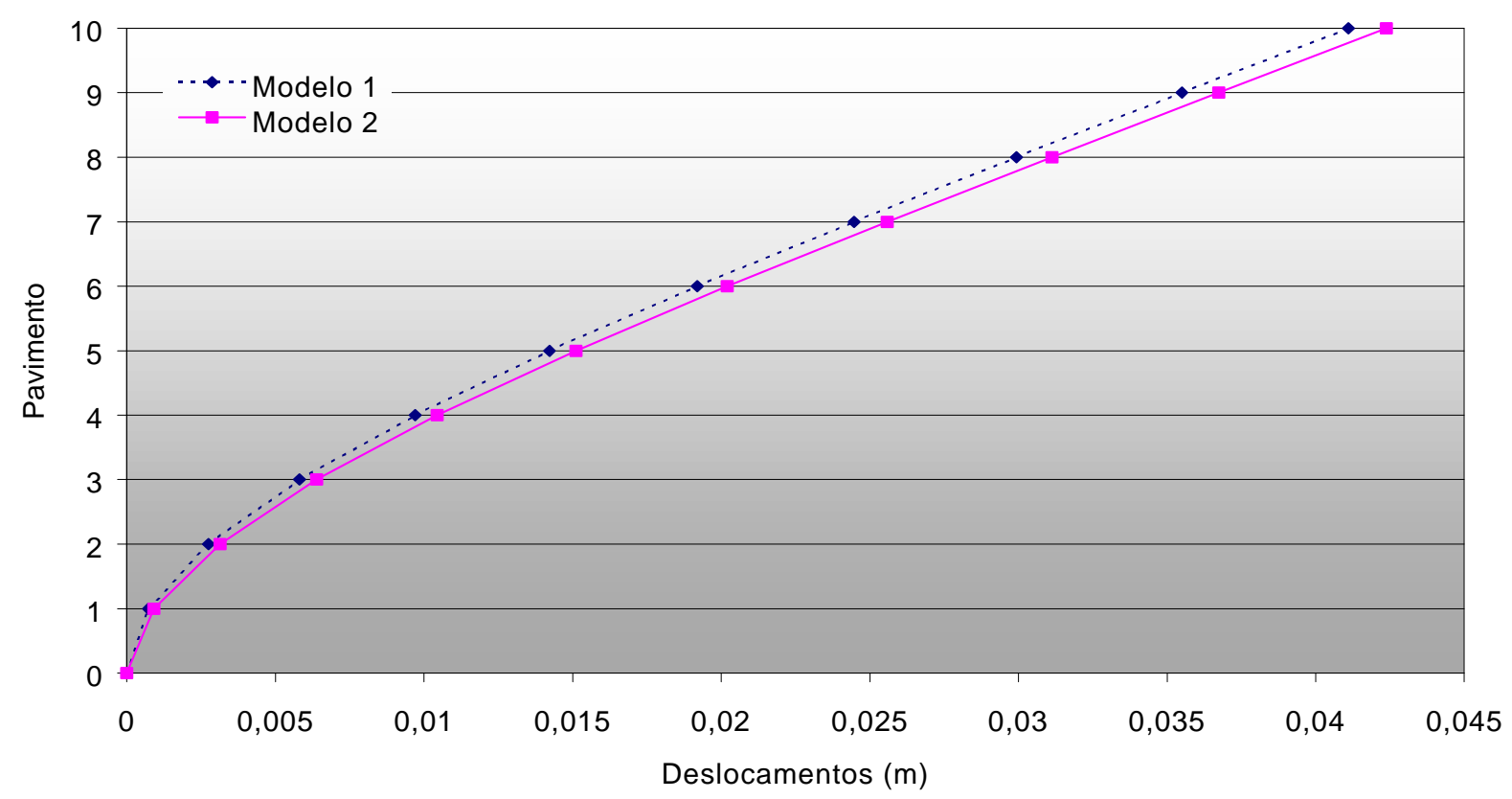

FIGURA 3.8 - Deslocamentos horizontais

As diferenças mais significativas ocorreram, como era esperado, na distribuição dos esforços cortantes entre as paredes de contraventamento, FIGURA 3.9, cujo decréscimo no esforço cortante máximo foi de 34\%, ocorrido na parede PY28.

Quanto à distribuição dos momentos fletores entre as paredes de contraventamento, FIGURA 3.10, observou-se uma diferença no momento fletor máximo de 8\%, também ocorrida na parede PY28

Vale ressaltar que a parede PY28 apresentou o máximo esforço cortante e momento fletor por possuir a maior rigidez (associada ao seu comprimento em planta). Em edifícios usuais de alvenaria estrutural, essas paredes surgem como divisoras de apartamentos. 


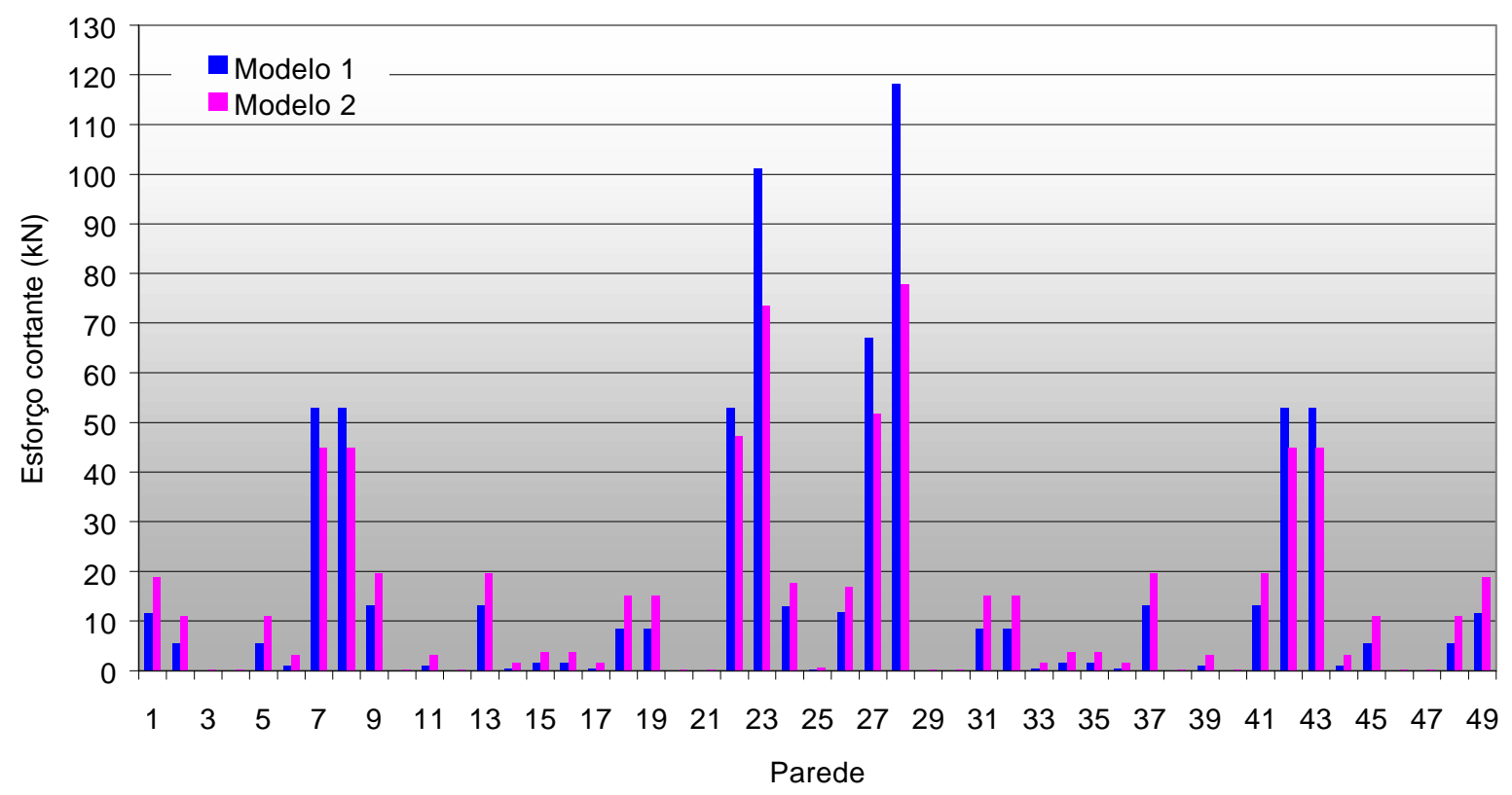

FIGURA 3.9 - Distribuição dos esforços cortantes entre as paredes de contraventamento

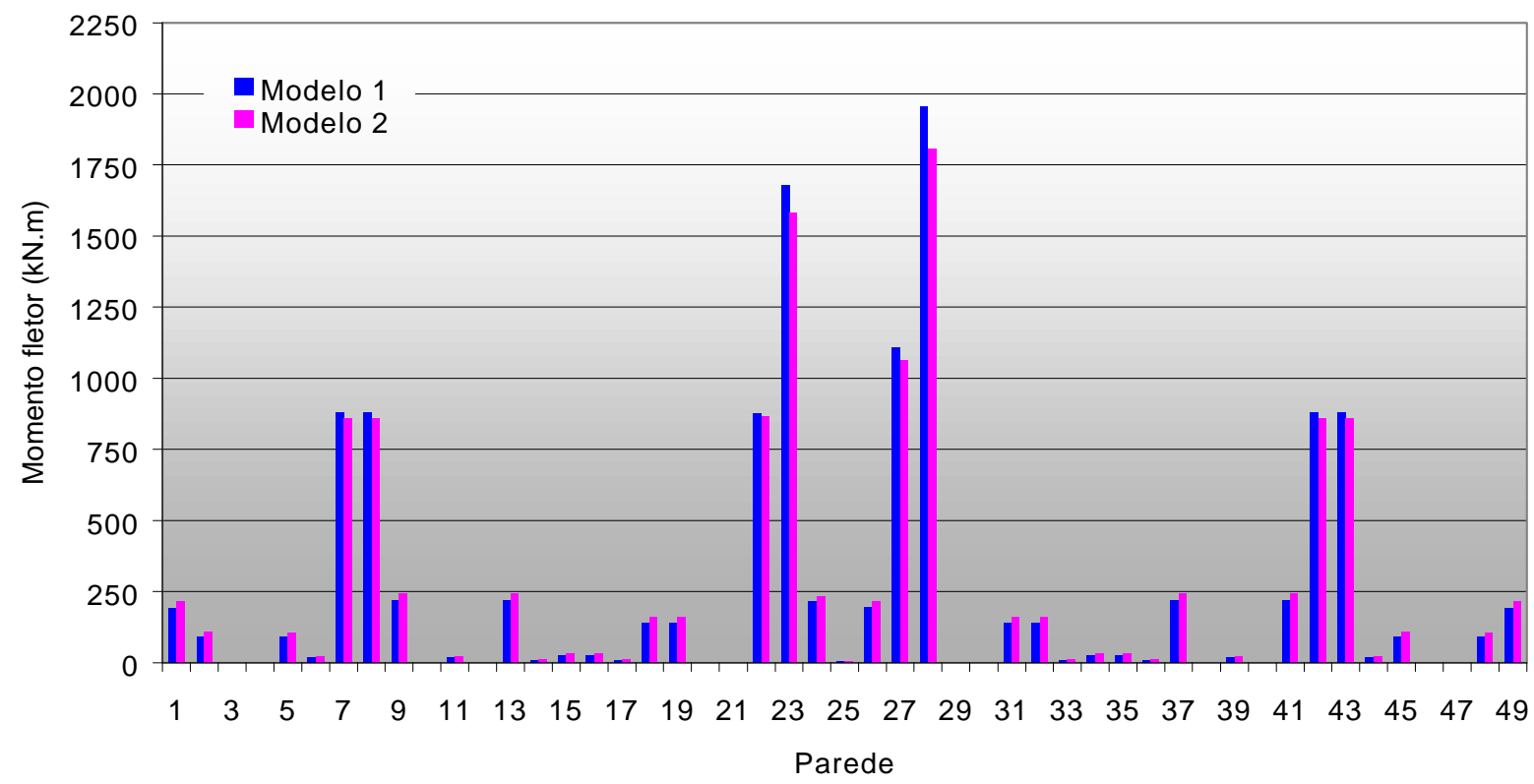

FIGURA 3.10 - Distribuição dos momentos fletores entre os painéis de contraventamento

Pode-se observar, também, uma tendência de redistribuição tanto dos esforços cortantes quanto dos momentos fletores, onde as paredes mais 
solicitadas tiveram seus esforços diminuídos e as menos solicitadas apresentaram um acréscimo desses esforços. Essa tendência de redistribuição resulta na melhoria do comportamento estrutural, diminuindo-se a resistência de bloco necessária ao dimensionamento com um aproveitamento mais racional do material.

A inclusão das deformações por cisalhamento nos modelos de análise é um fato importante devido ao tipo de elemento estrutural de que se dispõe, isto é, os tramos de parede entre pavimentos consecutivos apresentam uma relação largura/altura que sugere a incorporação dessas deformações. Uma segunda evidência da importância dessa modificação na modelagem dos edifício em alvenaria estrutural é o alívio das solicitações de cisalhamento. A tensão de cisalhamento admissivel pode ser tomada como $\mathrm{f}_{\text {cis }}=0,15 \mathrm{MPa}^{4}$. A parede mais solicitada apresenta as seguintes solicitações de cisalhamento: $\tau_{1}=0,16 \mathrm{MPa}$ e $\tau_{2}=0,11 \mathrm{MPa}$, associadas respectivamente aos modelos 1 e 2. Como a tensão de cisalhamento prevista com o modelo 1 superou a admissivel, o projetista deve prever reforços adicionais como grauteamento e/ou armação, o que não ocorre para a tensão obtida com o modelo 2. Esse decréscimo de tensões reforça a importância da consideração das deformações por cisalhamento.

Um outro fato bastante interessante que pode ser comentado é o comportamento dos diagramas de esforço cortante, FIGURA 3.11. O modelo 1 apresenta valor máximo na base das paredes, enquanto que o modelo 2 apresenta seu valor máximo num pavimento intermediário. Segundo STAMATO(1980), em estruturas cujas deformações devidas ao cisalhamento não são significativas, o diagrama de esforço cortante assemelha-se ao diagrama do modelo 1; enquanto que em estruturas cujas deformações devidas ao cisalhamento são significativas, seus diagramas de esforço cortante assemelham-se ao diagrama do modelo 2. Esse fato pode ser considerado como mais uma evidência da importância da inclusão das

4 Essa tensão admissivel foi adotada considerando-se, segundo a NBR-10837, alvenaria não-armada e argamassa com resistência característica $f_{a}$ entre $5,0 \mathrm{MPa}$ e $12,0 \mathrm{MPa}$ 
deformações devidas ao cisalhamento no estudo do sistema de contraventamento dos edifícios em alvenaria estrutural.

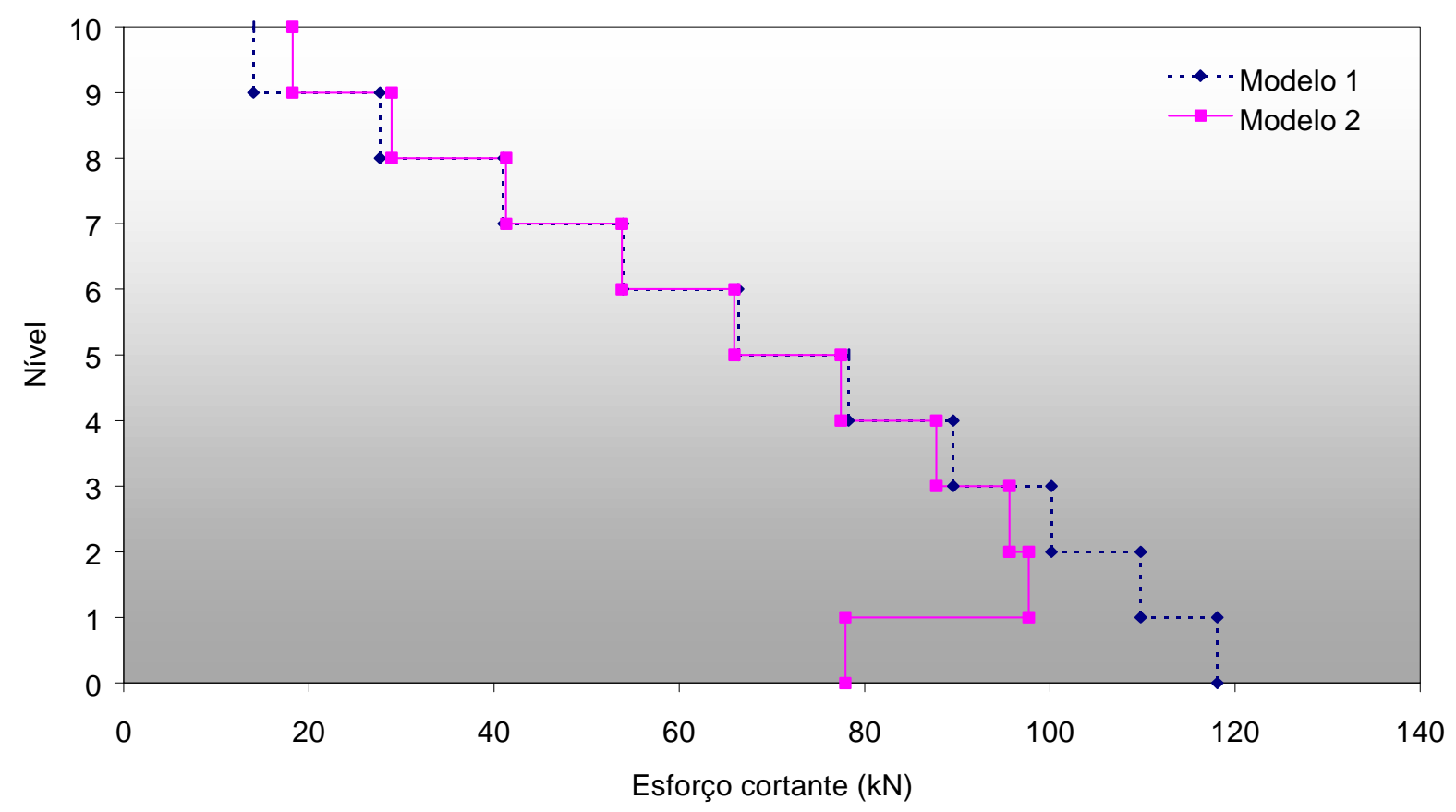

FIGURA 3.11 - Diagrama de esforço cortante ao longo da altura da parede mais solicitada - PY28

Os diagramas de momento fletor, FIGURA 3.12, não apresentaram diferenças consideráveis, tendo o mesmo aspecto com os dois modelos analisados. 


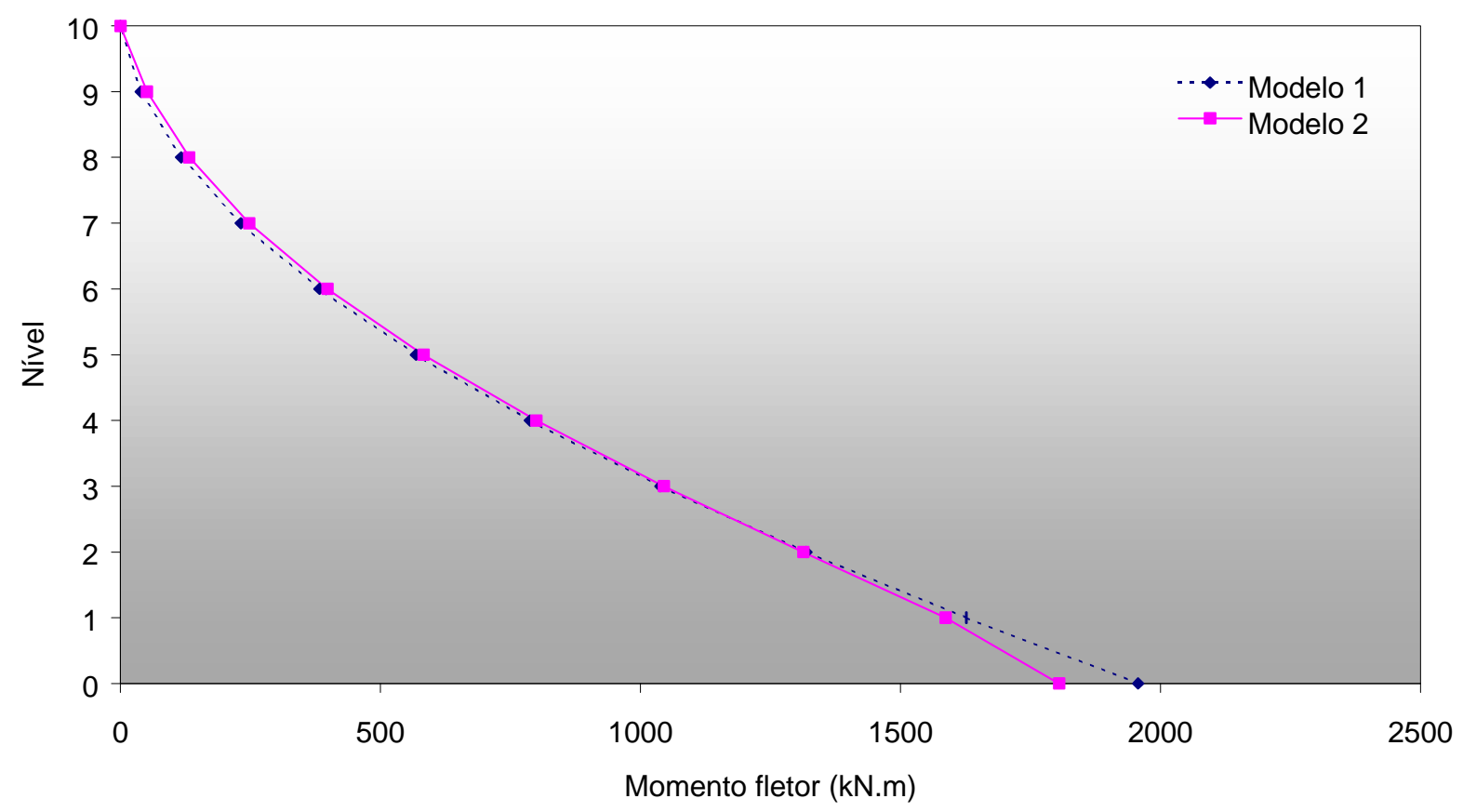

FIGURA 3.12 - Diagrama de momento fletor ao longo da altura da parede mais solicitada - PY28

\section{2 - Modelo de pórtico tridimensional}

\subsection{1 - Apresentação}

A modelagem descrita a seguir pode ser considerada, no âmbito dos modelos com elementos barra, como uma das mais precisas e completas.

As paredes de contraventamento são discretizadas por elementos barra tridimensional, os quais possuem seis graus de liberdade em cada extremidade. Essas barras devem possuir as mesmas características geométricas das respectivas paredes que representam, bem como devem ser posicionadas no centro de gravidade da seção da parede. No caso dessas seções não se considera sua composição com abas ou flanges, já que essa contribuição está incorporada ao modelo, como se mostrará a seguir. 
As paredes que se interceptam são interligadas/conectadas por barras horizontais rígidas, de modo a se considerar a interação que efetivamente se desenvolve entre as paredes bem como as excentricidades associadas às forças de interação. As extremidades comuns a duas paredes são consideradas articuladas, FIGURA 3.13. As informações relativas às características das barras horizontais rígidas são apresentadas no item 3.2.3.

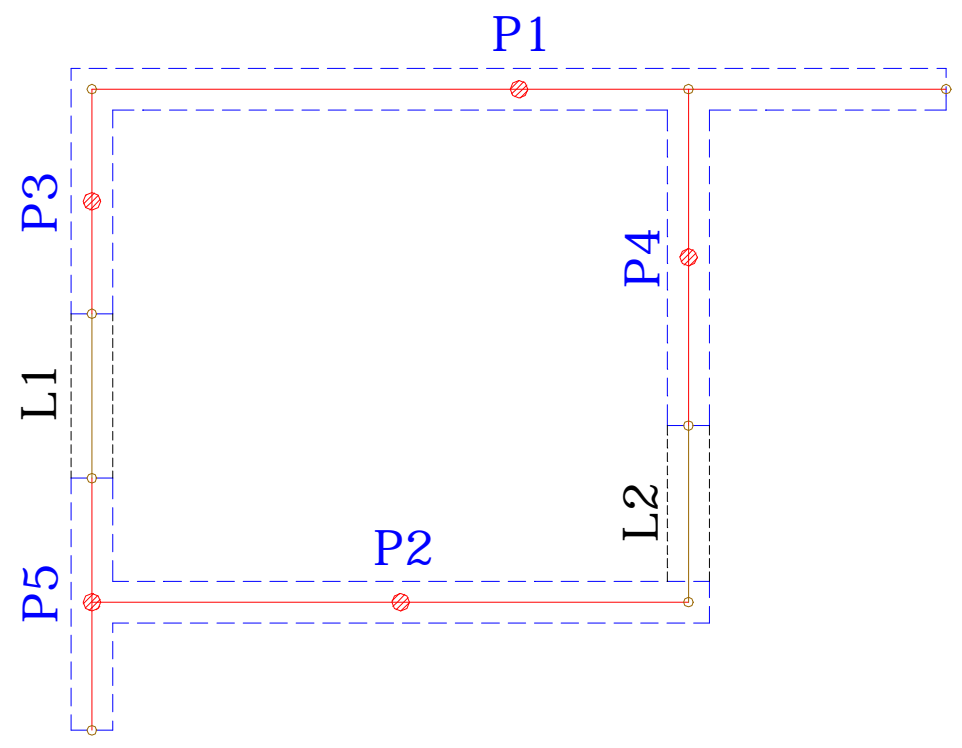

FIGURA 3.13 - Planta baixa da modelagem tridimensional dos painéis de contraventamento com elementos barra

Existe, também, a possibilidade de inclusão de lintéis no modelo, FIGURA 3.13. Esses lintéis podem ser observados nos trechos de parede situados entre as aberturas de portas e janelas, e podem aumentar significativamente a rigidez do edifício quando solicitado pelas ações horizontais, como será evidenciado nos exemplos numéricos apresentados no próximo capítulo.

Toma-se como referência para os graus de liberdade considerados nos elementos barra horizontais (barras rígidas e lintéis), os eixos da FIGURA 3.14. 


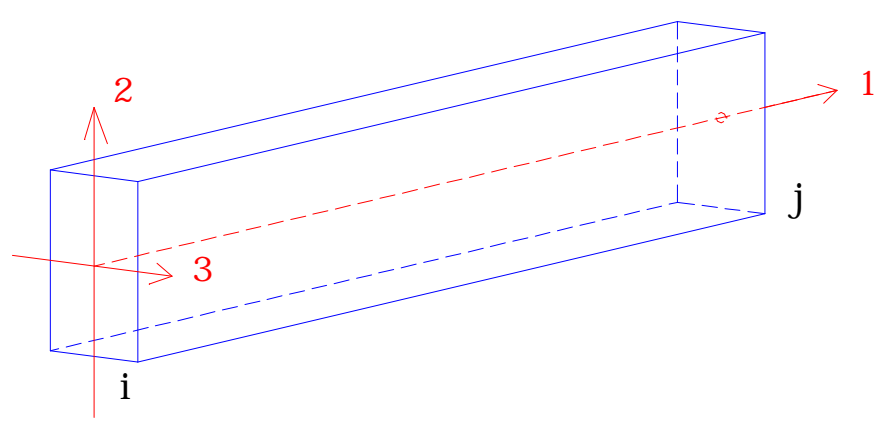

FIGURA 3.14 - Eixos de referência para os graus de liberdade dos elementos barra

A interação de paredes é associada ao desenvolvimento de esforços verticais (esforços cortantes) em suas interseções. Sendo as barras rígidas responsáveis pela simulação desses esforços, utilizam-se articulações nas extremidades comuns, de modo que o único grau liberdade associado a essa extremidade é a translação vertical segundo o eixo 2 da FIGURA 3.14.

O comprimento e o número de barras rígidas na modelagem das paredes depende das interseções que ocorrem entre essas paredes e da inclusão ou não dos lintéis.

Observe-se a FIGURA 3.15. Cada parede possui um nó no centro de gravidade da seção e aqueles definidos pela interseção entre paredes. O nó do CG é utilizado na incidência das barras verticais. Os nós de interseção, juntamente com o nó do CG da seção, determinam a incidência das barras rígidas. De acordo com a FIGURA 3.15, a parede P1 possui três barras rígidas; a primeira do nó 11 ao 6 , a segunda do nó 6 ao 12, e uma terceira do nó 12 ao 18. 


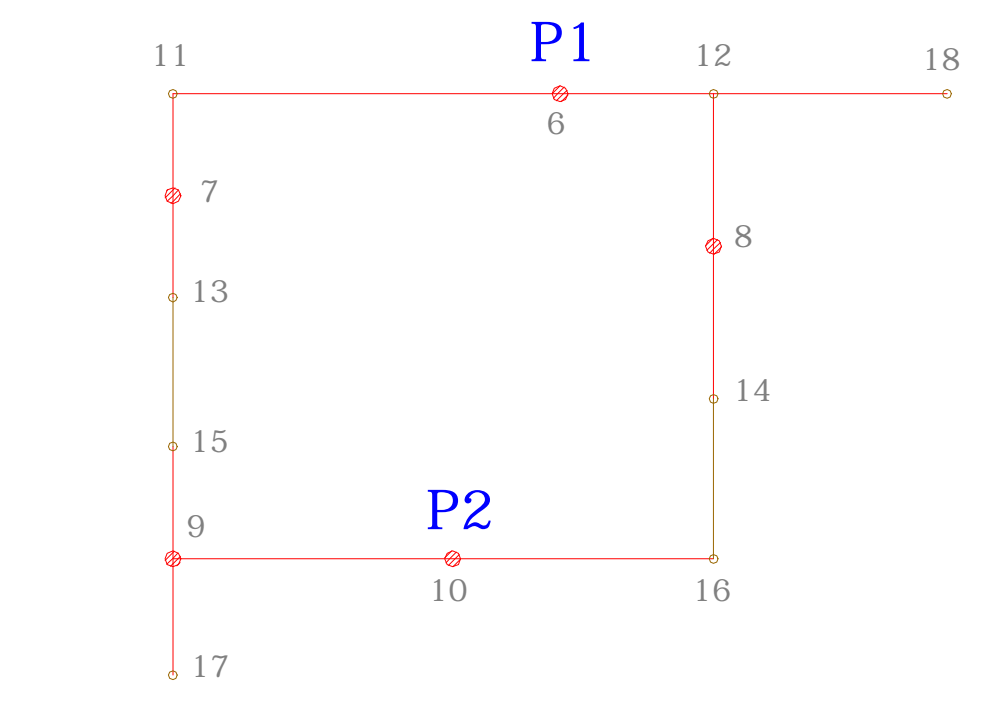

FIGURA 3.15 - Incidência das barras horizontais rígidas no modelo tridimensional

Na primeira barra rígida, a extremidade inicial é articulada, pois o nó 11 determina um ponto extremo na modelagem da parede, e a extremidade final permanece sem liberação de vínculos, pois o nó 6 determina um ponto interno na modelagem da parede. A segunda barra rígida apresenta as duas extremidades contínuas, pois os nós 6 e 12 determinam pontos internos na modelagem. A terceira barra rígida possui extremidade inicial contínua pelas mesmas razões expostas anteriormente, e extremidade final articulada, pois o nó 18 determina um ponto extremo na modelagem. Caso a terceira barra não apresente interseção em sua extremidade final com um lintel ou outra parede, sua inclusão no modelo é desnecessária. Desse modo, tal barra é excluída do modelo, e a barra anterior passa a ter sua extremidade final articulada. Quanto aos lintéis, se os mesmos forem incluídos no modelo, suas extremidades devem possuir ligação contínua (sem liberação de vínculos) com as extremidades das barras horizontais rígidas.

Quanto à modelagem da laje, a mesma é idealizada como um diafragma rígido em seu plano, o que possibilita a utilização do recurso do 
nó mestre para a compatibilização dos deslocamentos ao nível dos pavimentos. Esses deslocamentos são associados às duas translações independentes no plano do pavimento e uma rotação em torno do eixo normal a esse plano.

Em resumo, um trecho de parede sem abertura situado entre pavimentos consecutivos é discretizado por elementos barra tridimensional, diferenciados por barras verticais flexíveis e barras horizontais rígidas, FIGURA 3.16.

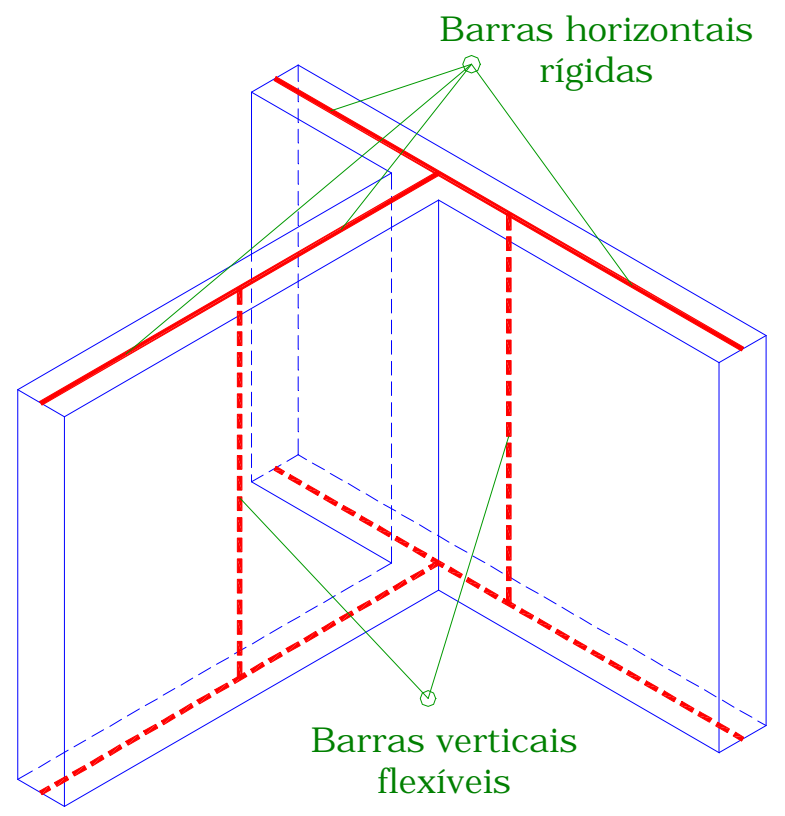

FIGURA 3.16 - Modelagem das paredes de contraventamento

A barra vertical possui as características da seção retangular da parede e suas extremidades são ligadas continuamente a barras rígidas horizontais. Os nós inicial e final dessa barra são associados aos nós mestres dos respectivos pavimentos.

As barras rígidas horizontais são dispostas ao nível dos pavimentos e têm por objetivo simular o efeito do comprimento das paredes e a interação que se desenvolve entre elas.

Essa modelagem é equivalente, fazendo-se algumas adaptações, às das paredes dos núcleos estruturais em concreto armado que utilizam 
elementos barra. A discretização para um conjunto de paredes que se interceptam apresentada anteriormente, é baseada no modelo proposto por YAGUI(1978) para a discretização dos núcleos estruturais.

Vale salientar que o modelo utilizado nesse trabalho leva em consideração a deformação por cisalhamento das paredes, e avalia de forma indireta e aproximada os efeitos causados pelo empenamento da seção composta formada pelas paredes. O modelo anteriormente descrito para um conjunto de paredes que se interceptam é denominado, nesse trabalho, "modelo de pórtico tridimensional".

\subsection{2 - Deformação por cisalhamento}

Os resultados obtidos para a análise da deformação por cisalhamento nos edifícios de alvenaria estrutural (item 3.1.3), demonstraram a importância desse efeito. Desse modo, sua inclusão no modelo de pórtico tridimensional torna-se um fator bastante interessante e simples, como será descrito a seguir.

A deformação por cisalhamento é considerada mediante determinação do fator de forma da seção. Com esse fator de forma obtém-se uma área de cisalhamento, equação (3.19), que será utilizada para modificar-se adequadamente a matriz de rigidez do respectivo elemento barra.

$$
\mathrm{A}_{\mathrm{S}}=\frac{\mathrm{A}}{\mathrm{C}}
$$

sendo: $\mathrm{A}_{\mathrm{S}}=$ área de cisalhamento

$$
\begin{aligned}
& \mathrm{A}=\text { área da seção transversal } \\
& \mathrm{c}=\text { fator de forma da seção }
\end{aligned}
$$

Esse efeito é considerado nas barras verticais do pórtico tridimensional, que possuem as características geométricas das seções retangulares das paredes. 
O fator de forma para uma seção retangular é bastante conhecido na literatura, apresentando o valor $\mathrm{c}=1,2$. Esse é o fator de forma básico utilizado para cálculo da área de cisalhamento das barras verticais de modo a considerar as deformações por cisalhamento das paredes do edifício. Vale ressaltar que no caso de seções compostas o fator de forma c assume outros valores, conforme apresentado no início do capítulo.

\subsection{3 - Barras horizontais rigidas e lintéis}

A utilização de barras horizontais rígidas no modelo de pórtico tridimensional, como mencionado no item 3.2.1, tem por objetivo considerar as excentricidades dos esforços de interação avaliando o nível de transmissão que ocorre entre paredes que se interceptem, bem como a modificação na distribuição da rigidez relativa quando considera-se a contribuição dos lintéis.

A interação de paredes é simulada através dos esforços cortantes que surgem nos nós de interseção das barras rígidas. As extremidades de barras rígidas que incidam nesses nós são articuladas, garantindo que a rigidez do nó só apresente contribuições associadas aos deslocamentos verticais.

Quando consideram-se os lintéis no modelo, as extremidades das barras rígidas que se interceptem com esses lintéis devem estar engastadas, caso contrário a efetiva contribuição dos mesmos não seria levada em consideração no modelo.

As características das barras rígidas utilizadas no modelo de pórtico tridimensional seguem as recomendações encontradas em CORRÊA(1991). Segundo o autor, as barras rígidas horizontais, referidas em seu trabalho como "elementos de grande rigidez", são utilizadas como uma das soluções para a consideração dos nós de dimensões finitas encontrados nos pórticos de edifícios em concreto armado, FIGURA 3.17. 


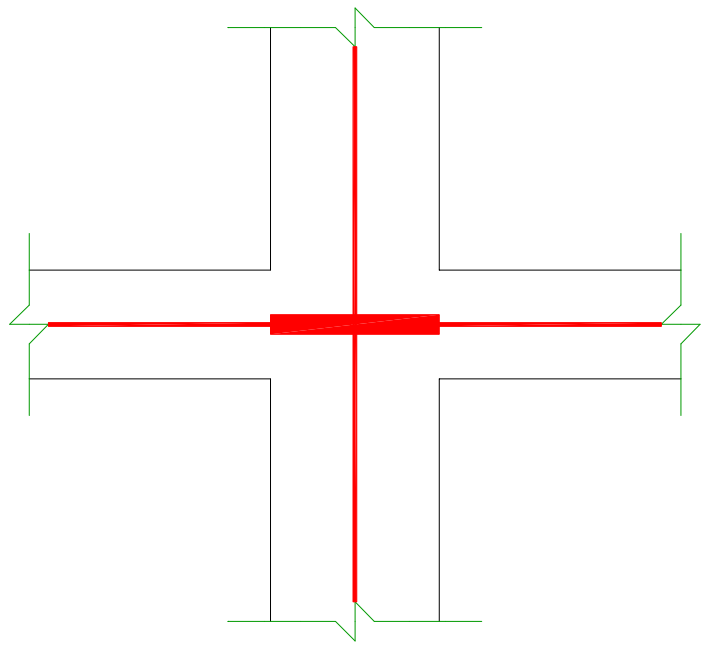

FIGURA 3.17 - Simulação de trechos rígidos utilizando-se elementos barra [adaptado de CORRÊA(1991)]

No caso das paredes com interseção dos edifícios de alvenaria estrutural, os elementos de grande rigidez foram aplicados com base no modelo de YAGUI para núcleos estruturais. Esses elementos, segundo CORRÊA(1991), têm que apresentar características da seção transversal de modo a simular o trecho rígido da estrutura com uma rigidez suficientemente grande para que seja alcançado o objetivo da simulação e sem perturbar a estabilidade numérica da solução. Segundo o autor a discrepância muito acentuada de rigidez no modelo pode produzir um resultado catastrófico e, o que é pior, sem controle por parte do usuário e dependente do tratamento dado às variáveis reais no "software". A experiência do autor com o sistema LASER, que também é utilizado no processamento dos edifícios neste trabalho, mostrou ser satisfatória a utilização de barras com seções de largura igual à do pilar ou da parede, e altura igual ao pé-direito.

Uma outra aplicação das barras rígidas é apresentada em CORRÊA(1991). Paredes com abertura podem ser discretizadas por elementos finitos de chapa FIGURA 3.18a ou por elementos barra com a utilização de trechos rígidos FIGURA 3.18b. Segundo o autor, a modelagem com elementos barra torna-se mais eficaz, quando se deseja, por exemplo, estudar o comportamento global do sistema estrutural de um edifício, sob a 
ação do vento, modelando-se em conjunto seus painéis de contraventamento.

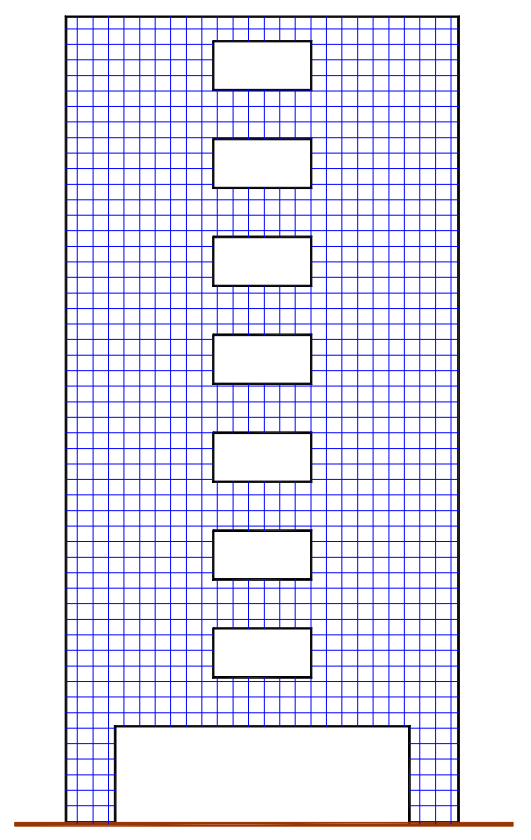

a - Modelagem com elementos de chapa

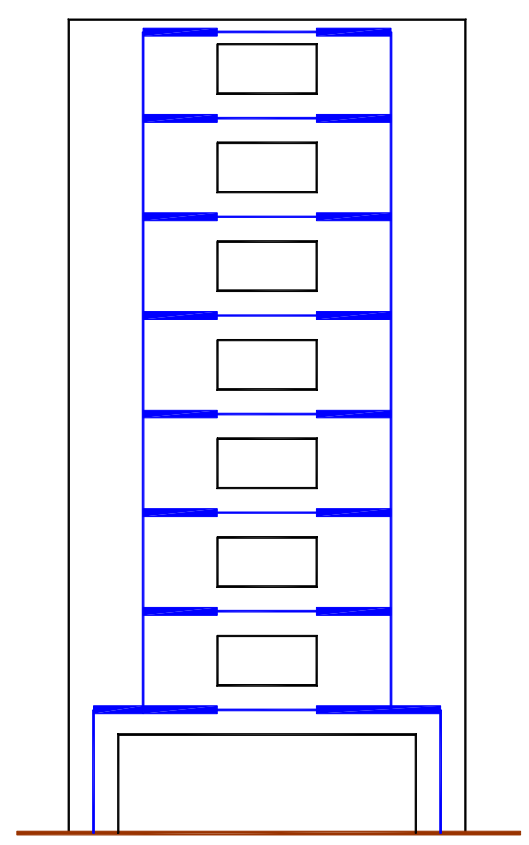

b - Modelagem com elementos barra

FIGURA 3.18 - Paredes com aberturas

Essa modelagem é utilizada quando deseja-se considerar o efeito das aberturas dos painéis de contraventamento, isto é, incluir a contribuição dos lintéis na rigidez do sistema estrutural.

No caso das aberturas usuais em edifícios residenciais de alvenaria, esses lintéis aumentam significativamente a rigidez global da estrutura, diminuindo os deslocamentos horizontais e redistribuindo os esforços entre os painéis de contraventamento. Essa redistribuição é ocasionada por meio de uma modificação na rigidez relativa desses painéis, como será evidenciado no capítulo de exemplos.

A inclusão dos lintéis no modelo deve ser uma decisão bastante criteriosa. É vantajoso para aumentar a rigidez do edifício às ações 
horizontais, mas pode exigir reforço com armadura dependendo dos esforços de cisalhamento neles desenvolvidos.

\subsection{4 - Interação de paredes}

As paredes de um edifício em alvenaria estrutural podem ser analisadas considerando-se que ocorre uma transmissão de esforços entre as mesmas, bastando para isso que a ligação/interseção entre elas seja capaz de desenvolver esses esforços de interação, FIGURA 3.19.
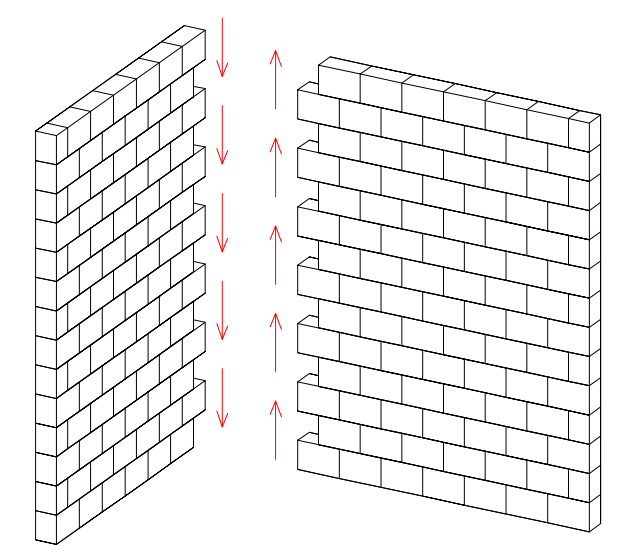

a- Paredes com interseção
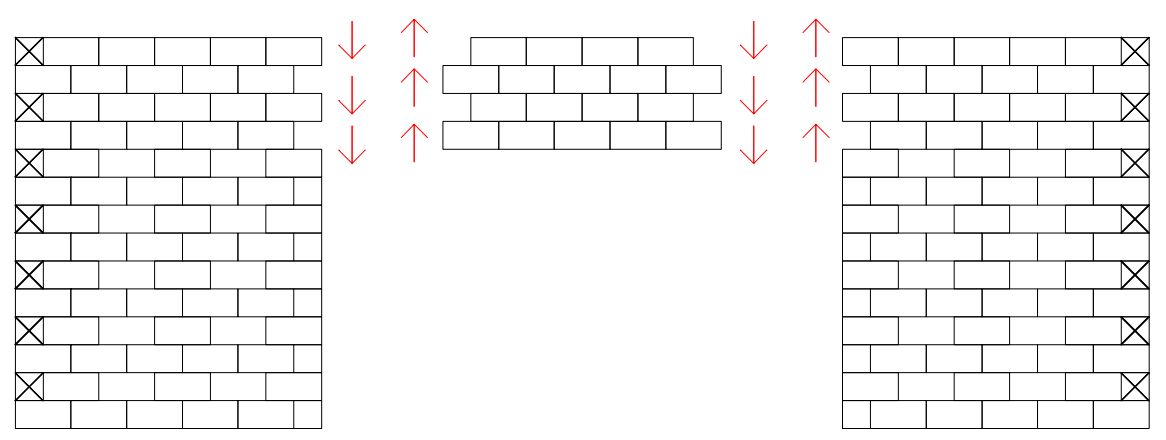

b - Paredes ligadas por lintéis

FIGURA 3.19 - Esforços de interação entre paredes [adaptado de CORRÊA E RAMALHO (1998)] 
A interação pode ocorrer entre paredes que se interceptem, FIGURA 3.19a, ou entre paredes ligadas por lintéis, FIGURA 3.19b.

No segundo caso, a transmissão dos esforços ocorre devido à presença do lintel, permitindo-se que haja a interação das paredes ligadas por esse lintel.

Aplicando-se uma ação horizontal no painel, essa interação é avaliada considerando-se uma contribuição com flanges para os painéis de contraventamento. No modelo de pórtico tridimensional, a contribuição da flange é considerada pelas barras horizontais rígidas. Atualmente estudos estão sendo desenvolvidos no Departamento de Engenharia de Estruturas da EESC para quantificar a efetiva contribuição que ocorre.

O modelo de pórtico tridimensional, a princípio, pode ser considerado como o mais adequado para uma análise dos esforços provenientes das ações horizontais, primeiro por representar melhor a rigidez relativa dos painéis e, segundo por permitir uma análise dos efeitos da torção do edifício, quantificando-se as alterações nos valores dos esforços cortantes absorvidos pelos diversos painéis.

\subsection{5 - Efeitos de torção nos edifícios}

Os efeitos de torção nas edificações podem ser associados a várias causas, podendo-se citar, segundo BLESSMANN(1989): desigual distribuição das pressões do vento; assimetria do sistema estrutural de contraventamento; turbulência do vento incidente; incidência oblíqüa do vento. Ensaios em túneis de vento mostraram que, mesmo em edifícios prismáticos de planta retangular ou quadrada e com eixo de torção coincidindo com o eixo geométrico da estrutura, aparecem esforços de torção consideráveis. Esse efeito corresponde a algumas incidências oblíqüas do vento. Ainda segundo o autor, mesmo no caso de incidência perpendicular pode-se verificar a ocorrência da torção, originada pela turbulência do vento que causa uma distribuição assimétrica das pressões num determinado instante. Da mesma forma, as condições de vizinhança 
podem alterar significativamente os valores dos coeficientes aerodinâmicos dos edifícios e, conseqüentemente, as ações devidas ao vento.

Com a finalidade de se considerarem os efeitos que causam torção da edificação, a NBR-6123 sugere a consideração de excentricidades para a força devida ao vento que incide perpendicularmente às fachadas dessas edificações, de acordo com a tabela 3.2. A obtenção detalhada dessas excentricidades pode ser encontrada em BLESSMANN(1989).

TABELA 3.2 - Excentricidades da ação do vento

\begin{tabular}{|c|c|c|c|}
\hline \multirow[t]{2}{*}{ Efeito associado } & \multicolumn{2}{|c|}{ Excentricidade } & \multirow[t]{2}{*}{ Observações } \\
\hline & $\begin{array}{c}\text { Vento na direção } \\
\mathrm{X} \quad\left(\mathrm{e}_{\mathrm{X}}\right)\end{array}$ & $\begin{array}{c}\text { Vento na direção } \\
\mathrm{Y}\left(\mathrm{e}_{\mathrm{Y}}\right)\end{array}$ & \\
\hline $\begin{array}{l}\text { Incidência oblíqua } \\
\text { do vento }\end{array}$ & $0,075 a$ & $0,075 b$ & \multirow{2}{*}{$\begin{array}{l}\text { a = maior dimensão } \\
\text { em planta da fachada } \\
\text { de incidência para o } \\
\text { vento na direção X } \\
\mathrm{b}=\text { maior dimensão } \\
\text { em planta da fachada } \\
\text { de incidência para o } \\
\text { vento na direção Y }\end{array}$} \\
\hline $\begin{array}{c}\text { Efeitos de } \\
\text { vizinhança }\end{array}$ & $0,15 a$ & $0,15 b$ & \\
\hline
\end{tabular}

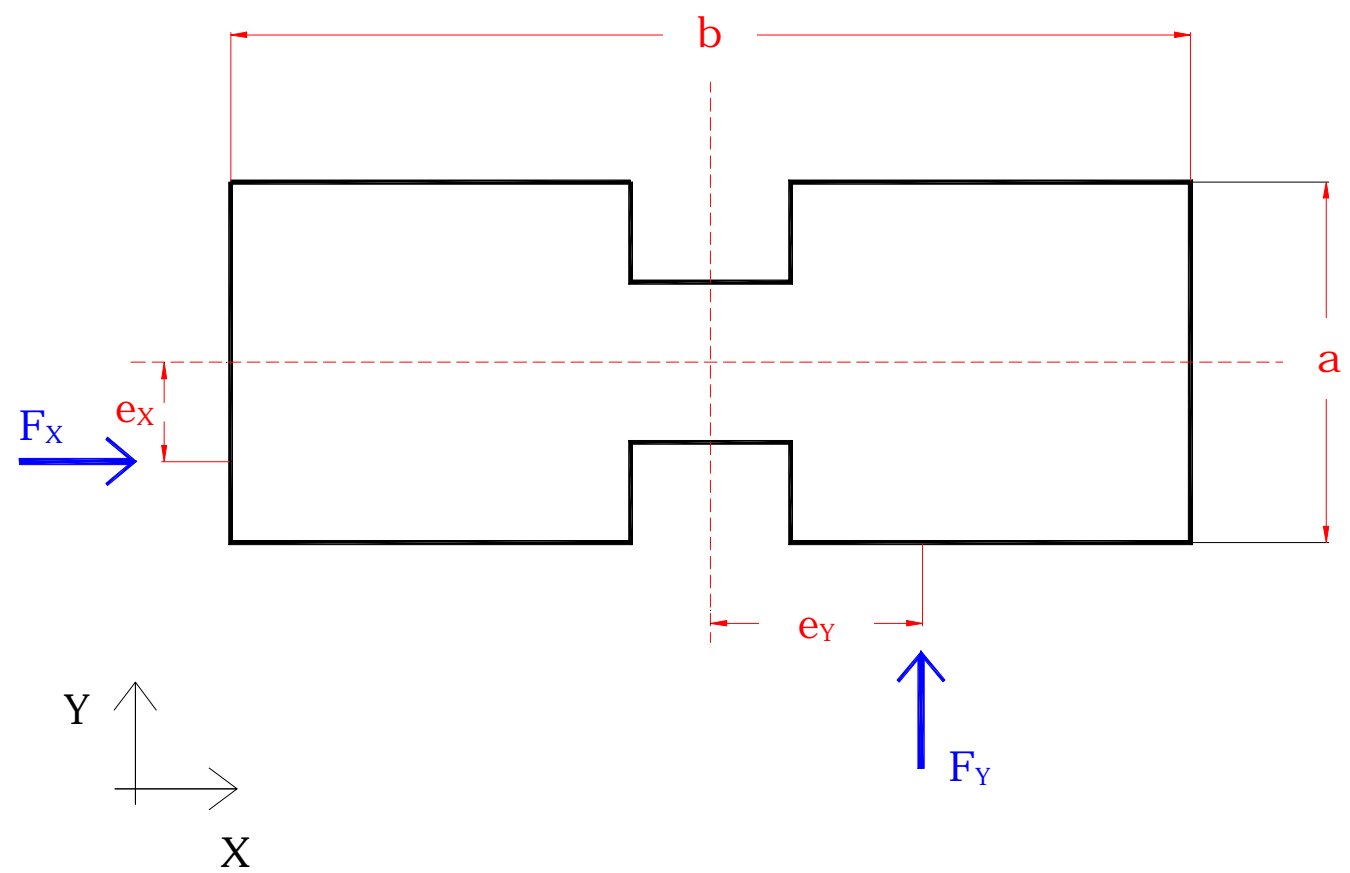

FIGURA 3.20 - Excentricidades da ação do vento 


\section{EXEMPLOS}

\section{1 - Introdução}

Os modelos descritos anteriormente foram utilizados para se desenvolverem análises de alguns edifícios. As plantas baixas dos edifícios foram cuidadosamente escolhidas de modo a permitir análises simples e satisfatórias, segundo a necessidade de investigação dos resultados.

Os modelos foram validados comparando-os com duas análises experimentais de estruturas tridimensionais:

- A primeira consiste na análise de uma estrutura em alvenaria de tijolos cerâmicos em escala 1:6 constituída de duas paredes. O carregamento foi aplicado excentricamente ao centro elástico das paredes, sendo os deslocamentos laterais antes e após à torção avaliados teoricamente através do método dos elementos finitos. Os resultados experimentais consistem na medição dos deslocamentos laterais após a torção da estrutura;

- A segunda equivale ao estudo de um modelo reduzido com uma disposição menos simples das paredes. A estrutura foi submetida a um momento de torção aplicado na última laje. A análise compreende a avaliação das rotações das lajes através do modelo de pórtico tridimensional, bem como dos resultados experimentais obtidos com a instrumentação da estrutura. 
Maiores detalhes a respeito dos modelos reduzidos podem ser encontrados no item 4.2.

Em seguida desenvolveu-se uma análise detalhada de um edifício de sete pavimentos, considerado neste trabalho como exemplo básico para análise dos resultados. O estudo apresenta resultados de deslocamentos ao nível dos pavimentos; análises de distribuição das esforçoss cortantes, bem como momentos fletores entre as paredes consideradas no contraventamento; diagramas de esforços cortantes e momentos fletores das paredes mais solicitadas. São avaliados os modelos de paredes isoladas e pórtico tridimensional, investigando-se as modificações devidas às deformações por cisalhamento, acréscimos de esforços provenientes da torção do edifício e, redistribuições dos esforços cortantes e momentos fletores entre as paredes de contraventamento quando incorporam-se os lintéis ao modelo de pórtico tridimensional. As análises foram desenvolvidas segundo as duas direções principais do edifício.

Por fim, são analisados dois edifícios, um de treze e outro de nove pavimentos, sendo avaliados os resultados mais significativos de acordo com as indicações do edifício básico. O penúltimo exemplo tem por finalidade comparar o modelo usual empregado em escritórios de projeto com o modelo de pórtico tridimensional proposto nesse trabalho. As análises são desenvolvidas para ação do vento considerada simétrica. O último exemplo, cuja planta apresenta-se sob forma mais alongada, tem por finalidade quantificar os acréscimos nos esforços de cisalhamento devidos à torção do edifício, aplicando-se ações do vento com excentricidades normalizadas. Da mesma forma são comparados o modelo de barras isoladas e o modelo de pórtico tridimensional.

Os modelos utilizados nas análises são referidos nesse trabalho como:

Modelo 1: paredes isoladas, paralelas à direção de atuação do vento, sem inclusão da deformação por cisalhamento das paredes;

Modelo 2: paredes isoladas, paralelas à direção de atuação do vento, com inclusão da deformação por cisalhamento das paredes;

Modelo 3: pórtico tridimensional considerando-se a deformação por cisalhamento das paredes e sem contribuição dos lintéis;

Modelo 4: pórtico tridimensional considerando-se a deformação por cisalhamento das paredes e com contribuição dos lintéis. 


\section{2 - Exemplos de consolidação dos modelos}

Para validar o modelo de pórtico tridimensional proposto, foram utilizados dois estudos experimentais em modelos reduzidos. Um com quantidade menor e distribuição mais simples das paredes, outro com quantidade maior e distribuição mais complexa.

O primeiro exemplo tomado como parâmetro foi uma análise experimental desenvolvida por KALITA U. C. and HENDRY A. W.(1970). Um modelo reduzido tridimensional composto por duas paredes simétricas e quatro lajes, FIGURAS 4.1, foi ensaiado experimentalmente, sendo sua estrutura construída na escala 1:6 com tijolos maciços cerâmicos.

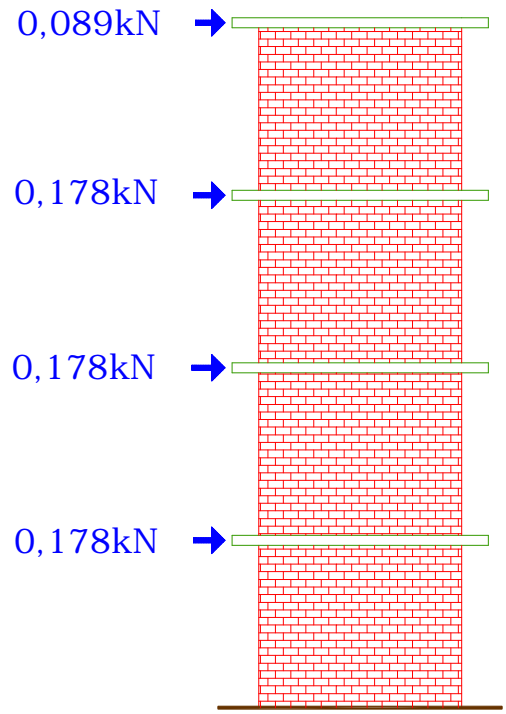

(a) - Vista Lateral

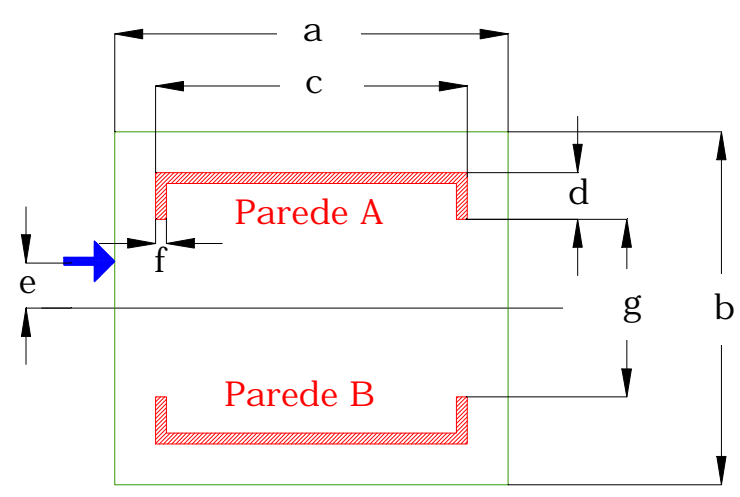

(c) - Planta Baixa

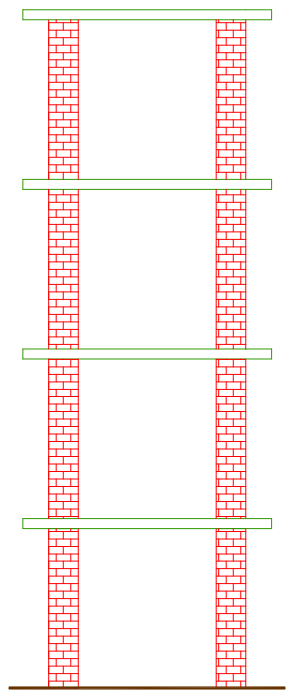

(b) - Vista Frontal

FIGURA 4.1 - Modelo reduzido ensaiado por U. C. KALITA and A. W. HENDRY (1970) 
Aplicaram-se previamente cargas verticais para simular o efeito da pré-compressão das paredes, e os modelos teóricos utilizados consideram a variação do módulo de deformação transversal G com a pré-compressão segundo resultados apresentados em KALITA U. C. and HENDRY A. W. (1969). A relação entre os módulos de elasticidade E e G foi utilizada, de modo que a variação do módulo transversal G corresponde aos seguintes módulos de Yang: E=2596MPa para as paredes na base da estrutura, $\mathrm{E}=2078 \mathrm{MPa}$ entre a primeira e segunda lajes, $\mathrm{E}=1602 \mathrm{MPa}$ entre a segunda e terceira lajes e $\mathrm{E}=1213 \mathrm{MPa}$ entre a terceira e quarta lajes. Ao nível das lajes foram aplicadas ações horizontais, com macacos hidráulicos, de $0,178 \mathrm{kN}$ nas lajes intermediárias e $0,089 \mathrm{kN}$ na última laje, FIGURA 4.1a, todas com uma excentricidade $\mathrm{e}=7,62 \mathrm{~cm}$.

Utilizaram-se as seguintes dimensões:

$$
\begin{array}{lll}
\mathrm{a}=50,80 \mathrm{~cm} & \mathrm{~d}=7,62 \mathrm{~cm} & \text { pé-direito de } 43,18 \mathrm{~cm} \\
\mathrm{~b}=50,80 \mathrm{~cm} & \mathrm{f}=1,75 \mathrm{~cm} & \text { espessura da laje de } 2,54 \mathrm{~cm} \\
\mathrm{c}=44,14 \mathrm{~cm} & \mathrm{~g}=28,90 \mathrm{~cm} &
\end{array}
$$

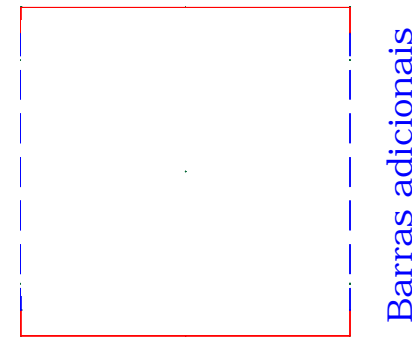

(a) - Vista superior

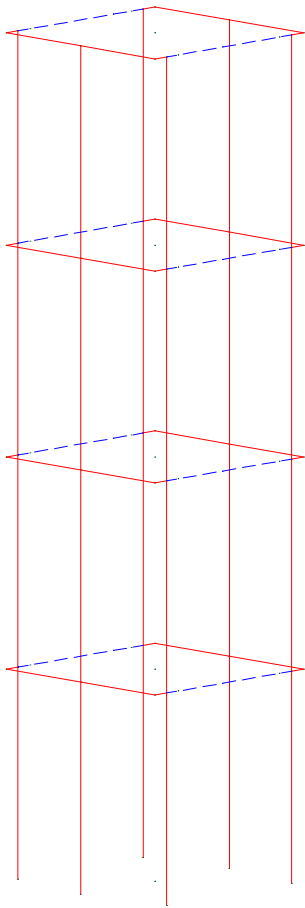

(b) - Vista em perspectiva

FIGURA 4.2 - Modelo de pórtico tridimensional do exemplo experimental ensaiado em KALITA U. C. and HENDRY A. W. (1970) 
Para validação do modelo de pórtico tridimensional (modelo 3), avaliaram-se os deslocamentos horizontais das lajes. Os deslocamentos resultantes sem rotação das lajes são comparados com um modelo em elementos finitos, e os deslocamentos resultantes quando inclui-se a rotação das lajes são comparados com aqueles obtidos experimentalmente. A modelagem teórica desenvolvida com o método dos elementos finitos foi extraída de KALITA U. C. and HENDRY A. W.(1970). Esse modelo incorpora a contribuição das lajes no sistema de contraventamento. No modelo de pórtico tridimensional, a contribuição da laje foi simulada considerando-se barras horizontais com módulo de elasticidade $E=30.337 \mathrm{MPa}$ e características geométricas correspondentes à espessura da laje e à largura colaborante segundo KALITA U. C. and HENDRY A. W.(1969). Essas barras adicionais interligam as barras verticais dos trechos menores das paredes $\mathrm{A}$ e B, FIGURAS 4.2 .

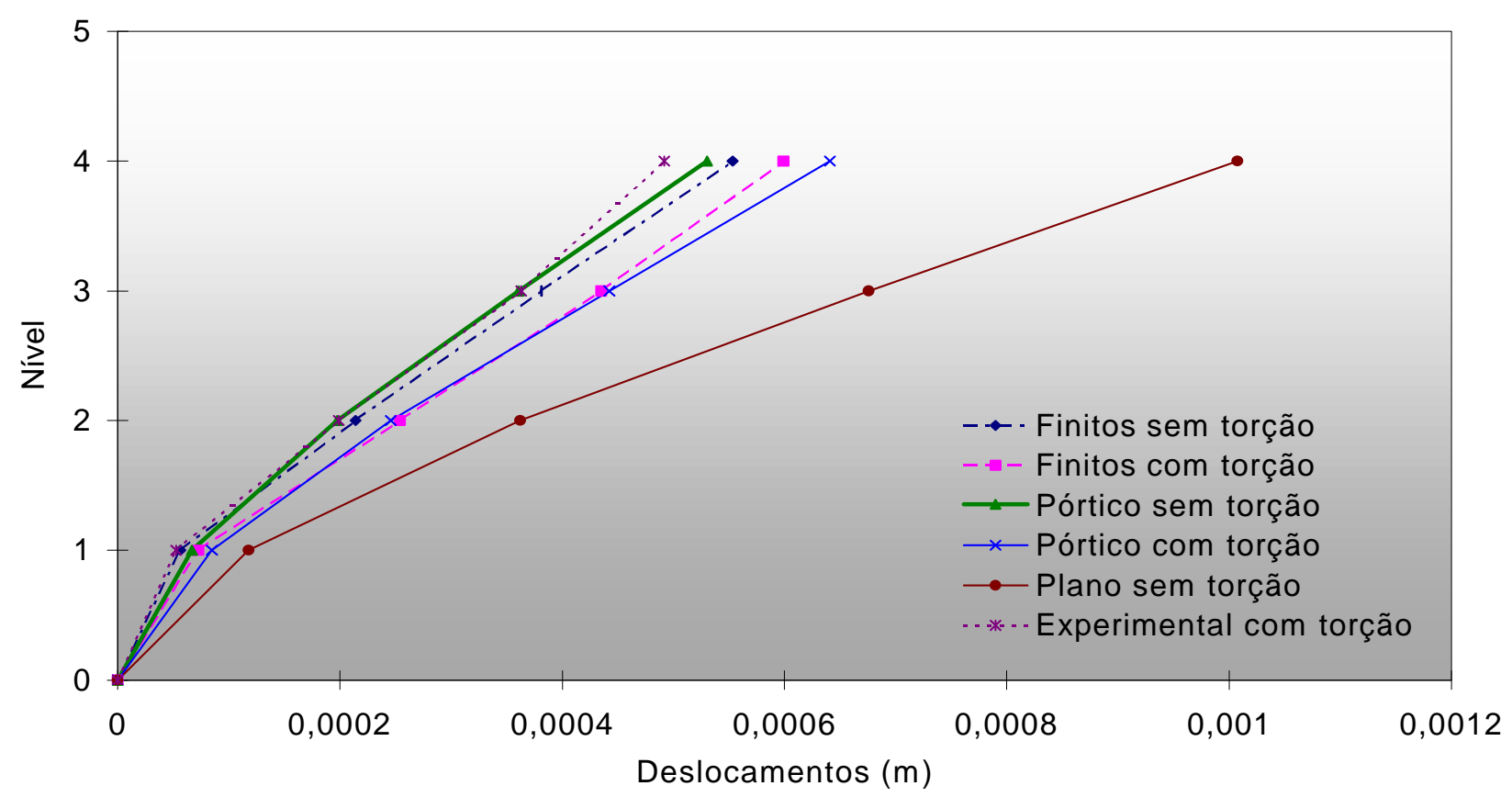

FIGURA 4.3 - Deslocamentos horizontais da Parede A 


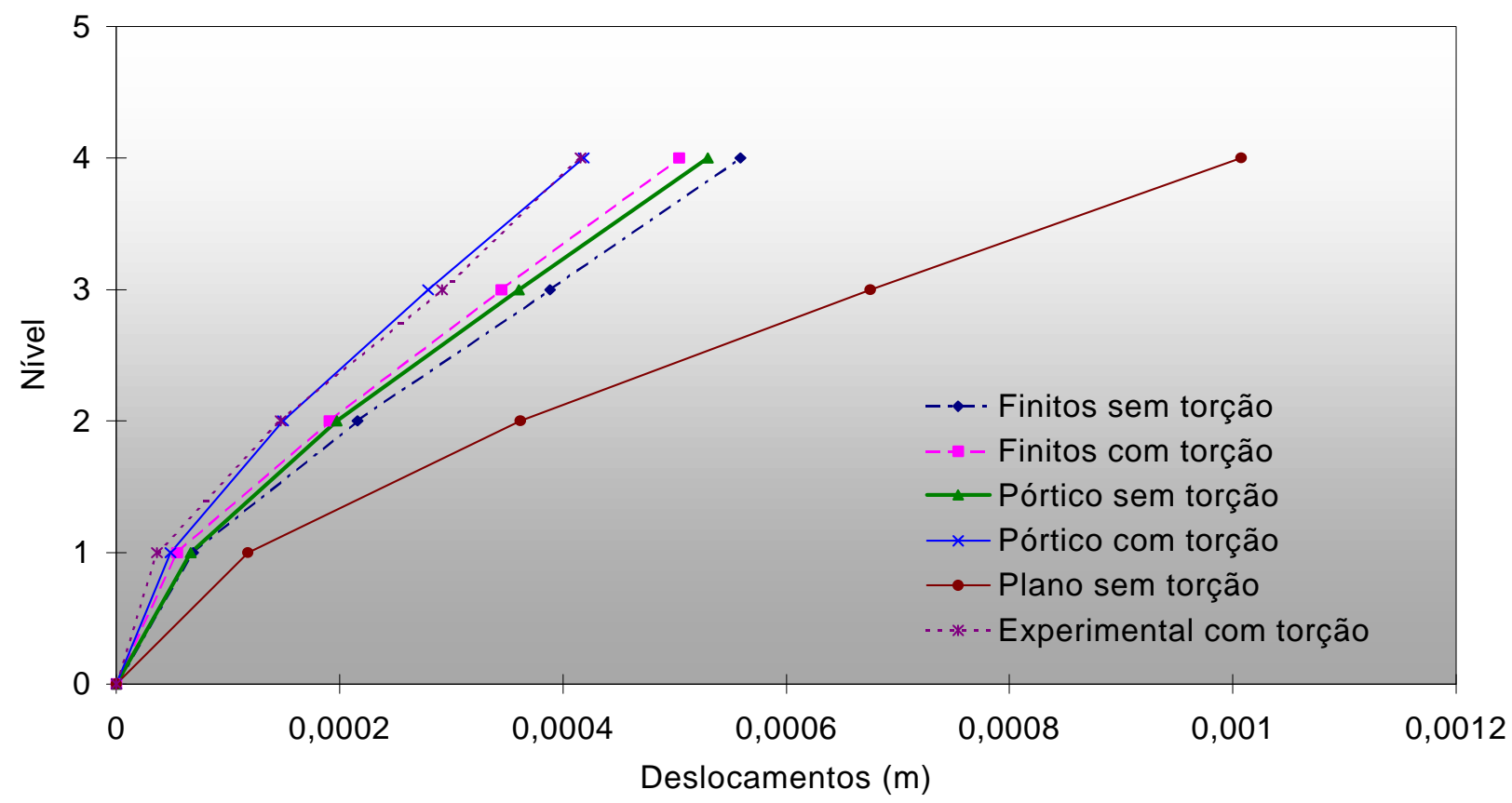

FIGURA 4.4 - Deslocamentos horizontais da Parede B

Observando-se os gráficos de deslocamentos da Parede A, FIGURA 4.3, percebe-se uma proximidade significativa entre os modelos teóricos na análise sem rotação das lajes. Nessa análise o pórtico tridimensional resultou em deslocamentos menores, permitindo-se concluir que pode ser um modelo mais rígido que o modelo em elementos finitos adotado. Da mesma forma verifica-se essa tendência para os deslocamentos da Parede B, FIGURA 4.4. Ao se incluir a rotação das lajes, os deslocamentos da Parede A, obtidos com o modelo de pórtico tridimensional, praticamente coincidiram com o modelo em elementos finitos. No caso da parede $\mathrm{B}$, o modelo de pórtico tridimensional obteve resultados praticamente iguais ao modelo experimental, evidenciando-se a qualidade dessa modelagem. Nessa análise a variação dos deslocamentos, isto é, o acréscimo de deslocamentos para a Parede A e decréscimo para a Parede B, foi maior no modelo de pórtico tridimensional. Isso pode ter ocorrido devido ao tipo de modelagem utilizada para discretizar a laje. O modelo em elementos finitos permite que seja feita uma discretização mais refinada, principalmente nas regiões de ligação da laje com a parede. Essa diferença pode explicar a maior flexibilidade, na torção, do modelo de pórtico tridimensional. Vale salientar 
que se fez a análise desse exemplo com o modelo de barras isoladas (associação plana), obtendo-se resultados insatisfatórios como pode ser comprovado nas FIGURAS 4.3 e 4.4 .

O segundo estudo experimental consiste num modelo reduzido em escala 1:3 de uma estrutura em alvenaria de blocos com cinco lajes e dez paredes, ensaiado por KESKIN, O.(1974), FIGURA 4.5. É uma estrutura simétrica cuja disposição e comprimento das paredes permite que haja uma contribuição mais significativa das abas no sistema de contraventamento.

As dimensões utilizadas foram as seguintes:

$$
\begin{array}{lll}
\mathrm{a}=243,90 \mathrm{~cm} & \mathrm{~b}=228,60 \mathrm{~cm} & \text { pé-direito de } 96,52 \mathrm{~cm} \\
\mathrm{c}=121,99 \mathrm{~cm} & \mathrm{~d}=91,45 \mathrm{~cm} & \text { espessura da laje de } 5,08 \mathrm{~cm} \\
\mathrm{~L}_{1}=45,70 \mathrm{~cm} & \mathrm{~L}_{2}=28,00 \mathrm{~cm} &
\end{array}
$$

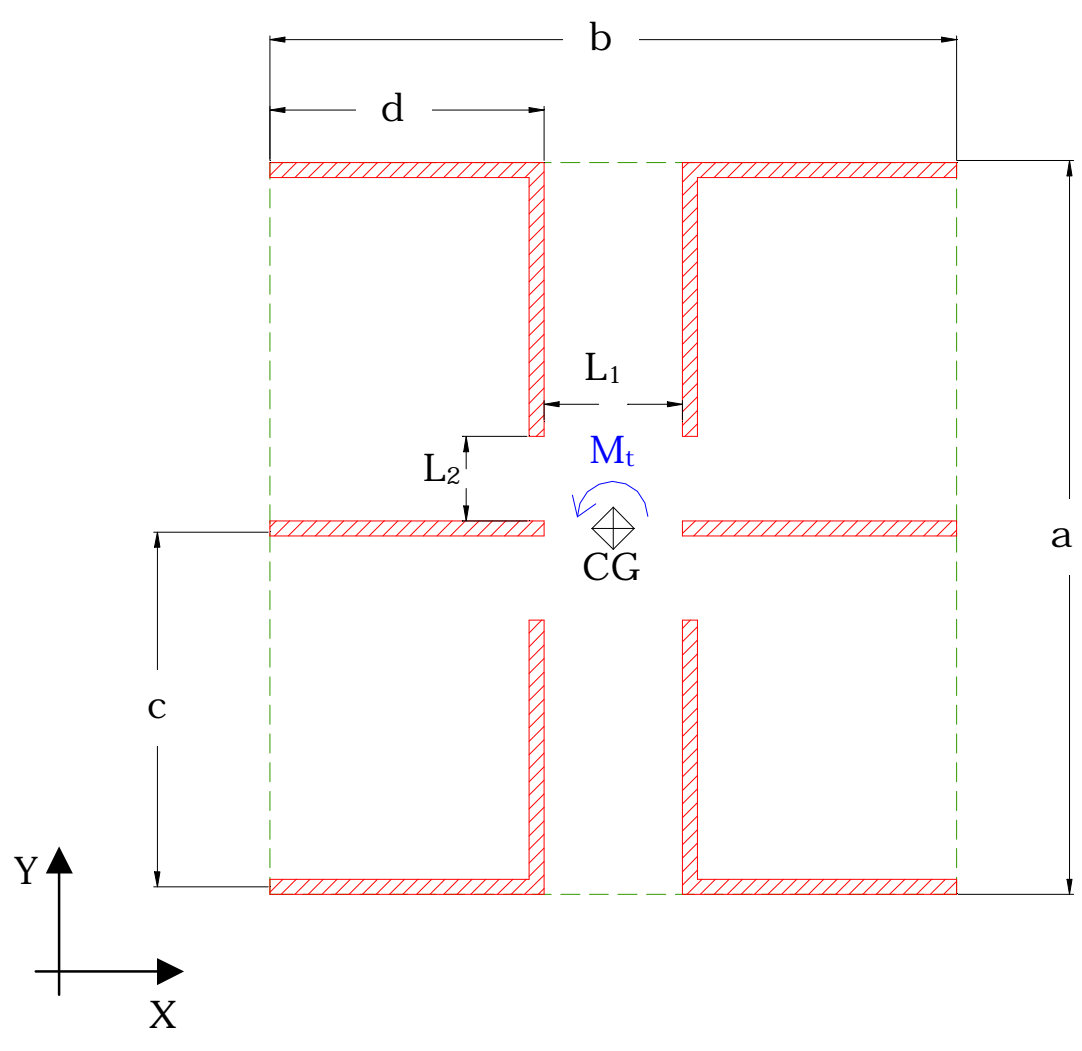

FIGURA 4.5 - Planta baixa do modelo reduzido ensaiado por KESKIN, O. (1974) 
O modelo reduzido foi submetido à ação de um momento de torção aplicado no centro geométrico da última laje $\mathrm{M}_{\mathrm{t}}=3,35 \mathrm{kN} . \mathrm{m}$, o que equivale ao momento de uma força concentrada $F=2,75 \mathrm{kN}$ aplicada segundo a direção X com uma excentricidade e e igual à metade da largura da laje. Os resultados são avaliados através das rotações das lajes obtidas experimentalmente, e pelo modelo de pórtico tridimensional (modelo 3). Da mesma forma que no exemplo anterior, o modelo de pórtico tridimensional, FIGURA 4.6, incorporou a contribuição da laje por meio de barras adicionais com módulo de elasticidade $\mathrm{E}=30.337 \mathrm{MPa}$ e características geométricas segundo as recomendações encontradas em KALITA U. C. and HENDRY A. W. (1969). Essas barras adicionais são ligadas continuamente às correspondentes barras verticais que modelam as paredes. No caso das paredes, considerou-se um único módulo de deformação elástico $\mathrm{E}=7171 \mathrm{MPa}$ para todos os níveis.

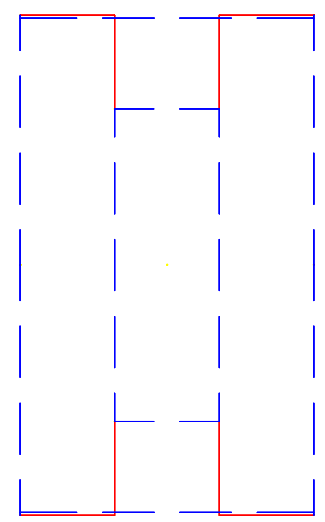

(a) - Vista superior

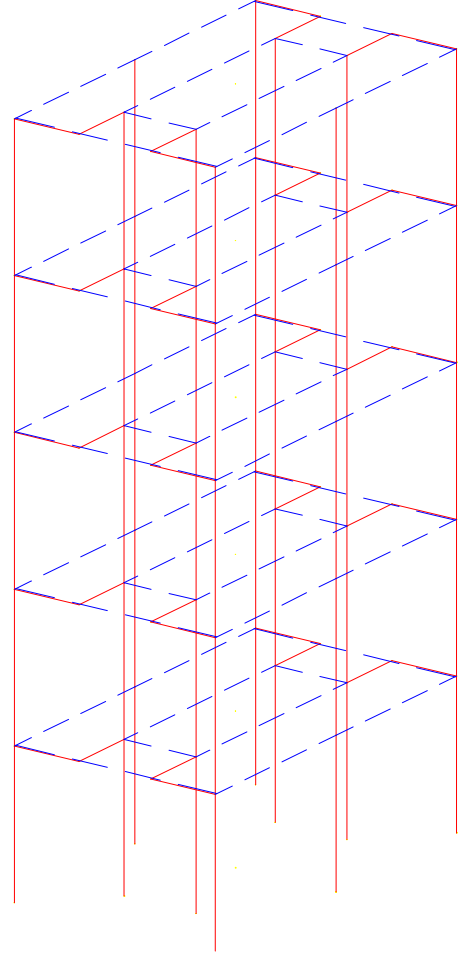

(b) - Vista em perspectiva

FIGURA 4.6 - Modelo de pórtico tridimensional do exemplo experimental ensaiado por KESKIN, O. (1974) 


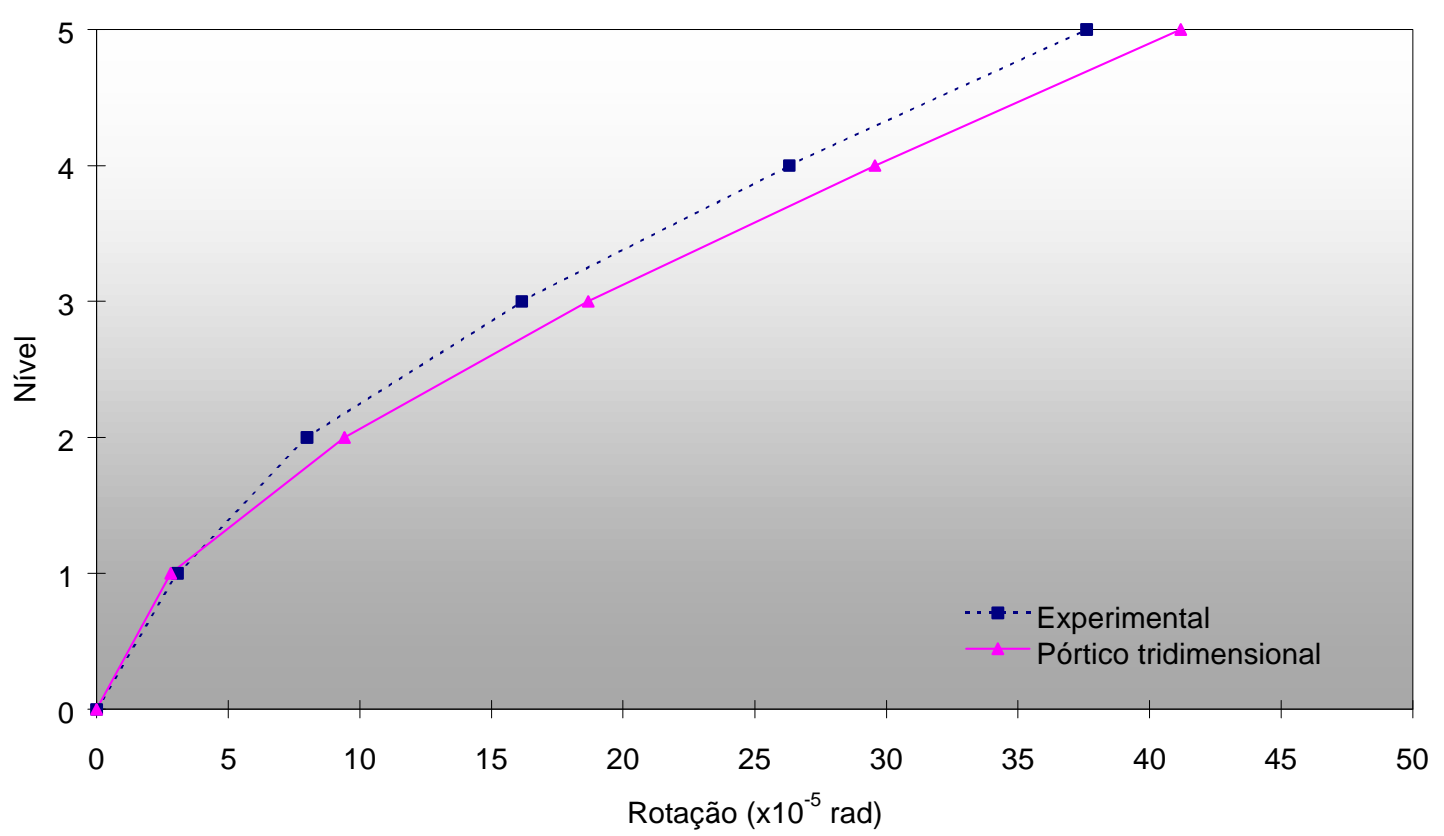

FIGURA 4.7 -Rotações das lajes

Observando-se os resultados obtidos para as rotações das lajes, FIGURA 4.7, percebe-se que o comportamento do modelo de pórtico tridimensional é bastante semelhante ao do modelo experimental com

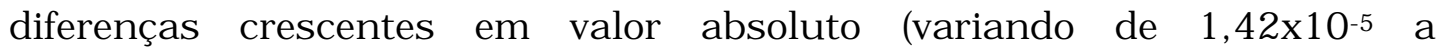
$3,57 \times 10^{-5} \mathrm{rad}$ ) e decrescentes em percentuais (variando de $18 \%$ a 9\%). Além disso, os deslocamentos são maiores que os da análise experimental, o que pode garantir a segurança do modelo de pórtico.

Esses dois exemplos com análises experimentais, confirmam a validade do modelo de pórtico tridimensional proposto, onde os resultados obtidos apresentaram boa aproximação. Desse modo, pode-se concluir previamente que o modelo está apto a ser aplicado na análise dos edifícios em alvenaria estrutural. 


\section{3 - Exemplo básico para análise geral dos resultados}

Com o intuito de se obterem informações a respeito dos prováveis resultados mais significativos na análise dos edifícios, desenvolveu-se o estudo detalhado de um projeto básico. Foi extraída uma grande quantidade de informações a respeito dos modelos empregados na análise estrutural, enfatizando-se os resultados de deslocamentos horizontais da estrutura ao nível dos pavimentos, de distribuição dos esforços cortantes, e quando conveniente os de distribuição de momentos fletores, bem como os diagramas de momento fletor e esforço cortante da parede mais solicitada.

O edifício utilizado nesse exemplo possui sete pavimentos cuja distância de piso a piso mede 2,80m. A planta do pavimento tipo é apresentada na FIGURA 4.8a e esquematizada em diagrama unifilar na FIGURA 4.8b. Foram utilizados blocos de concreto que variam de 6,0MPa a 4,5MPa da base ao topo, considerando-se um módulo de elasticidade $\mathrm{E}=2960 \mathrm{MPa}$ em todas as paredes. O carregamento devido ao vento foi determinado segundo a NBR-6123, considerando-se uma velocidade básica $\mathrm{V}_{0}=38 \mathrm{~m} / \mathrm{s}$ e um edifício de classe 2 e categoria 4 .

Inicialmente desenvolveu-se a análise avaliando-se os resultados obtidos pelos modelos 1 e 2. A direção $\mathrm{Y}$ de análise foi priorizada por apresentar maior área de obstrução à ação do vento. Vale salientar que a direção $\mathrm{X}$ também foi analisada, tendo apresentado o mesmo comportamento quanto ao aspecto da distribuição dos esforços. Para se evitar repetição, esta análise não é aqui apresentada. 


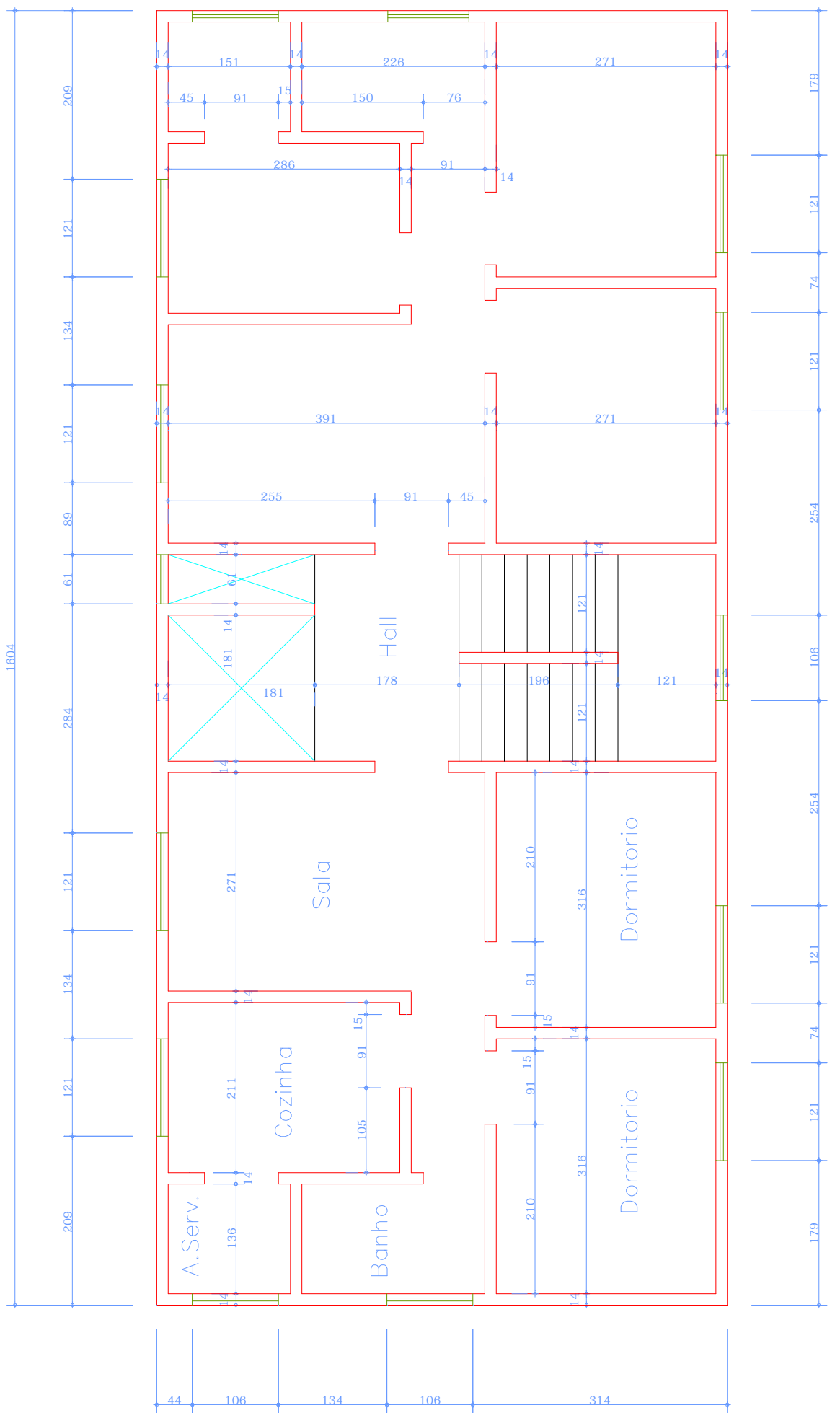

FIGURA 4.8a - Planta baixa do pavimento tipo 


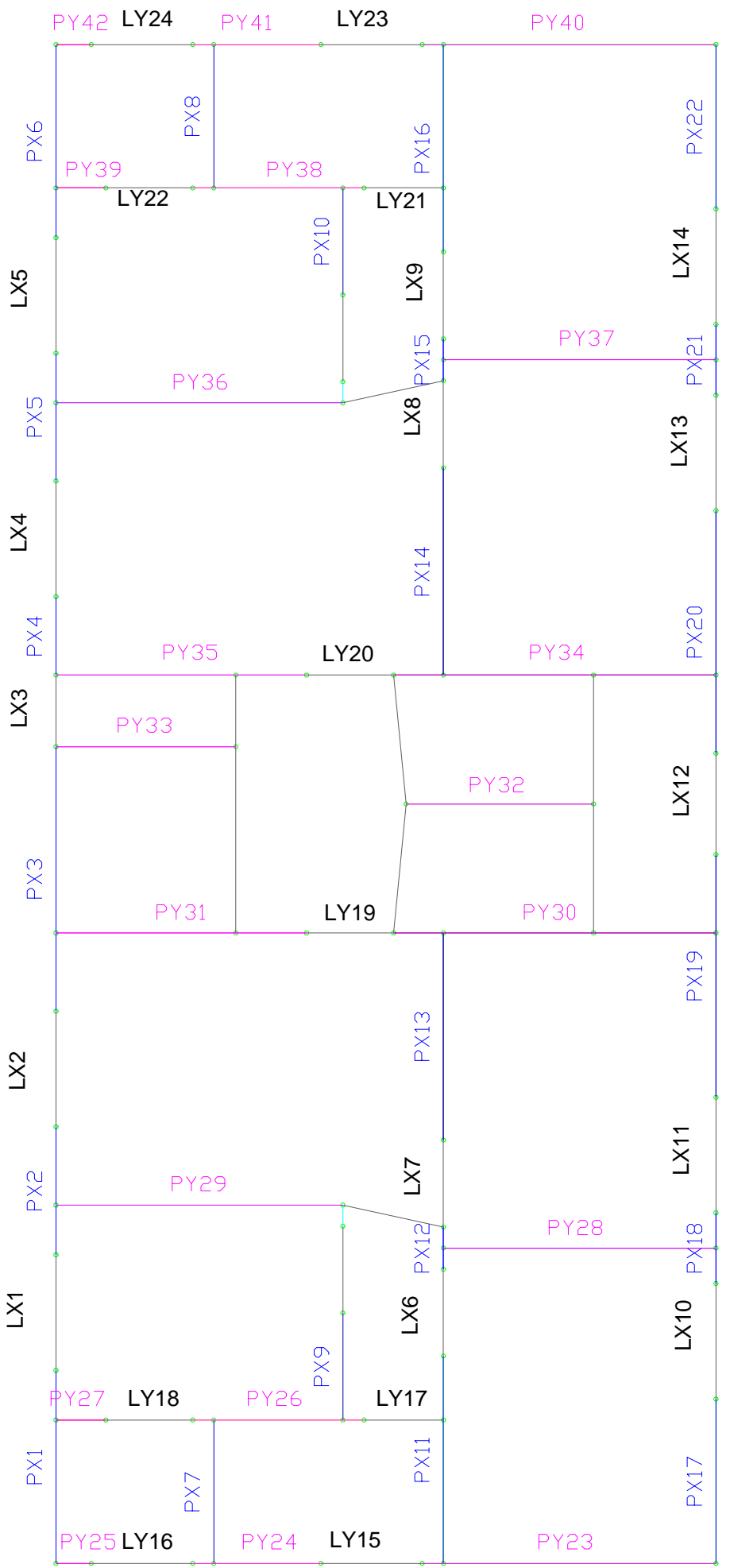

FIGURA 4.8b - Diagrama unifilar das paredes em planta 
Os resultados obtidos na análise desse exemplo vêm confirmar os resultados do exemplo estudado no item 3.1.3. Os deslocamentos horizontais, FIGURA 4.9, apresentaram um acréscimo pouco significativo de $4 \%$ no topo da estrutura.

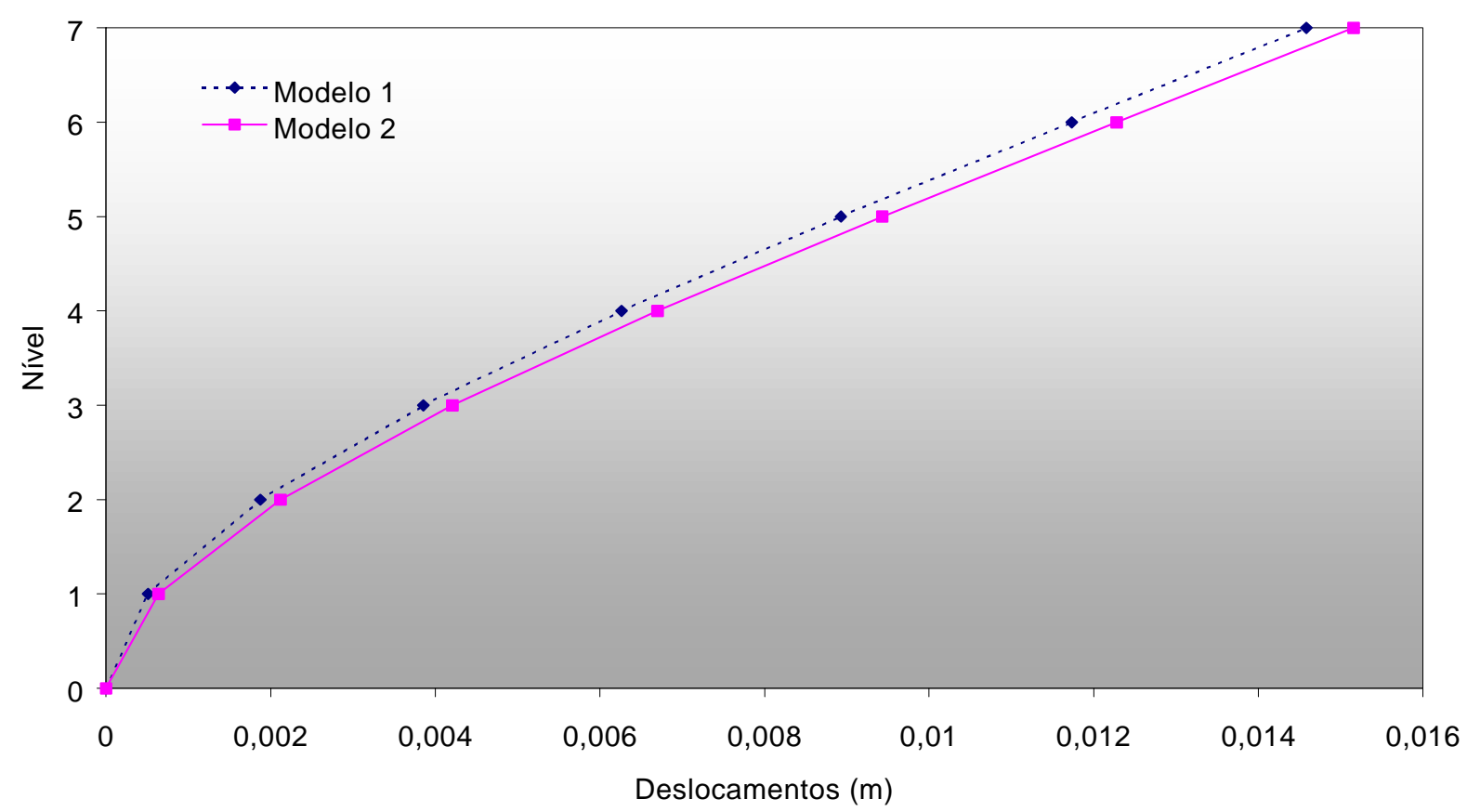

FIGURA 4.9 - Deslocamentos horizontais, vento Y

Os momentos fletores na base das paredes, FIGURA 4.11, resultaram numa diferença na máxima intensidade de 6\% nas paredes PY30 e PY34, enquanto que as diferenças mais significativas ocorreram, novamente, na distribuição dos esforços cortantes, FIGURA 4.10, com decréscimo máximo de $22 \%$ nas paredes PY30 e PY34.

Da mesma forma observa-se a tendência de redistribuição dos esforços cortantes e dos momentos fletores, com decréscimo de máximos e acréscimos de mínimos. 


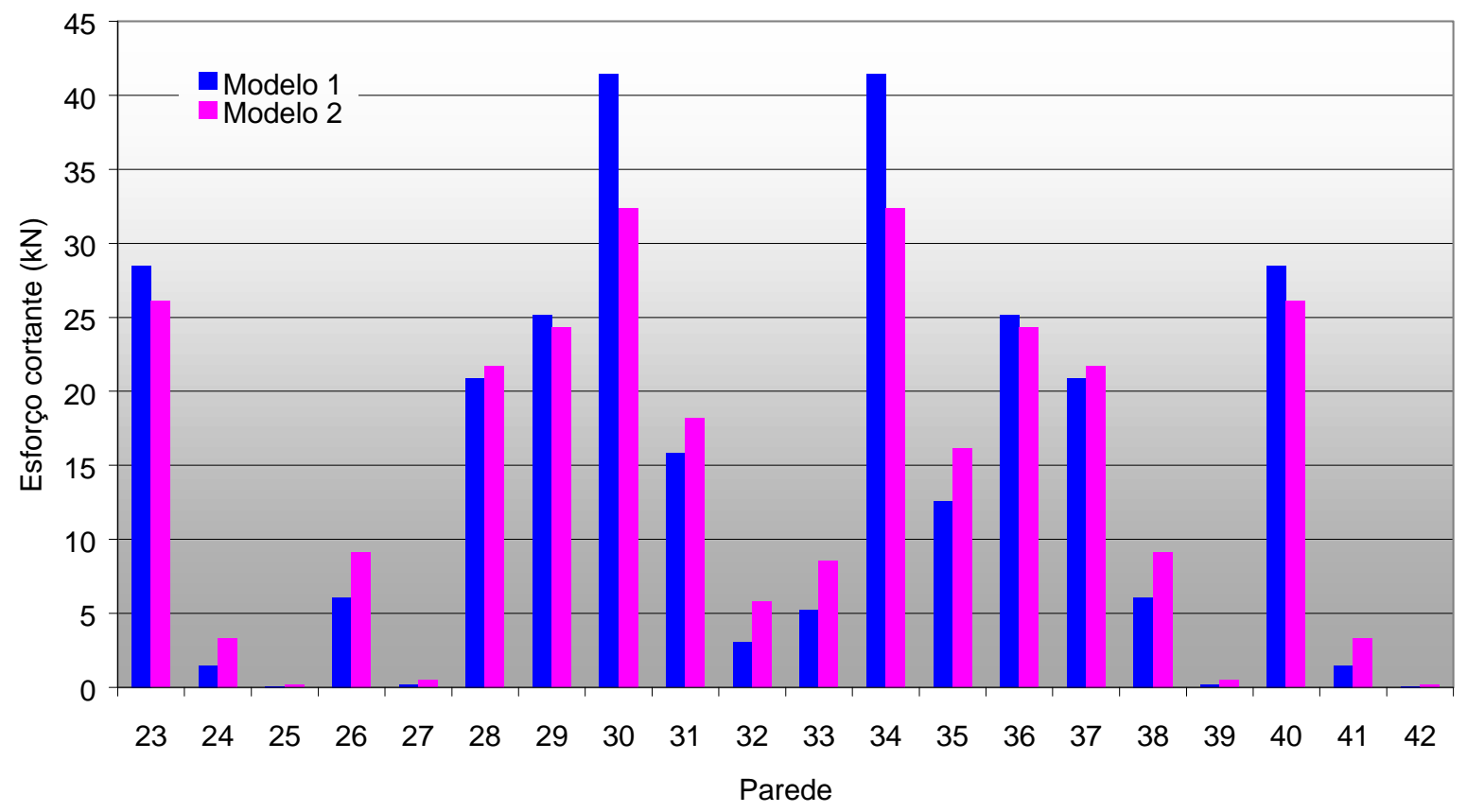

FIGURA 4.10 - Distribuição dos esforços cortantes entre as paredes de contraventamento, vento $\mathrm{Y}$

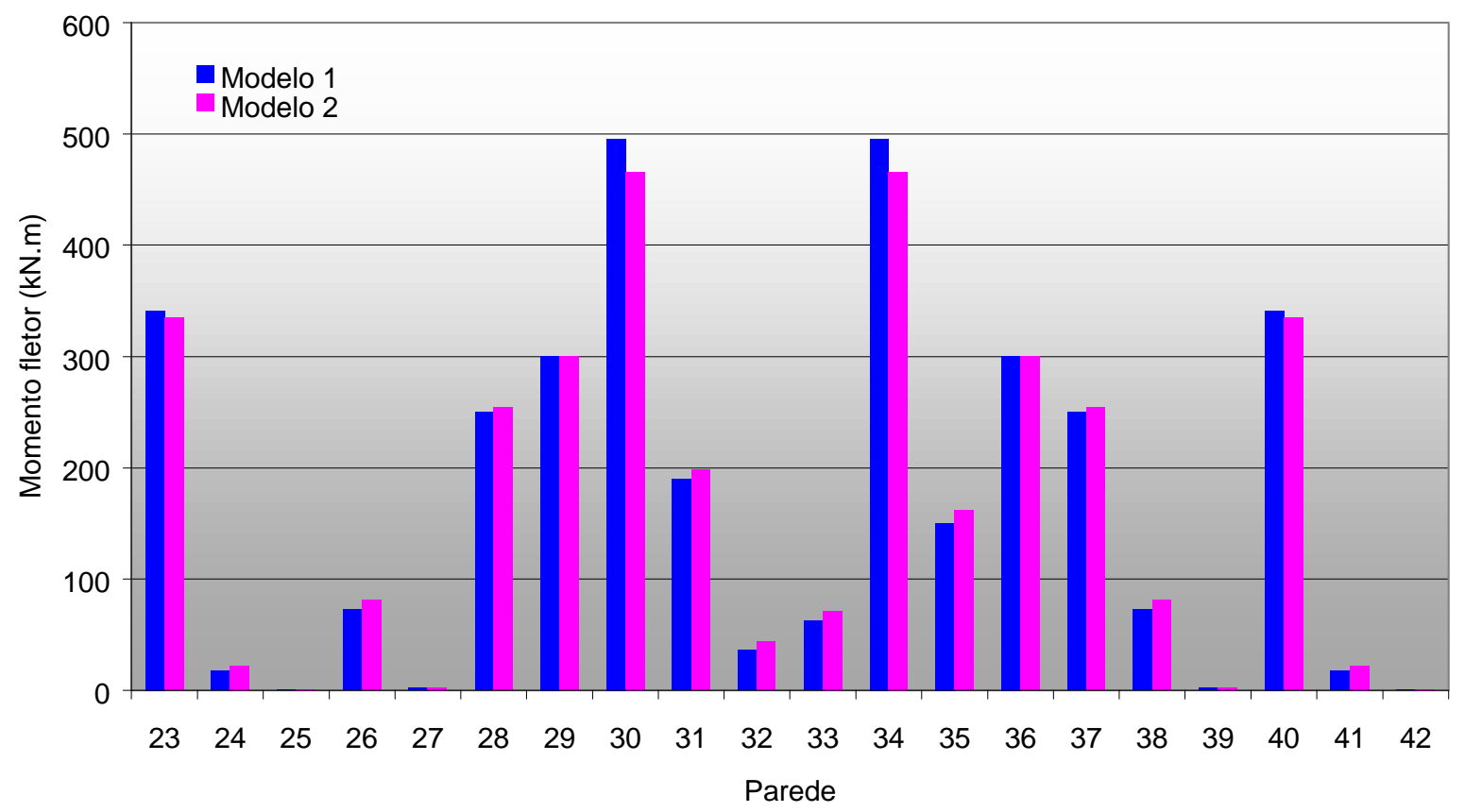

FIGURA 4.11 - Distribuição dos momentos fletores entre as paredes de contraventamento, vento $\mathrm{Y}$ 
Também observa-se a modificação no aspecto do diagrama de esforço cortante da parede mais solicitada, FIGURA 4.12, e a semelhança entre os diagramas de momento fletor, FIGURA 4.13. Esse exemplo permite avaliar o modelo 2 como mais adequado que o modelo 1 , tanto no que se refere ao decréscimo dos esforços, quanto à melhoria do comportamento estrutural, devido à tendência de redistribuição.

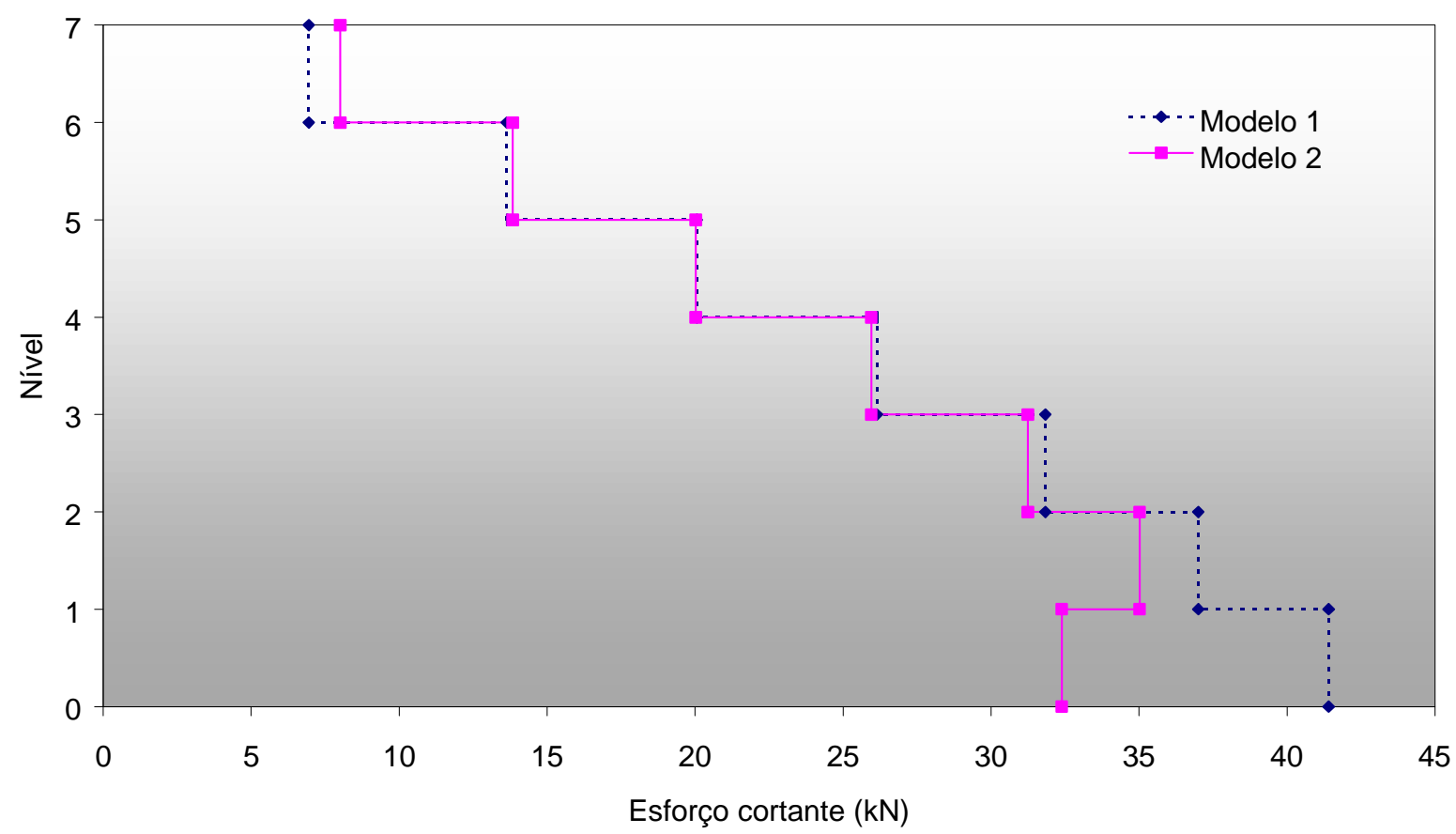

FIGURA 4.12 - Diagrama de esforço cortante da parede mais solicitada, PY30 


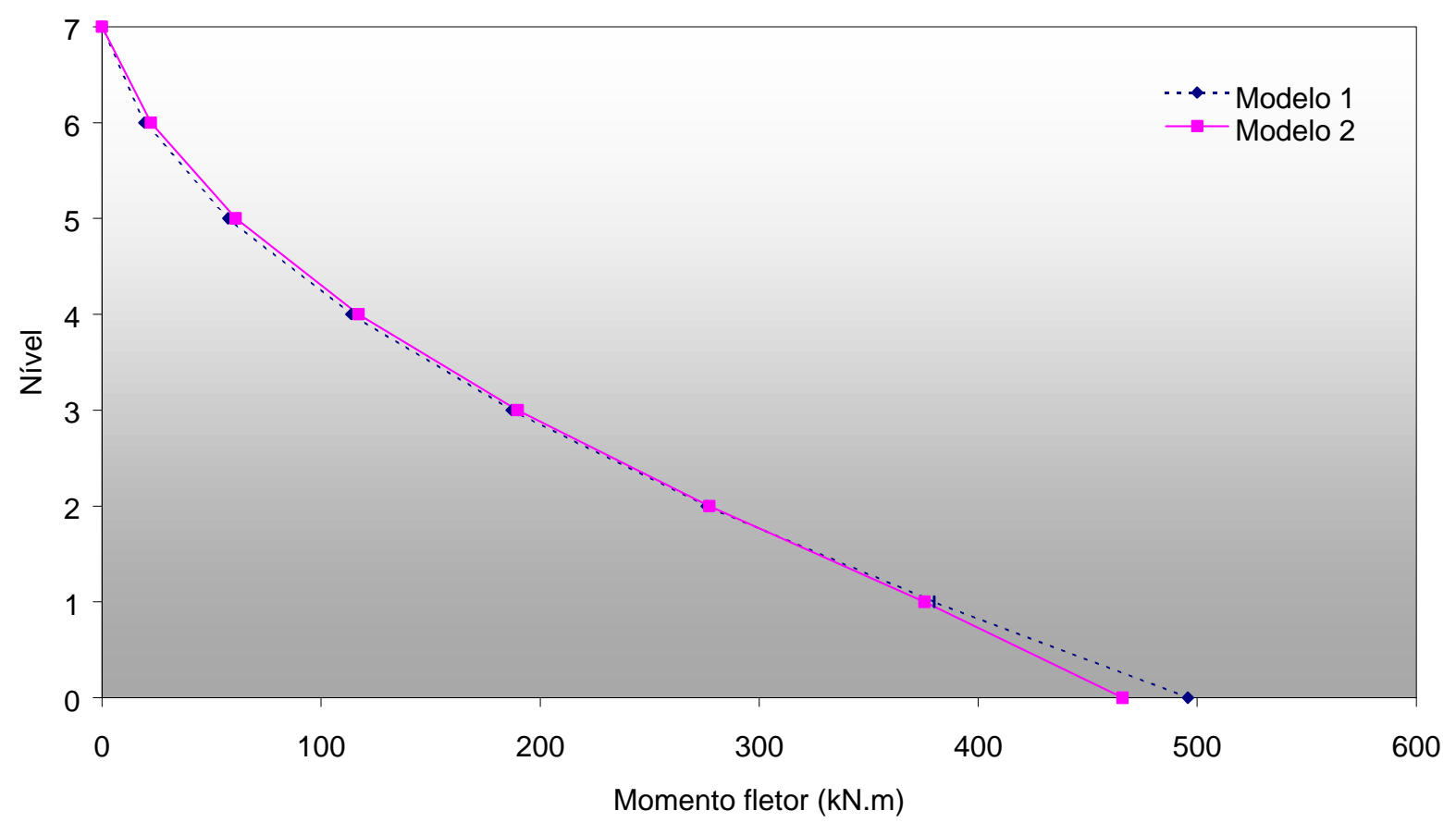

FIGURA 4.13 - Diagrama de momento fletor da parede mais solicitada, PY30

Em seguida desenvolveu-se a análise dos modelos de pórtico tridimensional sem consideração do efeito da torção, modelos 3 e 4 . Foram aplicadas ações segundo as direções principais X e Y no centro geométrico de cada pavimento do edifício. As paredes dispostas perpendicularmente a uma direção de análise, por exemplo as paredes da direção X na análise do vento $\mathrm{Y}$, apresentaram pequena influência na distribuição dos esforços cortantes e dos momentos fletores. Mesmo no caso da análise na direção $X$, que apresenta assimetria na distribuição das paredes, essa influência foi desprezivel.

Foram avaliados, também, os resultados obtidos para distribuição dos esforços cortantes nas paredes e diagrama de esforço cortante na parede mais solicitada com os modelos 1 e 4, avaliando-se as diferenças entre o modelo mais simples e modelagens mais refinadas.

Os lintéis do modelo 4 são analisados quanto aos esforços cortantes e tensões de cisalhamento, comparando-se com limites normalizados. 
O gráfico de deslocamentos, tanto para direção X, FIGURA 4.14, quanto para direção Y, FIGURA 4.15, mostram o ganho de rigidez dos modelos 3 e 4 em relação aos modelos 1 e 2 . O modelo 3 apresenta diferenças consideráveis, (21\% para o vento X e 14\% para o vento $\mathrm{Y}$ ) no deslocamento do topo da estrutura, em relação ao modelo 1. O modelo 4 demonstrou o efeito benéfico da consideração dos lintéis no sistema de contraventamento, diminuindo ainda mais os deslocamentos. Esses lintéis aumentam substancialmente a rigidez do edifício por formarem-se painéis bastante longos, permitindo-se uma interação mais forte no sistema de contraventamento. Além disso, esses elementos são, geralmente, curtos com altura elevada da seção transversal.

É importante alertar para o fato de que essas análises foram desenvolvidas considerando-se comportamento elástico linear da estrutura, não avaliando-se portanto, o grau de fissuração e a perda de rigidez dos lintéis. Neste caso torna-se necessário um estudo mais detalhado do comportamento desses lintéis, considerando-se a não-linearidade física do material.

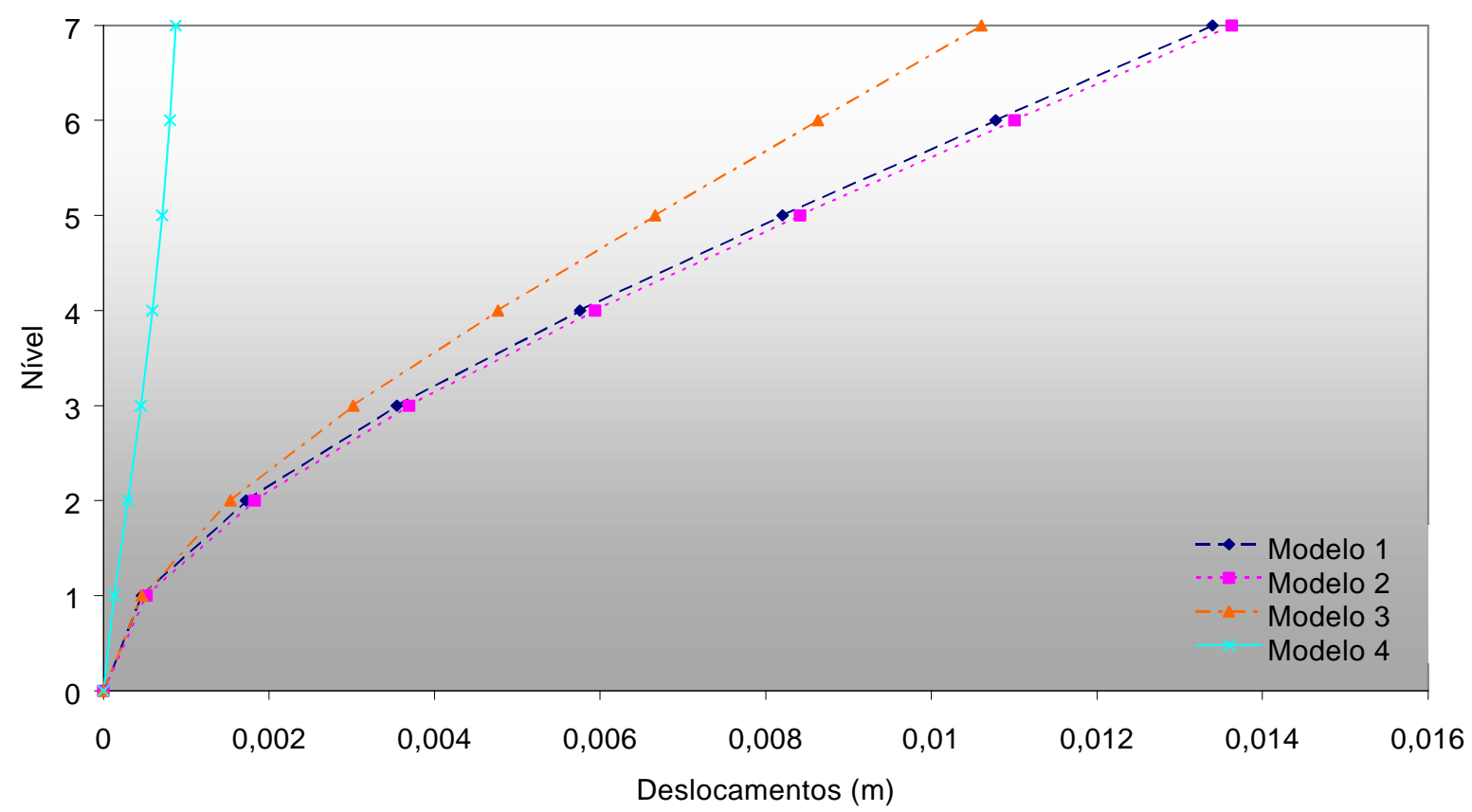

FIGURA 4.14 - Deslocamentos horizontais, vento X 


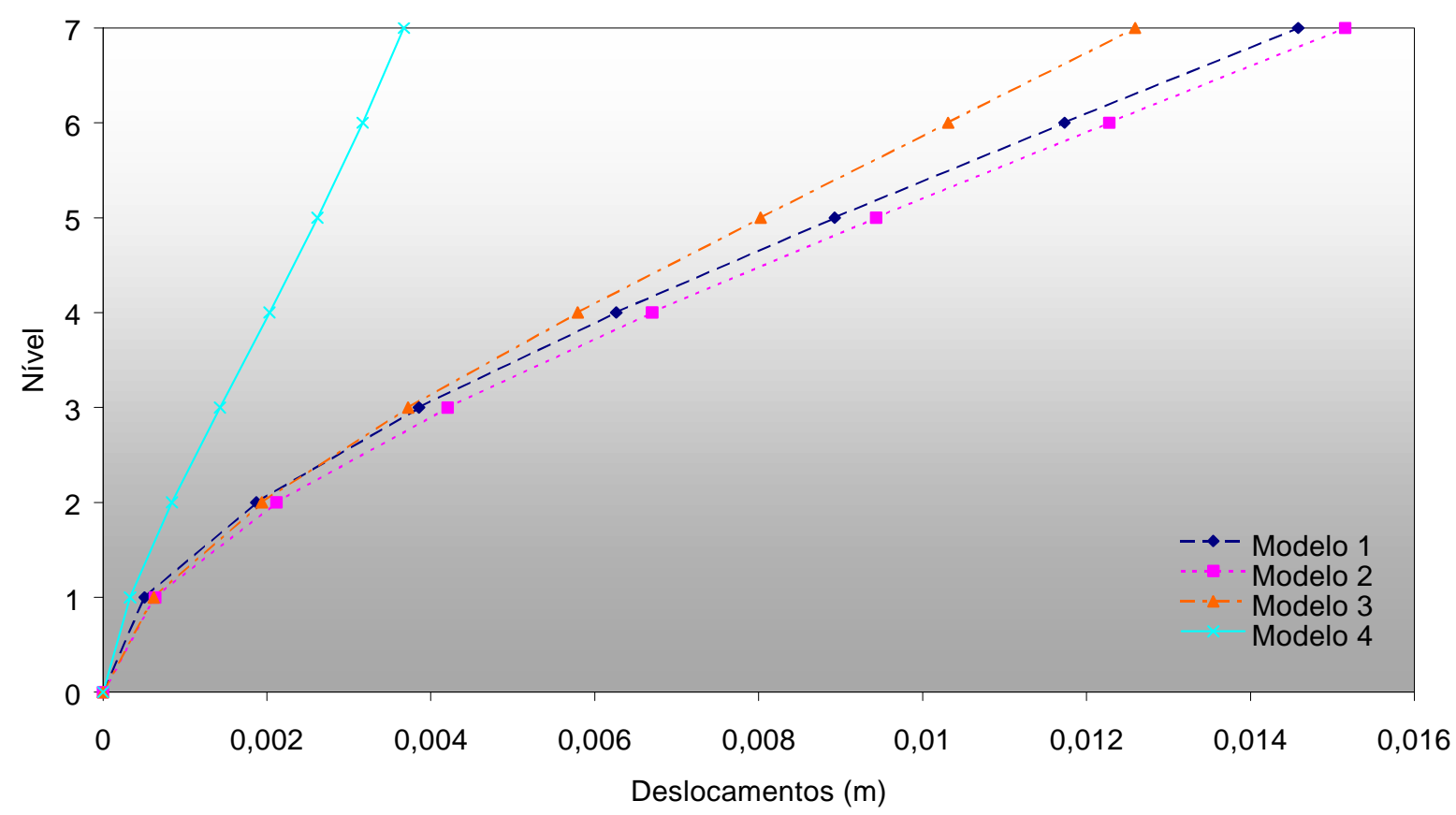

FIGURA 4.15 - Deslocamentos horizontais, vento Y

A comparação na distribuição dos esforços cortantes entre os modelos 1 e 4, FIGURA 4.16a, tem por objetivo mostrar as diferenças entre os dois modelos extremos. As diferenças máximas ocorreram na parede PX3 para a direção X, e PY30 e PY34 para a direção Y, com valores percentuais de 29\% e 28\% respectivamente. No caso das paredes PY30 e PY34, seus esforços diminuiram de $41,3 \mathrm{kN}$ para $29,7 \mathrm{kN}$, segundo os modelos 1 e 4 respectivamente. Esses esforços correspondem a tensões de cisalhamento $\tau_{1}=0,08 \mathrm{MPa}$ e $\tau_{4}=0,06 \mathrm{MPa}$, para uma tensão admissível $\mathrm{f}_{\text {cis }}=0,15 \mathrm{MPa}^{5}$.

Nos gráficos de distribuição de esforços cortantes, FIGURA 4.16a e FIGURA 4.16b, percebe-se claramente a tendência de redistribuição dos mesmos à medida que refina-se a modelagem.

5 Obtida considerando-se, segundo a NBR-10837, alvenaria não-armada e argamassa com resistência variando de 5,0MPa a 12,0MPa. 


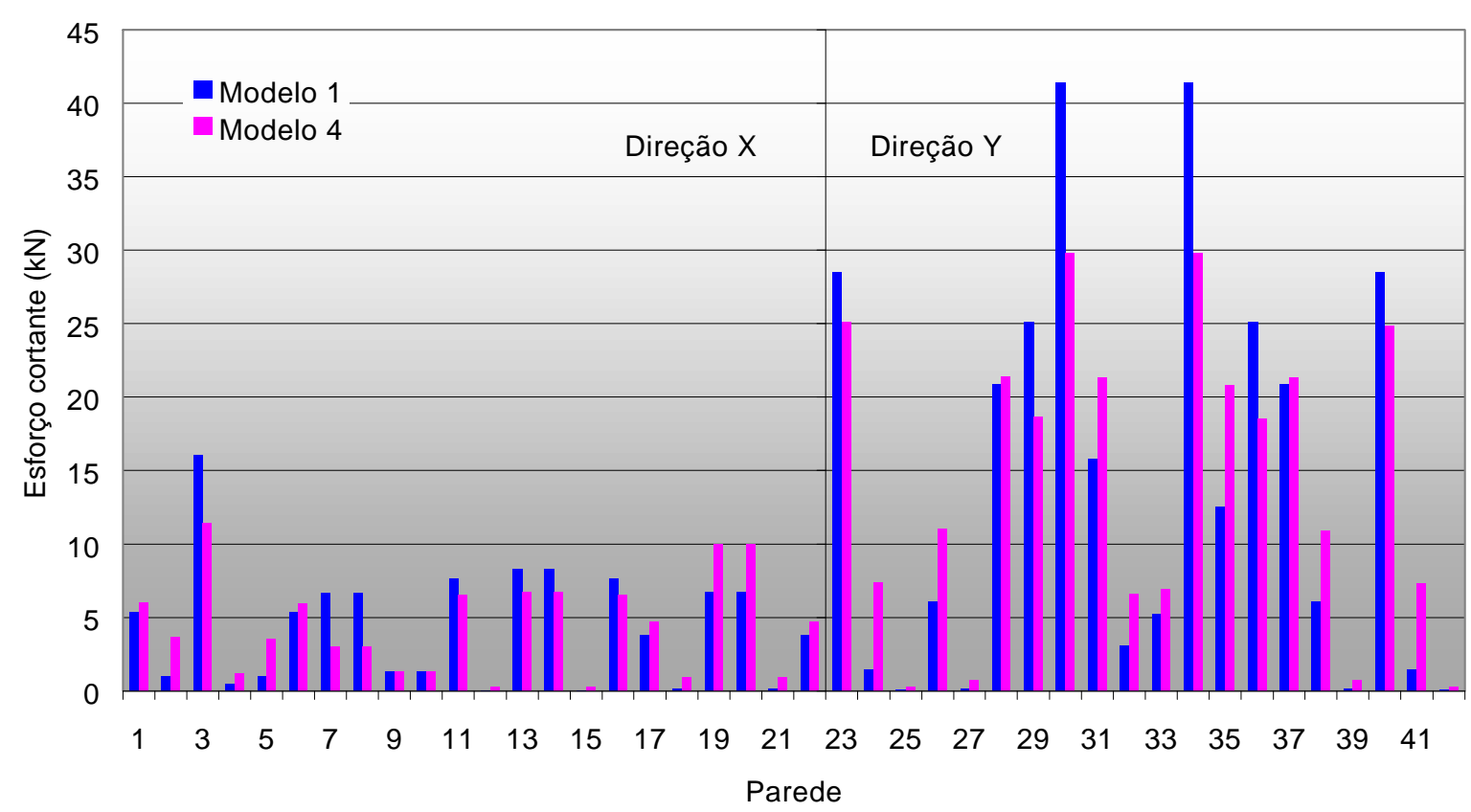

a - Comparação entre os modelos 1 e 4

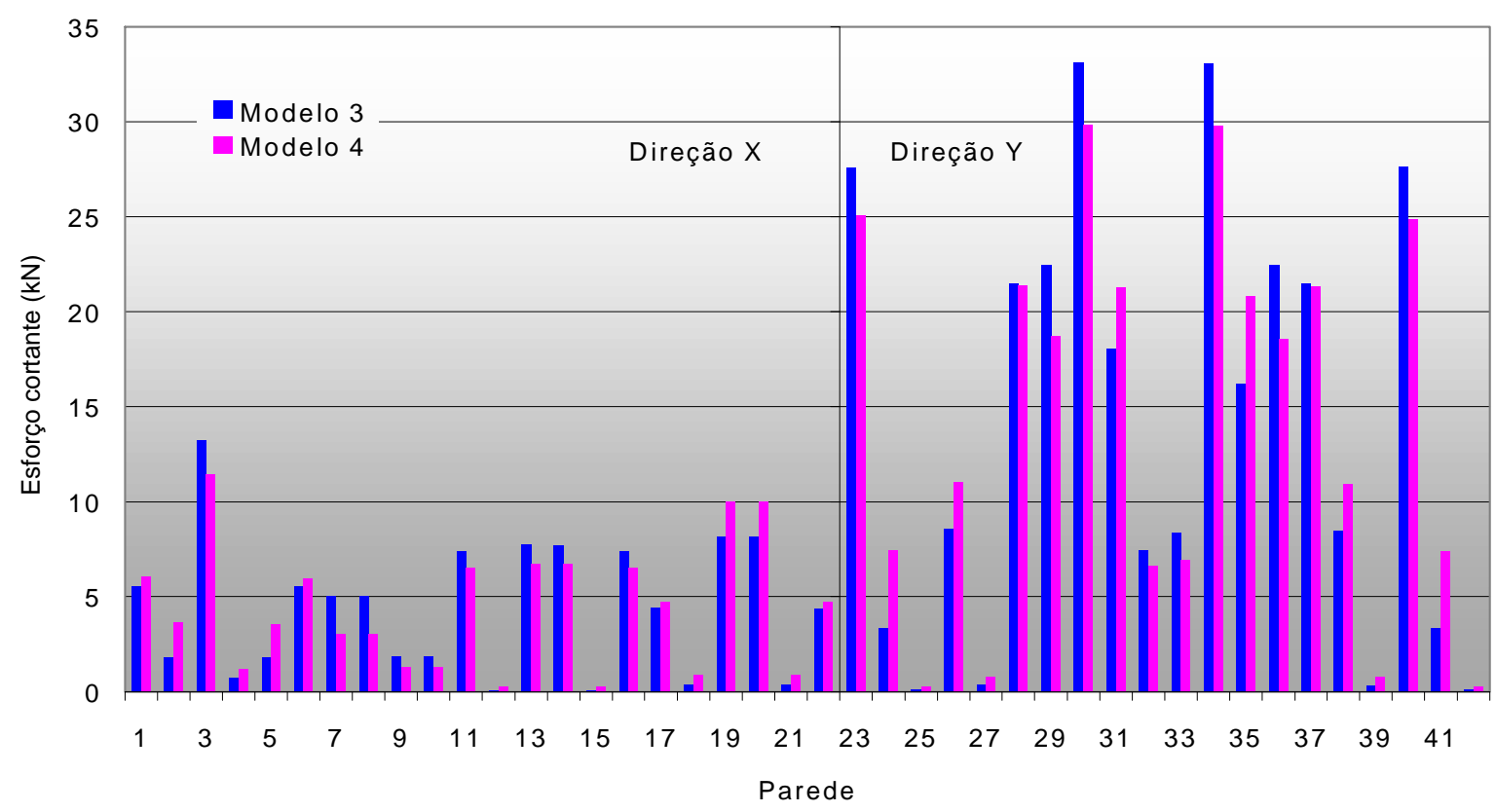

b - Comparação entre os modelos 3 e 4

FIGURA 4.16 - Distribuição dos esforços cortantes entre as paredes de contraventamento com atuação do vento segundo as direções X e Y 
As análises com os modelos 3 e 4 objetivam avaliar o efeito dos lintéis no sistema de contraventamento. A consideração dos lintéis não implica apenas em diminuição de deslocamentos, o que pode ser comprovado com a distribuição dos esforços cortantes e momentos fletores entre as paredes, FIGURA 4.16b e FIGURA 4.17, respectivamente. O decréscimo no esforço cortante máximo (ocorrido nas paredes PY30 e PY34) foi da ordem de 10\%, enquanto que no momento fletor máximo atingiu 53\%. A maior diferença ocorre na distribuição dos momentos fletores, que pode ser explicada pelo fato da consideração dos lintéis implicar no aparecimento de forças normais excêntricas nas paredes, originando reações verticais que formam um binário que resiste ao momento de tombamento da estrutura, FIGURA $4.17 \mathrm{~b}$. Cabe ressaltar que o decréscimo elevado dos momentos implica em acréscimo das forças normais nas paredes.

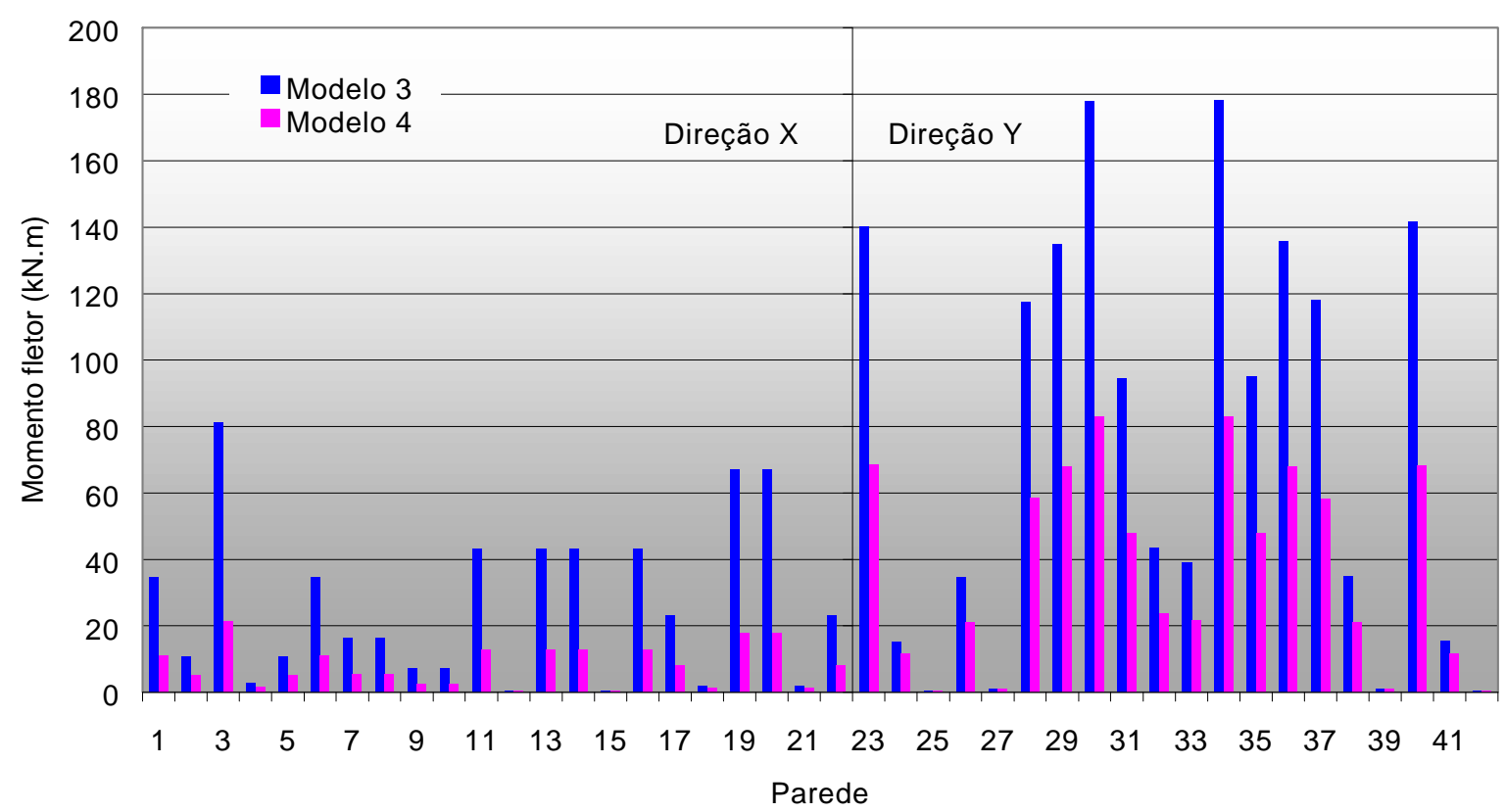

FIGURA 4.17a - Distribuição dos momentos fletores entre as paredes de contraventamento com atuação do vento segundo as direções X e Y 


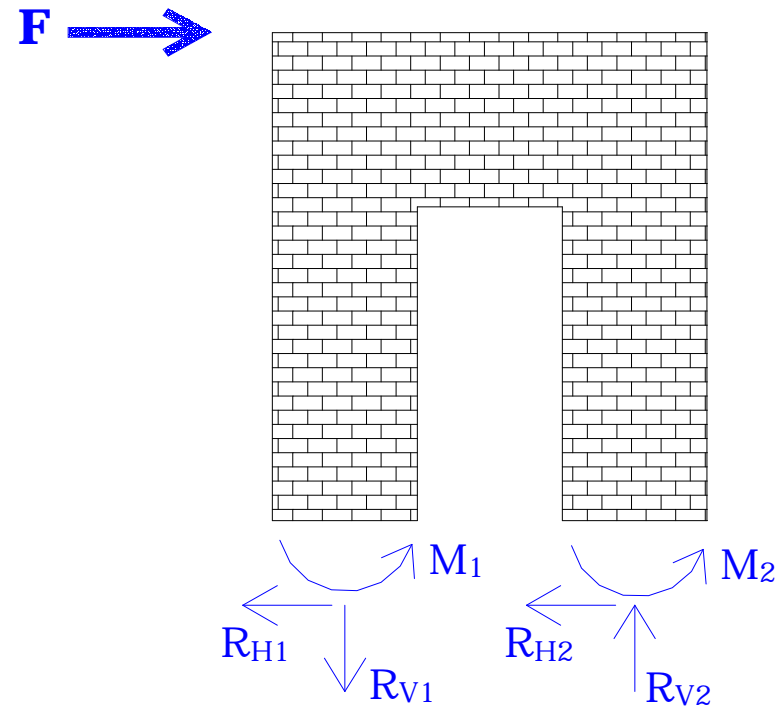

FIGURA $4.17 \mathrm{~b}$ - Momento de tombamento devido a força horizontal originando momentos na base e binário formado pelas reações verticais

Os diagramas de esforço cortante, FIGURA 4.18, mostram os distintos comportamentos estruturais de cada modelo. O modelo 1 apresenta um cortante máximo na base da parede, enquanto que o modelo 2 apresenta seu máximo num nível intermediário, demonstrando a importância das deformações por cisalhamento nos edifícios em alvenaria estrutural. O modelo 3 comportou-se de forma semelhante ao modelo 2 , em níveis um pouco maiores de solicitação. E o modelo 4 assemelha-se ao modelo 1, em níveis menores de solicitação. Essa seqüência mostra a melhoria da representação do comportamento estrutural à medida que refina-se a modelagem. Os modelos 2 e 3 podem ser classificados como intermediários, e os modelos 1 e 4 como o menos e mais refinado, respectivamente. 


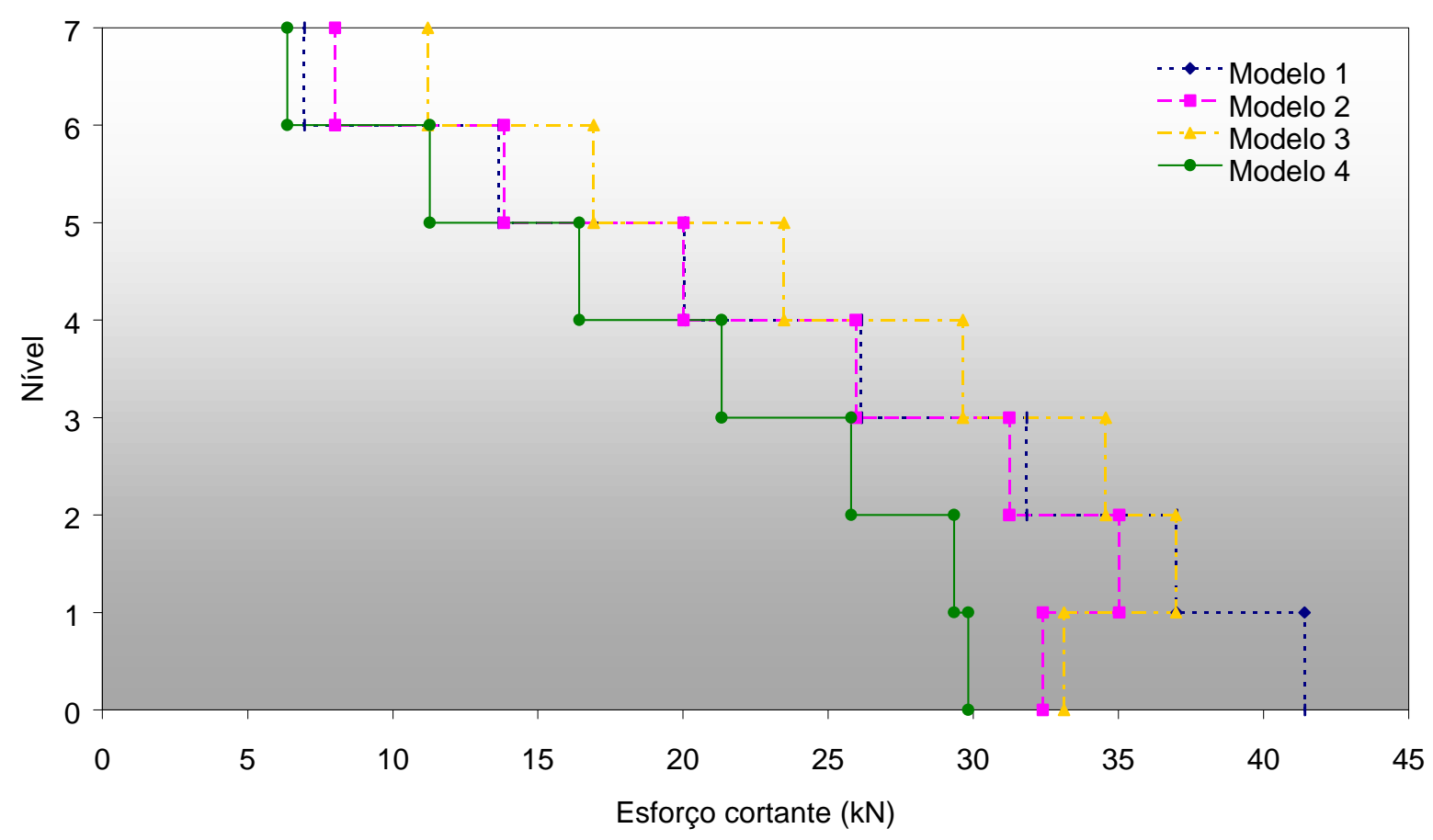

FIGURA 4.18 - Diagrama de esforço cortante da parede mais solicitada, PY30

Os diagramas de momento fletor, FIGURA 4.19, para os modelos 3 e 4 apresentam um comportamento bastante distinto, ocorrendo uma variação menor no diagrama do modelo 4 (quase nula do quarto para o quinto pavimento). As descontinuidades nos diagramas podem ser explicadas pela presença da barra rígida no modelo de pórtico tridimensional. Como essas barras são ligadas continuamente às barras verticais que modelam as paredes, ocorre a transmissão de momento, que provoca a descontinuidade nos diagramas da parede. 


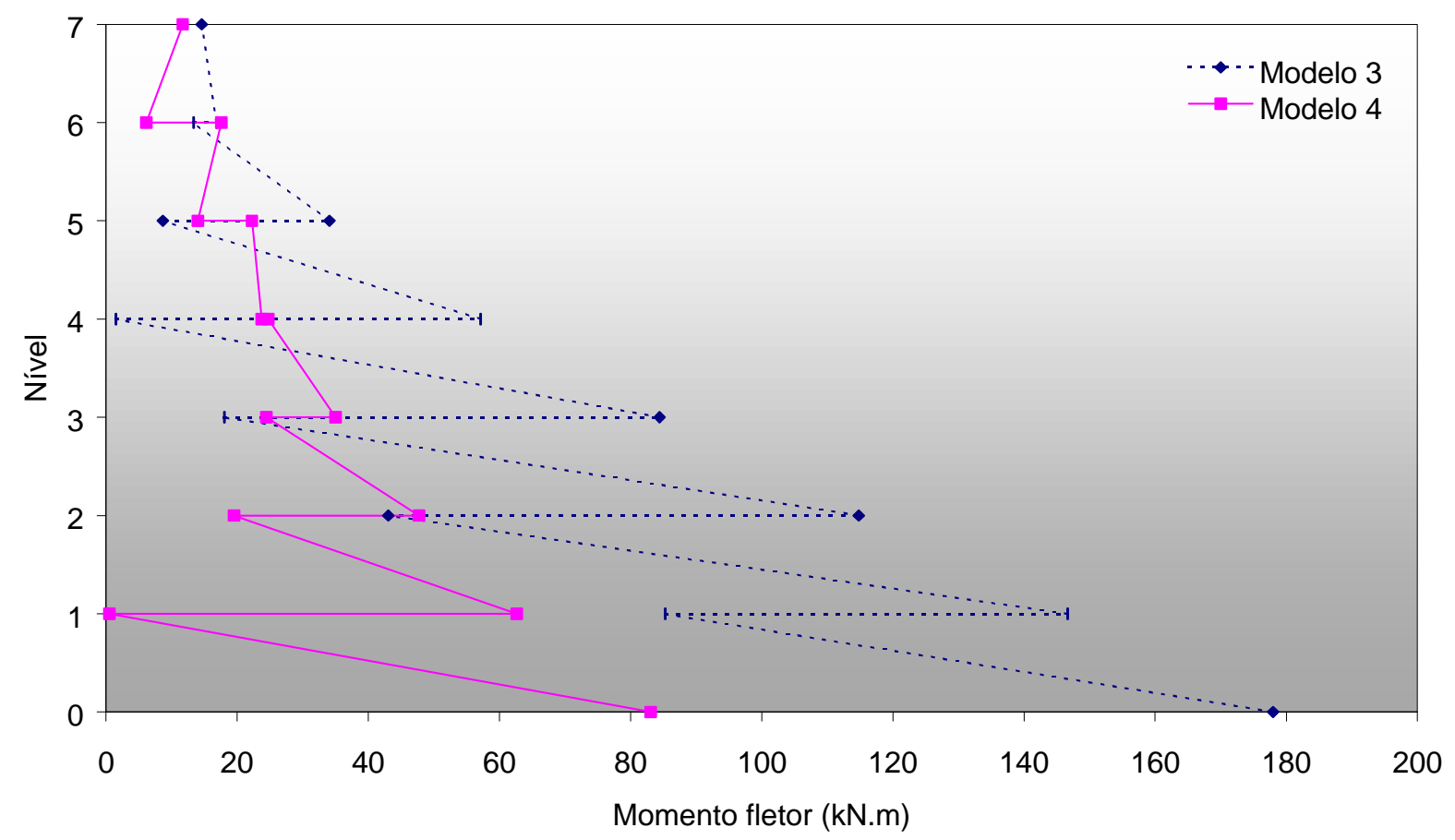

FIGURA 4.19 - Diagrama de momento fletor da parede mais solicitada, PY30

Quanto aos lintéis, percebe-se que os mais solicitados posicionam-se na direção que recebe a maior carga do vento (nesse exemplo a direção $\mathrm{Y}$ ), FIGURA 4.20. Vale salientar que os lintéis mais solicitados LY19 e LY20 são os de menor altura da seção, isto é, os lintéis localizados em aberturas de portas. $\mathrm{O}$ vento $\mathrm{X}$ solicita os lintéis $\mathrm{Y}$ em níveis bastante baixos, no entanto os lintéis $\mathrm{X}$ são enormemente influenciados pelo vento $\mathrm{Y}$, a exemplo dos lintéis LX6 e LX9. 


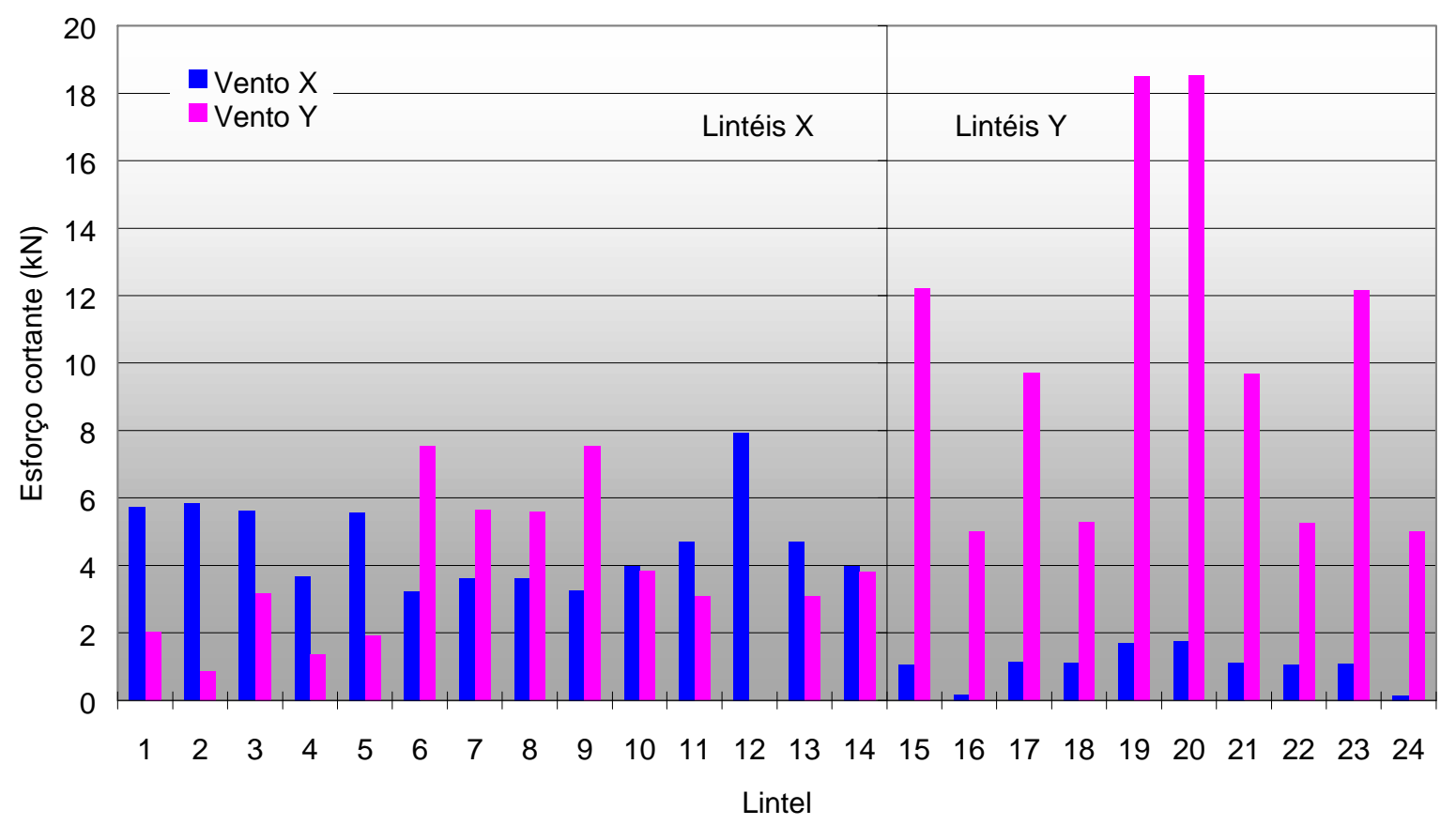

FIGURA 4.20 - Esforços cortantes máximos nos lintéis

Os lintéis mais solicitados LY19 e LY20, apresentam esforço cortante $\mathrm{V}=18,5 \mathrm{kN}$, FIGURA 4.20. Foram considerados blocos de concreto com resistência característica $\mathrm{f}_{\mathrm{bk}}=6,0 \mathrm{MPa}$ no $1 \underline{0}$ e $2 \underline{0}$ pavimentos. A tensão de cisalhamento admissível $\overline{\mathrm{f}}_{\text {cisl }}=0,20 \mathrm{MPa}^{6}$ impõe o limite da solicitação de cisalhamento no lintel para que seja dispensada a utilização de barras verticais/estribos.

Os referidos lintéis possuem seção transversal com b=14cm e d=55cm, de modo que resultam numa solicitação de cisalhamento $\tau=0,24 \mathrm{MPa}$, que indica a necessidade de reforço com estribos. A máxima tensão tangencial permitida para a alvenaria pode ser, nesse instante, tomado como $\overline{\mathrm{f}}_{\text {cis2 }}=0,55 \mathrm{MPa}^{7}$. A armadura, calculada de acordo com a NBR-10837, deve

${ }^{6}$ Obtida considerando-se uma eficiência $\eta=0,8$ e, segundo a NBR-10837, alvenaria armada para elementos fletidos sem armadura para combate ao cisalhamento.

7 Obtida considerando-se uma eficiência $\eta=0,8$ e, segundo a NBR-10837, alvenaria armada para elementos fletidos com armadura para combate ao cisalhamento. 
possuir área $\mathrm{A}_{\mathrm{s}}=0,31 \mathrm{~cm}^{2}$ distribuída em cada furo dos blocos (espaçamento de $15 \mathrm{~cm}$ ), correspondendo por exemplo, a $\phi 6,3$ por furo para estribo de um ramo.

Como o grauteamento do lintel seria inevitável devido à presença dos estribos, torna-se interessante analisar a alternativa de prismas cheios. Desse modo, dobra-se a resistência de prisma, resultando numa tensão admissivel $\overline{\mathrm{f}}_{\text {cisl }}=0,27 \mathrm{MPa}$. Nesse caso, seria suficiente o grauteamento de toda a seção do lintel, sem necessidade de estribos.

Vale salientar que os lintéis são, também, solicitados por flexão, com aspecto do diagrama de momentos semelhante à FIGURA 4.21a. Nesse caso, deve-se determinar uma área de armadura adicional à armadura de flexão obtida com a análise das cargas verticais. Os lintéis sob aberturas de porta apresentam menor altura da seção transversal, de modo que deve-se verificar a necessidade de armadura dupla quando superpõem-se as solicitações de flexão provenientes das ações horizontais e das cargas verticais.

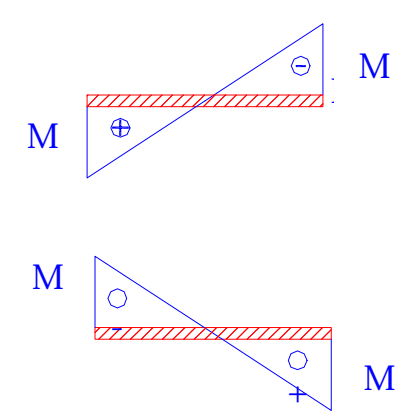

a - Aspectos do diagrama de momentos
Asc

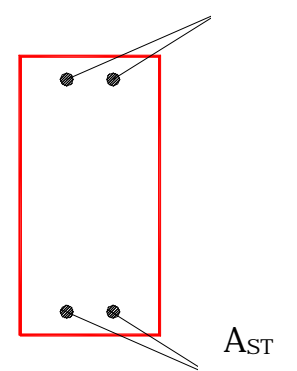

b - Seção duplamente armada

FIGURA 4.21 - Flexão dos lintéis 
A análise seguinte objetiva avaliar os efeitos da torção no edifício. Consideraram-se ações do vento segundo as direções principais X e Y com as respectivas excentricidades ${ }^{8}$ previstas em norma. Apresentam-se resultados para a distribuição dos esforços cortantes, analisando-se todos os modelos descritos anteriormente. Os modelos 1 e 2 podem ser utilizados numa análise com torção, desde que as paredes sejam discretizadas com elementos barra tridimensional e compatibilizem-se os deslocamentos ao nível dos pavimentos (de preferência utilizando-se o recurso do nó mestre). Essa é uma análise simplificada, sem a consideração da flexo-torção, adotada nesse trabalho para efeito de avaliação da capacidade de representação dos efeitos globais da torção. A rigor é necessária a determinação do centro de cisalhamento, da área setorial, bem como do momento setorial de inércia da seção composta, segundo KESKIN, O. et al(1974), aqui não realizada.

As modificações na distribuição dos esforços cortantes devidas à torção, foram avaliadas utilizando-se o modelo 3. A ação do vento foi considerada com uma excentricidade que originou rotação das lajes no sentido anti-horário.

Foram avaliadas as contribuições das paredes dispostas perpendicularmente à direção de análise, ou seja as paredes da direção X segundo a análise do vento $\mathrm{Y}$, utilizando-se os modelos 3 e 4 . Da mesma forma, avaliam-se os acréscimos dos esforços cortantes nas paredes utilizando-se dois modelos intermediários, modelos 2 e 3. E para se ter uma visão geral do comportamento de todos os modelos na torção, apresentam-se seus resultados num único gráfico.

Os lintéis do modelo 4 também são analisados quanto aos esforços cortantes e tensões de cisalhamento, verificando-se os limites normalizados.

${ }^{8}$ Adotadas prevendo-se os efeitos de vizinhança, vide Tabela 3.2. 
A análise dos efeitos da torção do edifício com o modelo 3 apresenta dois resultados:

- Paredes direção X: resultados dos esforços cortantes nas paredes dessa direção para uma análise do vento na mesma direção.

- Paredes direção Y: resultados dos esforços cortantes nas paredes dessa direção para uma análise do vento na mesma direção.

De acordo com esses resultados, FIGURA 4.22, a torção com o vento X não modificou consideravelmente a distribuição dos esforços cortantes, ocorrendo apenas um pequeno decréscimo na parede PX3 e acréscimo nas paredes PX19 e PX20, sendo a primeira a mais solicitada para a análise dessa direção. Essas modificações apresentaram-se de forma insignificante, pois a ação do vento $\mathrm{X}$ possui pequena intensidade e excentricidade, comparada com o vento Y. Além disso, as paredes dessa direção possuem comprimentos consideráveis.

Ao contrário, a torção com o vento $\mathrm{Y}$ modificou bastante a distribuição dos esforços cortantes. As paredes dispostas simetricamente apresentaram acréscimos e decréscimos de intensidade com variações semelhantes, a exemplo das paredes PY23 e PY40. Houve alteração da parede mais solicitada e do máximo esforço cortante do pavimento. Sem a torção, as paredes mais solicitadas eram PY30 e PY34 com uma intensidade de $33,10 \mathrm{kN}$ (correspondente a uma tensão de cisalhamento $\tau_{3}=0,07 \mathrm{MPa}$ ), provavelmente por serem as de maior comprimento em planta e com contribuições de uma quantidade maior de abas. Com a torção, a intensidade dos esforços cortantes dessas paredes modificou para $29,6 \mathrm{kN}$ e $36,1 \mathrm{kN}$, respectivamente (uma variação de $10 \%$ e 9\%). Esses novos esforços cortantes correspondem a tensões de cisalhamento $\tau_{3}=0,06 \mathrm{MPa}$ e $\tau_{3}=0,08 \mathrm{MPa}$. Como as rotações das lajes são anti-horárias, a intensidade do esforço cortante da parede PY30 deve diminuir e da PY34 deve aumentar. A parede mais solicitada passou a ser a PY40 com intensidade do esforço cortante de $45,7 \mathrm{kN}$, um acréscimo de $65 \%$ em relação a situação sem torção $(27,6 \mathrm{kN})$ e de $38 \%$ em relação ao máximo esforço cortante do pavimento sem a consideração da torção $(33,10 \mathrm{kN})$. Esses esforços cortantes da parede 
PY40 correspondem a tensões $\tau_{3}=0,11 \mathrm{MPa}$ e $\tau_{3}=0,06 \mathrm{MPa}$, segundo as análises com e sem torção, respectivamente. Provavelmente, a parede PY40 apresentou o maior acréscimo por possuir grande comprimento e por localizar-se mais distante do centro elástico do edifício.

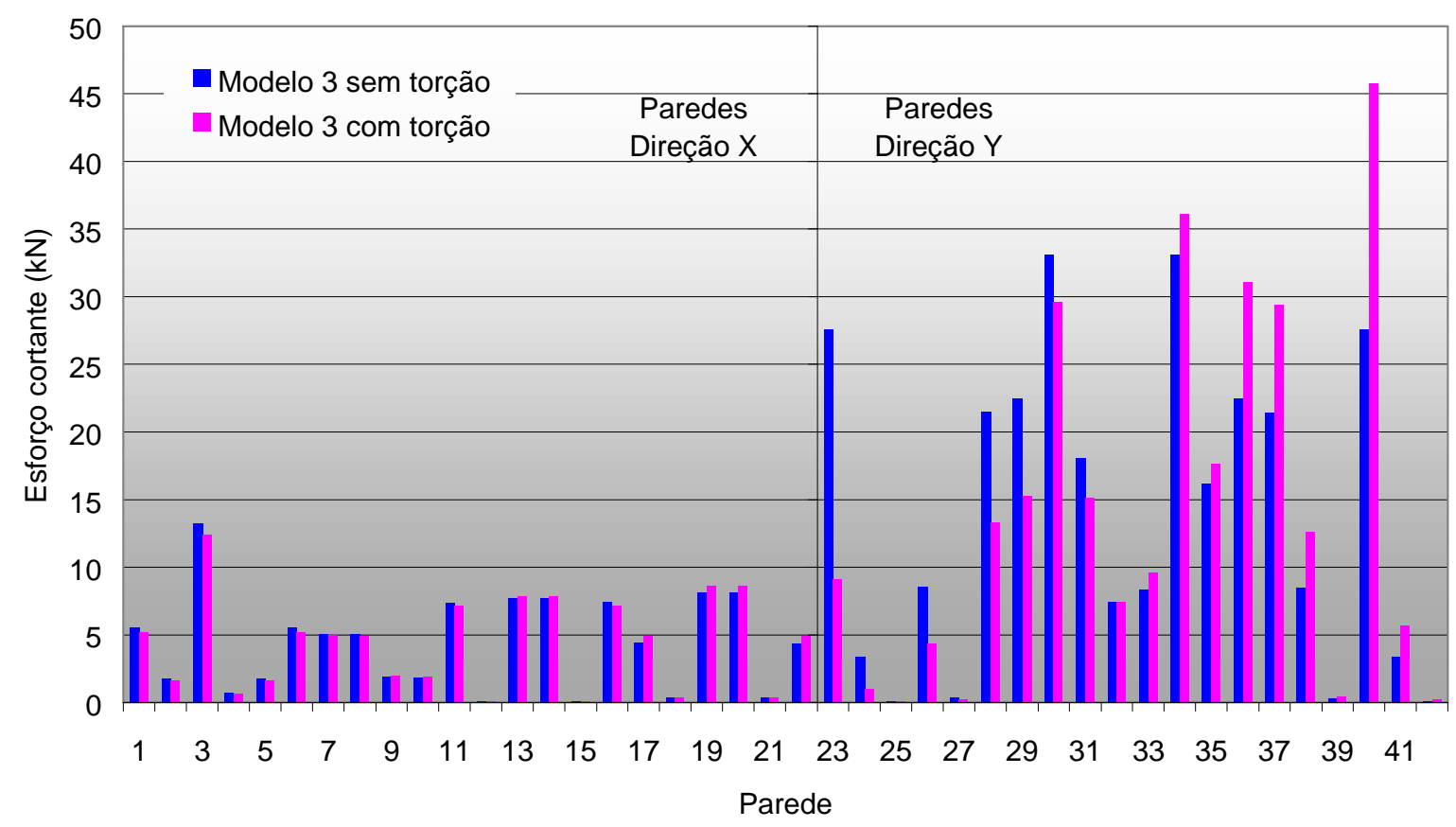

FIGURA 4.22 - Distribuição dos esforços cortantes entre as paredes de contraventamento, análise do efeito da torção para vento segundo as direções $\mathrm{X} \mathrm{e} \mathrm{Y}$

A análise dos efeitos da torção foi, também, desenvolvida com o modelo 4 avaliando-se seus resultados com os obtidos pelo modelo 3. Nesse estudo percebe-se uma melhor redistribuição dos esforços cortantes utilizando-se o modelo 4. A apreciável tendência de redistribuição observada, praticamente igualou os esforços cortantes absorvidos pelas paredes PX3, PX19 e PX20, na análise do vento X, FIGURA 4.23a. O modelo 3 resultou num esforço cortante de $12,4 \mathrm{kN}$ para a parede PX3, e $8,6 \mathrm{kN}$ para as paredes PX19 e PX20, enquanto que o modelo 4 resultou num cortante de 10,5kN para PX3 (decréscimo de 15\%), e 10,8kN para PX19 e PX20 (acréscimo de 25\%). Percebe-se, também, que no modelo 3 aparecem solicitações nas paredes da direção Y (perpendicular à direção analisada). 
Por exemplo nas paredes PY26 e PY38 que absorvem esforço cortante superior ao de algumas paredes dispostas paralelamente à direção de atuação do vento. No modelo 4 ocorre, de modo geral, alívio nos esforços cortantes dessas paredes secundárias. Essas mesmas tendências podem ser observadas na análise correspondente ao vento Y, FIGURA 4.23b. As paredes PY40 e PY34 apresentaram os maiores cortantes do pavimento, $36,1 \mathrm{kN}$ e $45,7 \mathrm{kN}$ com o modelo 3 , respectivamente, e $32,7 \mathrm{kN}$ (decréscimo de $9 \%$ ) e $39,7 \mathrm{kN}$ (decréscimo de $13 \%$ ) com o modelo 4 . A forte tendência de redistribuição dos esforços cortantes, também pode ser aqui observada.

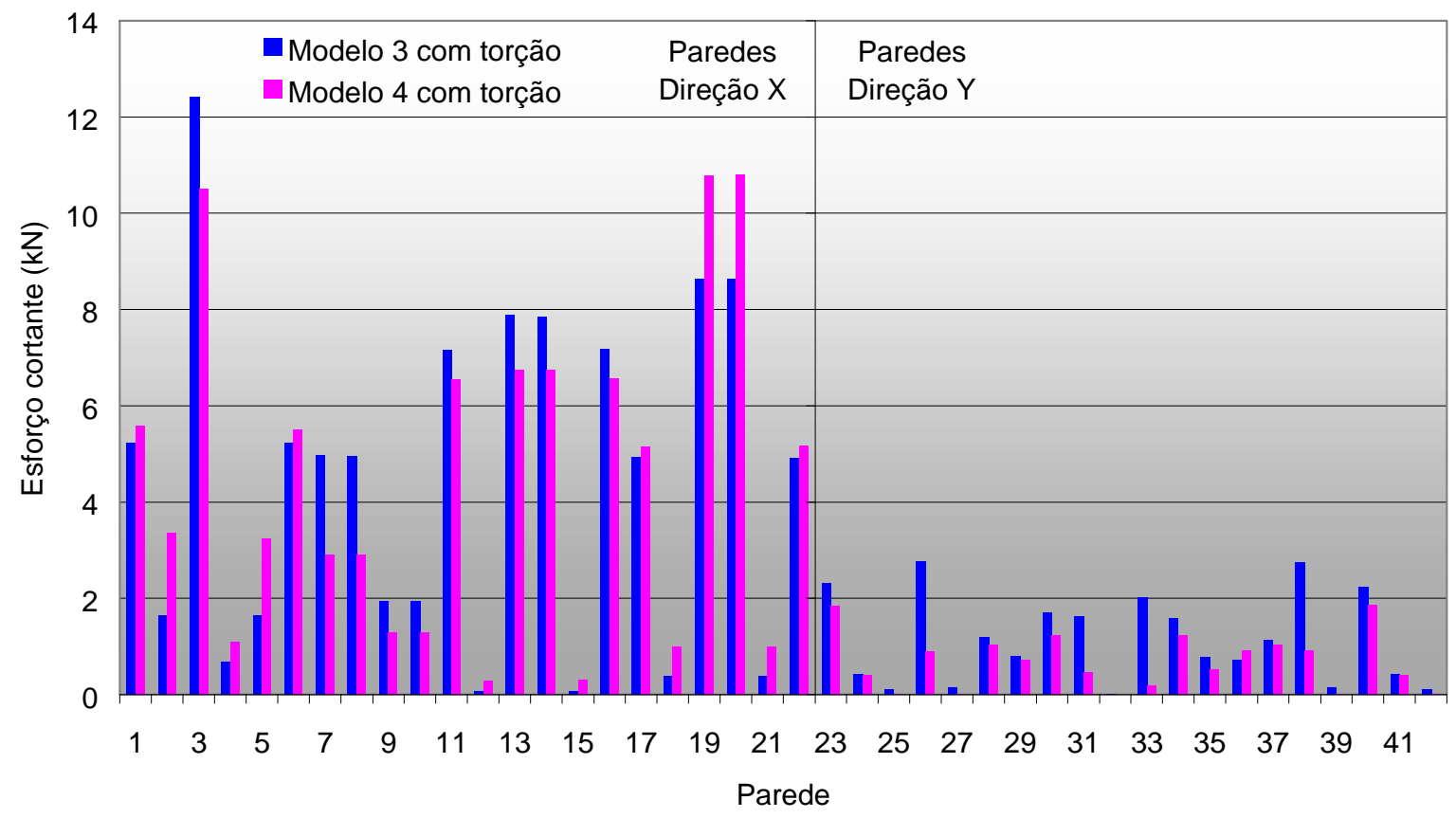

FIGURA 4.23a - Distribuição dos esforços cortantes entre as paredes de contraventamento, modelos 3 e 4 com torção - Vento X com excentricidade 


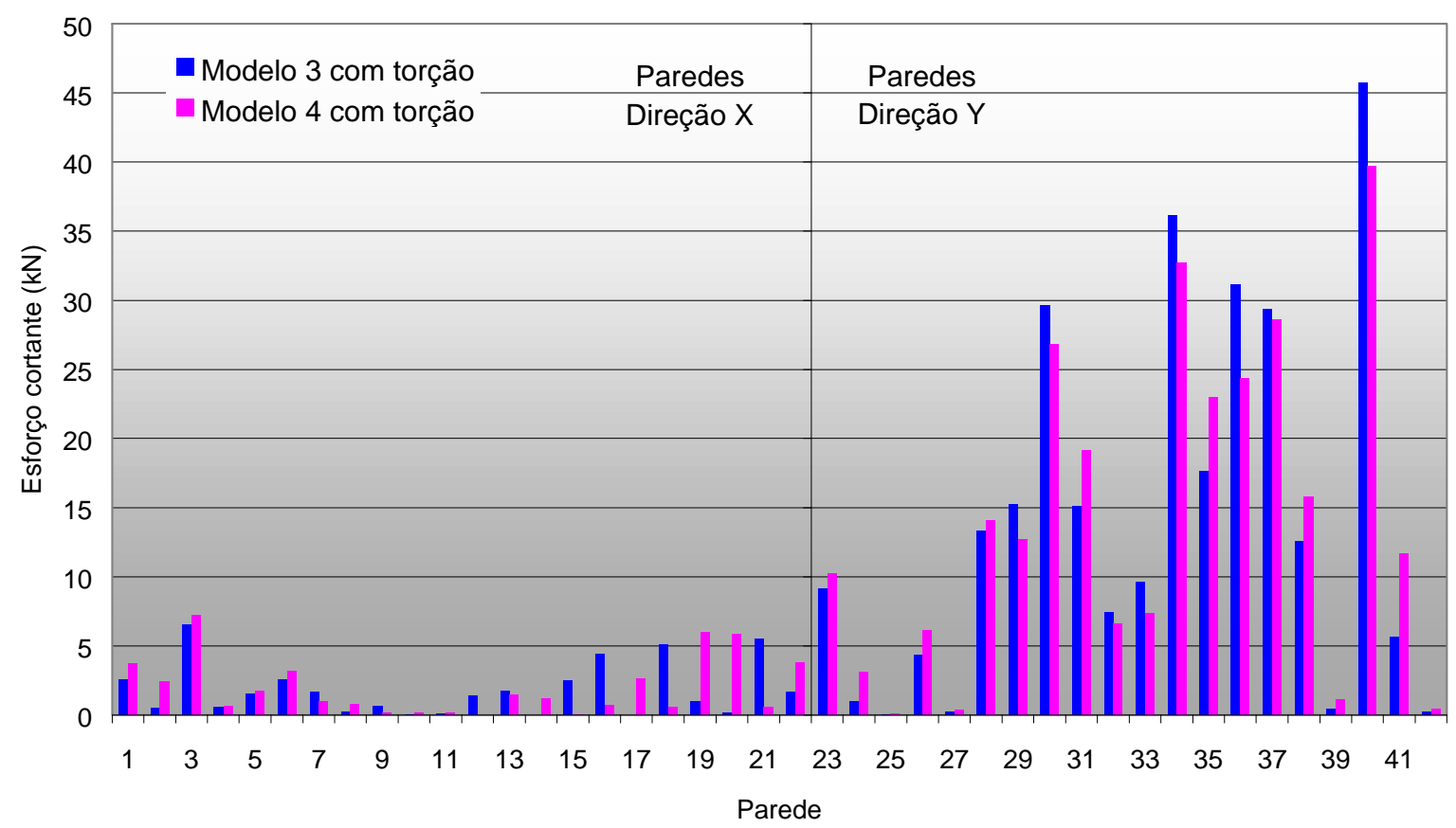

FIGURA 4.23b - Distribuição dos esforços cortantes entre as paredes de contraventamento, modelos 3 e 4 com torção - Vento Y com excentricidade

Os modelos 2 e 3, considerados nesse trabalho como intermediários, também foram avaliados sob o aspecto da torção. Foram apresentados os resultados, FIGURAS 4.24a e 4.24b, obtidos com esses dois modelos para duas situações de carregamento: ação do vento sem excentricidade e ação do vento com excentricidade. Os resultados com os dois modelos para a análise das duas direções sem excentricidade da força do vento, apresentaram-se bastante próximos, não havendo variações significativas. Mesmo a direção X que possui assimetria na distribuição das paredes não apresentou variações consideráveis. No entanto, considerando-se a ação do vento com excentricidade, isto é, incluindo-se a rotação das lajes, o modelo 2 apresentou resultados bem distintos quanto à distribuição dos esforços cortantes na análise do vento X, FIGURA 4.24a. A parede PX3 absorve $6,1 \mathrm{kN}$ e $12,4 \mathrm{kN}$ segundo os modelos 2 e 3, respectivamente, uma diferença superior a 100\%, enquanto que as paredes PX19 e PX20 absorvem um esforço cortante de $11,6 \mathrm{kN}$ e $8,6 \mathrm{kN}$ segundo os modelos 2 e 3 , respectivamente, diferença de 30\%. No caso da análise da direção Y, 
FIGURA $4.24 \mathrm{~b}$, os dois modelos apresentaram resultados bem próximos, onde observa-se semelhante distribuição dos esforços cortantes entre as paredes de contraventamento.

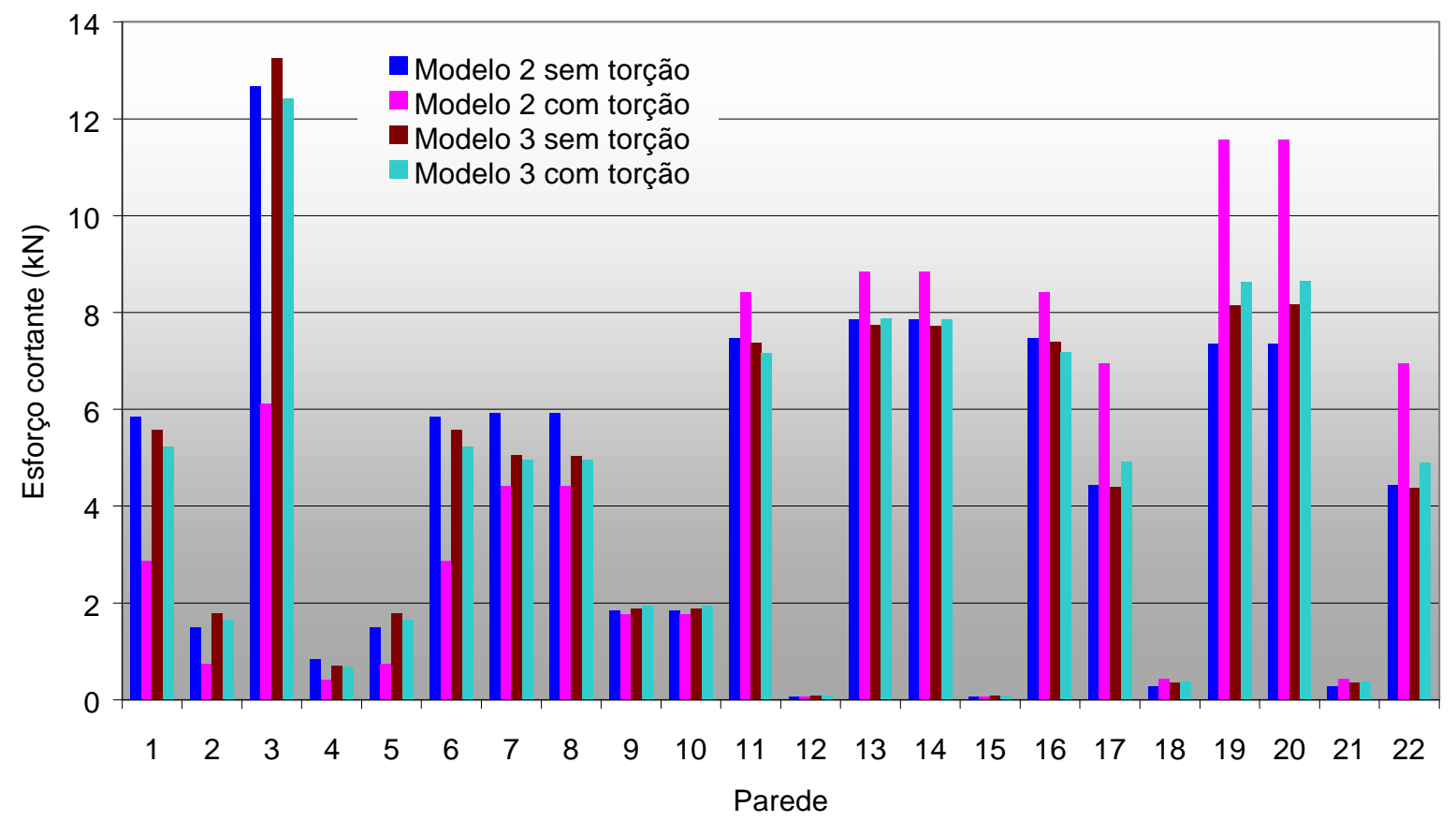

FIGURA 4.24a - Distribuição dos esforços cortantes entre as paredes de contraventamento, análise dos efeitos da torção - Vento segundo a direção X 


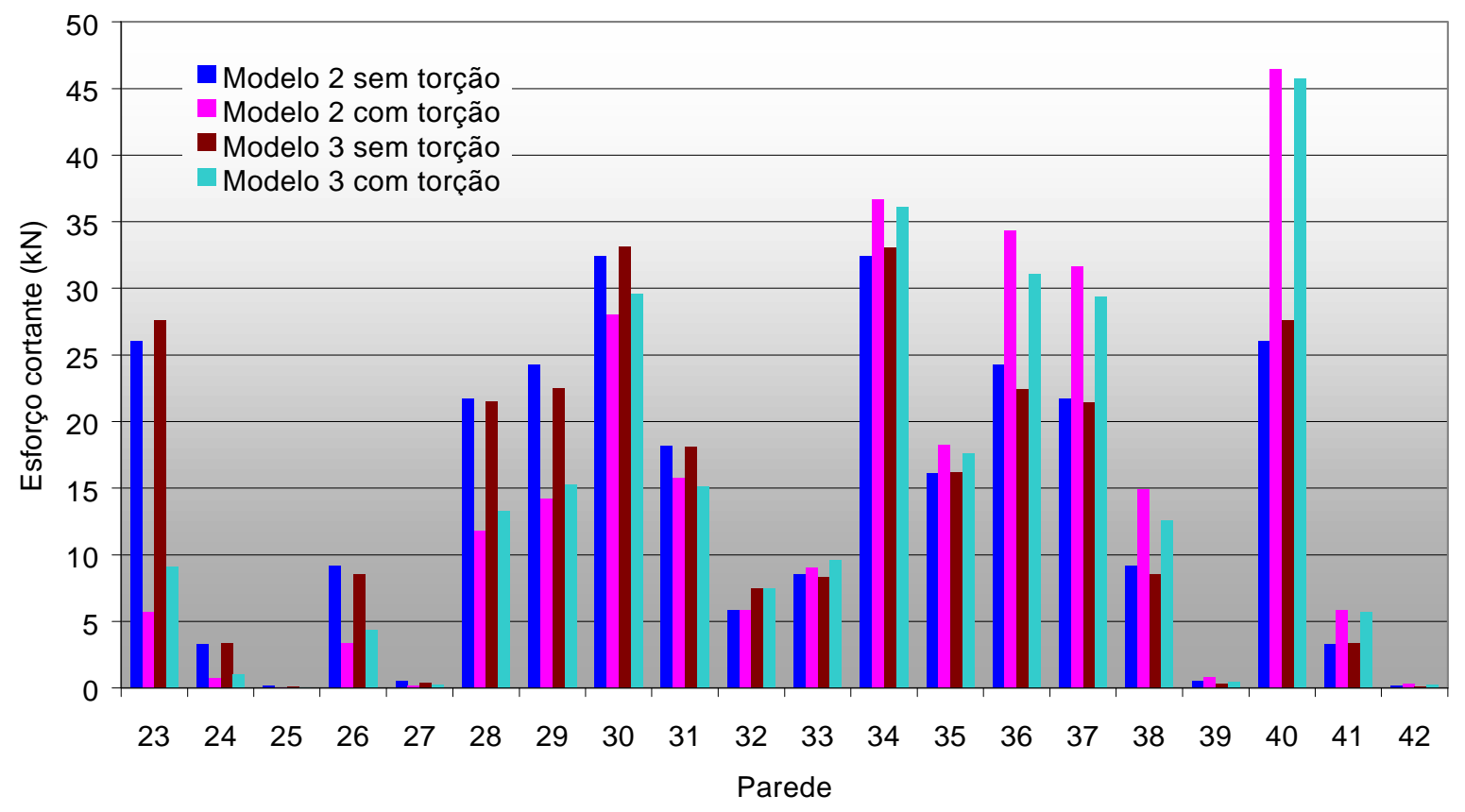

FIGURA 4.24b - Distribuição dos esforços cortantes entre as paredes de contraventamento, análise dos efeitos da torção - Vento segundo a direção Y

Para se observar de modo geral o comportamento de todos os modelos avaliados, apresentam-se os resultados obtidos para a distribuição dos esforços cortantes das análises com e sem torção do edifício, FIGURAS $4.25 \mathrm{a}$ e $4.25 \mathrm{~b}$.

Os resultados para as análises sem torção comprovam o conservadorismo do modelo 1 quanto aos esforços das paredes de maior comprimento em planta. Nesse caso obtêm-se intensidades elevadas dos cortantes máximos com uma distribuição pouco uniforme dos esforços entre as demais paredes.

Evidencia-se a transição que ocorre com o refinamento da modelagem, observando-se uma tendência de redistribuição dos esforços cortantes. Os modelos 2 e 3 podem ser definidos como intermediários por representarem essa transição, e os modelo 1 e 4 podem ser definidos como extremos por representarem, respectivamente, o menor e o maior refinamento da modelagem com elementos barra. 


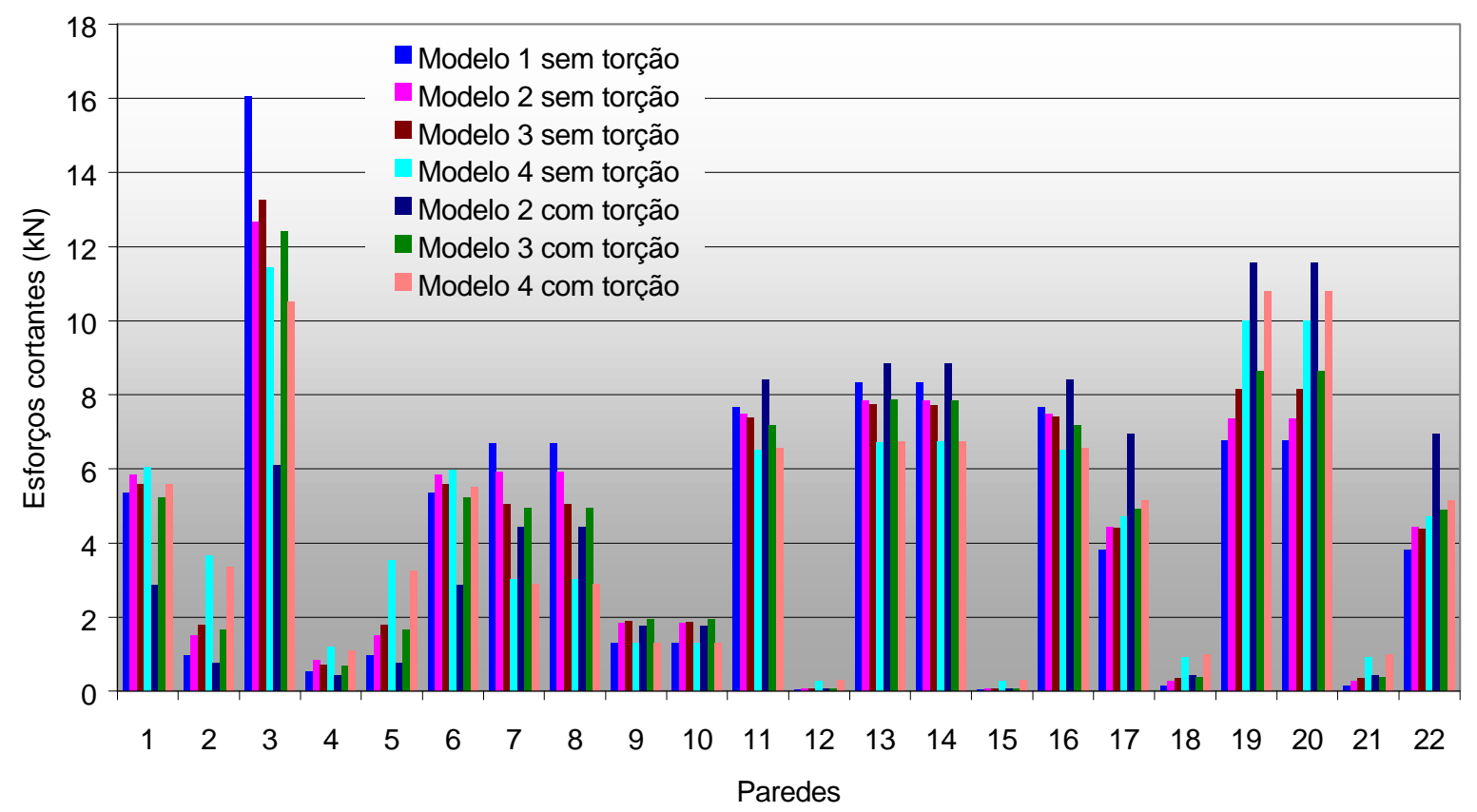

a - Vento segundo a direção X

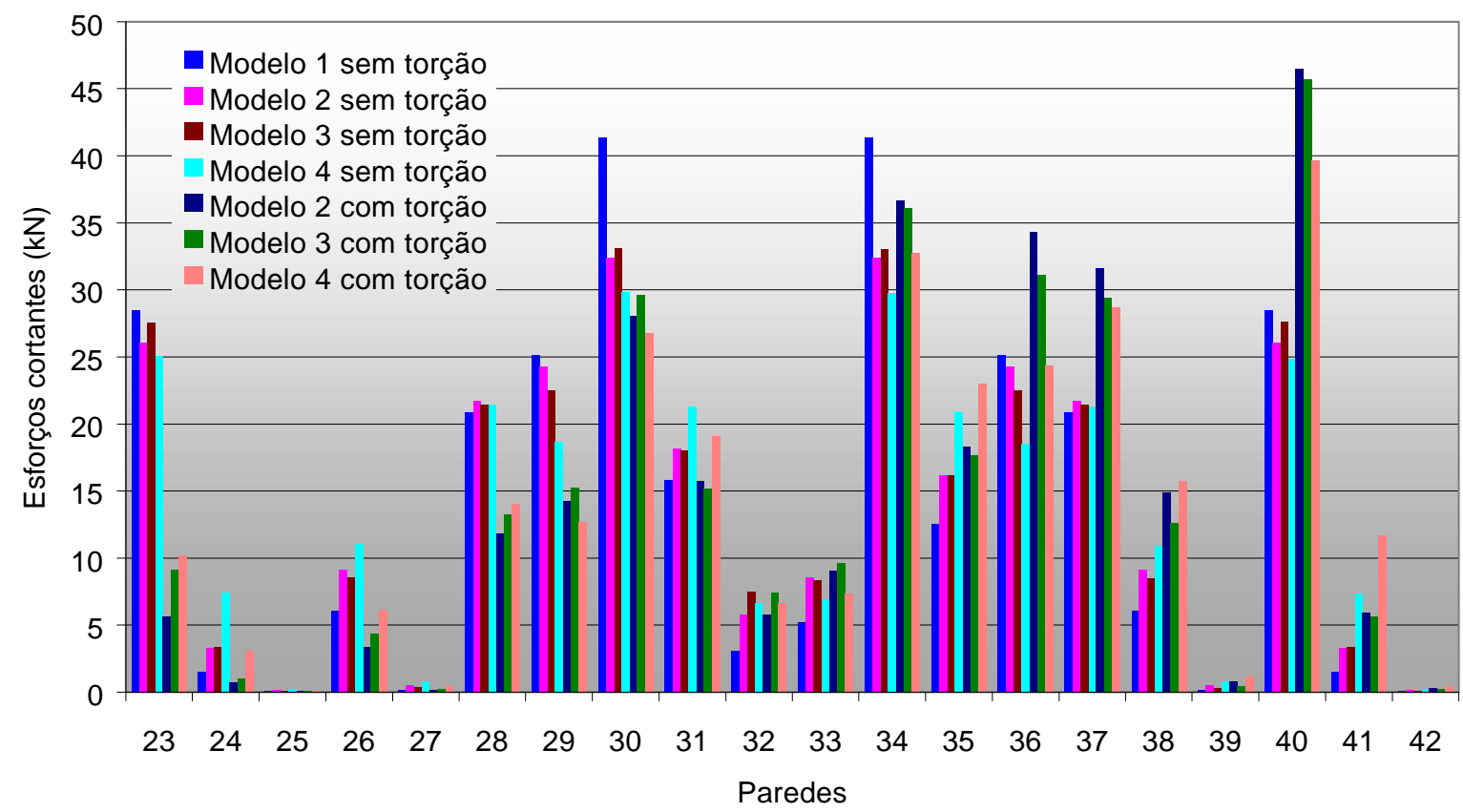

b - Vento segundo a direção Y

FIGURA 4.25 - Distribuição dos esforços cortantes entre as paredes de contraventamento, análise geral de todos os modelos 


\section{4 - Exemplo de carregamento simétrico}

Os modelos 3 e 4 foram avaliados novamente nesse exemplo. A direção Y, por ser simétrica, foi escolhida para análise.

Da mesma forma que no item 4.3 foram analisados os resultados obtidos para distribuição dos esforços cortantes e diagrama de esforço cortante com os modelos 1 e 2 , avaliando-se as diferenças entre os modelos mais simples e os modelos 3 e 4, mais refinados.

Os lintéis foram, também, analisados quanto aos esforços cortantes e tensões de cisalhamento, comparando-se com limites normalizados.

Foram enfatizados os resultados de deslocamentos horizontais da estrutura ao nível dos pavimentos, de distribuição dos esforços cortantes, e de distribuição de momentos fletores, bem como os diagramas de momento fletor e esforço cortante das paredes mais solicitadas.

O edifício utilizado nesse exemplo possui treze pavimentos com pédireito de $2,80 \mathrm{~m}$ cuja planta do pavimento tipo é apresentada na FIGURA 4.26a e esquematizada em diagrama unifilar na FIGURA 4.26b. Foram utilizados blocos que variam de 10,0MPa a 4,5MPa da base ao topo, adotando-se módulo de elasticidade longitudinal E=2960MPa para todas as paredes. A ação do vento foi determinada de acordo com a NBR-6123, considerando-se uma velocidade básica $V_{0}=38 \mathrm{~m} / \mathrm{s}$ e edificação de classe $2 \mathrm{e}$ categoria 4.

O modelo de pórtico tridimensional foi, também, avaliado nesse exemplo pelos modelos 3 e 4 . Considerou-se a ação do vento segundo a direção principal Y do edifício, sem excentricidades.

Avaliam-se, também, os modelos 1 e 2 confrontando seus resultados com os modelos 3 e 4 . O modelo 1 é analisado com o resultado de distribuição dos esforços cortantes entre as paredes de contraventamento (esforços cortantes na base das paredes). O modelo 2 surge na avaliação do diagrama de esforço cortante, juntamente com os demais modelos.

Os lintéis do modelo 4 são analisados quanto aos esforços cortantes e tensões de cisalhamento, comparando-os aos limites normalizados. Essas análises apresentam resultados segundo as duas direções de incidência do vento. 


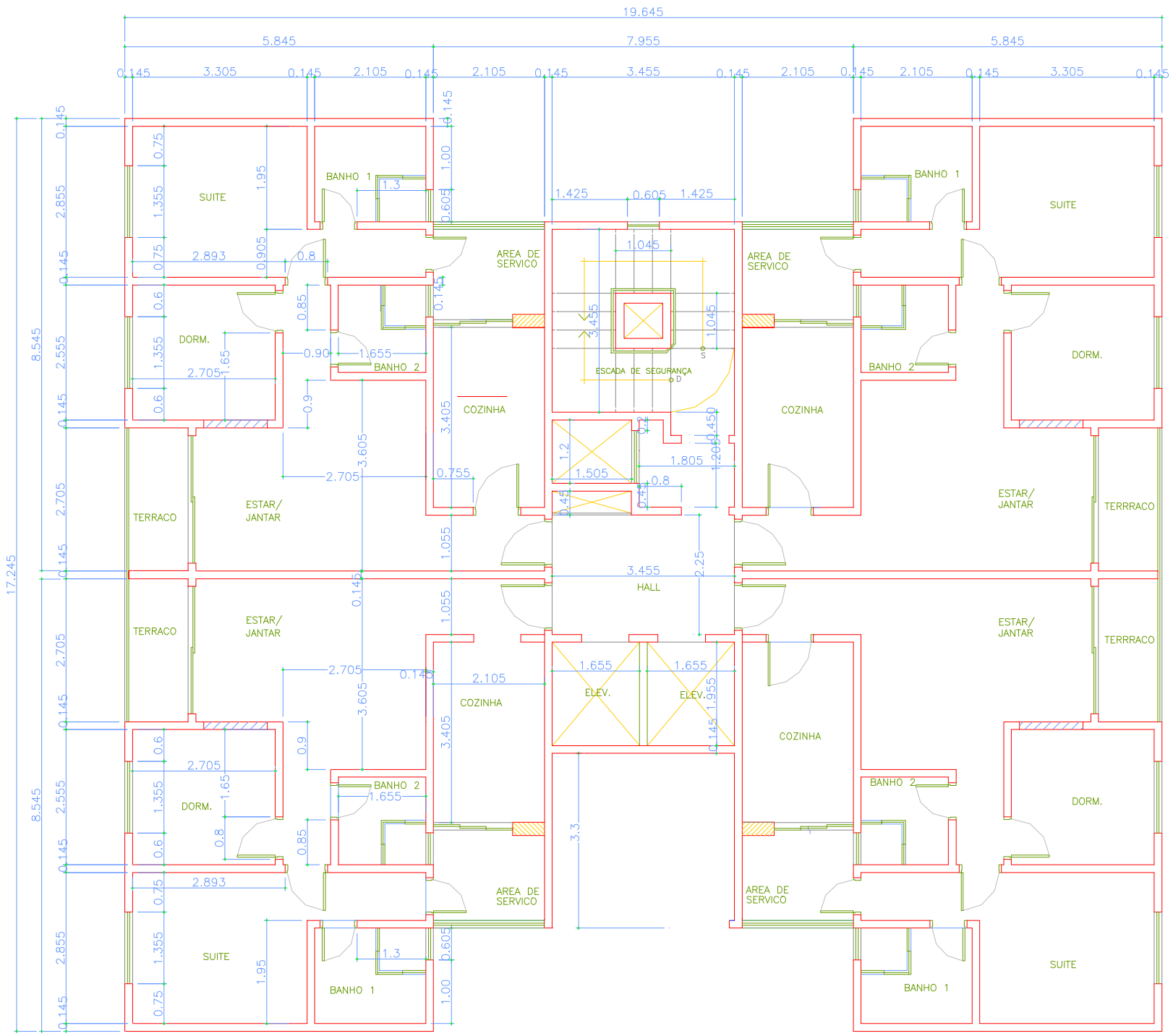

FIGURA 4.26a - Planta baixa do pavimento tipo 


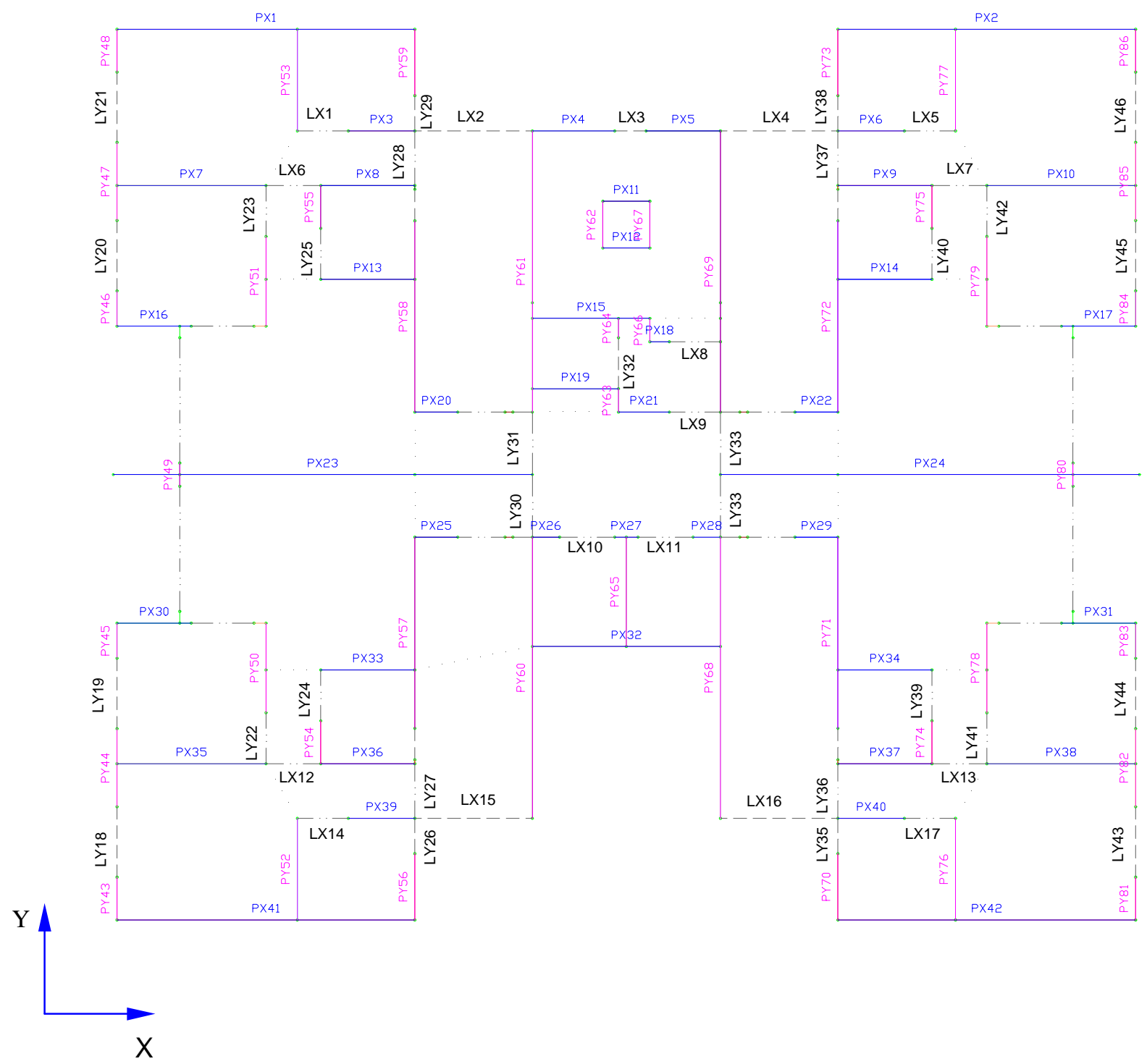

FIGURA 4.26b - Diagrama unifilar das paredes em planta 
O resultado dos deslocamentos, FIGURA 4.27, assim como no projeto básico, mostrou o ganho de rigidez dos modelos 3 e 4 em relação aos modelos 1 e 2. O modelo 3 apresenta uma diferença de 14\% no deslocamento do topo da estrutura, em relação ao modelo 1. O modelo 4 continuou apresentando o efeito benéfico da consideração dos lintéis, com um decréscimo de 79\% no deslocamento do topo, em relação ao modelo 3. Esse enorme decréscimo nos deslocamentos pode, também aqui, ser associado a um acréscimo substancial na rigidez do edifício, devido à formação de seqüências de pórticos no sistema de contraventamento.

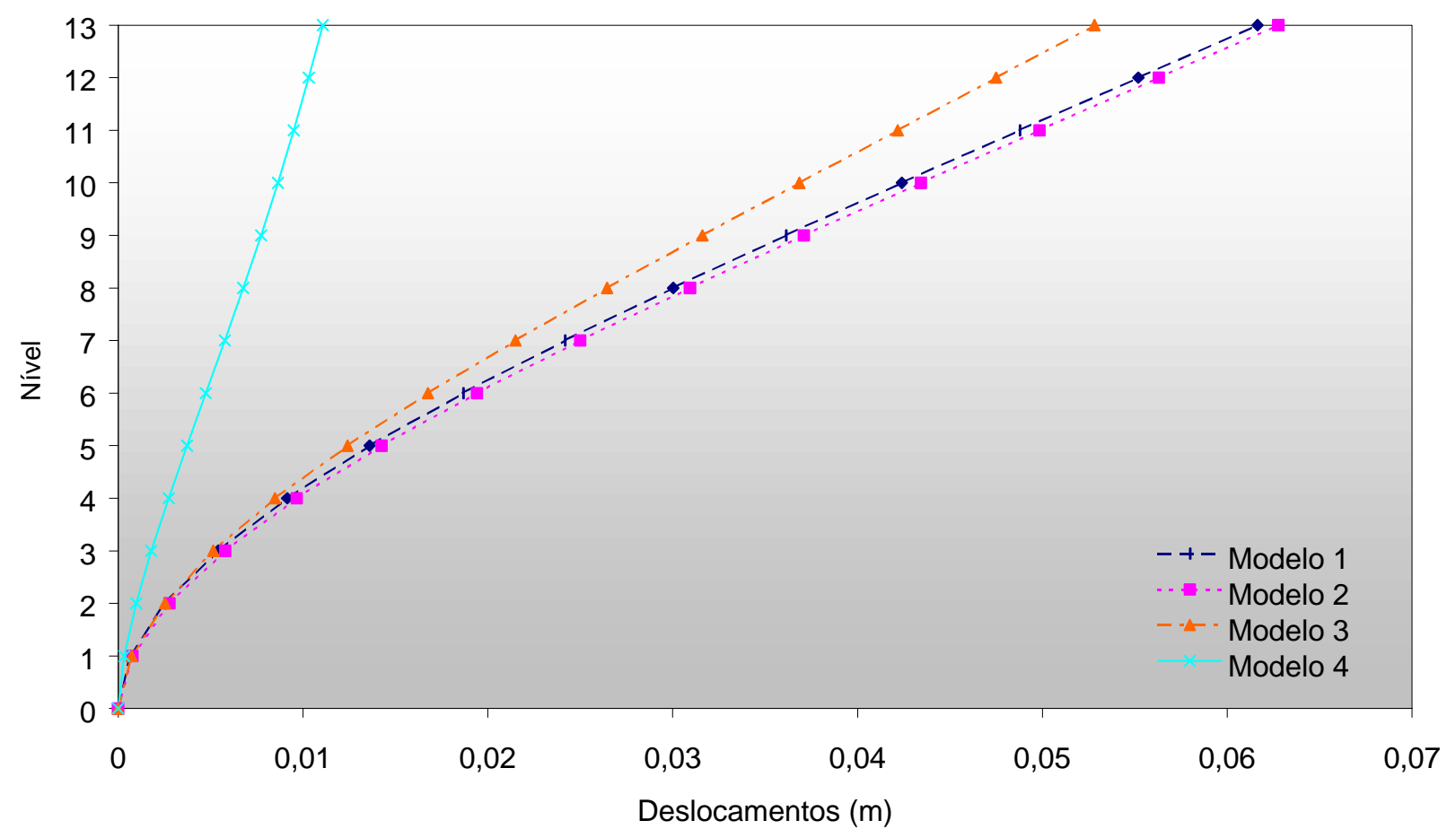

FIGURA 4.27 - Deslocamentos horizontais, vento segundo a direção Y

A análise com os modelos 1 e 4, FIGURA 4.28a, apresenta as modificações na distribuição dos esforços cortantes, comparando-se o modelo mais simples (modelo 1) e o modelo mais refinado (modelo 4). O 
esforço cortante máximo ocorreu na parede PY61 com $49,7 \mathrm{kN}$ referente ao modelo 4 e $86,1 \mathrm{kN}$ referente ao modelo 1 , correspondendo a um decréscimo percentual de $42 \%$. Esses esforços cortantes correspondem a tensões de cisalhamento $\tau_{4}=0,20 \mathrm{MPa}$ e $\tau_{1}=0,34 \mathrm{MPa}$ segundo os modelos $4 \mathrm{e} 1$, respectivamente. A tensão de cisalhamento admissivel pode ser adotada $\mathrm{f}_{\text {cis }}=0,15 \mathrm{MPa}^{9}$, indicando que a parede PY61 necessita de reforço para absorver esses esforços. Nesse caso, pode-se avaliar a opção de aumento da área efetiva grauteando-se alguns furos, bem como de utilização de uma argamassa mais resistente ${ }^{10}$ que permita considerar-se a tensão admissivel de $\overline{\mathrm{f}}_{\text {cis }}=0,20 \mathrm{MPa}$. Da mesma forma, as paredes PY60, PY68 e PY69 apresentam solicitações intensas: 58,6kN, 58,6kN e $65,2 \mathrm{kN}$, respectivamente, associadas ao modelo 1 , e $44,7 \mathrm{kN}, 44,8 \mathrm{kN}$ e $47,7 \mathrm{kN}$, respectivamente, associadas ao modelo 4; resultando em decréscimos percentuais de 23\% para as paredes PY60 e PY68, e 26\% para a parede PY69. No caso da parede PY69 obtém-se para intensidade das tensões de cisalhamento $\tau_{4}=0,09 \mathrm{MPa}$ e $\tau_{1}=0,12 \mathrm{MPa}$, inferiores à admissível .

9 Considerando-se, segundo a NBR-10837, alvenaria não-armada e argamassa com resistência entre 5,0MPa e 12,0MPa.

10 Em geral, a adoção de argamassa mais resistente não é a solução mais adequada. Nesse caso agravam-se os problemas relativos às variações volumétricas de temperatura e retração, relacionadas com o alto teor de cimento contido nessas argamassas. 


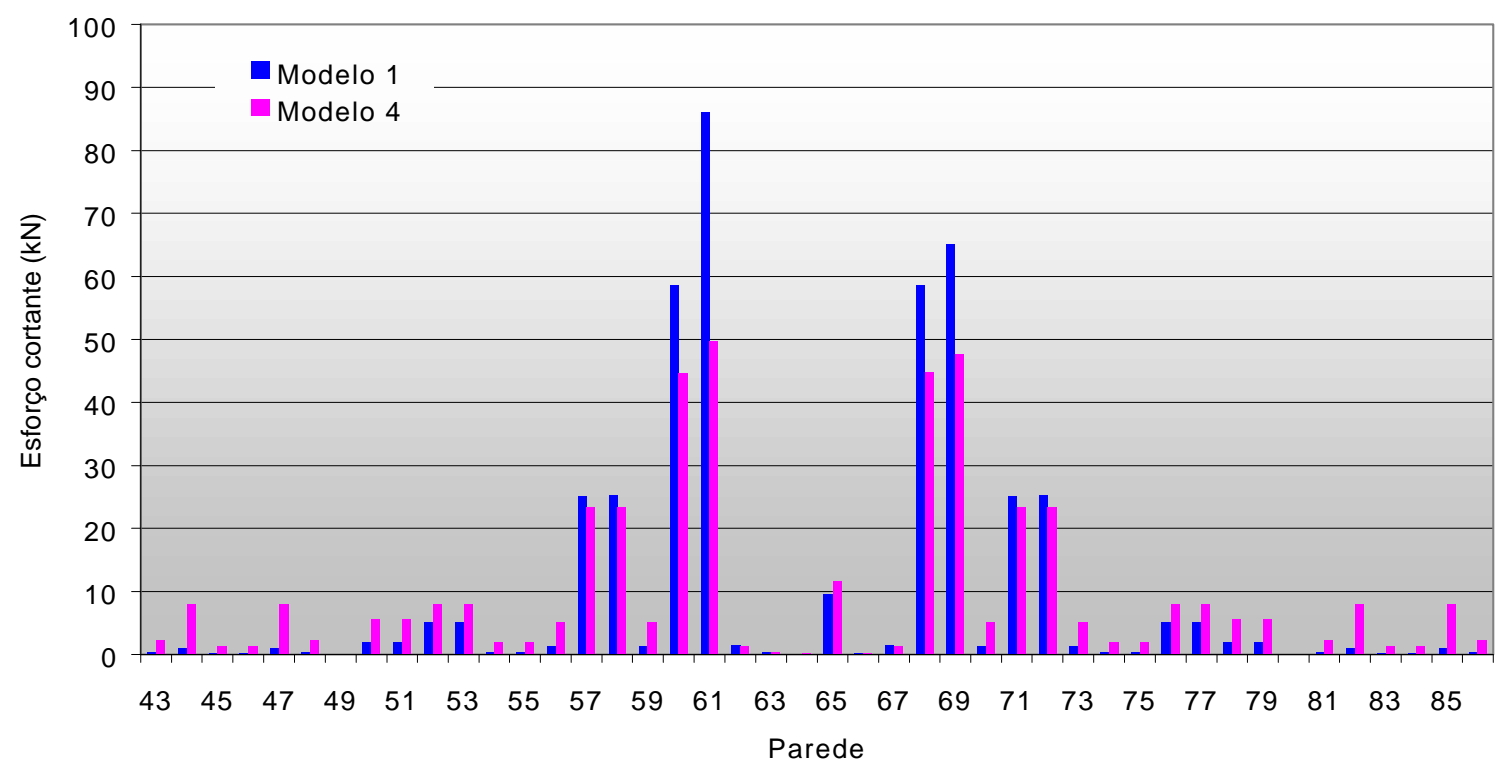

FIGURA 4.28a - Distribuição dos esforços cortantes entre as paredes de contraventamento, vento Y - Comparação entre os modelos 1 e 4

A contribuição dos lintéis é avaliada pelo confronto entre os modelos 3 e 4, onde analisam-se as distribuições de esforços cortantes, FIGURA 4.28b, e momentos fletores, FIGURA 4.29. As paredes mais solicitadas apresentam decréscimos em seus esforços cortantes, a exemplo da parede PY61 que apresenta o maior cortante com $59,1 \mathrm{kN}$ e $49,7 \mathrm{kN}$ segundo os modelos 3 e 4 , respectivamente, resultando numa diferença percentual de 15\%. Assim como no projeto básico, as maiores diferenças ${ }^{11}$ ocorrem na distribuição dos momentos fletores. As paredes mais solicitadas PY60, PY61, PY68 e PY69 apresentam $870 \mathrm{kN} . \mathrm{m}, 835,3 \mathrm{kN} . \mathrm{m}, 874 \mathrm{kN} . \mathrm{m}$ e $867,3 \mathrm{kN} . \mathrm{m}$, segundo o modelo 3 , 323,1kN.m, 303,7kN.m, 322,9kN.m e $311,4 \mathrm{kN} . \mathrm{m}$, segundo o modelo 4; resultando em decréscimos percentuais de 63\%, 45\%, 63\% e $64 \%$, respectivamente.

A tendência de redistribuição com o refinamento da modelagem também pode ser percebida na distribuição dos esforços cortantes.

${ }^{11}$ Essas diferenças podem, também aqui, ser associadas ao aparecimento de forças normais na seção das paredes que formam um binário resistente ao momento de tombamento da estrutura. 


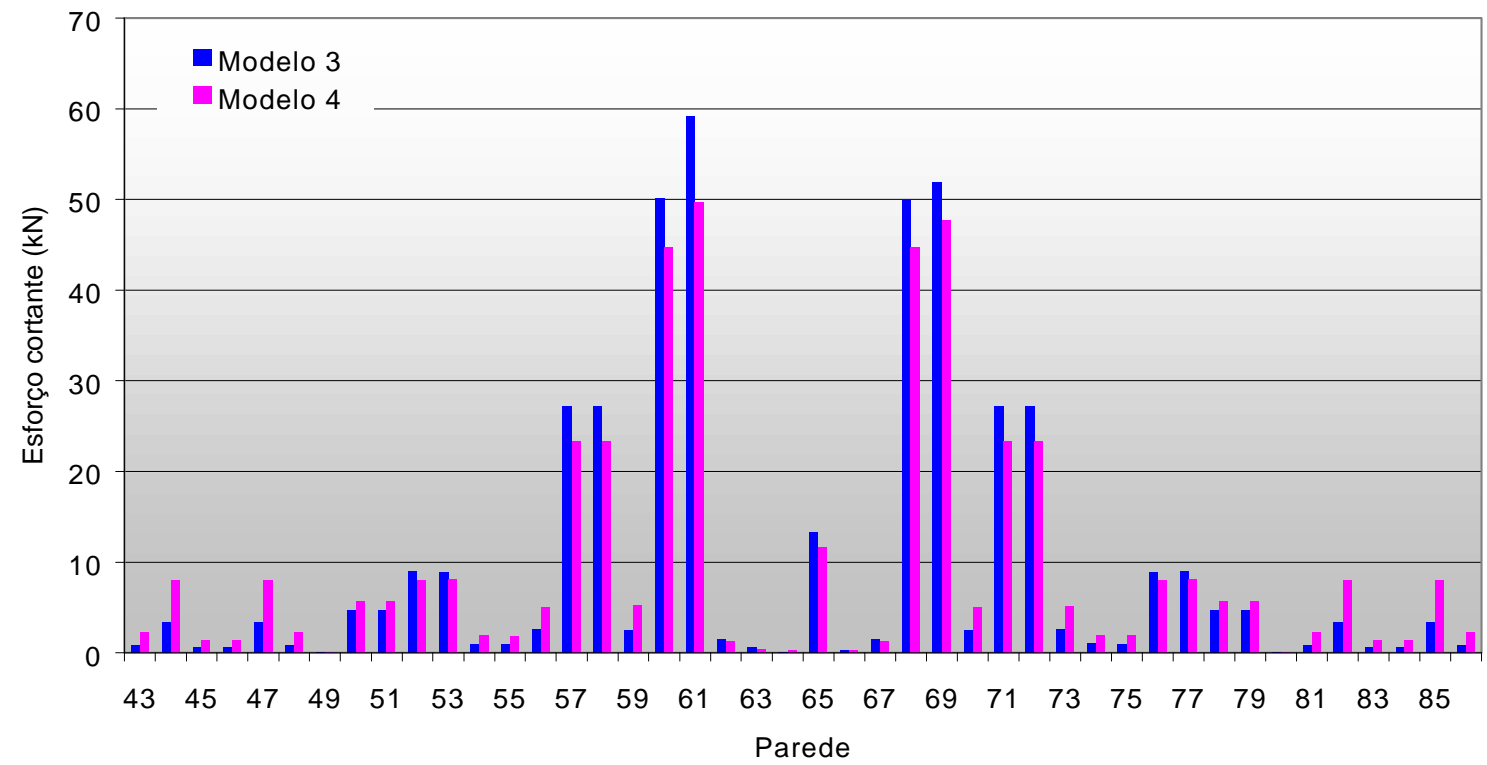

FIGURA 4.28b - Distribuição dos esforços cortantes entre as paredes de contraventamento, vento Y - Comparação entre os modelos 3 e 4

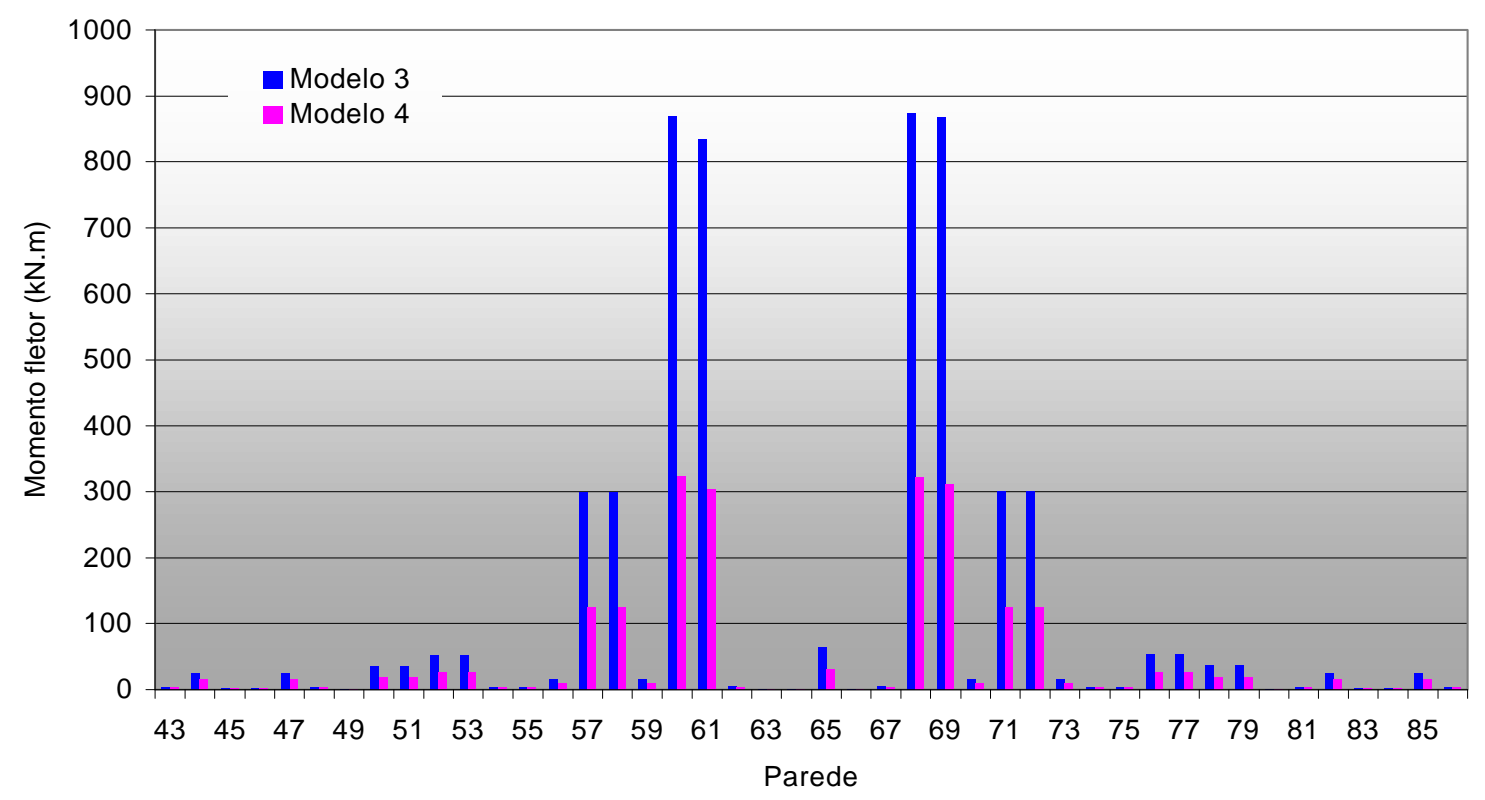

FIGURA 4.29 - Distribuição dos momentos fletores entre as paredes de contraventamento com vento segundo a direção $\mathrm{Y}$, comparação entre os modelos 3 e 4

Os aspectos dos diagramas de esforço cortante, FIGURA 4.30, são semelhantes aos apresentados no projeto básico. O máximo esforço cortante ocorre com o modelo 1 na base, enquanto que o modelo 2 
apresenta um cortante máximo num nível intermediário (primeiro pavimento). O modelo 3 comportou-se semelhantemente ao modelo $2 \mathrm{em}$ níveis menores de solicitação. Da mesma forma o modelo 4 assemelha-se ao modelo 1, quanto ao aspecto do diagrama, mas com redução da solicitação. A melhoria na representação do comportamento estrutural pode ser observada pelo decréscimo do cortante máximo.

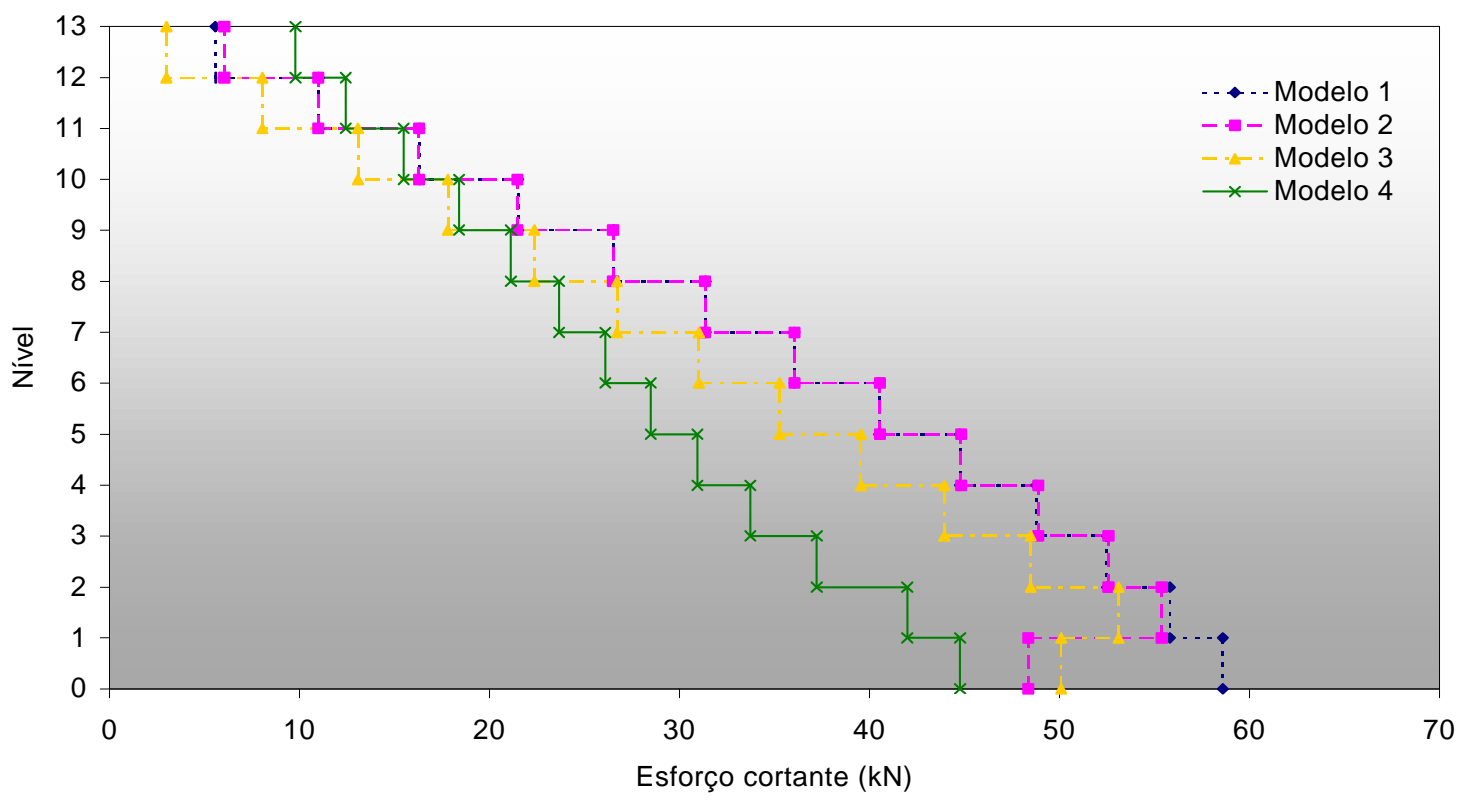

FIGURA 4.30 - Diagrama de esforço cortante da parede mais solicitada PY68, comparação entre todos os modelos

Os diagramas de momento fletor, FIGURA 4.31, continuaram apresentando o comportamento observado no projeto básico, resultando em variações maiores com o modelo 3 e menores com o modelo 4. As descontinuidades ocasionadas nos diagramas também são causadas pela presença das barras horizontais rígidas no modelo de pórtico tridimensional. 


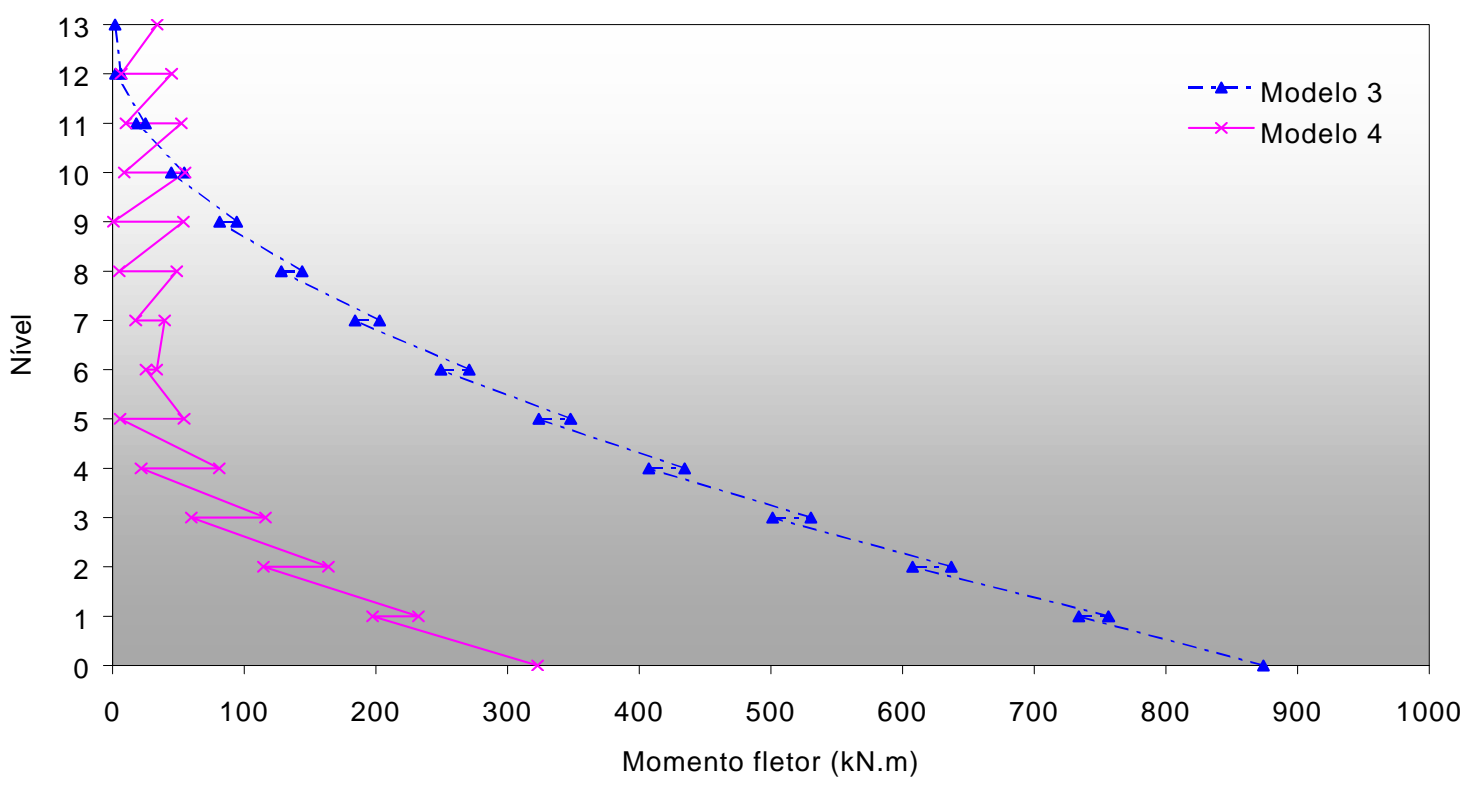

FIGURA 4.31 - Diagrama de momento fletor da parede mais solicitada PY68, comparação entre os modelos 3 e 4

A distribuição dos esforços cortantes entre os vários lintéis é apresentada na FIGURA 4.32. Os lintéis mais solicitados dispõem-se segundo a direção X, podendo-se citar: LX3, LX6, LX7, LX12 e LX13, com $10,9 \mathrm{kN}, 9,1 \mathrm{kN}, 9,1 \mathrm{kN}, 9,2 \mathrm{kN}, 9,2 \mathrm{kN}$, respectivamente.

Os lintéis da direção Y também apresentam solicitações consideráveis, a exemplo do LY29 e do LY38, ambos com 8,8kN, assim como LY18, LY21, LY26, LY35, LY43 e LY46, todos com 8,0kN.

Pode-se verificar, também, que alguns lintéis $\mathrm{X}$ são solicitados pelo vento $\mathrm{Y}$, bem como alguns lintéis $\mathrm{Y}$ são solicitados pelo vento $\mathrm{X}$, embora com intensidade bastante reduzida. Verifica-se também que alguns lintéis particulares apresentam esforço cortante praticamente igual, independentemente da direção de atuação do vento, a exemplo do LX15 e LY31.

Considerando-se blocos com resistência característica $\mathrm{f}_{\mathrm{bk}}=10 \mathrm{MPa}$ (utilizados no 1 pavimento), bem como eficiência $\eta=0,8$, obtém-se uma 
tensão de cisalhamento admissível $\overline{\mathrm{f}}_{\text {cisl }}=0,25 \mathrm{MPa}^{12}$. O lintel mais solicitado LX3 apresenta um esforço cortante $V=10,8 \mathrm{kN}$, e seção transversal com $\mathrm{b}=14,5 \mathrm{~cm}$ e $\mathrm{d}=165 \mathrm{~cm}$, resultando numa tensão de cisalhamento $\tau=0,05 \mathrm{MPa}$, bem inferior à admissível. Os lintéis LX12 e LX13 apresentam esforço cortante $\mathrm{V}=9,2 \mathrm{kN}$, no entanto suas seções possuem altura menor que a do lintel $\mathrm{LX} 3$, correspondendo $\mathrm{a} b=14,5 \mathrm{~cm}$ e $\mathrm{d}=55 \mathrm{~cm}$. Nesse caso, $\mathrm{a}$ tensão de cisalhamento apresenta intensidade $\tau=0,12 \mathrm{MPa}$, maior que a do lintel mais solicitado, mas ainda inferior à admissível.

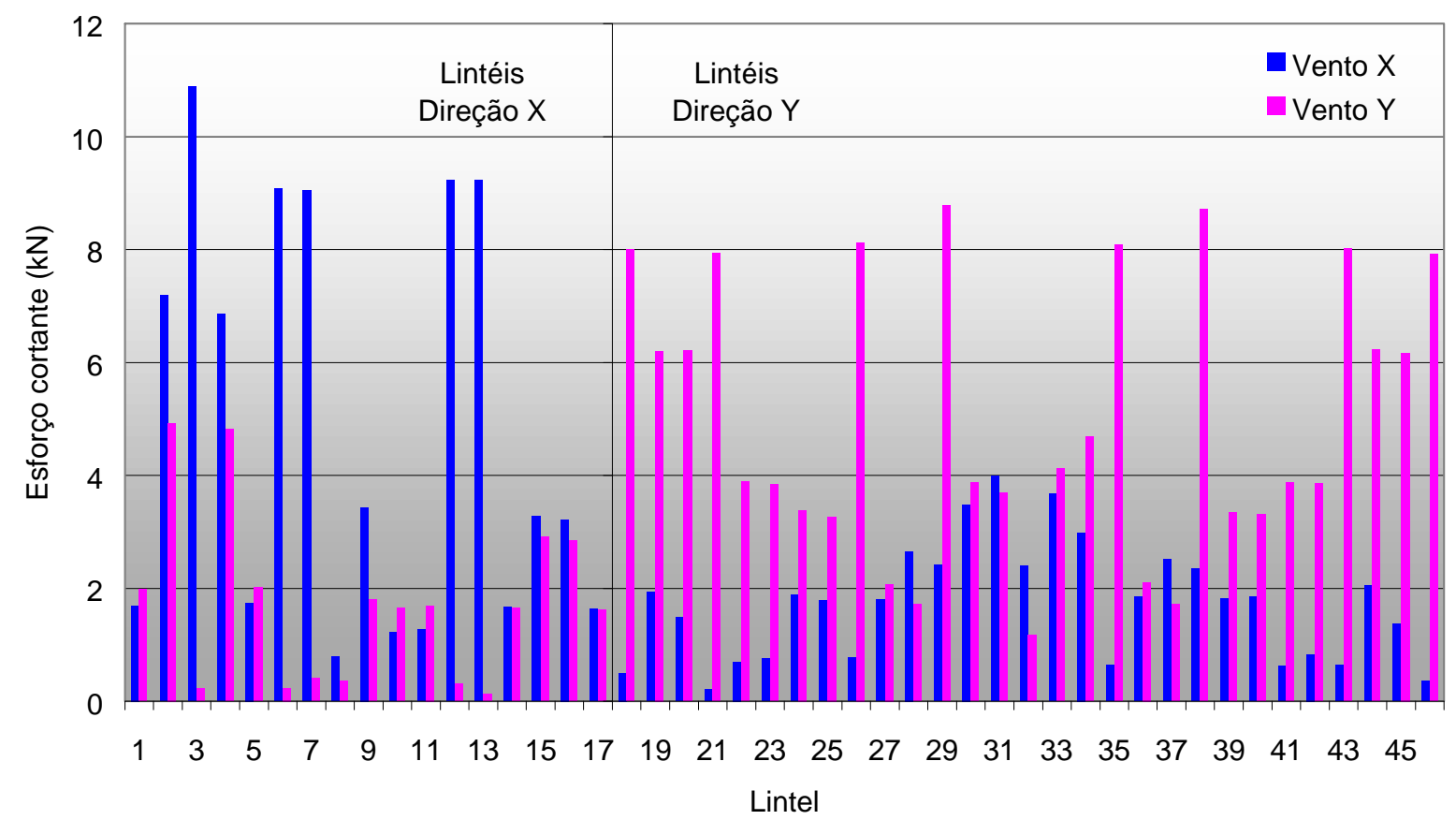

FIGURA 4.32 - Esforços cortantes nos lintéis

12 Obtida de acordo com a NBR-10837, considerando-se alvenaria armada e elemento fletido. Essa tensão admissível define o limite para não se utilizarem estribos no elemento estrutural. 


\section{5 - Exemplo de carregamento com torção}

Finalmente, o último exemplo tem por finalidade avaliar os efeitos da torção. O edifício analisado possui nove pavimentos com pé-direito de $2,80 \mathrm{~m}$. Foram utilizados blocos que variam de $10 \mathrm{MPa}$ a $4,5 \mathrm{MPa}$ da base ao topo da estrutura. A planta baixa do pavimento tipo é apresentada na FIGURA 4.33a e esquematizada em diagrama unifilar na FIGURA 4.33b.

Aplicaram-se ações segundo as direções X e Y com excentricidades ${ }^{13}$ normalizadas. As excentricidades foram consideradas de modo que provocassem uma rotação das lajes no sentido anti-horário. Foram analisadas as duas direções para avaliarem-se as distintas torções ocorridas, uma com maior intensidade da força devida ao vento (maior área de obstrução) e maior excentricidade, e outra com menor intensidade (menor área de obstrução) e menor excentricidade. São apresentados apenas os resultados para as paredes dispostas na mesma direção de análise, pois o projeto básico demonstrou que as paredes perpendiculares à direção analisada não apresentam influência significativa no comportamento estrutural.

A modificação na distribuição dos esforços cortantes devido à torção do edifício é, inicialmente, analisada pelo modelo 3. Da mesma forma, os modelos 3 e 4 são avaliados sob o aspecto da torção, averiguando-se as diferenças entre os dois modelos de pórtico tridimensional.

Os modelos 2 e 3 são analisados através da distribuição dos esforços cortantes com e sem torção do edifício, avaliando-se as diferenças entre a modelagem com barras isoladas e o modelo de pórtico tridimensional.

Apresentam-se, também, os resultados da distribuição dos esforços cortantes obtidos com todos os modelos num único gráfico, de modo a poder-se avaliar o comportamento geral dessas modelagens na torção.

Da mesma forma que no projeto básico, os lintéis do modelo 4 foram analisados quanto aos esforços cortantes e tensões de cisalhamento, mediante comparação com os limites normalizados.

\footnotetext{
${ }^{13}$ Prevendo-se os efeitos causados pela vizinhança da edificação, vide Tabela 3.2
} 


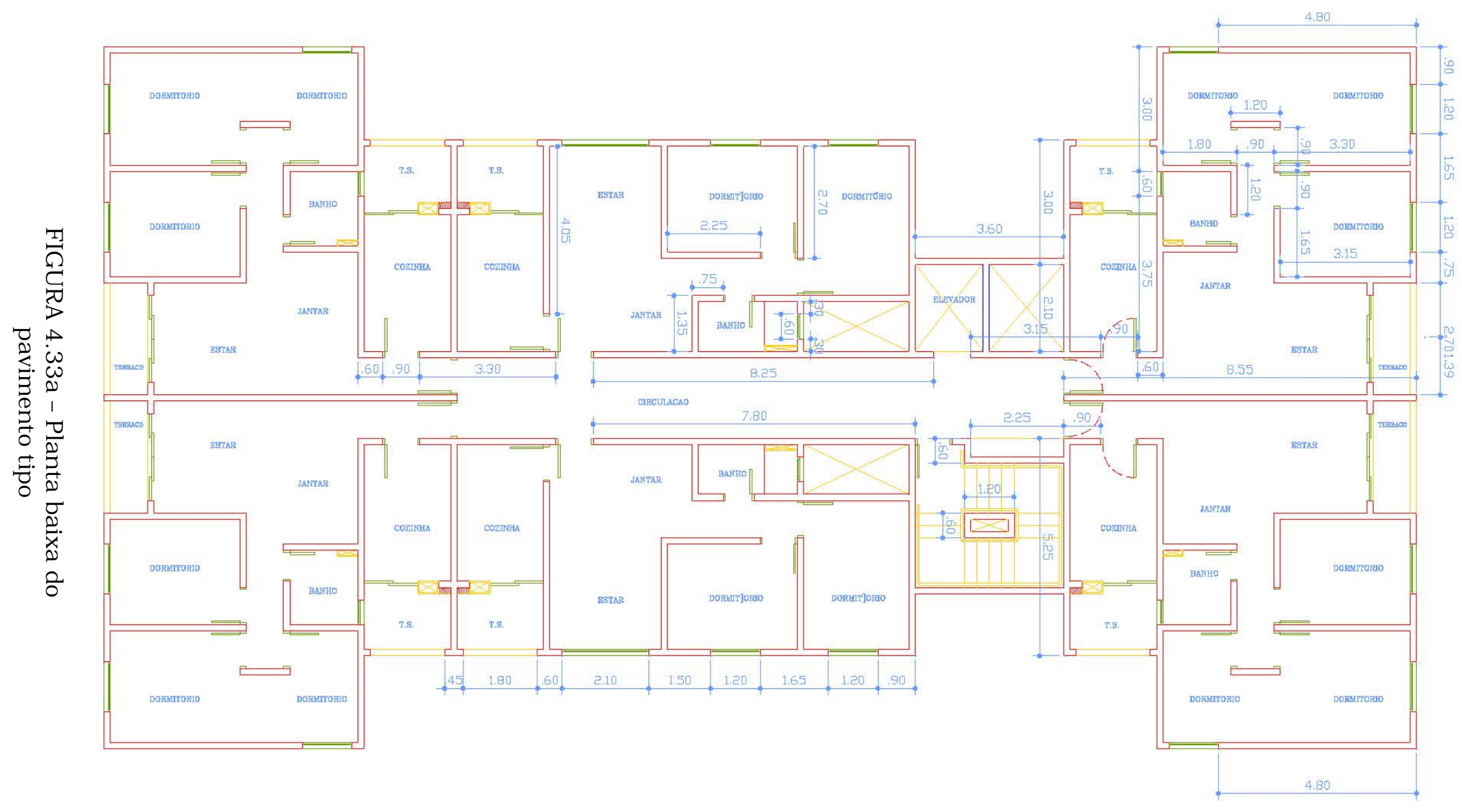




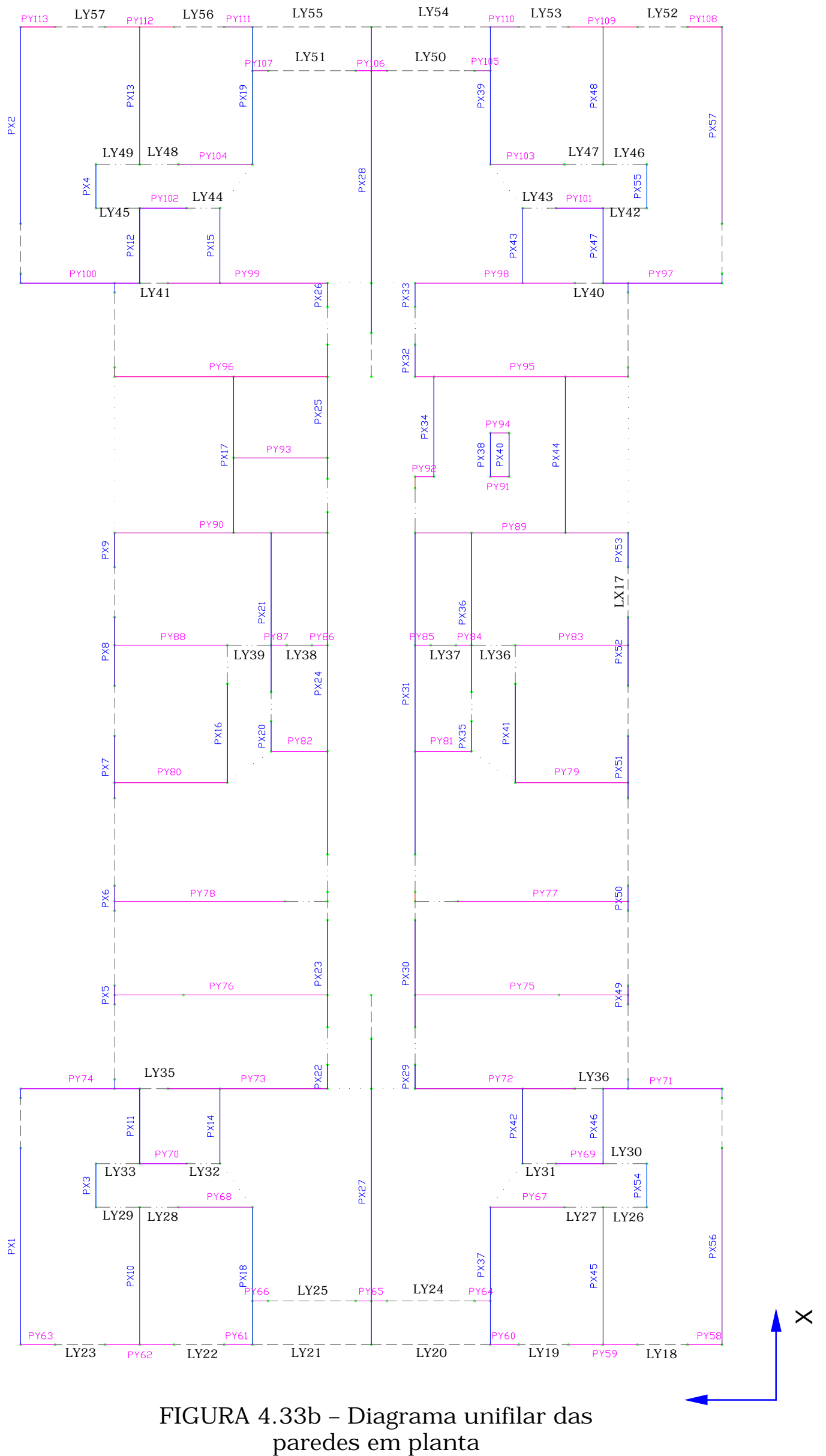


O modelo 3 é utilizado para avaliar-se a redistribuição dos esforços devida às rotações das lajes, averiguando-se os acréscimos e decréscimos dos esforços cortantes nas paredes de contraventamento.

A análise do vento $\mathrm{X}$, FIGURA 4.34a, confirmou os resultados obtidos no projeto básico, onde a torção não apresentou modificações significativas na distribuição dos esforços cortantes. Essa direção de análise apresenta tanto a intensidade da força do vento quanto a excentricidade pequenas quando comparada com a direção Y. Adicionalmente, as paredes dessa direção apresentam comprimentos razoáveis, de modo que os pórticos formados possuem barras horizontais rígidas maiores, bem como barras verticais com maiores inércias. As paredes PX24 e PX31 apresentaram os maiores esforços com $30,1 \mathrm{kN}$ e $27,2 \mathrm{kN}$ segundo a análise sem torção, e $29,1 \mathrm{kN}$ e $28,0 \mathrm{kN}$ segundo a análise com torção, diferenças de $3 \%$ para as duas paredes. Como essa direção apresenta uma disposição de paredes em planta bastante simétrica, as paredes PX27 e PX28 permaneceram com seus esforços cortantes praticamente inalterados.

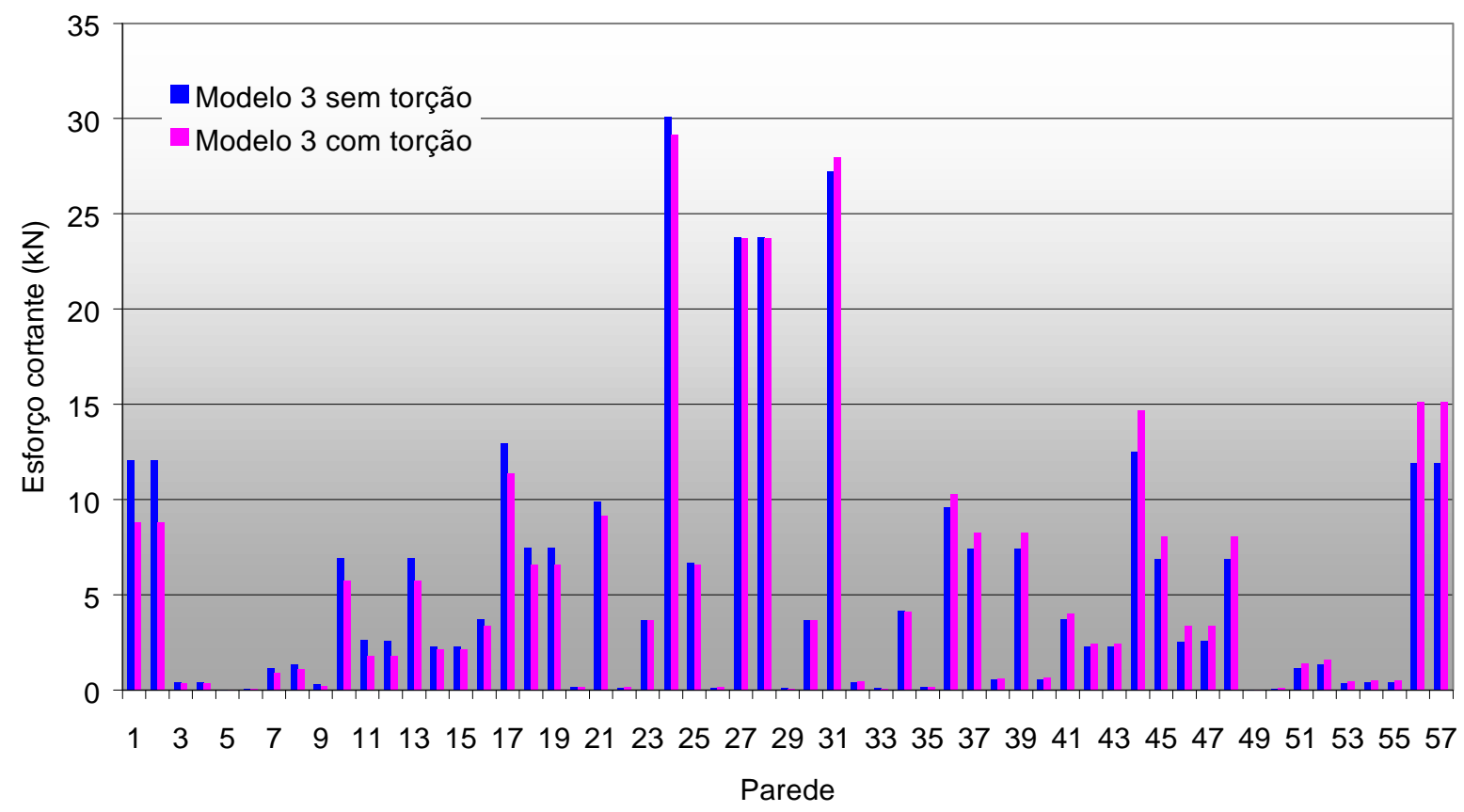

FIGURA 4.34a - Distribuição dos esforços cortantes entre as paredes de contraventamento, análise do efeito da torção - Ação do vento segundo a direção $\mathrm{X}$ 
No caso do vento Y, FIGURA 4.34b, ocorre uma modificação considerável na distribuição dos esforços cortantes. O intervalo de paredes compreendido entre PY58 e PY82 apresentou decréscimo em seus esforços, como pode-se notar em PY75 e PY76 que absorvem $32,1 \mathrm{kN}$ e $48,7 \mathrm{kN}$ segundo os modelos com e sem torção respectivamente, apresentando um decréscimo percentual de 34\%. Esses esforços correspondem a tensões de cisalhamento $\tau_{3}=0,13 \mathrm{MPa}$ e $\tau_{3}=0,20 \mathrm{MPa}$, relativas às análises com e sem torção, respectivamente. O intervalo compreendido entre PY88 e PY113 apresentou acréscimos significativos em seus esforços cortantes máximos. As paredes PY89 e PY90 eram as mais solicitadas na análise sem torção com 49,3kN e 48,6kN, respectivamente, correspondendo a tensões $\tau_{3}=0,06 \mathrm{MPa}$ e $\tau_{3}=0,08 \mathrm{MPa}$, respectivamente. O efeito da torção aumentou seus esforços para $55,8 \mathrm{kN}$ e $56,2 \mathrm{kN}$ (acréscimos de $13 \%$ e $16 \%$ ), correspondendo a tensões tangenciais de $\tau_{3}=0,07 \mathrm{MPa}$ e $\tau_{3}=0,10 \mathrm{MPa}$, respectivamente. No entanto, as paredes PY95 e PY96, que absorvem $47,4 \mathrm{kN}$ e $44,7 \mathrm{kN}$ pela análise sem torção, passam a absorver $64,9 \mathrm{kN}$ e $60,6 \mathrm{kN}$ respectivamente, pela análise com torção (acréscimos de $37 \% \mathrm{e}$ 35\%), tornando-se as paredes mais solicitadas dentre todas. Esses esforços cortantes correspondem a tensões de cisalhamento para a parede PY95 de $\tau_{3}=0,11 \mathrm{MPa}$ e $\tau_{3}=0,08 \mathrm{MPa}$ segundo as análises com e sem torção, respectivamente; e para a parede PY96 de $\tau_{3}=0,15 \mathrm{MPa}$ e $\tau_{3}=0,11 \mathrm{MPa}$ segundo as análises com e sem torção, respectivamente. 


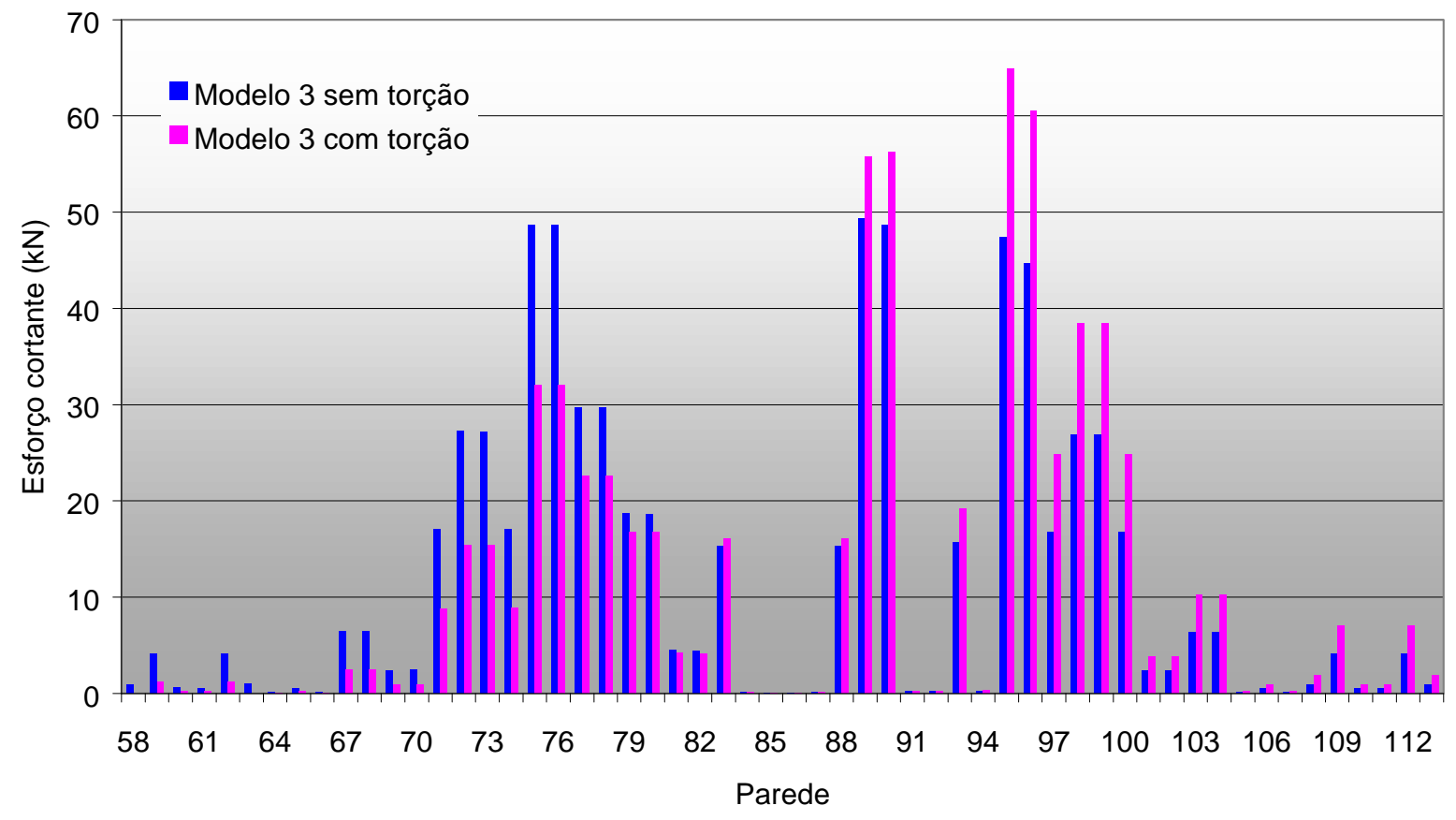

FIGURA 4.34b - Distribuição dos esforços cortantes entre as paredes de contraventamento, análise do efeito da torção - Ação do vento segundo a direção $Y$

O efeito da torção pode modificar significativamente a distribuição dos esforços cortantes, dependendo da planta baixa do edifício. Por um lado algumas paredes apresentam um alivio em suas tensões de cisalhamento, a exemplo da parede PY75 que sem a consideração da torção possui tensão $\tau_{3}=0,20 \mathrm{MPa}$ superior à admissível $\overline{\mathrm{f}}_{\text {cisl }}=0,15 \mathrm{MPa}$ (obtida considerando-se eficiência de prisma $\eta=0,8$ e, segundo a NBR-10837, alvenaria armada com elemento fletido), e considerando-se o efeito da torção apresenta $\tau_{3}=0,13 \mathrm{MPa}$ inferior à admissível. Vale salientar que esse decréscimo da tensão de cisalhamento não pode ser considerado na análise da parede, pois no caso de carregamento que origina torção em sentido contrário ao analisado ocorre acréscimo dessa tensão. Por outro lado, ocorre um acréscimo significativo dessas tensões em algumas paredes, a exemplo da PY95 que possui uma tensão $\tau_{3}=0,24 \mathrm{MPa}$ sem considerar-se o efeito da 
torção e $\tau_{3}=0,33 \mathrm{MPa}$ considerando-se tal efeito, ambas superiores à tensão admissível. Nesse caso, deve-se reforçar a parede especificando-se grauteamentos ou determinando-se a área de estribos que deve ser adicionada às juntas horizontais.

Os modelos 3 e 4 foram utilizados para a análise da estrutura submetida à torção, de modo a avaliar o modelo de pórtico tridimensional com e sem lintéis. Segundo os resultados apresentados pelo projeto básico, a influência das paredes perpendiculares à determinada direção de análise é pouco significativa, por isso apresentam-se apenas os resultados das paredes dispostas paralelamente às respectivas direções de atuação do vento, isto é, paredes PY para o vento Y e paredes PX para o vento X.

Da mesma forma que no projeto básico, o modelo 4 apresentou tendência de redistribuição com redução das máximas solicitações, tanto para a análise da direção X quanto da direção Y. De acordo com a análise do vento X, FIGURA 4.35a, as paredes PX24 e PX31 são as mais solicitadas com $29,1 \mathrm{kN}$ e $28,0 \mathrm{kN}$ segundo o modelo 3 , e $26,0 \mathrm{kN}$ e $24,4 \mathrm{kN}$ segundo o modelo 4, resultando em decréscimos de $10 \%$ e $13 \%$, respectivamente. No caso da análise do vento Y, FIGURA $4.35 \mathrm{~b}$, as paredes mais solicitadas PY95 e PY96 absorvem 64,9kN e 60,6kN segundo o modelo 3, e 53,0kN e $50,3 \mathrm{kN}$ segundo o modelo 4, resultando em decréscimos de $18 \%$ e $17 \%$, respectivamente. 


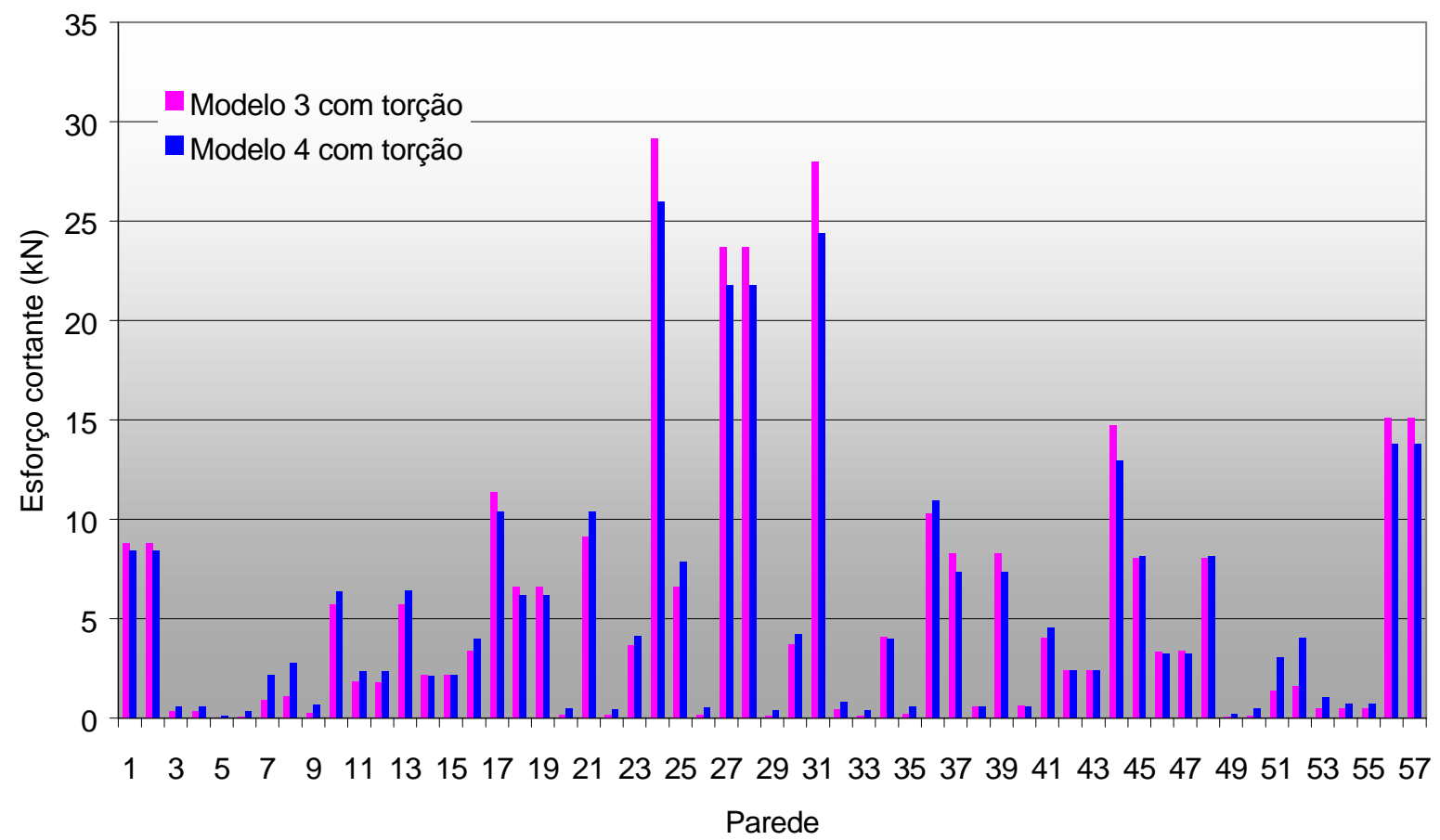

a - Ação do vento segundo a direção X

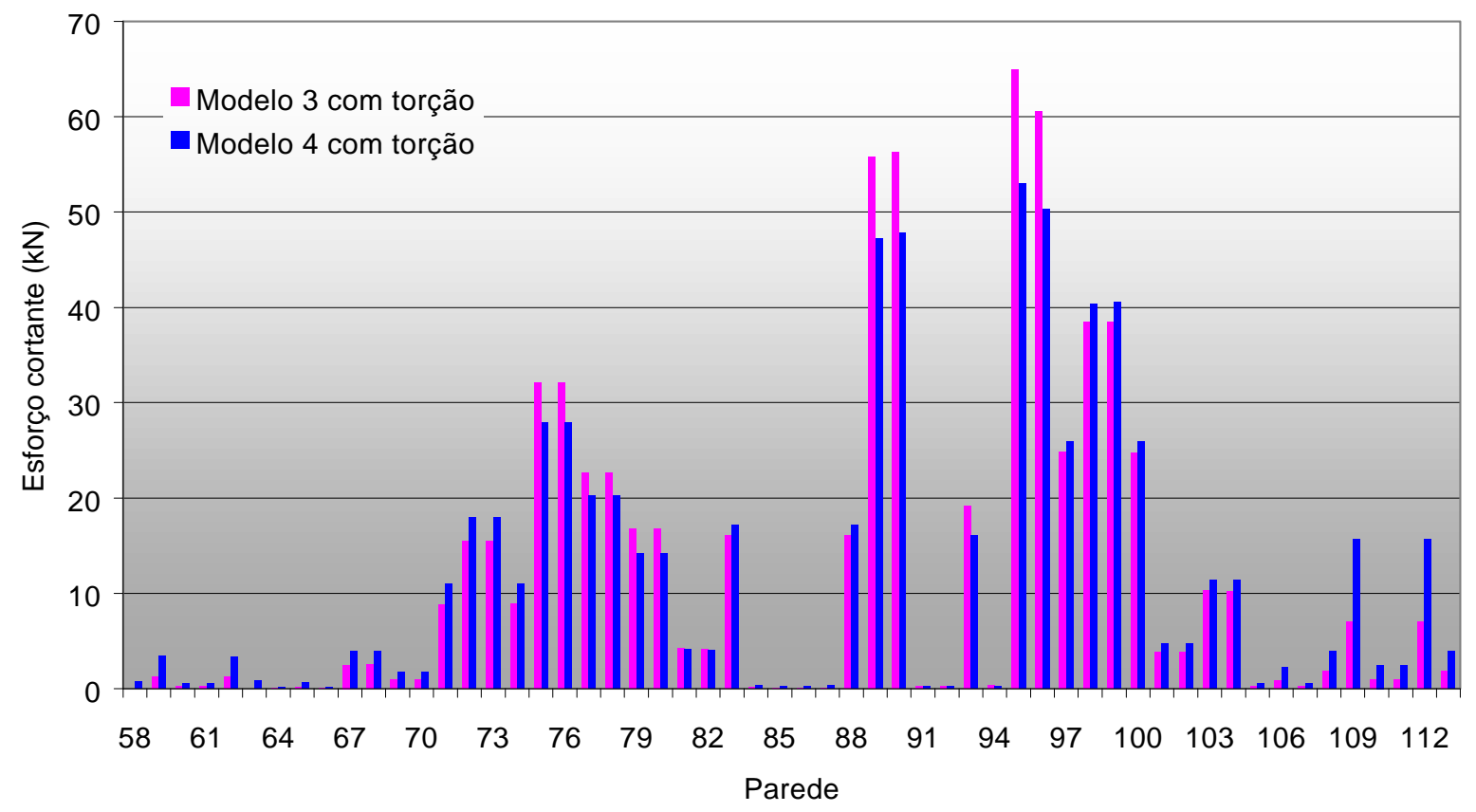

b - Ação do vento segundo a direção Y

FIGURA 4.35 - Distribuição dos esforços cortantes entre as paredes de contraventamento, comparação entre os modelos 3 e 4 
Os modelos 2 e 3 também foram confrontados para esse edifício, a exemplo do projeto básico, sob o aspecto da torção. As análises foram desenvolvidas para ações do vento com e sem excentricidades. Os resultados para a análise sem torção do edifício comprovam que os dois modelos apresentam comportamento muito parecido nas duas direções avaliadas, sem diferenças apreciáveis na distribuição dos esforços cortantes. Mesmo a análise segundo a direção Y, FIGURAS 4.37a e 4.37b, que poderia resultar em modificações devido a assimetria apresentada na parte intermediária da planta do edifício, não houve alterações significativas, a exemplo da parede mais solicitada PY90 que absorve $50,5 \mathrm{kN}$ segundo o modelo 2 e $48,6 \mathrm{kN}$ segundo o modelo 3 (4\% de diferença).

No entanto, repetindo-se o comportamento do projeto básico, ao incorporar-se o efeito da torção, os modelos diferenciaram-se quanto à distribuição dos esforços cortantes. Na análise do vento X, FIGURAS 4.36a e 4.36b, essas diferenças não tornam os resultados do modelo 2 insatisfatórios, pois as solicitações máximas apresentaram diferenças aceitáveis, quando comparadas ao modelo 3. Nesse caso pode-se citar a parede PX31 que apresenta um esforço cortante de $30,0 \mathrm{kN}$ segundo o modelo 2 e $28,0 \mathrm{kN}$ segundo o modelo 3, resultando numa diferença de $6 \%$. Essa pequena diferença pode ser explicada pelo fato da parede mais solicitada dispor-se próxima ao centro elástico do edifício, onde o efeito da torção é menos acentuado. No caso de paredes que possuam solicitações consideráveis e que localizem-se mais distantes do centro elástico, as diferenças entre os dois modelos tornam-se maiores, a exemplo das paredes PX56 e PX57 que absorvem segundo os modelos 2 e 3 solicitações de $22,1 \mathrm{kN}$ e $15,1 \mathrm{kN}$ respectivamente, correspondendo à diferença de $46 \%$. 


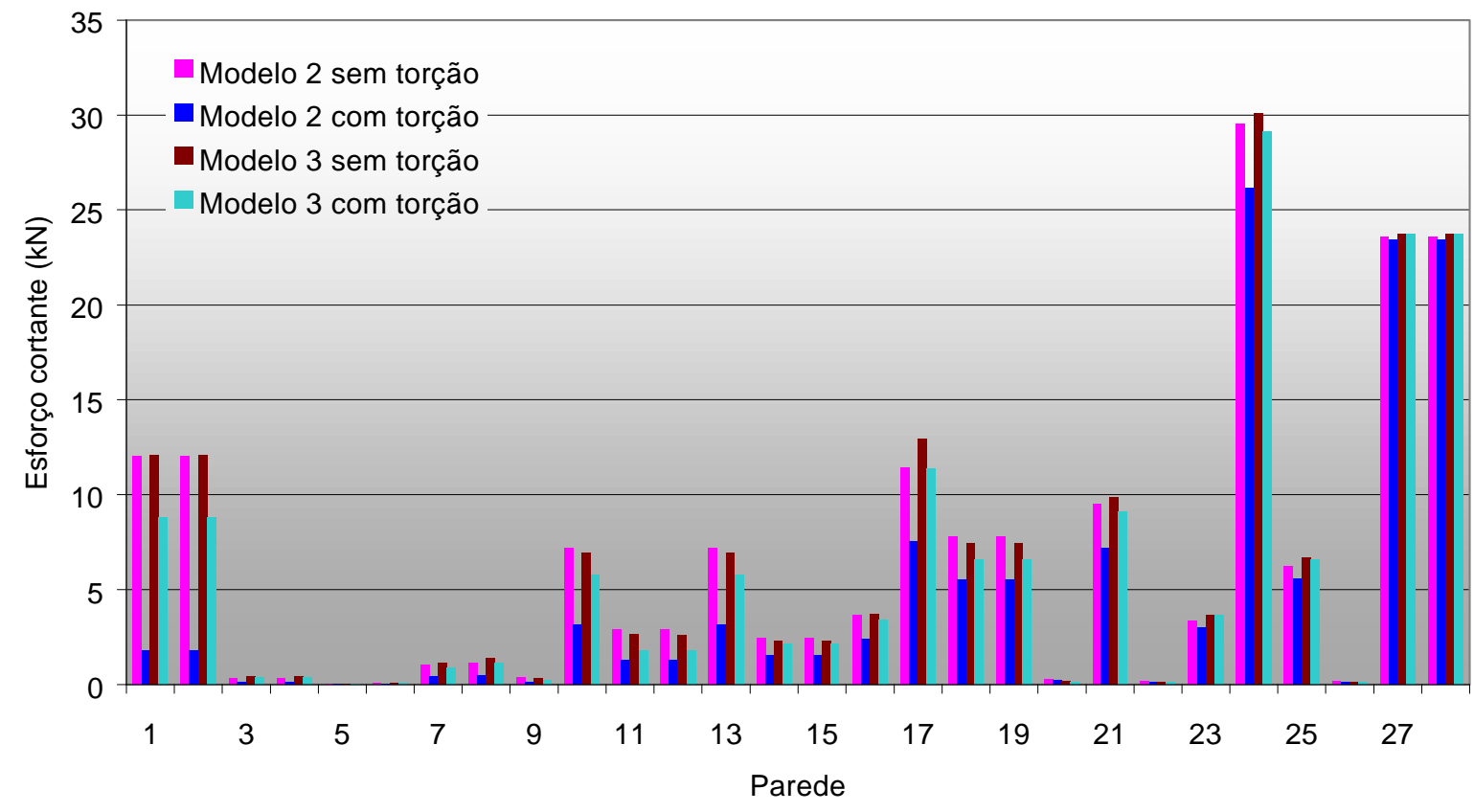

a - Intervalo de paredes entre PX1 e PX28

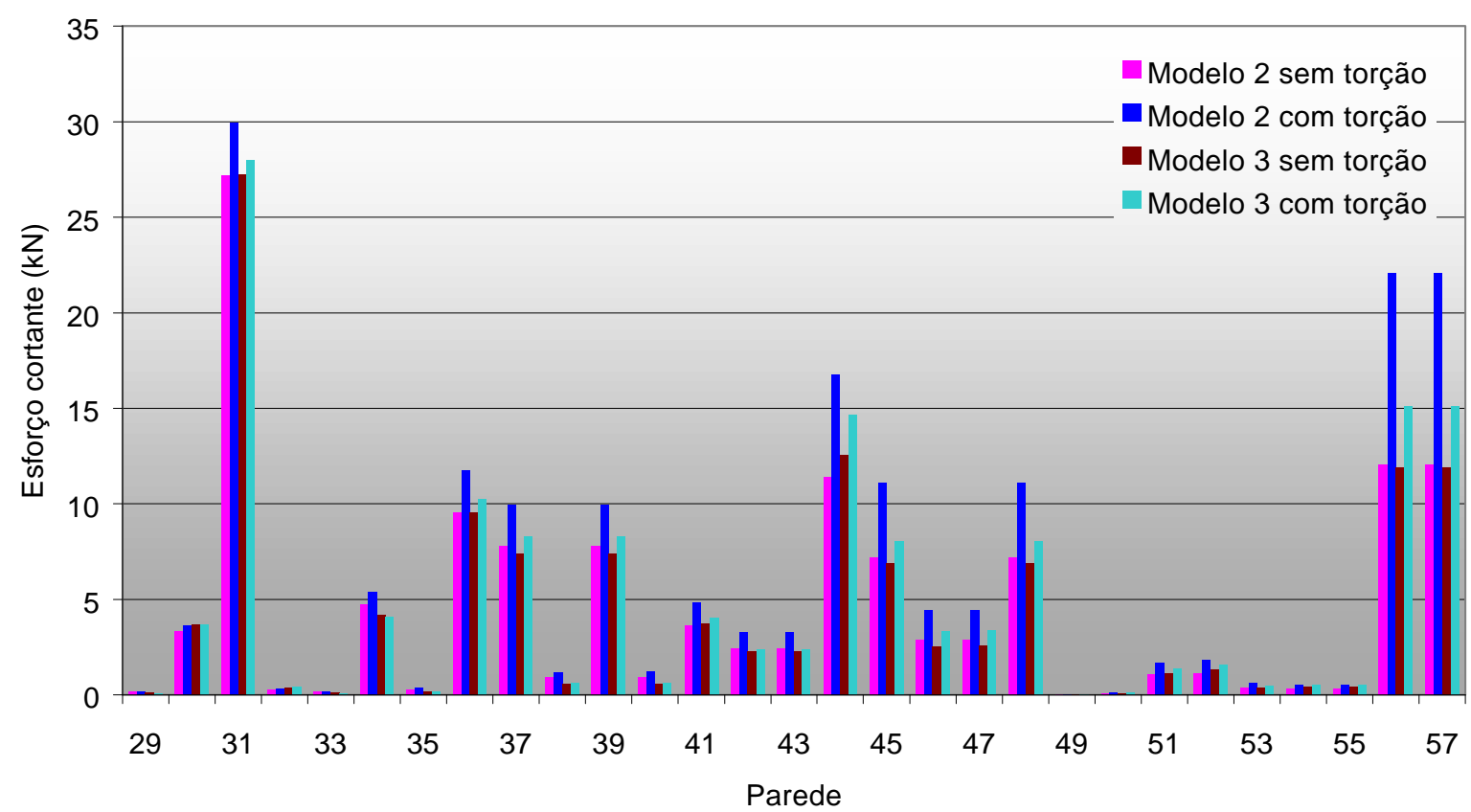

b - Intervalo de paredes entre PX29 e PX57

FIGURA 4.36 - Distribuição dos esforços cortantes entre as paredes de contraventamento para vento segundo a direção X, comparação entre os modelos 2 e 3 
Quanto à análise do vento Y, FIGURAS 4.37a e 4.37b, as diferenças tornam-se um pouco maiores para as máximas solicitações. Como exemplo citam-se as paredes PY95 e PY96, que apresentam um esforço cortante de $71,6 \mathrm{kN}$ e $71,2 \mathrm{kN}$ segundo o modelo 2 , e $64,9 \mathrm{kN}$ e $60,6 \mathrm{kN}$ segundo o modelo 3 , resultando em diferenças de $10 \%$ e $17 \%$, respectivamente.

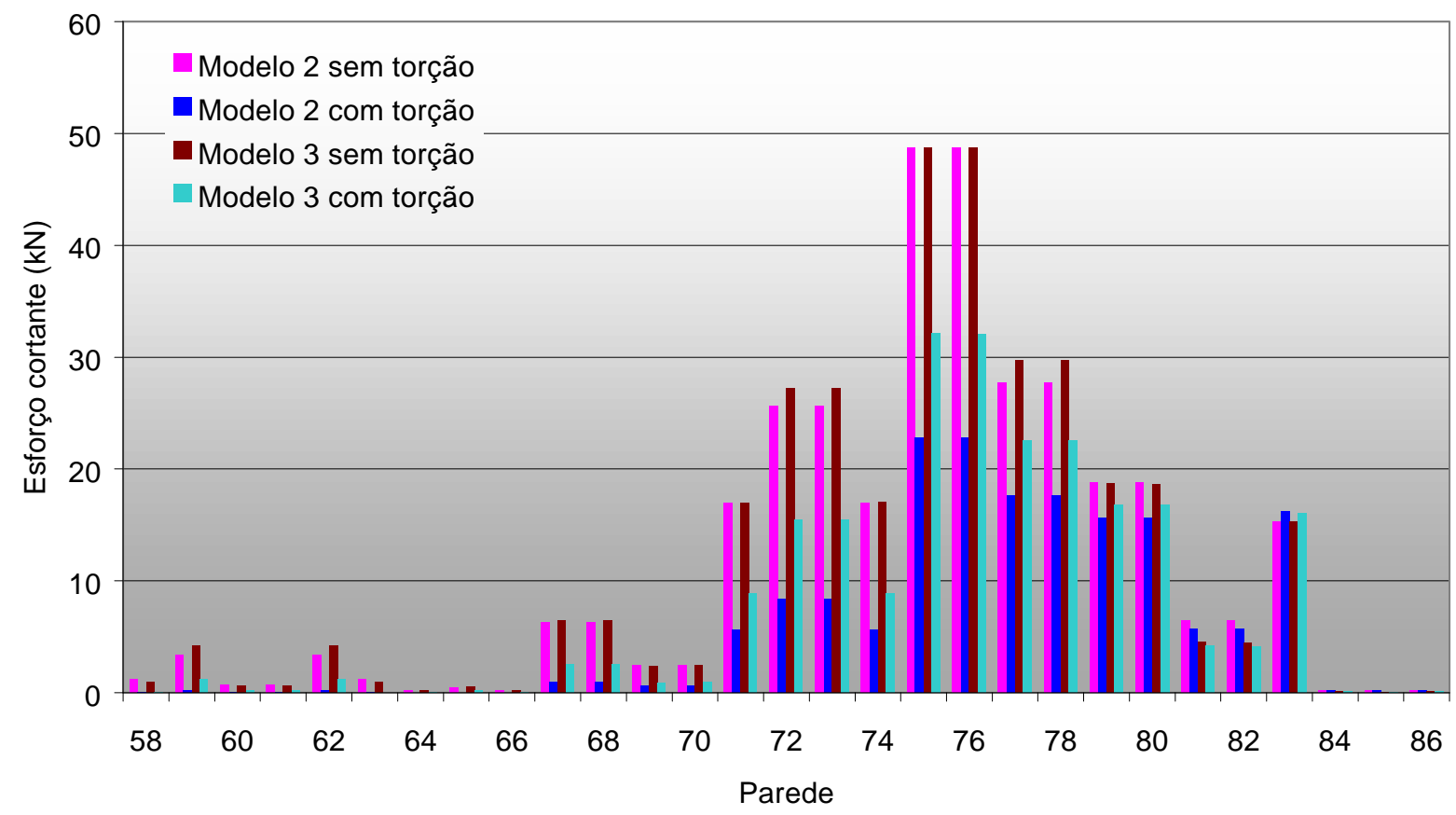

FIGURA 4.37a - Distribuição dos esforços cortantes entre as paredes de contraventamento para vento segundo a direção $\mathrm{Y}$, comparação entre os modelos 2 e 3 - Intervalo de paredes entre PY58 e PY86 


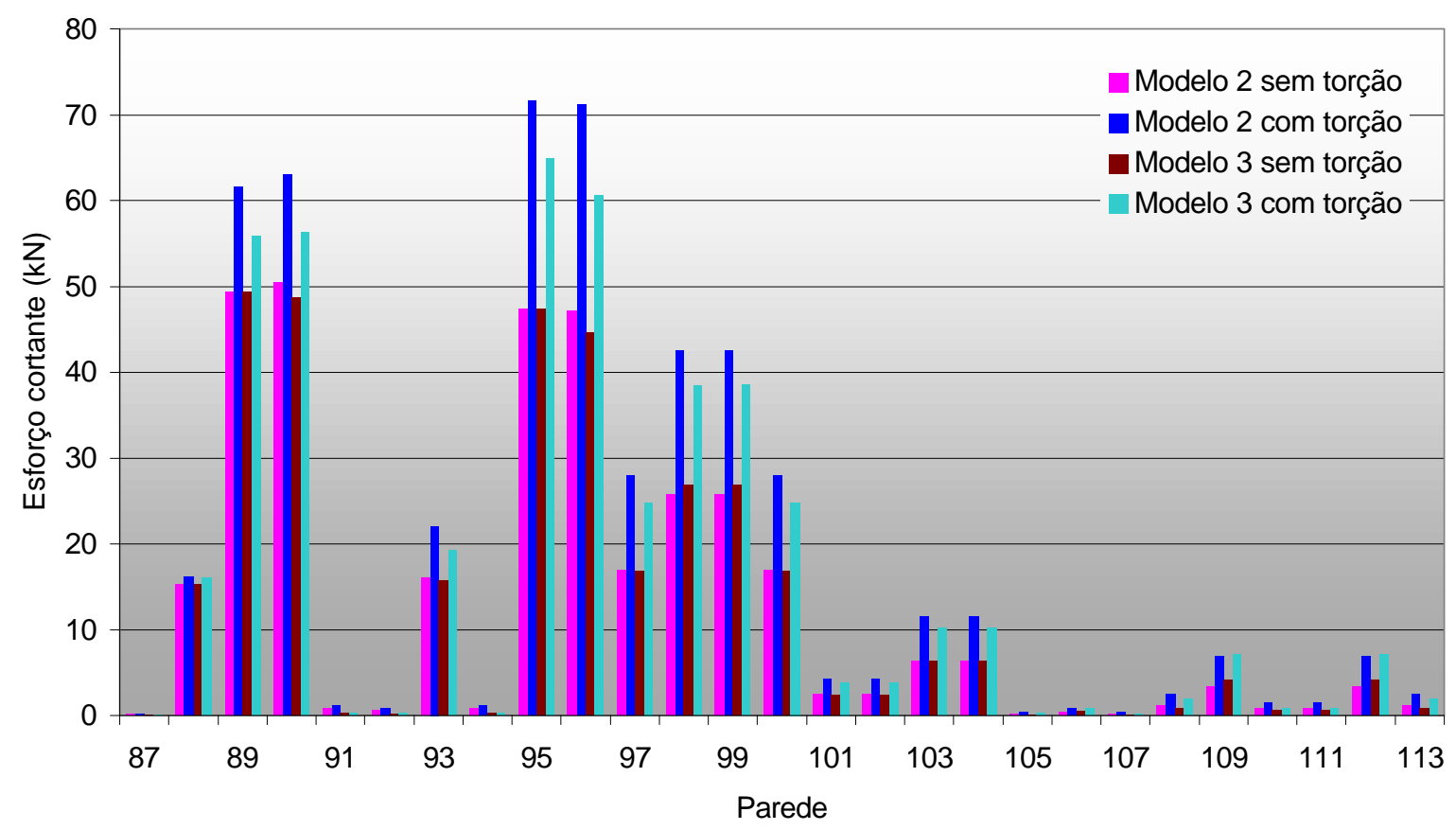

FIGURA 4.37b - Distribuição dos esforços cortantes entre as paredes de contraventamento para vento segundo a direção Y, comparação entre os modelos 2 e 3 - Intervalo de paredes entre PY87 e PY113

Os quatro gráficos seguintes, FIGURAS 4.38a e 4.38b e FIGURAS $4.39 \mathrm{a}$ e $4.39 \mathrm{~b}$, estabelecem as variações que ocorrem no comportamento global da estrutura entre as várias modelagens utilizadas neste trabalho.

$\mathrm{Da}$ mesma forma que no projeto básico, confirma-se o conservadorismo do modelo 1 na distribuição dos esforços cortantes entre as paredes de contraventamento, onde as máximas solicitações são superestimadas e as mínimas subestimadas, obtendo-se distribuições pouco uniformes.

Os modelos 2, 3 e 4 apresentam comportamento semelhante na análise sem torção, com variações menores na distribuição dos esforços cortantes quando dispõe-se de pavimentos simétricos, e variações maiores nessa distribuição quando dispõe-se de pavimentos assimétricos. Nessa análise, sempre ocorre uma maior tendência de redistribuição à medida que refina-se a modelagem. 
Os modelos de pórtico tridimensional apresentaram resultados que evidenciam sua qualidade na avaliação dos efeitos da torção do edifício, principalmente no caso de estruturas assimétricas. Da mesma forma, a modelagem com barras isoladas, mais especificamente o modelo 2, apresentou resultados que comprovam sua qualidade quanto às ações do vento sem consideração da torção. Caso considere-se a ação do vento com excentricidade, o modelo 2 apresenta resultados razoáveis apenas nos casos em que as paredes mais solicitadas posicionam-se próximas ao centro elástico do edifício.

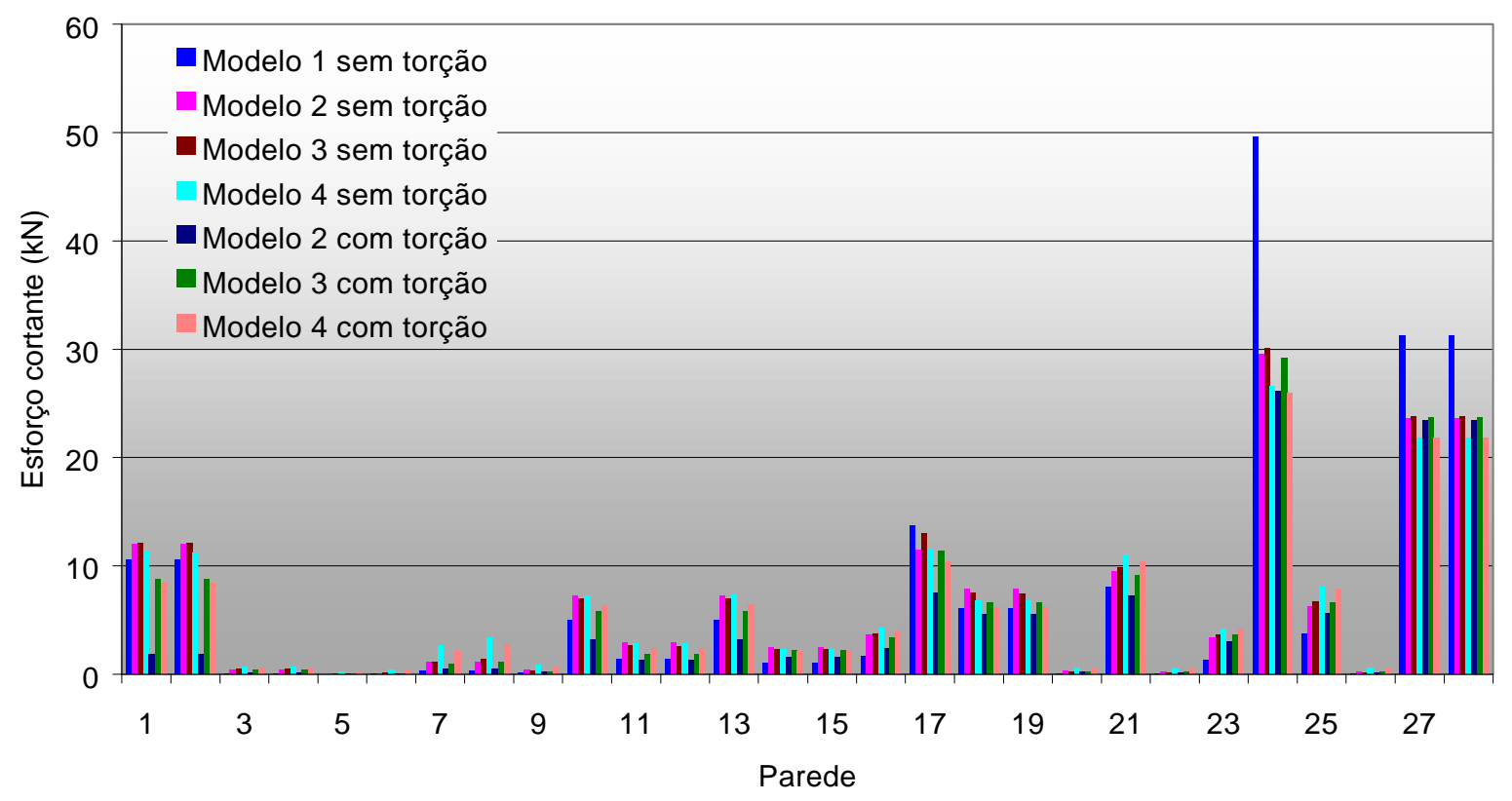

FIGURA 4.38a - Distribuição dos esforços cortantes entre as paredes de contraventamento para vento segundo a direção $\mathrm{X}$, análise de todos os modelos - Intervalo de paredes entre PX1 e PX28 


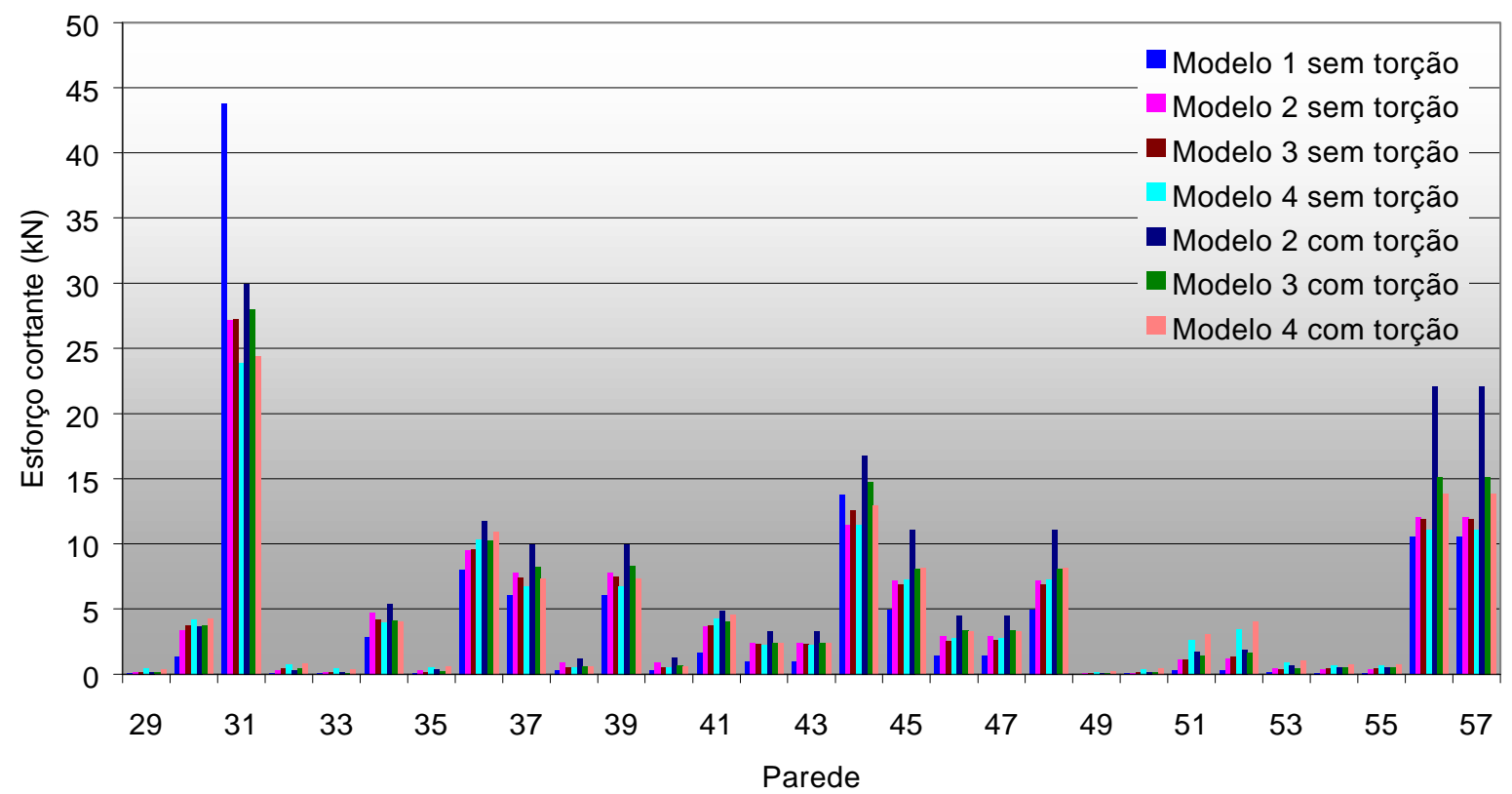

FIGURA 4.38b - Distribuição dos esforços cortantes entre as paredes de contraventamento para vento segundo a direção $\mathrm{X}$, análise de todos os modelos - Intervalo de paredes entre PX29 e PX57

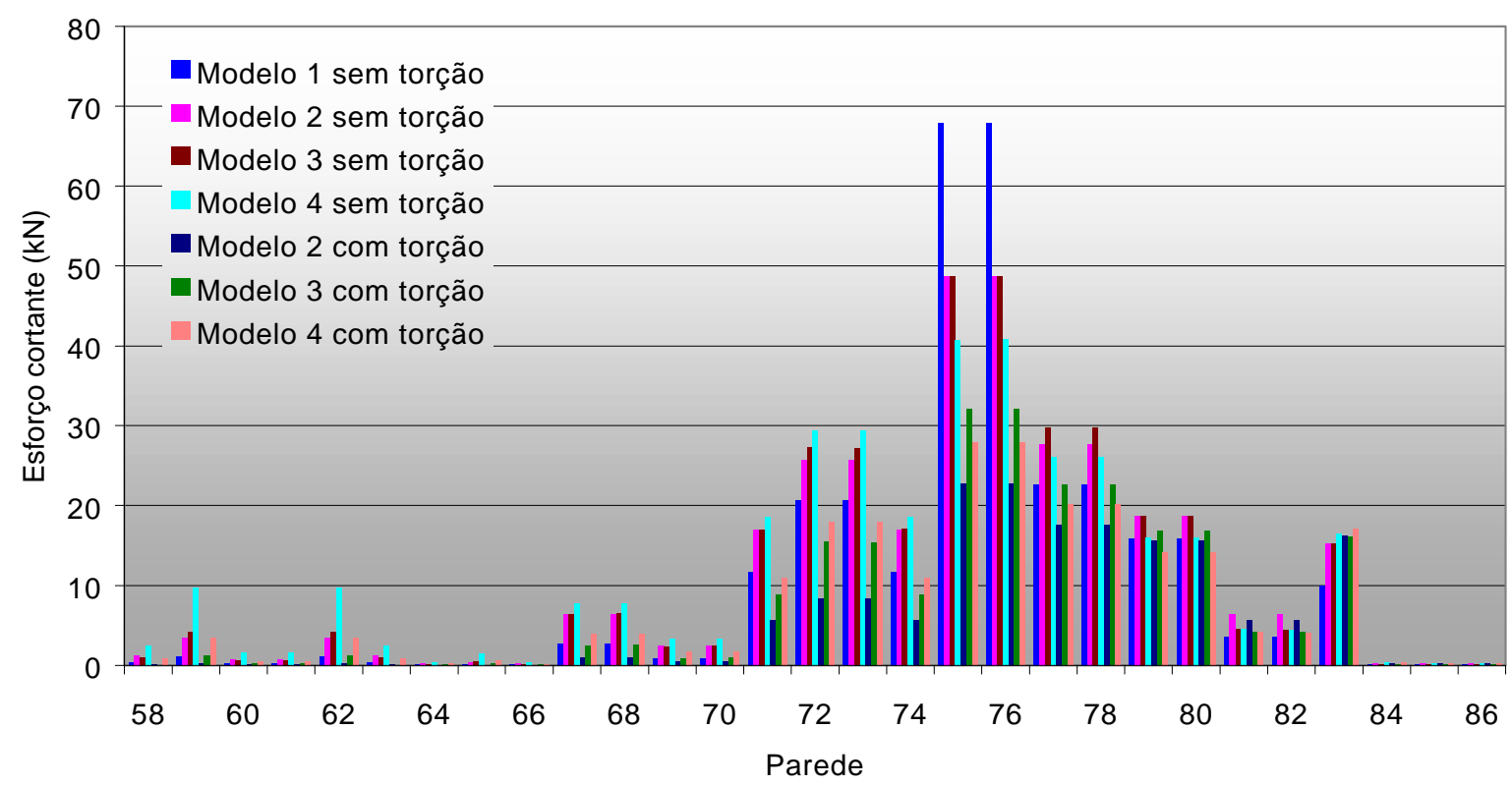

FIGURA 4.39a - Distribuição dos esforços cortantes entre as paredes de contraventamento para vento segundo a direção $\mathrm{Y}$, análise de todos os modelos - Intervalo de paredes entre PY58 e PY86 


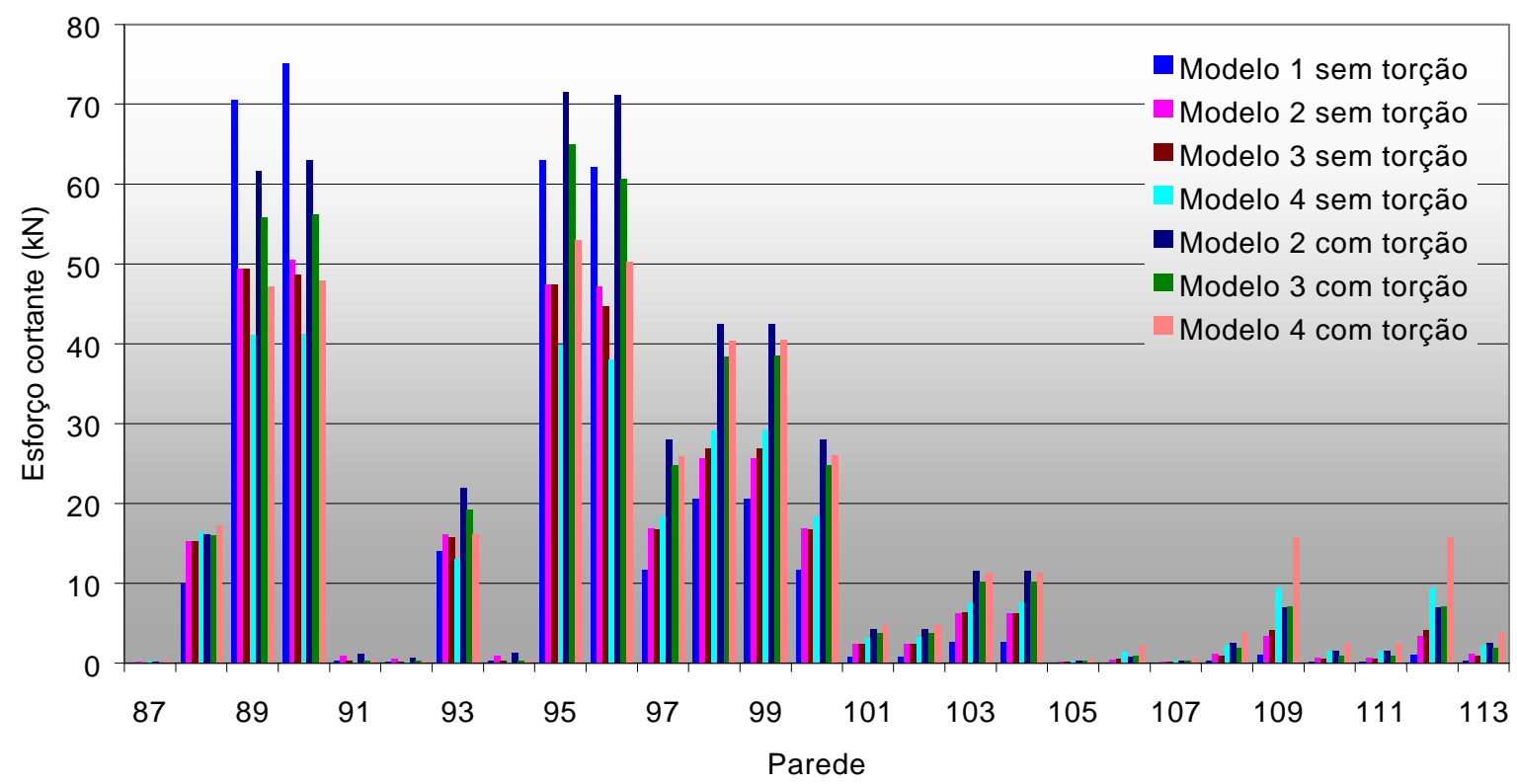

FIGURA 4.39b - Distribuição dos esforços cortantes entre as paredes de contraventamento para vento segundo a direção $\mathrm{Y}$, análise de todos os modelos - Intervalo de paredes entre PY87 e PY113

Os lintéis foram avaliados com o modelo 4, FIGURA 4.40, segundo duas análises:

Lintéis dispostos na direção $\mathrm{X}$ do eixo global da estrutura sob a ação do vento, segundo a mesma direção, com e sem excentricidade.

Lintéis dispostos na direção Y do eixo global da estrutura sob a ação do vento, segundo a mesma direção, com e sem excentricidade.

Os lintéis segundo a direção $\mathrm{X}$ apresentaram baixas solicitações de cisalhamento, bem como modificações pouco significativas ao introduzir-se a torção do edifício. Observa-se nesse caso, as pequenas variações do esforço cortante em alguns lintéis, a exemplo de LX3, LX4, LX16 e LX17. Essa direção possui grande quantidade de painéis de contraventamento, aliado ao fato de apresentar menor área de obstrução ao vento e menor excentricidade. 


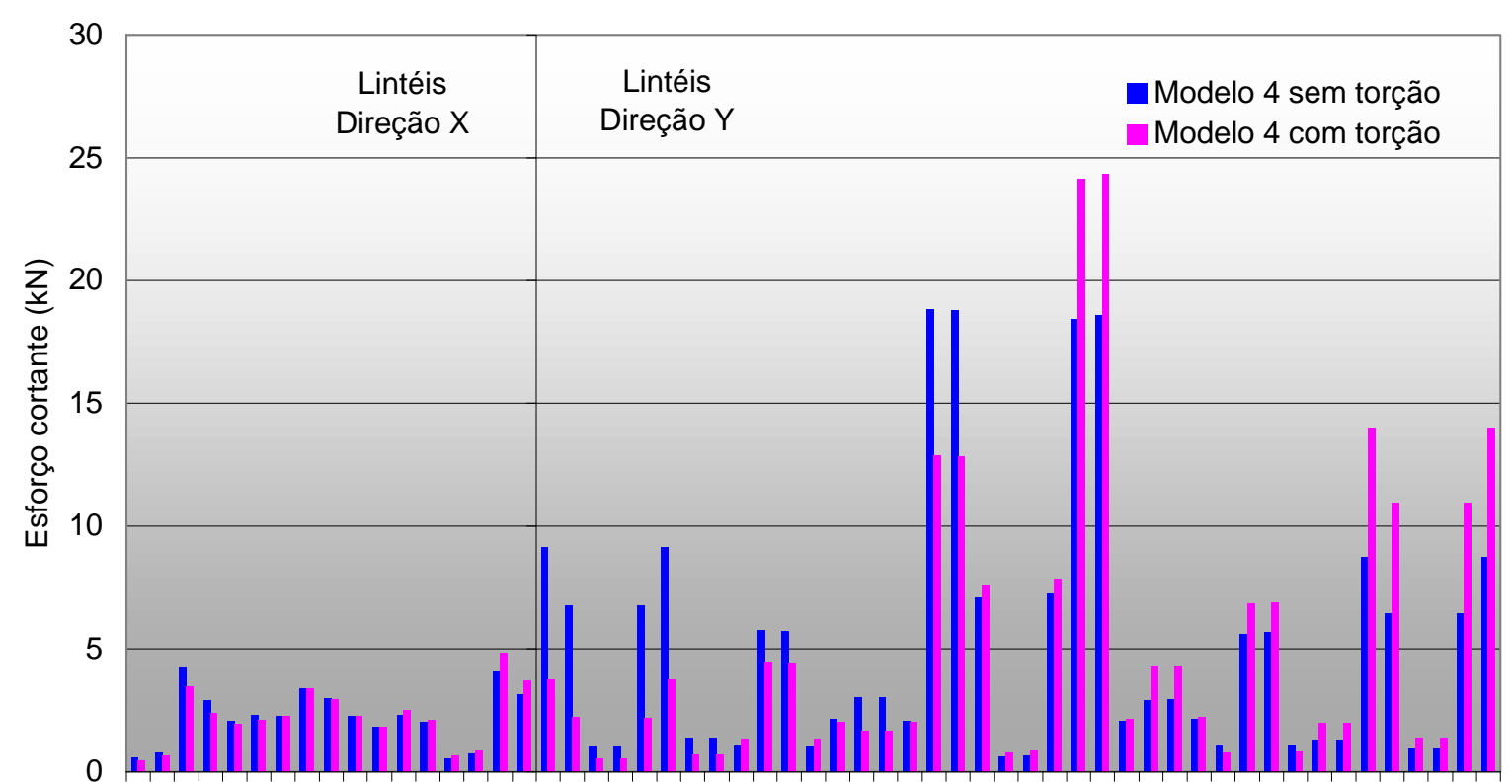

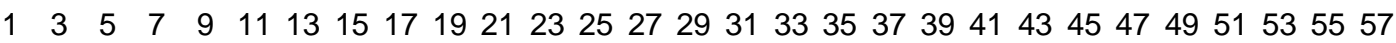
Lintel

FIGURA 4.40 - Esforços cortantes nos lintéis, avaliação das modificações devidas à torção do edifício

Ao contrário, os lintéis segundo a direção Y apresentaram elevadas solicitações do esforço cortante e modificações consideráveis na distribuição desses esforços ao introduzir-se a torção do edifício. Os lintéis situados no intervalo entre LY18 e LY35 apresentaram decréscimos, a exemplo de LY34 e LY35 que aborvem $12,9 \mathrm{kN}$ e $18,9 \mathrm{kN}$ segundo as análises com e sem torção, respectivamente, resultando num decréscimo de 32\%. Esses esforços cortantes correspondem a tensões de cisalhamento $\tau=0,09 \mathrm{MPa}$ e $\tau=0,06 \mathrm{MPa}$. Ao contrário, os lintéis situados no intervalo entre LY36 e LY57 apresentaram acréscimos em seus esforços, a exemplo de LY40 e LY41 que absorvem $24,3 \mathrm{kN}$ e $18,6 \mathrm{kN}$ segundo as análises com e sem torção, respectivamente, resultando num acréscimo de 30\%. Esses esforços correspondem a tensões de cisalhamento $\tau=0,30 \mathrm{MPa}$ e $\tau=0,23 \mathrm{MPa}$. Foram utilizados blocos de 10,0MPa no térreo e primeiro pavimentos, onde ocorrem as máximas intensidades do esforço cortante. Adotando-se uma 
eficiência $\eta=0,8$ para o prisma oco, obtém-se para tensão admissível $\overline{\mathrm{f}}_{\text {cisl }}=0,25 \mathrm{MPa}^{14}$. Nesse caso os lintéis LY40 e LY41 necessitam de reforço quando o efeito da torção é considerado. Considerando-se o prisma cheio, obtém-se uma tensão admissível $\overline{\mathrm{f}}_{\text {cisl }}=0,36 \mathrm{MPa}^{14}$, determinando que todos os furos dos referidos lintéis devam ser grauteados, para absorção das solicitações tangenciais sem necessidade de prever estribos.

14 Obtida considerando-se, segundo a NBR-10837, alvenaria armada e elemento fletido. Essa tensão admissível impõe o limite para dispensar-se o reforço com estribos. 


\section{CONCLUSÕES}

O desenvolvimento desse trabalho consistiu basicamente em:

- Analisar sistematicamente a consideração da deformabilidade por cisalhamento das paredes de contraventamento;

- Aplicar um modelo de pórtico tridimensional, modelo de Yagui adaptado, na análise dos edifícios em alvenaria estrutural sob ação do vento;

- Avaliar detalhadamente os efeitos causados pela torção do edifício.

Os edifícios analisados são representativos de situações usualmente empregadas na prática de construção no Brasil.

O estudo da deformabilidade por cisalhamento, das paredes do sistema de contraventamento, foi desenvolvido considerando-se duas modelagens tridimensionais para essas paredes, denominadas nesse trabalho como modelo 1 e modelo 2, de acordo com o item 4.1. Essa análise demonstrou que a deformação por cisalhamento apresenta influência significativa nos edifícios residenciais usuais em alvenaria estrutural com blocos de concreto. Sua inclusão na modelagem implica em reduções significativas das máximas solicitações de cisalhamento, bem como em modificações no comportamento estrutural das paredes. Como pode ser evidenciado no item 3.1.3, essas reduções chegam a 34\% nos máximos esforços cortantes, de acordo com o exemplo apresentado. Como 
conseqüência dessas reduções ocorre o decréscimo das tensões de cisalhamento que, para o exemplo analisado indicou não haver necessidade de reforçar a respectiva parede ao cisalhamento. Quanto a modificação no comportamento estrutural percebeu-se uma tendência de redistribuição dos esforços, com decréscimo de máximos e acréscimo de mínimos, bem como um aspecto do diagrama de esforço cortante comum às estruturas cujas deformações associadas aos esforços tangenciais são significativas.

Os modelos de pórtico tridimensional, modelos 3 e 4 seguindo as denominações do item 4.1, podem ser considerados como modelagens alternativas mais apuradas. A validade desses modelos foi comprovada mediante comparação com resultados experimentais tanto de translação quanto de rotação das lajes das estruturas analisadas no item 4.2.

A análise dos exemplos considerando-se a ação atuando simetricamente sob a estrutura, apresentou resultados bastante interessantes.

Os deslocamentos horizontais da estrutura sempre decresceram, o que era de se esperar, à medida que refinava-se a modelagem. Notadamente, os deslocamentos obtidos com o modelo 4 demonstraram o enorme acréscimo de rigidez que os lintéis proporcionam ao sistema de contraventamento com a formação de painéis bastante longos, principalmente aqueles situados no contorno da estrutura.

A distribuição dos esforços cortantes entre as paredes de contraventamento apresentou resultados com diferenças apreciáveis. Os decréscimos nas máximas solicitações chegaram a 42\%, no caso do exemplo do item 4.4, confrontando-se os modelos 1 e 4. Analisando-se os modelos 3 e 4, perceberam-se decréscimos mais expressivos na distribuição dos momentos fletores, em todas as paredes, onde o modelo 4 apresentou redução de 63\% na máxima solicitação em relação ao modelo 3 , de acordo com o exemplo do item 4.4. Esse decréscimo acentuado na distribuição dos momentos fletores pode ser atribuído ao aparecimento de reações verticais na base das paredes que formam um binário resistente ao momento de tombamento da estrutura.

O comportamento estrutural apresentado em cada modelo pode ser avaliado através dos diagramas de esforço cortante e momento fletor, 
FIGURA 4.30 e FIGURA 4.31, por exemplo. Percebeu-se que ocorre uma melhor representação do comportamento estrutural, sob o ponto de vista da solicitação tangencial, à medida que refina-se a modelagem. Quanto ao comportamento sob solicitação de flexão, surgiram descontinuidades no diagrama de momentos da parede. Essas descontinuidades podem ser associadas à transmissão de momentos das barras rígidas horizontais para a barra flexivel vertical da parede. As baixas intensidades, bem como as menores variações observadas no diagrama de momentos obtido com o modelo 4, podem ser associadas tanto aos esforços cortantes quanto aos momentos fletores desenvolvidos nas extremidades dos lintéis.

A consideração dos lintéis no modelo de pórtico tridimensional implica na verificação desses elementos estruturais quanto aos esforços tangenciais. As duas análises sem torção do edifício, itens 4.3 e 4.4, apresentaram resultados de tensões de cisalhamento que necessitaram de soluções bastante distintas. No caso do edifício do item 4.3 houve a necessidade de reforçarem-se os lintéis para absorção dessas solicitações, enquanto que no edifício do item 4.4 não houve essa necessidade. A diferença nesses resultados pode ser explicada pelo fato do edifício do item 4.3 apresentar maior área de obstrução para o vento, resultando numa maior intensidade dessa força, e por possuir um número menor de lintéis na direção de atuação desse vento. Cabe aqui recomendar a verificação desses lintéis em qualquer situação, estabelecendo prioridade à direção que apresentar simultaneamente maior força devida ao vento e menor número de lintéis. Além disso, deve-se ter atenção especial com os lintéis situados sobre abertura de portas. Nesse caso, o lintel mesmo não absorvendo o maior esforço cortante, pode ser solicitado pela maior tensão cisalhante, por apresentar menor seção transversal.

A avaliação dos efeitos da torção do edifício, item 4.5, demonstrou que tais efeitos podem modificar substancialmente a distribuição dos esforços cortantes entre as paredes de contraventamento, de modo que não devem ser desprezados. Segundo os resultados apresentados na FIGURA 4.34b, houve acréscimos nos esforços cortantes com diferenças percentuais de até 37\%, observando-se modificações tanto na distribuição desses esforços quanto na localização da parede submetida ao máximo esforço cortante. 
Nesse caso, a determinação da parede mais solicitada não depende apenas de sua rigidez, mas também, da sua posição em relação ao centro elástico do edifício. A combinação dessas duas características é decisiva para a intensidade da solicitação. Com isso, pode-se dizer que as paredes com maiores comprimentos, que dispuzerem-se mais distantes do centro elástico, têm grande probabilidade de absorverem os máximos esforços cortantes do pavimento, quando consideram-se os efeitos da torção do edifício.

Quanto aos lintéis, cabem as mesmas recomendações descritas anteriormente, observando-se as redistribuições dos esforços cortantes, que também ocorrem para esses elementos estruturais ao considerar-se a torção do edifício. Convém ressaltar o fato que os lintéis posicionados nas paredes externas são, geralmente, os mais rígidos por situarem-se sobre aberturas de janela.

As alternativas de modelagens numéricas avaliadas nesse trabalho comprovaram a melhor representatividade do comportamento estrutural à medida que utilizou-se um modelo mais refinado, sendo observadas reduções das máximas solicitações com uma tendência de redistribuição dos esforços entre as paredes. As comparações entre os modelos 1 e 2 demonstram que é imprescindivel a consideração das deformações por cisalhamento das paredes. Quanto aos modelos 3 e 4 pode-se dizer que representam as modelagens mais refinadas, com elementos barra tridimensional, para a análise do comportamento global do edifício. Desse modo, são os mais recomendáveis para analisar as modificações na distribuição dos esforços ao considerar-se o efeito da torção do edifício, principalmente quando dispõe-se de eixos assimétricos. 


\section{REFERÊNCIAS BIBLIOGRÁFICAS}

ACCETTI, K. M. (1998). Contribuições ao projeto estrutural de edificios em alvenaria. 247 p. Dissertação (Mestrado) - Escola de Engenharia de São Carlos, Universidade de São Paulo.

ASSOCIAÇÃO BRASILEIRA DA CONSTRUÇÃO INDUSTRIALIZADA (1990). Manual técnico de alvenaria. São Paulo, ABCI / Projeto.

ASSOCIAÇÃO BRASILEIRA DE NORMAS TÉCNICAS (1987). NBR 6123 - Forças devidas ao vento em edificações. Rio de Janeiro.

BARBOSA, J. A. (1978). Edificios com parede de seção aberta contraventadas por lintéis, sob carga lateral. Dissertação (Mestrado) Escola de Engenharia de São Carlos, Universidade de São Paulo.

BLESMANN, J. (1989). Efeitos do vento em edificações. 2.ed. Porto Alegre, Editorada UFRGS. (Série Engenharia Estrutural, 7).

CORRÊA, M. R. S. (1991). Aperfeiçoamento de modelos usualmente empregados no projeto de sistemas estruturais de edificios. São Carlos. Tese (Doutorado) - Escola de Engenharia de São Carlos, Universidade de São Paulo.

CORREAA, M. R. S.; RAMALHO, M. A. (1994a). Efeitos de aberturas em painéis de alvenaria estrutural. In: INTERNATIONAL SEMINAR ON STRUCTURAL MASONRY FOR DEVELOPING COUNTRIES, 5., Florianópolis, Brazil, 21-24 Aug. 1994. Proceedings. Florianópolis, Univ. Fed. Santa Catarina / University of Edinburgh/ ANTAC, 1994. p. 359-367 
CORRÊA, M.R.S.; RAMALHO, M.A. (1994b). Procedimento para análise de edificios de alvenaria estrutural submetidos a ações verticais. In: INTERNATIONAL SEMINAR ON STRUCTURAL MASONRY FOR DEVElOPING CONTRIES, 5., Florianópolis, Brazil, 21-24 Aug. 1994. Proceedings. Florianópolis, Univ. Fed. Santa Catarina / University of Edinburgh/ ANTAC, p.305-314.

CORRÊA \& RAMALHO (1998). Procedure for the analysis of masonry buildings under vertical loads. In: AUSTRALIAN MASONRY CONFERENCE, 5., Gladstone, Australia. Proceedings. Gladstone, Central Queensland University. p.255-64.

DICKEY, W. L. ; SCHNEIDER, R. R. (1994). Reinforced mansory design. Englewood Cliffs, Prentice Hall.

DRYSDALE G. R. et al (1994). Masonry structures - behavior and design. Englewood Cliffs, Prentice Hall.

GERE, J. M. y WEAVER JR, W. (1970) Análisis de estructuras reticulares. 2ed. Compania editorial continental, S. A.

HENDRY, A. W. et al (1981). An introduction to load bearing brickwork design. New York, Halsted Press.

KALITA, U. C. \& HENDRY, A. W. (1969) An experimental and theoretical investigation of the stresses and deflections in model cross-wall structures. The British Ceramic Research Association. Technical note. No. 148.

KALITA, U. C. \& HENDRY, A. W. (1970) An investigation of the stresses and deflections in model cross-wall structure subjected to lateral load and torsion. The British Ceramic Research Association. Technical note. No. 161. 
KESKIN, O. (1974) Torsional effects in masonry structures under lateral loading. Ph.D., Thesis, Edinburgh, University of Edinburgh.

KESKIN, O. \& DAVIES, S. R. (1974) The effect of torsion on multi-storey structures. In: INTERNATIONAL SYMPOSIUM ON LOADBEARING BRICKWORK. London.

KWAN, A. K. H. (1991) Analysis of coupled wall/frame structures by frame method with shear deformation allowed. Proc. Instn. Civ. Engrs, Part 2, June, p. 273-297.

LA ROVERE, H. L. (1994) Comparação entre métodos de análise de paredes estruturais com aberturas. In: International Seminar on Structural Masonry for Developing Countries, 5., Florianópolis, Brazil, 21-24 Aug. Proceedings. Florianópolis, Univ. Fed. Santa Catarina / University of Edinburgh/ ANTAC, p. 346-358.

MORI, D. D. (1992). Os núcleos estruturais e a não-linearidade geométrica na análise de estruturas tridimensionais de edificios altos. Tese (Doutorado) - Escola de Engenharia de São Carlos, Universidade de São Paulo.

PEREIRA, G. S. (1997). Contribuições a análise de estruturas de contraventamento de edificios em alvenaria. Dissertação (Mestrado) Escola de Engenharia de São Carlos, Universidade de São Paulo.

SAFFARINI, H. S., WILSON, E. L. (1983) New approaches in the structural analysis of building systems. Report no. UCB/SESM-83/08, Departament of Civil Engineering, University of California, Berkeley, CA, June.

SERRA, J. L. F. A. (1994). Contribuição ao estudo de núcleos resistentes de concreto armado. Tese (Doutorado) - Escola de Engenharia de São Carlos, Universidade de São Paulo. 
SILVA, I. M. (1996). Análise de edificios de alvenaria estrutural sujeitos as ações do vento. Dissertação (Mestrado) - Escola de Engenharia de São Carlos, Universidade de São Paulo.

SMITH, S. and GIRGIS, A. - Simple Analogous Frames for Shear Wall Analysis. Journal of Structural Engineering, Vol. 110, No. 11, November, 1984, pp.2655-2666.

STAMATO, M. C. (1980) Associação contínua de painéis de contraventamento. São Carlos. Universidade de São Paulo - Escola de Engenharia de São Carlos.

TIMOSHENKO, S. P. \& GOODIER, J. N. (1970) Teoria de elasticidade. 3ed. Rio de Janeiro, Editora Guanabara Dois S. A.

\section{BIBLIOGRAFIA COMPLEMENTAR}

AMRHEIN, J. E. . Reinforced masonry engineering handbook. Masonry Institute of America.

ASSOCIAÇÃO BRASILEIRA DE NORMAS TÉCNICAS (1980). NBR 6136 - Blocos vazados de concreto simples para alvenaria estrutural. Rio de Janeiro.

ASSOCIAÇÃO BRASILEIRA DE NORMAS TÉCNICAS (1983). NBR 8215 - Prismas de blocos vazados de concreto simples para alvenaria estrutural: preparo e ensaio à compressão. Rio de Janeiro.

ASSOCIAÇÃO BRASILEIRA DE NORMAS TÉCNICAS (1989). NBR-10837 - Cálculo de alvenaria estrutural de blocos vazados de concreto. Rio de Janeiro. 
ASSOCIAÇÃO BRASILEIRA DE NORMAS TÉCNICAS (1985).

NBR 8798 - Execução e controle de obras de alvenaria estrutural de blocos vazados de concreto. Rio de Janeiro.

BASSO, A. et al (1997). Fissuras em paredes de alvenaria estrutural sob lajes de cobertura de edificios. In: CONGRESSO IBEROAMERICANO DE PATOLOGIA DAS CONSTRUÇÕES, 4. / CONGRESSO DE CONTROLE DE GUALIDADE, 6., Porto Alegre, 21-24 out. Anais. Porto Alegre, UFRGSCPGEC, v.1, p. 367-374.

BASTOS, P. S. S. (1993). Contribuições ao projeto de edifícios de alvenaria estrutural pelo método das tensões admissíveis. Dissertação (Mestrado) - Escola de Engenharia de São Carlos, Universidade de São Paulo.

HENDRY, A. W. (1981). Structural brickwork. London, MacMillan Press.

LIAUW, T. C. (1977). On the behavior and the analysis of multi-storey infilled frames subject to laterial load. Proc. Instn. Civ. Engrs., Part 2, 63, Sept., 641-656.

OLIVEIRA JÚNIOR, V. (1992). Recomendações para o projeto de edificios em alvenaria estrutural. Dissertação (Mestrado) - Escola de Engenharia de São Carlos, Universidade de São Paulo.

OLIVEIRA JR., V. ; PINHEIRO, L. M. (1994a). Análise de paredes de alvenaria estrutural calculadas no estado limite último. In: INTERNATIONAL SEMINAR ON STRUCTURAL MASONRY FOR DEVELOPING CONTRIES, 5., Florianópolis, Brazil, 21-24 Aug. 1994. Proceedings. Florianópolis, Univ. Fed. Santa Catarina / University of Edinburgh/ ANTAC, pp.295-304. 
OLIVEIRA JR., V. ; PINHEIRO, L. M. (1994b). Método prático para distribuição das ações verticais em paredes de alvenaria. In: INTERNATIONAL SEMINAR ON STRUCTURAL MASONRY FOR DEVElOPING CONTRIES, 5., Florianópolis, Brazil, 21-24 Aug. 1994. Proceedings. Florianópolis, Univ. Fed. Santa Catarina / University of Edinburgh/ ANTAC, p.315-322

SABBATINI, F. H. Considerações sobre a alvenaria estrutural. São Paulo, FDTE/EPUSP/IPT, s.d. 13p.

SMITH, B. S. (1966). Behavior of square infilled frames. Journal of the Structural Division, Proceedings of the American Society of Civil Engeneers, Vol. 92, No. ST1, February.

TOMAZELA, C. A. (1995). Ação conjunta parede-viga na alvenaria estrutural. Dissertação (Mestrado) - Escola de Engenharia de São Carlos, Universidade de São Paulo.

YAGUI, T. (1978). Análise de estruturas de edificios constituídas de núcleo de concreto armado e pilares ou pendurais de aço (carregamento crítico de instabilidade). Tese (livre-docência) - Universidade Estadual de Campinas. 